DOE/NASA/0100-1

NASA CR-165342

SCl Special Report 81520

NASA-CR-165342

.

1176005015822

Design, Evaluation, and

Fabrication of Low-Cost

Composite Blades for

Intermediate-Size Wind Turbines

Oscar Weingart

Structural Composites Industries, Inc.

September 1981

Prepared for

National Aeronautics and Space Administration Lewis Research Center

Under Contract DEN 3-100
19820010819

NATSA-CR-16S,342 


\begin{abstract}
NOTICE
This report was prepared to document work sponsored by the United States Government Neither the Unted States nor its agent. the United States Department of Energy nor any Federal employees. nor any of their contractors. Subcontractors or their employees. makes any warranty. express or implied. or assumes any legal liabilify or responsibility for the accuracy, completeness, or usefuiness of any information. apparatus. product or process disciosed. or represents that its use would not infringe privately owned rights
\end{abstract}


Leilis Rosearch Center Department of Energy, llashington, D.C.

DOE/RASA/0100-1

DESIG:, EVALUATION, AUD FABRICATION OF LOH-COST COHPOSITE BLAOES FOR IITERRIEDIATE-SIZE UIHD TURBIHES. OsCer lleingart, SCI, Inc. Sept.1981. 200p.

5015322 recd 3-15-82 Route to: Bob Pegg 



\section{Design, Evaluation, and \\ Fabrication of Low-Cost \\ Composite Blades for \\ Intermediate-Size Wind Turbines}

Oscar Weingart

Structural Composites Industries, Inc.

Azusa, California 91702

September 1981

Prepared for

National Aeronautics and Space Administration

Lewis Research Center

Cleveland, Ohio 44135

Under Contract DEN 3-100

for

U.S. DEPARTMENT OF ENERGY

Conservation and Renewable Energy

Division of Wind Energy Systems

Washington, D.C. 20545

Under Interagency Agreement DE-Al01-76ET20320

$$
\begin{aligned}
& N-151,938 \\
& N 82-186934
\end{aligned}
$$


The blades discussed in this report were manufactured under one or more of the following U.S. Patents issued to Structural

Composites Industries, Inc., Azusa, California:

$$
\begin{aligned}
& 4,260,332 \\
& 4,264,278 \\
& 4,273,601
\end{aligned}
$$

And other patents pending. 
1.0 SUMMARY

1.1 Dedication

2.0 INTRODUCTION 5

2.1 Background 5

2.2 Objectives 6

2.3 Scope $\quad 7$

3.0 CONCLUSIONS AND RECOMMENDATIONS 8

3.1 Conclusions $\quad 8$

3.2 Recommendations $\quad 8$

4.0 PHASE I - DESIGN AND EVALUATION 9

4.1 Specifications and Loads 9

4.2 Blade Description $\quad 14$

4.2.1 Hub Details 20

4.2.2 Balancing, Lightning Protection,

4.2.3 Materials of Construction 22

$\begin{array}{lll}4.3 & \text { Design and Analysis } & 27\end{array}$

4.3.1 Design Approach and Considerations 27

4.3.2 Candidate Designs and Trade Studies 39

4.3.3 Structural Analysis 50

4.3.3.1 Materials Selection and Properties 50

4.3.3.2 Allowables 56

4.3.3.3 B1ade Structura1 Properties 58

4.3.3.4 Weight, Center of Gravity
and Mass Moment of Inertia

4.3.3.5 Blade Design Analysis 69

4.3.3.6 Hub Joint Design Analysis 85

4.3.3.7 Root End Closure Analysis 94

4.3.3.8 Comparison to NASA Specifications 99

4.4 Manufacturing Considerations 99

4.4.1 Fabrication Procedures $\quad 99$

4.4.2 Quality Assurance 104

4.4.3 Tooling Design and Fabrication 104 
PAGE

4.4.4 Handling and Shipping 128

4.5 Cost and Weight Analysis 133

4.6 Subelement and Subscale Tests 133

4.6.1 Subelement Tests 139

4.6.2 Subscale Tests 155

$\begin{array}{lll}5.0 & \text { PHASE II - BLADE FABRICATION } & 167\end{array}$

5.1 Tooling and Equipment Fabrication 167

5.1.1 Winding Machine and Facility 167

5.1.2 D-Spar Mandrel and Supports 167

5.1.3 TFT Impregnation and Tensional Equipment 167

5.1.4 Curing, Extraction, Handing 170

5.1.5 Fixtures 170

5.2 Blade Fabrication $\quad 170$

5.2.1 Tool Tryout Blade 170

5.2.2 Fabrication of Prototype Blades 170

5.2.3 Results of Blade Inspection 175

5.2.4 Prototype Cost Evaluation 195

5.3 Recommendations For Future Production 195

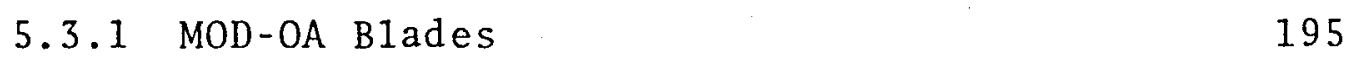

5.3.2 Other Large Composite Wind Turbine Blades 198

6.0 REFERENCES

199 
1 Static Flatwise Bending Moment 11

2 Flatwise Loads 12

3 Edgewise Loads 13

4 Allowable Cost/Weight Envelope 15

5 Blade Geometry Definition 16

6 Typical Blade Cross Section 17

7 Root End Details 19

8 Hub Adapter Details 21

9 Balance Weight Details 23

10 Ice Detector Installation 24

11 Lightning Protection 25

12 Materials of Construction (Prototype Blades) 26

13 The TFT Process 30

14 Transverse Filament Tape (TFT) 31

15 Ring Winder Concept For Composite Spar or Blade 36

16 Low Cost Composite Blade Design Iterations of Planform (Pages $1 \& 2$ )

17 LCCB Design Iterations - Typical Cross Sections 42

18 Root End Closure Concept - Designs 1 \& $5 \quad 44$

18 Root End Closure Concept - Designs 2, 3, \& 4

19 Alternate Hub Retention Concepts - Low Cost Blade 46

20 Alternate Hub Adapters - Low Cost Blade 49

21 Combined Stress Allowables - Typical Spar Composite 57

22 Composite Fatigue Allowables for $4 \times 10^{8}$ Cycles 59

23 Blade Flatwise Flexural Stiffness 60

24 Blade Edgewise Flexural Stiffness 6

25 Blade Torsional Stiffness 62

26 Blade Weight Distribution 68

27 Model of Blade Configuration 71

28 Blade Response to Simulated Shutdown Condition 74

29 Blade Vibrational Mode Shapes 81 
PAGE

30 Trailing Edge at STA 0.25

31 Laminate Properties and Strength Envelope of Trailing Edge

32 Schematic of Root End Closure Design

33 Fabrication Procedure (Prototype)

34 TFT Vacuum Impregnation

35 Respooling Impregnated TFT

36 Overall Winding Arrangement

105

37 Manufacturing Procedure (Prototype)

38 Manufacturing Approach

39 Blade Curing Arrangement 108

40 Mandrel Extraction 109

41 Quality Assurance Plan Flow Chart

42 Typical Mylar

116

43 Spar Mandre1 Rib Assembly

117

44 Mandrel Stringer Installation

45 Welded Skin Installation

46 Headstock and Tailstock

47 LCB Mandrel Schematic

48 Mandre1 Deflection

49 Mandrel Shear Distribution

50 Mandre1 Bending Moment

51 Mandrel Bending Stress Distributions

52 Shipping Procedure

53 Handling Concept

54 Manufacturing Procedure (Production)

55 Viscosity As a Function of CAB-0-SIL Concentration and Temperature

56 Effect of CAB-O-SIL on Composite Shear Strength

57 Foam Winding Tests

58 Glass U1timate Tensile Stress VS Transverse Filament Tape Weight

59 Flat Specimen Winding Fatigue Test Panels 


\section{LIST OF FIGURES}

$\underline{\text { PAGE }}$

61 Half Scale Hub Joint Fatigue Test Specimen 161

62 Finished Half Scale Spar 162

63 Winding Setup For $6 \mathrm{Ft}$ Subscale Blade Section 163

$646 \mathrm{Ft}$ Subscale Blade Cross Section 164

65 Effect of Resin Content on Composite Thickness, $6 \mathrm{Ft}$ Subscale Blade 165

66 Radius of Curvature Effect on Composite Thickness, $6 \mathrm{Ft}$ Subscale B1ade 166

67 D-Spar Mandre1 in Winding Machine 168

68 TFT Impregnation Station Dip and Wind Machine - 169

69 Oven and Heater 171

70 Bucking Rings and Extraction Jacks 172

71 Blade Alignment Fixtures 173

72 Winding D-Spar 176

73 Applying First Afterbody Core to D-Spar 177

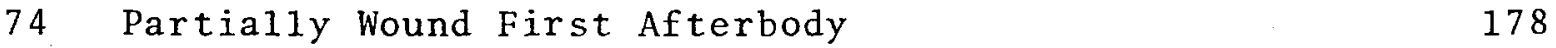

75 Application of Trailing Edge Core 179

76 Cross Section of Tool Tryout Blade 180

77 Painting Blade 181

Finished Blade With Ice Detector and Balance
Weight Provisions and Trim Painting

79 Loading Blade on Truck 183

80 S/N 018 Dimensional Errors, Histogram 190

81 S/N 019 Dimensional Errors, Histogram 191

82 Combined Dimensional Errors, Histogram 192 
$1 \quad$ Critical Load Conditions and Margins of Safety 51

2 General Nomenclature For Structural Analysis 52

3 Section Properties of Blade 64

4-A Dimensions For Stations Between 0.25R To 1.0R 65

4-B Dimensions For Stations Inboard of .25R 66

5 Initial Survival wind Loading Condition 73

6 Blade Buckling Allowables and Margins of Safety 76

7 Flatwise Fatigue Stress Margins of Safety 78

8 Edgewise Fatigue Stress Margins of Safety 79

9 Combined Stress Due To Flatwise and Edgewise Moments 80

10 Hub Joint Analysis Summary Operational Loads 90

10-A Hub Joint Analysis Summary Operational Loads (Continued) 91

11 Hub Joint Analysis Summary Limit Loads 92

11-A Hub Joint Analysis Summary Limit Loads (Continued) 93

12 Comparison to NASA Specifications 100

13 Receiving Inspection 111

13-A Receiving Inspection 112

14 In-Process Inspection 113

15 Final Inspection 114

16 Mandrel Structural Properties and Loading 123

17 Detailed Stress Analysis Summary For LCB Mandre1 129

$\begin{array}{lll}\text { Applicability of The Design and Fabrication } & \\ \text { Procedure to Blades 15-200 Feet Long } & 132\end{array}$

19 Blade Weight Summary (Prototype) 134

20 Materials Cost Summary - 100 Production Blades/Year 135

21 Estimated Blade Recurring Cost (Production) 136

22 Design Features That Contribute to Low Cost 138

Effect of CAB-O-SIL on Resin Migration and
Composite Properties

Fiber Wet-Out and Resin Migration Control By
Modification With CAB-O-SIL 
PAGE

25 Characterization Data of Glass Reinforcements

144

26 Rigid Polyurethane Foam Properties

27 Dimensional Stability Test Results of Rigid Polyurethane Foams

28 Adhesive Test Results of Metal-To-"Wet" TFT Bonding

29 Adhesive Test Results of Composite-To-Composite Bonding

30 Adhesive Test Results of Composite-To-Metal Bonding

31 Results of Surface Preparation on Laminate Bond Strength 152

32 Fatigue Panel Wrap Pattern and Construction (Pattern 1) 156

33 Fatigue Pane1 Wrap Pattern and Construction (Pattern 2) 157

34 Weight Comparisons 174

35 S/N 018 Dimensional Errors, Descriptive Statistics 184

36 S/N 019 Dimensional Errors, Descriptive Statistics 185

37 Combined Dimensional Errors, Descriptive Statistics 186

38 S/N 018 Dimensional Errors, Frequency Distribution 187

39 S/N 019 Dimensional Errors, Frequency Distribution 188

40 Combined Dimensional Errors, Frequency Distribution 189

41 LCCB Dimensional Errors, Analysis of Variance 193

42 Prototype Blade Cost Evaluation 196

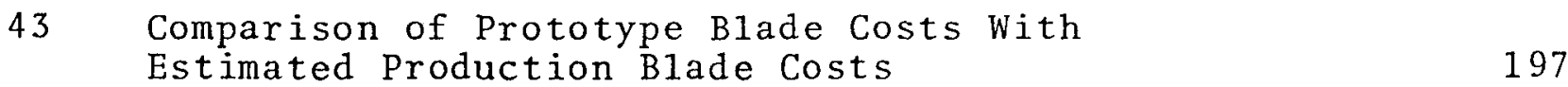


This Page Intentionally Left Blank 


\section{1. () SUMMARY}

This report describes the low-cost composite blade program, carried out by Structural Composites Industries, Inc. (SCI) under a contract to NASA-Lewis Research Center, (NASA), funded by the Department of Energy (DOE), involving design, evaluation and fabrication of a pair of low-cost composite rotor blades (LCCB) for the MOD-OA wind turbine. The objectives of the program were to identify low cost approaches to the design and fabrication of blades for a two-bladed $200 \mathrm{~kW}$ wind turbine and to assess the applicability of the techniques to larger and smaller blades.

Rotor blades represent a substantial portion of the cost of intermediate to large-size wind turbines, hence low-cost blades are needed to improve the overall cost effectiveness of these systems.

In Phase I of the program, several blade designs were developed to the point where reasonably accurate estimates could be made of the structural properties and costs of tooling and fabrication. The most cost-effective design was selected for detailed design in Phase II. Structural analysis of the selected design was performed, with assistance from NASA in some of the more specialized techniques (e.g. flutter analysis). Subelement and subscale specimens were fabricated in Phase I for testing by both SCI and NASA. These tests were used to: Confirm the physical and mechanical properties of the blade materials; develop and evaluate certain blade fabrication techniques and processes; confirm the structural adequacy of the root end joint design.

In Phase II, blade tooling was designed and fabricated. Major items included a $60 \mathrm{ft} \mathrm{D}-\mathrm{spar}$ mandre 1 and its supports, a $60 \mathrm{ft}$ cure oven with a $200 \mathrm{~kW}$ heater, and a transverse filament tape (TFT) pre-impregnation station. Two complete blades and a partial blade for tool tryout were built. A $100 \mathrm{ft}$ long "ringwinder" machine was designed and built by SCI.

The TFT process, developed by SCI and used to fabricate the spar for the DOE/NASA $150 \mathrm{ft}$ composite blade (Reference 1) was used, in this program, to wind the entire blade. This process allows rapid winding of an axially oriented composite onto a tapered mandrel, with tapered wall thickness. The TFT process thus is uniquely suited to low cost composite blade and spar fabrication. 
The ring winder/TFT process combination was used for the first time on this program. This approach allows the blade to be wound on a stationary mandrel, an improvement which alleviates some of the tooling and process problems encountered on previous composite blade programs (Reference 1, 2, 3). The stationary mandrel is not subjected to the constantly changing deflection and reversing stresses seen in a rotating airfoil-shaped or D-spar mandrel. The stationary mandrel, with it's chordline vertical, is in it's stiffest orientation, so deflection is small and constant. The absence of cyclic stresses reduces the chance of premature mandrel failure and assures long tooling life. In addition, doubts about the effect of constant mandrel flexing on the wet or partially cured composite are put to rest.

With the ring winder, the long slender D-spar mandrel can be supported only at the ends, so no steady rest is required. The entire blade length can thus be wound in one operation. (The $150 \mathrm{ft}$ spar was wound in two partial lengths due to the central steady rest). Secondary benefits of the stationary mandrel are (1) the ability to extract the cured blade from the mandrel without moving the mandrel itself. (2) Ability to easily patch, paint, and add sub-assemblies to the stationary blade during fabrication. (3) Low energy requirements and smaller machine components due to smaller rotating mass. Disadvantages are (1) resin migration due to gravity, with no rotation to redistribute it, and (2) need to pre-impregnate all winding materials.

The low cost blade adapts to the MOD-OA hub via a bolted circular metal flange. This flange is in an area of maximum steady and cyclic bending moments and shear forces. One challenge in composite blade design is to incorporate such a flange into the composite structure in a manner that facilitates low-cost fabrication while assuring adequate structural margins in this critical area.

In preparation for the low-cost blade program, SCI developed a patented metal hub fitting design which meets the goals stated. The flanged metal fitting is designed to fit over the winding mandre1. It is provided with angular grooves into which the TFT composite is pulled, by tensioned hoop windings, for a mechanical lock. This makes use of the ability of the TFT process to wind up to a square edge, producing a net finished part without trimming. The fitting also contains a bonded transition area where the stiffness gradually transitions from composite to steel. 
For redundancy, either the bonded or mechanical joint can accept the full load on the hub. This joint has been tested

by NASA on two half-scale spars provided during Phase I. Mandrel extraction forces on all subscale and full scale units were nomina 1 .

The use of an all-wound blade structure with a wound-in hub fitting, painted and cured in the winding machine, means that the blade is substantially complete when it leaves the winding area. Only minor trimming and assembly operations remain. This approach, with the improvements 1 isted in the conclusions and recommendations section, promises to provide low cost composite wind turbine blades in a production environment.

The two $60 \mathrm{ft}$ blades were transported to NASA-LeRC in Cleveland, Ohio from SCI in Azusa, California using one standard extendible $60 \mathrm{ft}$ truck. No crates or special handling fixtures were needed.

The projected cost of production blades in 1978 dollars, built in 100 unit lots, is $\$ 11,745$ each or $\$ 4.12 / 1 \mathrm{~b}$. for a $28521 \mathrm{~b}$. blade. This is well within the NASA guidelines.

This program took place over a period of 24 months. The NASA program manager was Raymond Lark. The SCI program manager was Oscar Weingart. SCI's principle consultant in aerodynamics and structural design was David J. Peery. Other SCI key personnel and consultants who made major contributions to the program were:

DESIGN AND ANALYSIS

A. C. Knoe11

R. E. Landes

L. J. Sullivan

R. E. Wilson

\section{MATERIALS AND FABRICATION}

R. R. Heitkamp

J. Phipps

M. Segimoto

C. Taylor

B. J. West

This program has successfully demonstrated:

- Ring winding of a complete low cost composite blade on a stationary mandrel using the TFT process.

- A low cost wound-in metal hub fitting design which provides ease of blade fabrication with adequate structural margins. 


\subsection{DEDICATION}

This report is dedicated to the memory of Dr. David J. Peery, who passed away on November 9, 1979. He was responsible for the rotor aerodynamics and structural design/ analysis for the low cost composite blades.

A distinguished aeronautical engineer and educator, who was associated with several large aerospace companies and major universities, Dr. Peery was a recognized authority on aircraft structures. His book Aircraft Structures (McGraw-Hi11, 1950) is a standard reference work in the field. More recently, he was a consultant on several NASA-LeRC studies for low cost wind turbine generator (WTG) blades. Dr. Peery was a regular member of NASA "Tiger Teams", investigating problems in major aerospace and energy programs. He was an Associate Fellow of AIAA and a member of American Society of Civil Engineers, American Society for Engineering Education and Tau Beta Pi. 
$2.1 \quad$ BACKGROUND

The U.S. Department of Energy (DOE) is responsible for the Federal program in wind turbine development. The management of one phase of the program - large horizontal axis wind turbine development - has been assigned to the Lewis Research Center (LeRC) of the National Aeronautics and Space Administration (NASA).

Experience in construction of large wind turbine systems has shown that blade costs are a major portion of the total system cost. To improve the cost effectiveness of these systems, low cost blades must be developed. The blades used to date on large wind turbines have been high technology items employing the latest in design, analysis and fabrication techniques. This was necessary to minimize technical $\mathrm{risk}$ in the early machines and to maximize energy from the available wind conditions. However, increased knowledge of operating conditions and analysis techniques indicates that only minor reductions in energy output result with less complex blade designs. It is expected that substantial reductions in blade costs can be achieved by using simplified designs and fabrication techniques.

Several previous composite wind turbine blade studies and programs have been carried out under NASA/DOE auspices. In 1975 Hamilton Standard and Hercules fabricated a $60 \mathrm{ft}$ filament wound composite blade using conventional helical filament winding techniques

(Reference 2). This same team fabricated a composite test spar for a MOD-1 blade in 1978 (Reference 3) under a subcontract from G.E. In 1977/78 SCI and Kaman Aerospace Corporation designed, fabricated and tested a $150 \mathrm{ft}$ composite blade using the SCI transverse filament tape (TFT) process for the D-spar. SCI subsequently granted a license to Kaman Aerospace to build blades using the TFT process. (Reference 1)

In 1978 Kaman received a contract to design and fabricate two $100 \mathrm{ft}$ blades for the MOD-1 wind turbine at Boone, North Carolina using a design and process similar to those used on the previous $150 \mathrm{ft}$ blade. These blades were completed in 1981 (Reference 4). Also in 1978 , SCI performed a preliminary design study of composite blades for the MOD- 2 wind turbine under subcontract from Boeing Engineering and Construction Division (Reference 5). 
In Apri1 1979, SCI was awarded a DOE/NASA contract to design, evaluate and fabricate two $60 \mathrm{ft}$ low cost composite blades for the MOD-OA wind turbine. That program is the subject of this report.

The SCI low cost blades will be installed on the MOD-OA wind turbine at Clayton, New Mexico for operational testing. They will be the first all fiberglass composite blades to be operated on a large (greater than $100 \mathrm{~kW}$ ) wind turbine.

\subsection{OBJECTIVES}

The objectives of this program were to identify low cost approaches to the design and fabrication of blades for a twobladed $200 \mathrm{~kW}$ wind turbine and to assess the applicability of the techniques for larger and smaller blades. 


\section{$2.3 \quad$ SCOPE}

The contract consisted of the following nine (9) tasks and subtasks:

PHASE I - BLADE DESIGN

TASK I

- PRELIMINARY DESIGN \& EVALUATION

A. DESIGN STUDIES

B. PRELIMINARY DESIGN REVIEW

TASK II

- DETAILED DESIGN AND ANALYSis

A. DESIGN

B. ANALYSIS AND EVALUATION

TASK III - FABRICATION PROCEDURE

TASK IV - FABRICATION COST ANALYSIS

TASK V - FINAL DESIGN REVIEW

PHASE II - PROTOTYPE BLADE FABRICATION

TASK VI - FINAL DESIGN DRAWINGS AND SPECIFICATIONS

TASK VII - FABRICATION OF TOOLING

TASK VIII - FABRICATION OF́ TWO BLADES

TASK IX - REPORTING REQUIREMENTS

(TASK IX IS COMMON TO PHASES I AND II) 
3.0 CONCLUSIONS AND RECOMMENDATIONS

3.1 CONCLUSIONS

- This program demonstrated a unique and potentially low cost approach to the design and fabrication of blades for a two-bladed $200 \mathrm{~kW}$ wind turbine.

- No technical limitations were found which would prevent the application of the same techniques to blades from 15 to 200 feet in length.

- The ring winder and TFT process are practical approaches to fabrication of complete large composite multi-cel1 blades, and eliminate the problems of mandrel deflection, while facilitating the wrapping of an axially oriented composite, with tapering wall thicknesses.

- The mechanically locked hub flange design is structurally adequate for use in large composite wind turbine blades.

\subsection{RECOMMENDATIONS}

The prototype low cost composite blades were well within the MOD-OA weight and gravity moment restrictions, but were costly to fabricate. Future wind turbines should have hub designs which are coordinated with the blade design to give the lowest possible cost of energy. The following recommended changes in the present design and process could then be implemented:

A. Two cell design with D-spar as the primary loadcarrying element.

B. Larger hub diameter to allow extraction of larger mandrel without using a metal root end adapter.

C. Mild steel hub fitting for lower cost.

D. Polyester resin for lower raw material and processing cost.

E. Continuous winding process without costly vacuum bag, peel ply and gel between winding steps.

F. Hollow afterbody wound on extractable mandrel. (If foam core must be used in afterbody, then foam in place in a mold).

G. Consider use of modified airfoil with blunt trailing edge. 
4.0 PHASE I - DESIGN AND EVALUATION

4.1 SPECIFICATIONS AND LOADS

The following blade specifications and loads were supplied by NASA.

\section{BLADE GEOMETRY}

The requirements for blade geometry are based on the MOD-OA and are summarized as follows:
Airfoil
NASA - $230 X X$
Twist
$10^{\circ}$
Maximum Thickness, Root
$40 \%$
Tip
$18 \%$
Hub Flange
NASA Dwg. CD. 758866
At Station 31.75 Inch.
(The MOD-OA Hub)
Planform
Straight, Stepped or Tapered
Maximum 25\% Root Cutout
Length
$60 \mathrm{ft}$ Hub Flange to Tip
Goals
Minimize Thickness to Chord
Ratio
Minimize Solidity Ratio

OPERATIONAL CONSIDERATIONS

The operational environmental requirements for the blade and rotor are as follows:

Number of Blades in Rotor

2

Ambient Operating Temperature

$-30^{\circ} \mathrm{F}$ to $120^{\circ} \mathrm{F}$

Environmental Resistance

Sun1ight, Salt Spray, Humidity, Fungus 
Three load cases were considered in the design of the blade. They were limit, fatigue, and rapid shutdown. The limit load was the hurricane wind (120 mph) condition. This wind condition was assumed to occur with the blades parked and feathered. The load was obtained by applying 50 psf flatwise to the blade superimposed on the gravity load of the blade. The flatwise bending moment distribution for this condition is shown in Figure 1 .

The fatigue requirements were based on the blades operating on MOD-OA at $40 \mathrm{rpm}$ in a $40 \mathrm{mph}$ wind. Flatwise and edgewise blade loading for this condition are shown in Figures 2 and 3 , respectively.

The rapid shutdown load was used only to calculate tip deflection. This load was simulated by superimposing 50 psf applied flatwise to the blade, the gravity load due to 70 precone angle, and the centrifugal moment at $45 \mathrm{rpm}$ due to precone.

\section{DESIGN REQUIREMENTS}

The design requirements for the blade are summarized as follows:

- No yielding of any structure under max wind load

- No buckling of primary structure under max wind load

- No failure in $4 \times 10^{8}$ cycles from fatigue loads

- Tip deflection not to exceed 103 inches

WEIGHT

The maximum allowable blade weight is 3000 lbs and the maximum allowable dead weight static bending moment of the blade is 47,000 ft/lbs at station 40 .

\section{TUNING REQUTREMENTS}

The allowable first mode natural frequency ranges of the blade are as follows: (Chordwise or Flatwise)

$\begin{array}{lllll}1.50 & \leq & f_{0}(\mathrm{~Hz}) & \leq & 1.85 \\ 2.15 & f_{0}(\mathrm{~Hz}) & \leq & 2.55 \\ 2.75 & f_{0}(\mathrm{~Hz}) & 3.15 \\ 3.45 & f_{0}(\mathrm{~Hz}) & 3.85\end{array}$




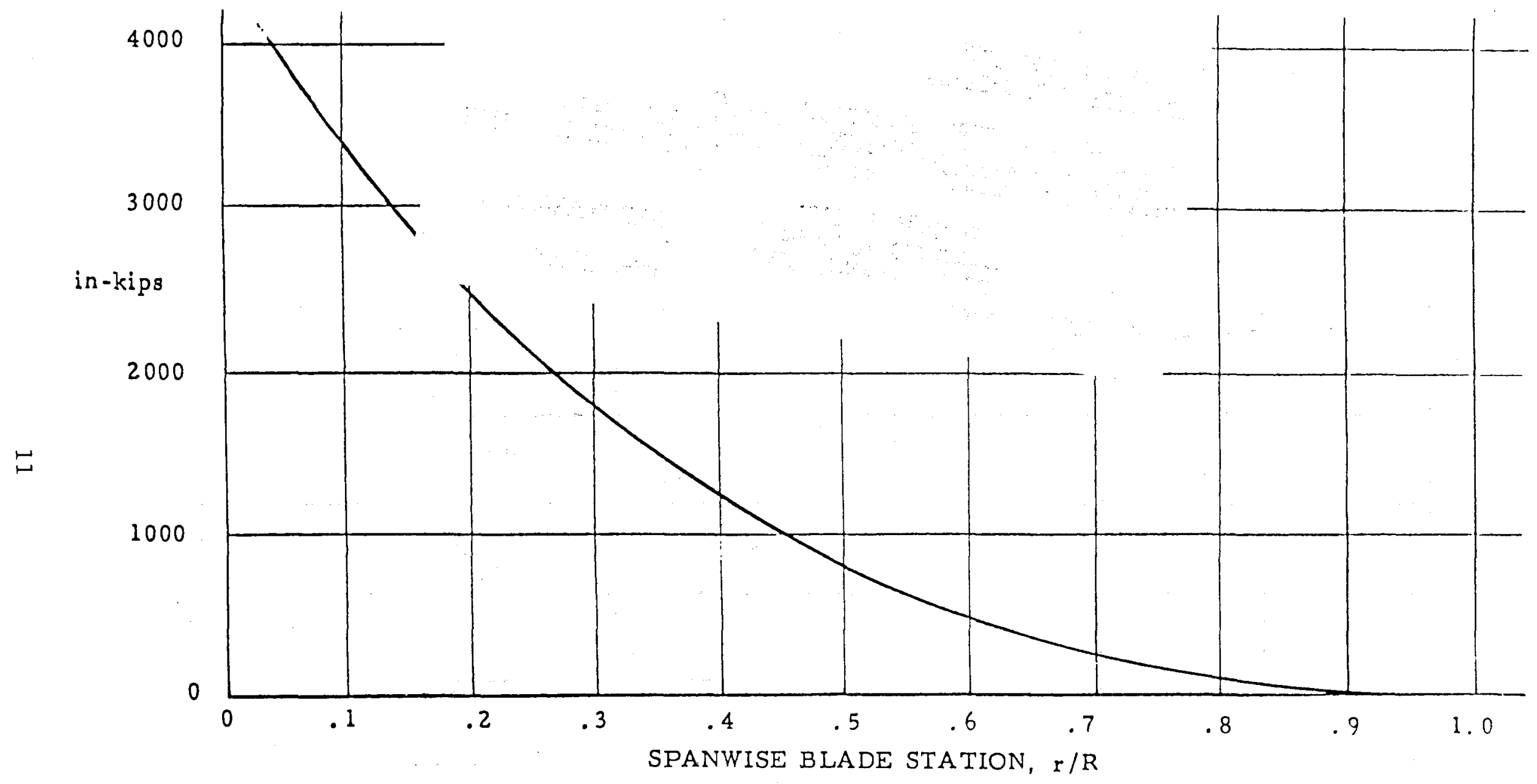

FIGURE 1 STATIC FLATWISE BENRING MOMENT, 50 PSF PLUS BLADE. DFAD I'EIGHT 


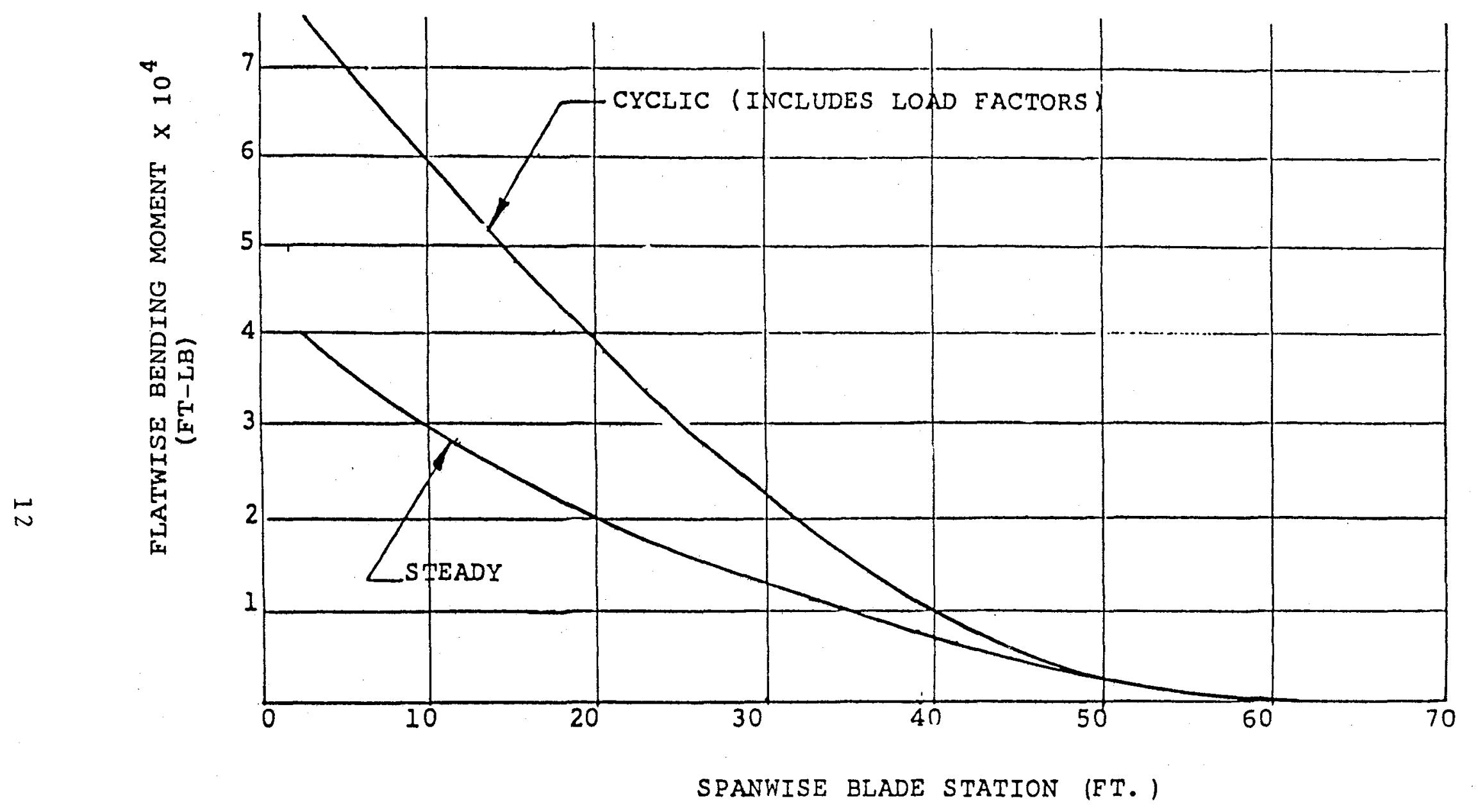

FIGURE 2 FLATWISE LOADS

$40 \mathrm{MPH}, 40 \mathrm{RPM}, 7^{\circ}$ CONING 


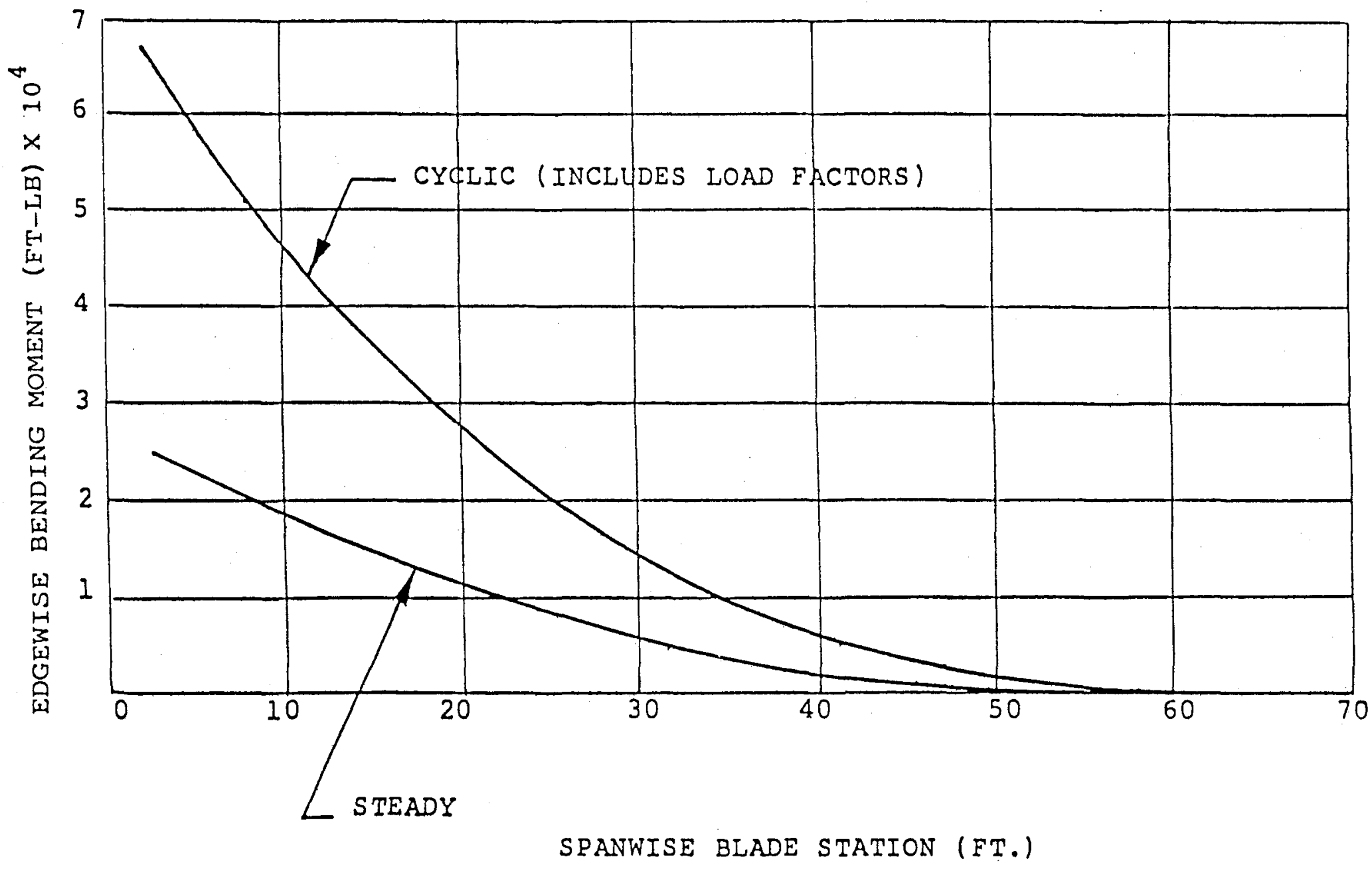

FIGURE 3 EDGEWISE LOADS

$40 \mathrm{MPH}, 40 \mathrm{RPM}, 7^{\circ}$ CONING 
Tolerance requirements on the blade physical design are as follows:

Blade to blade weight
Spanwise C G
Chordwise C G
Chordwise C G location

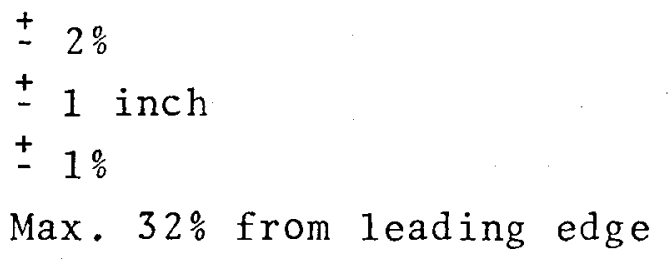

\section{COSTS}

An allowable cost-weight envelope was furnished by NASA (Figure 4) for costs of an average of 100 blades per year in 1978 dollars. The maximum allowable weight of $4000 \mathrm{Ibs}$ was 1 ater changed to a $3000 \mathrm{lb}$ absolute maximum, due to structural limitations of the MOD-OA hub.

\subsection{BLADE DESCRIPTION}

The final blade configuration, which was designed and analyzed to meet all the NASA design requirements, is shown in the planform sketch of Figure 5. The blade consists of a TFT glass-epoxy airfoil structure filament wound on to a steel root end fitting. The fitting is, in turn, bolted to a conical steel adapter section to provide for mounting attachment to the NASA hub.

A typical cross section of the blade is shown in Figure 6. The blade comprises a 3 cell design configuration containing a leading edge D-spar section followed by a foamed afterbody and a foamed trailing edge cell. The D-spar and the first afterbody cell constitutes the primary structural cells of the blade.

\section{EXTERNAL GEOMETRY}

Referring to Figure 5, the blade planform is linear tapered with a 60 inear twist from station. $25 \mathrm{R}$ to the tip. The airfoil varies from NACA 23030 at station. $25 \mathrm{R}$ to NACA 23012 at the tip. Maximum chord is 55 inches and tapers to 22 inches at the tip. The D-spar cross section at station $0.125 \mathrm{R}$ is circular, transitioning to a true airfoil at station. $25 \mathrm{R}$. The root cutout of the afterbody is at $0.125 R$. The shape at that point is not a true airfoil, but serves to fair the circular spar and reduce drag. 


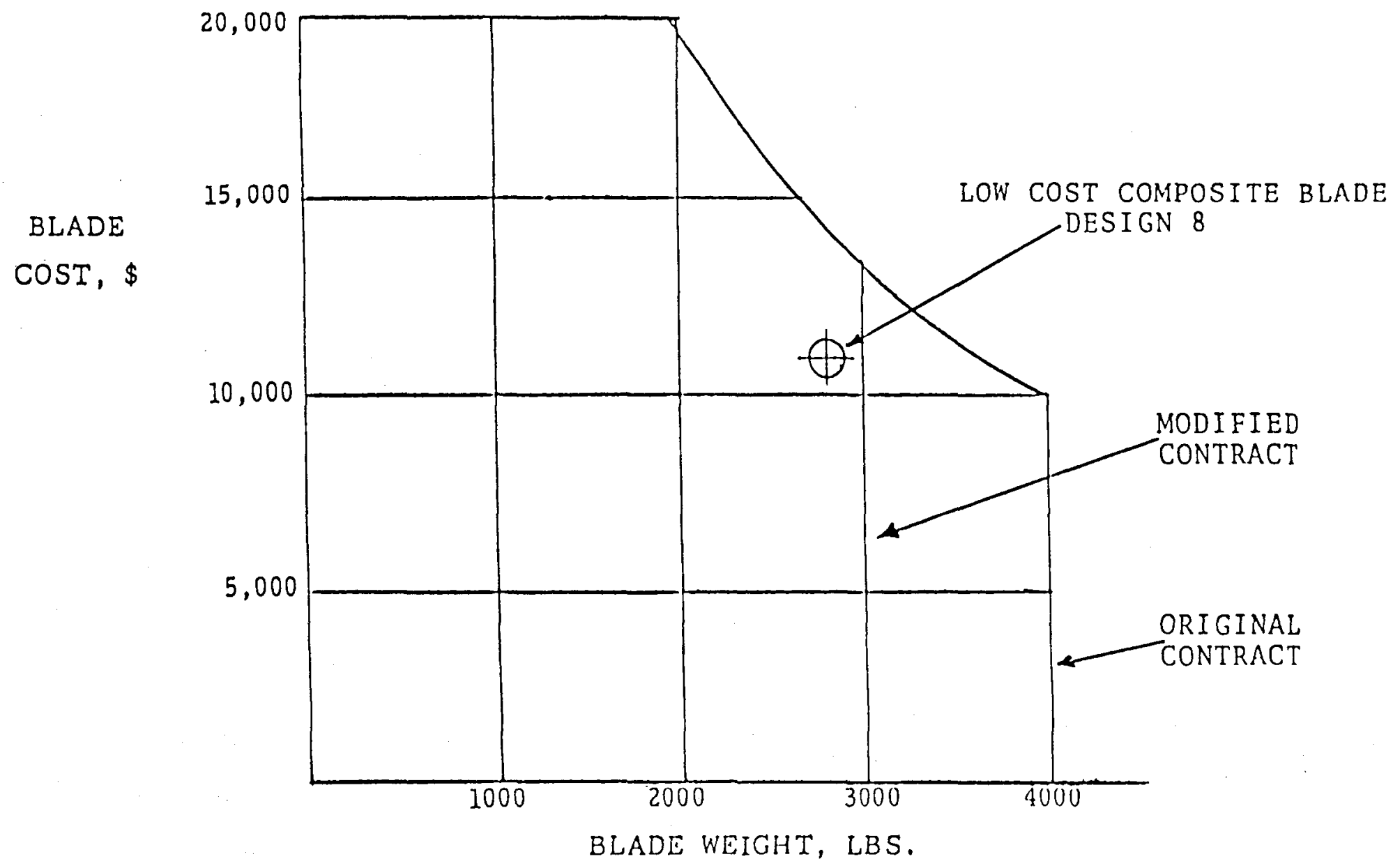

100 BLADES/YEAR, 1978 DOLLARS

FIGURE 4 ALLOWABLE COST/WEIGHT ENVELOPE 


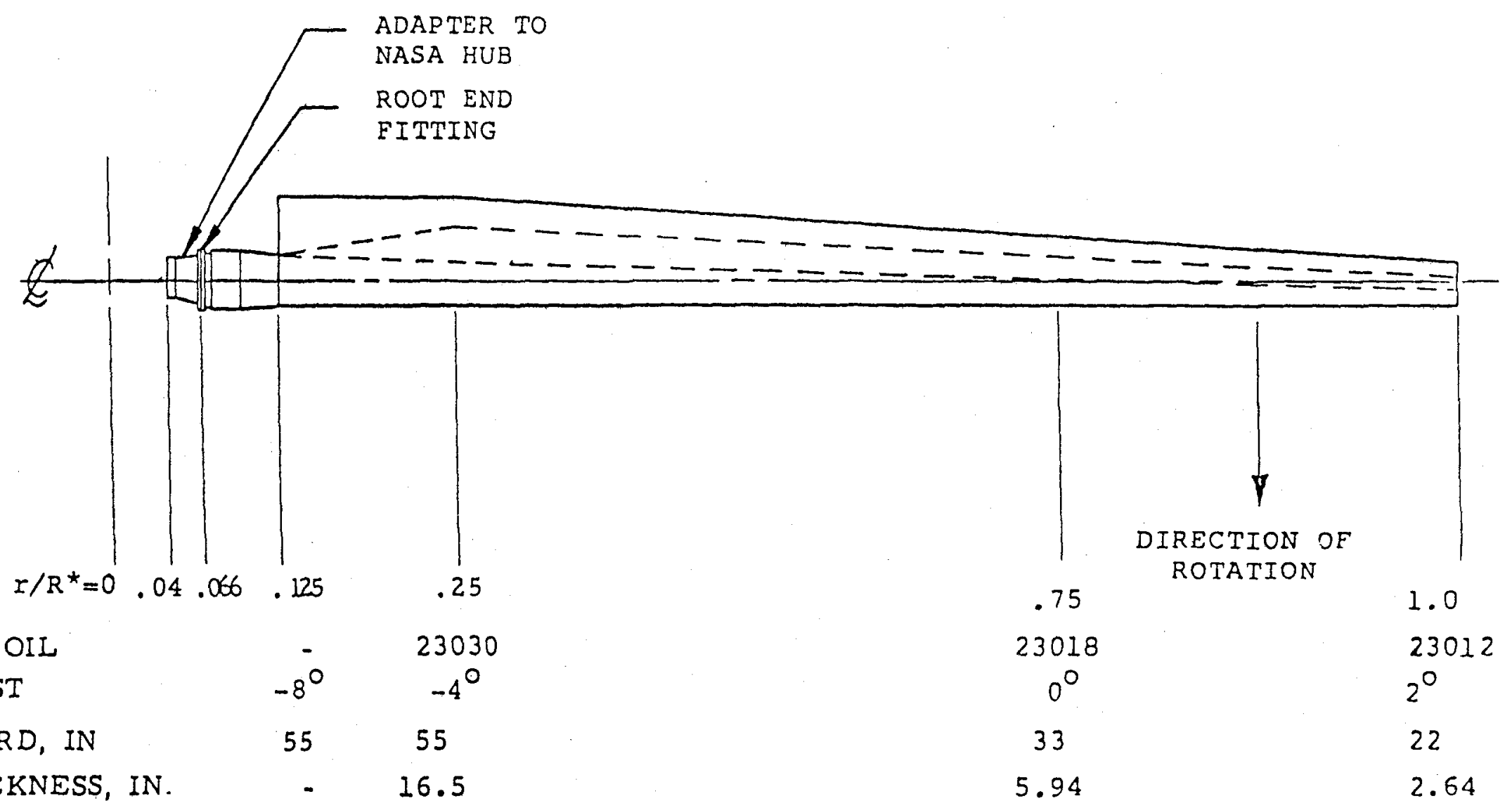

${ }^{*} R=62.646 \mathrm{Fr}=751.753 \mathrm{IN}$ 


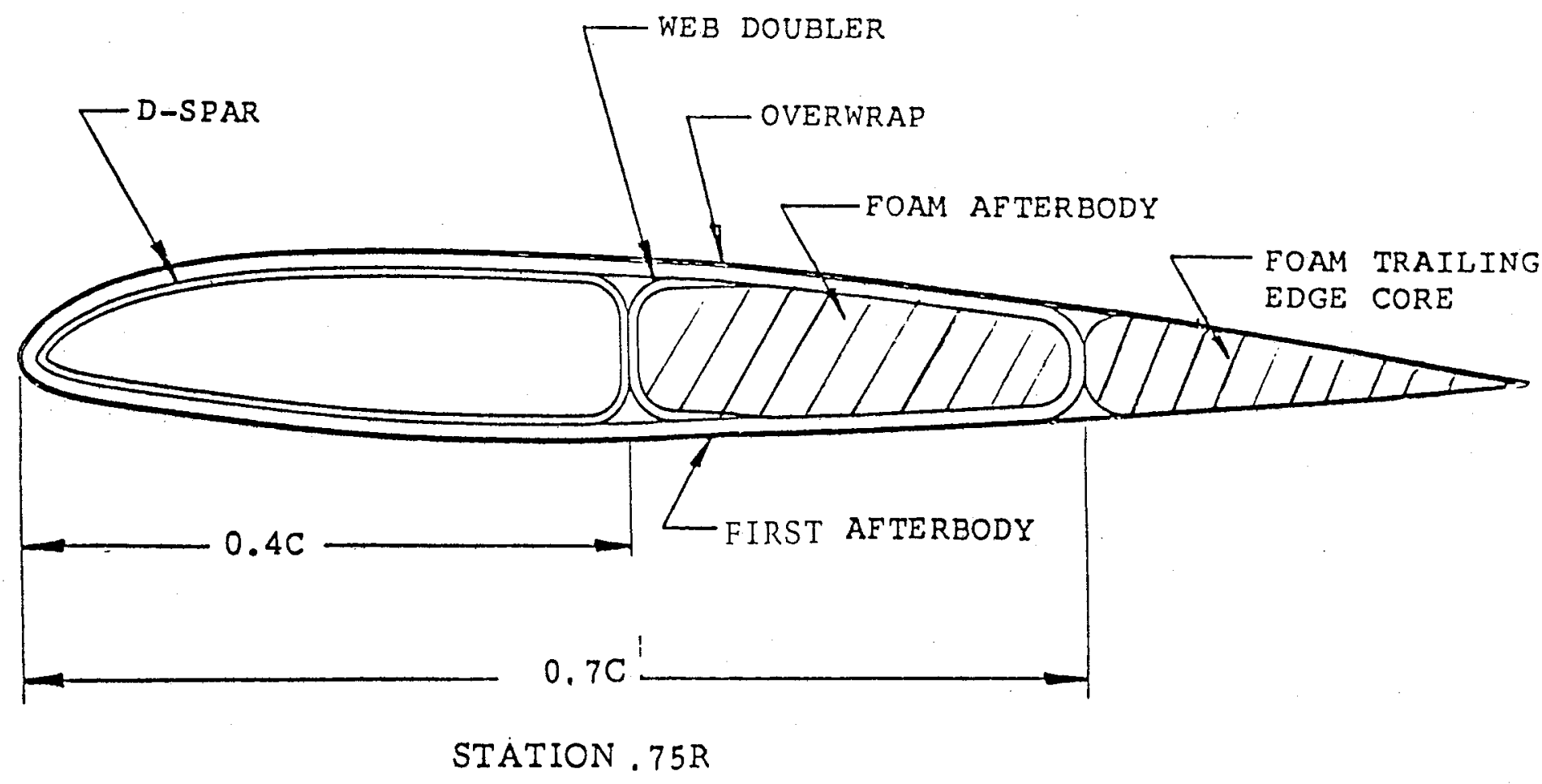

NACA 23018 AIRFOIL

FIGURE 6 TYPICAL BLADE CROSS SECTION 
Referring to Figure 5 and 6 , the typical blade cross section contains four composite elements and two foam cores.

- D-Spar

D-spar is a relatively thin hollow shape wound on a removeable mandrel. From station $0.25 \mathrm{R}$ to the tip, the D-spar is a true airfoil. From station $0.25 \mathrm{R}$ to $0.125 \mathrm{R}$, it transitions to a circular cross section. It terminates in the outer groove of the hub fitting.

\section{- Web Doub1er}

This element increases the thickness of the D-spar web and fairs aft into the first afterbody wrap. The web doubler and D-spar aft web form an "X-spar" which reduces the unsupported chordwise length of the first afterbody. The web doubler is applied to the foam afterbody core by layup. It fades out at $0.125 \mathrm{R}$.

- First Afterbody

This element is actually the main structure of the blade. It is $70 \%$ of the chord which produces an adequate section modulus for the chordwise loads. The webs at $0.4 \mathrm{C}$ break the first afterbody into two cells. The aft cell is wound over a foam core which remains in place in the blade. This allows the first afterbody to return to the hub at $0.125 \mathrm{R}$ as shown in Figure 7 , thus forming a truss-1ike element which transmits the chordwise bending loads into the hub. A rib is provided at $0.25 \mathrm{R}$ to complete the truss. The first afterbody terminates at the inboard groove of the hub fitting.

\section{- Final overwrap}

The final overwrap forms the third cell and the airfoil shape of the blade. It is wrapped completely around the first afterbody and trailing edge core. The final overwrap is essentially a non-structural element which carries trailing edge air loads only. It is composed of a laminate which is "soft" in the spanwise direction so the blade can deflect in the chordwise direction without producing much stress in the overwrap. 
A

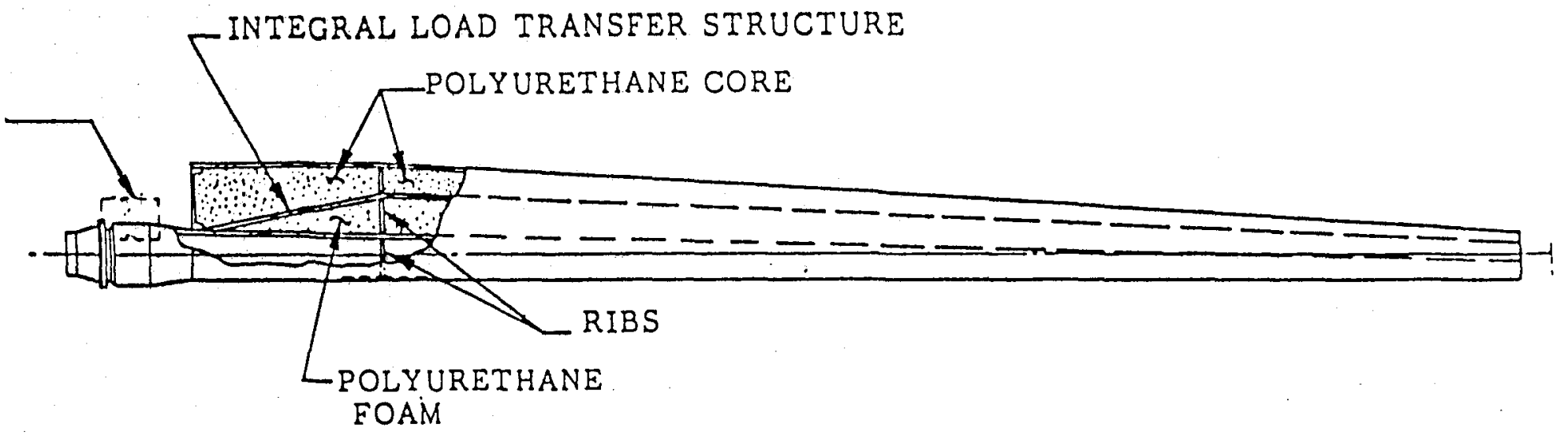

5

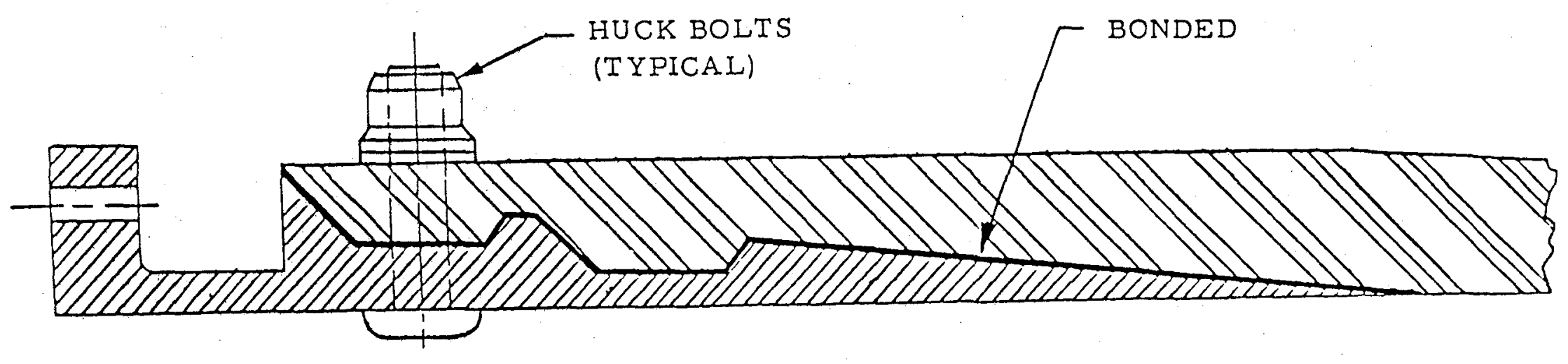

DETAIL A

FIGURE 7 R.OOT END DETAILS 
FOAM CORES

The first afterbody core is actually a wound in place permanent mandrel. It is used solely to form the shape of the first afterbody. It is made of $21 \mathrm{~b} / \mathrm{ft}^{3}$ foam.

The trailing edge core is made of $41 \mathrm{~b} / \mathrm{ft}^{3}$ foam because it sees concentrated loads during winding over the sharp trailing edge.

For purposes of structural analysis, neither core is assumed to contribute anything but weight.

4.2.1 HUB DETAILS

ROOT END FITTING

The steel root end fitting is shown schematically in Figure 7 .

The fitting contains two recessed groove areas to allow mechanical locking of the axial TFT filament wound composite onto the fitting. The locking is achieved by a series of $90^{\circ}$ hoop wraps at the groove locations. This SCI design

approach improves the structural reliability of the joint in the event of adhesive bond failure at the TFT-steel interface.

The gradual taper of the fitting at the outboard edge is designed for smooth load transfer between the spar and the fitting. The shallow conical angle of 40 also facilitates blade manufacturing during the filament winding process. The fitting is circular in cross section to mate to the hub adapter flange and to allow low cost fabrication by lathe turning of a ring forging. Three Huck-bolts are spaced radially around the circumference to positively prevent blade rotation in the event of adhesive bond failure.

HUB ADAPTER

The steel hub adapter for transferring blade loads to the NASA hub is shown schematically in Figure 8 . The adapter configuration and in particular the overall length was designed to minimize kick load effects at both the blade hub fitting and MOD-OA hub mounting interfaces. The bolted joint configuration at the hub/ fitting interface is designed to facilitate field installation of the blade. The internal bolting surface of the adapter at the hub/adapter interface requires assembly of the adapter to the hub prior to blade attachment to the adapter. 


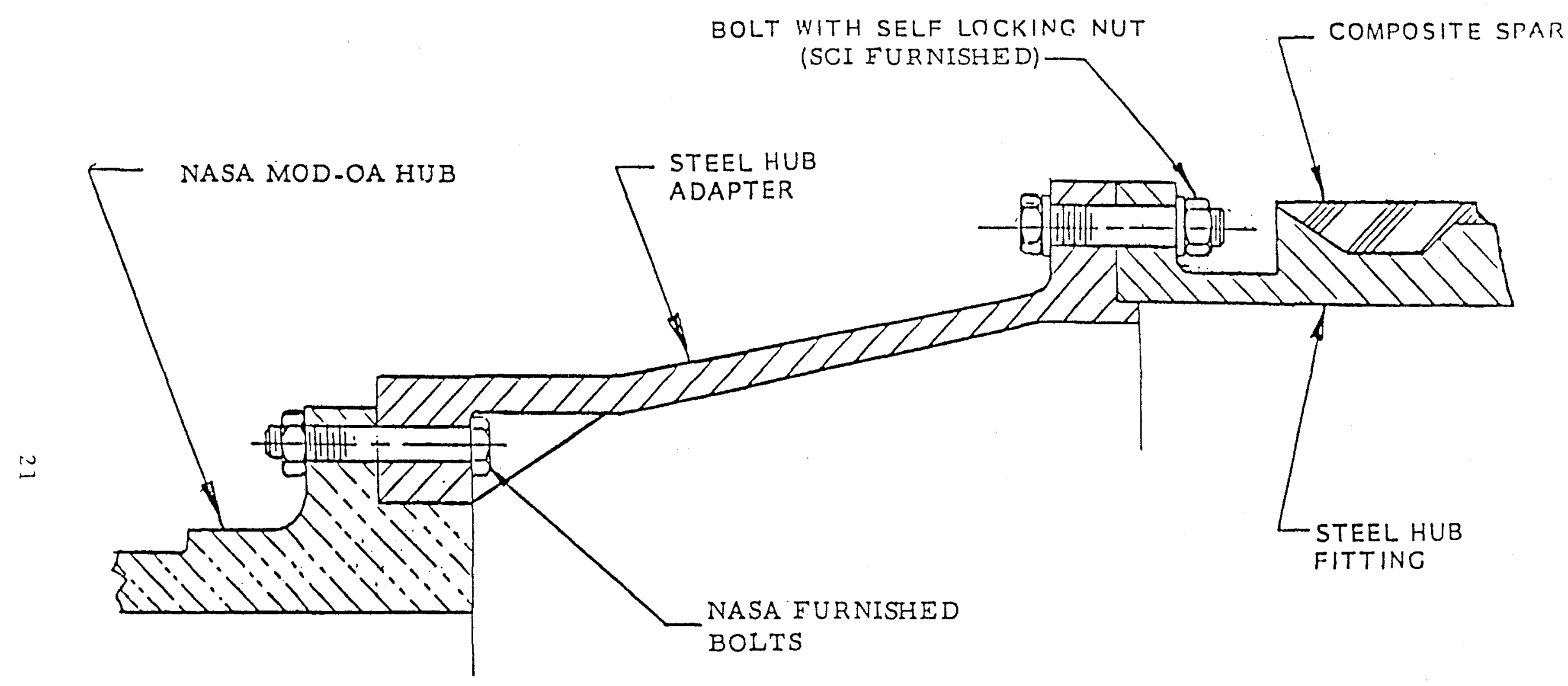

FIGURE 8 HUB ADAPTER DETAILS 
4.2.2 BALANCING, LIGHTNING PROTECTION, ICE DETECTION

BALANCING PROVISIONS

Figure 9 shows the balancing provisions built into the blade. Forward and aft tubes are provided at root and tip for chordwise and spanwise balancing and tuning. A large tube is provided near the c.g. for matching the weights of blades in a pair. Weight is added by injecting a non-metallic high density filled room temperature curing resin into these tubes.

ICE DETECTION

The NASA-furnished ice detector is mounted into a metal recessed flange which is wound into the trailing edge (Figure 10 ). The wiring conduit is routed along the aft end of the first afterbody wrap. This arrangement allows installation of the detector and wiring without cutting holes in any of the primary blade structure.

\section{LIGHTNING PROTECTION}

Since the composite blade is non-conductive, it is necessary to provide a conductive path along the blade surface from the aluminum tip cap to the hub fitting to ground any lightning strikes. A 6 in. wide by 0.004 in. thick aluminum foil strip is bonded along the trailing edge and routed to the hub as shown in Figure 11 .

\section{2 .3 MATERIALS OF CONSTRUCTION}

\section{BLADE}

Figure 12 summarizes the materials of construction for the blade. The principal reinforcement is E-glass continuous filament roving which has been woven into transverse filament tape (TFT), bias filament tape (BFT) and longitudinal filament tape (LFT). TFT has the primary filaments transverse to the axis of the tape. When this tape is wound circumferentially around the blade, it deposits the transverse filaments at approximately $0^{\circ}$ to the spanwise axis. In an analogous manner, BFT is used to provide $\pm 45^{\circ}$ reinforcement. LFT is used to produce $90^{\circ}$ reinforcement for chordwise strength. The resin matrix used is the same as that used on the $150 \mathrm{ft}$ composite blade. It is an amine-cured epoxy containing a reactive dilutent. 


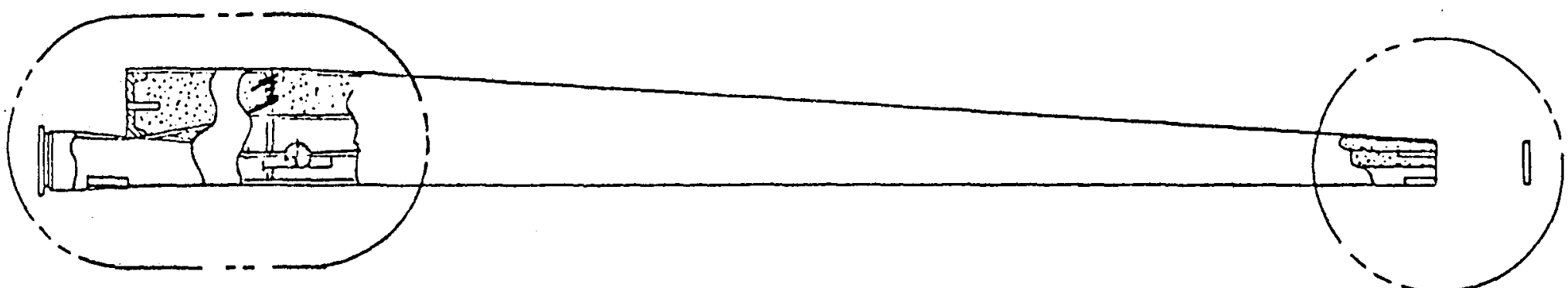

FIBER REINFORCED PLASTIC (FRP) TUBES

FRP TUBES

BONDED IN

PLACE

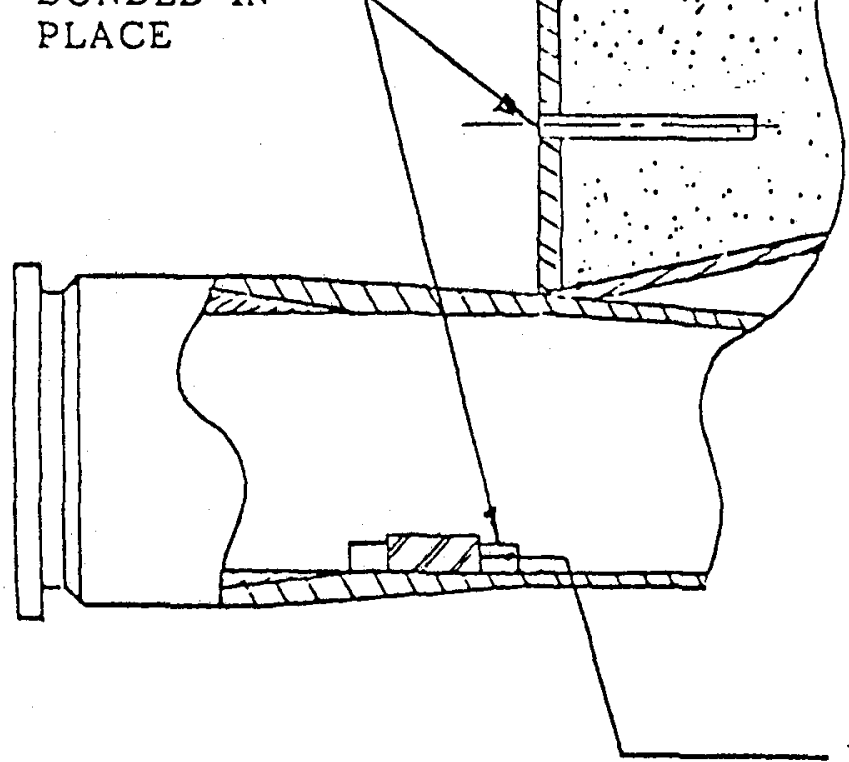

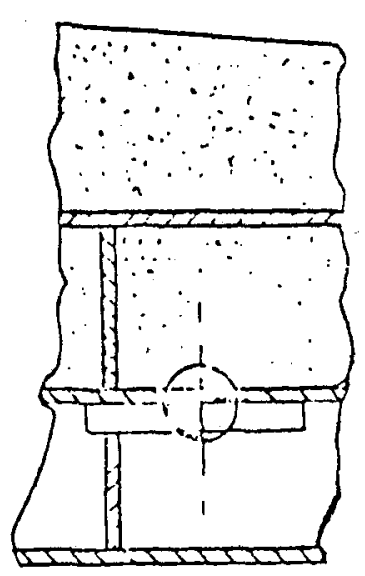

FRP LAYUP
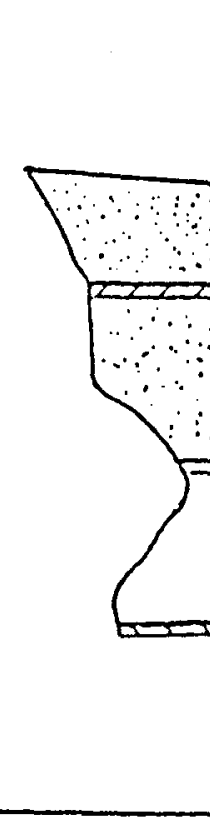
IN CAULKING GUN
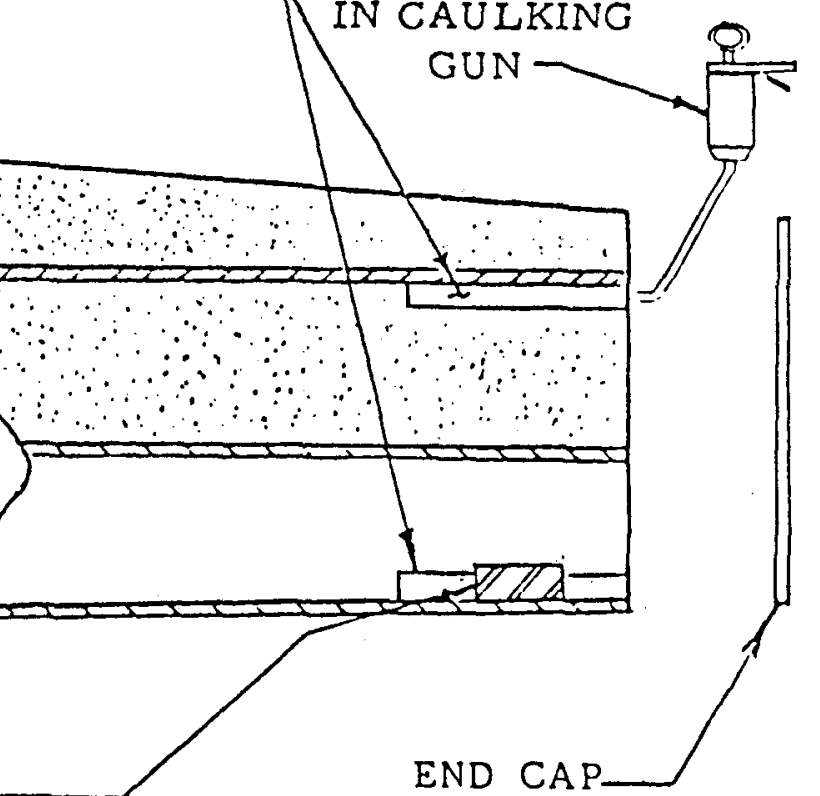

FIGURE 9 BALANCE WEIGHT DETAILS 


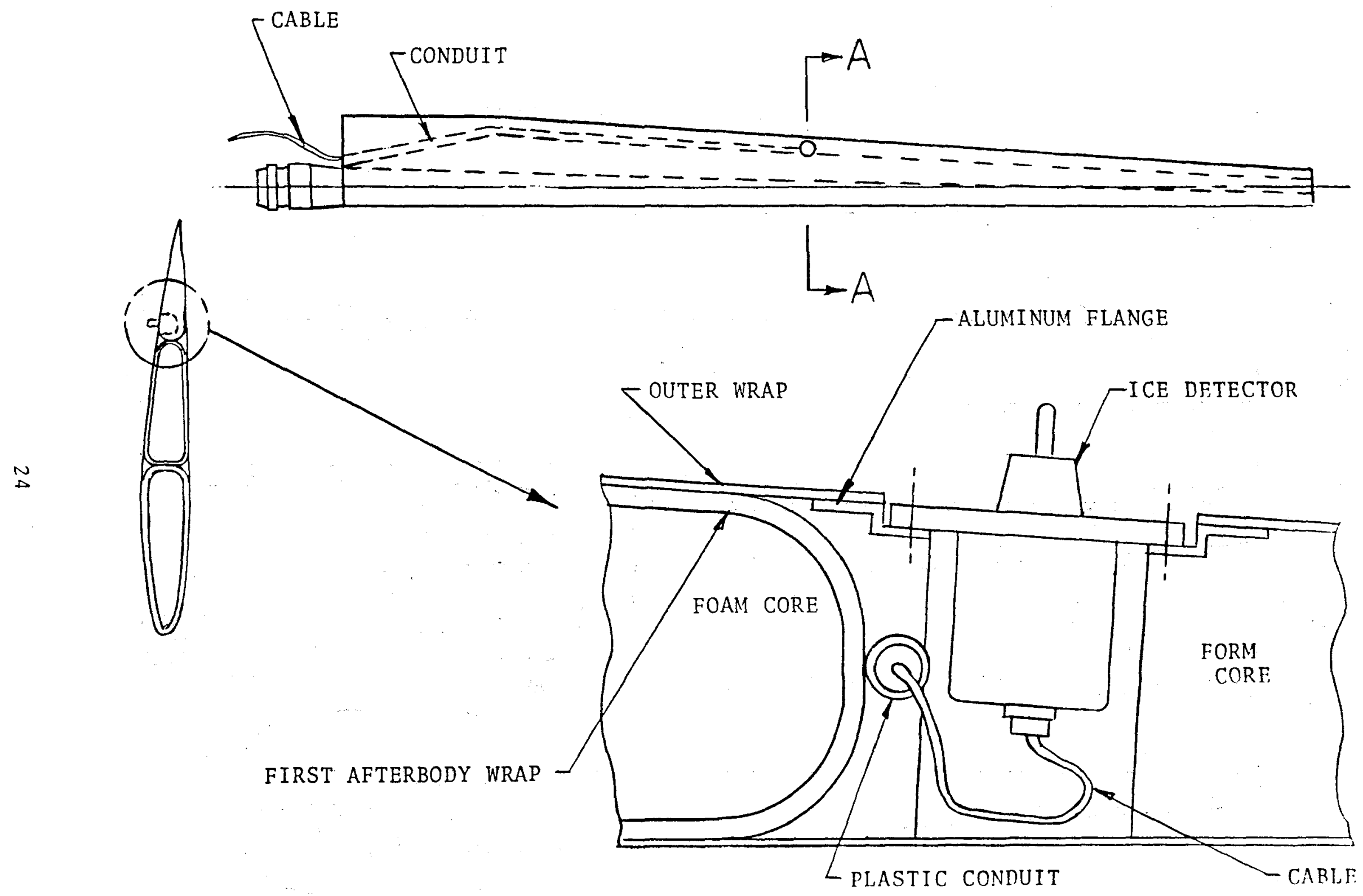

FIGURE 10 ICE DETECTOR INSTALLATION 


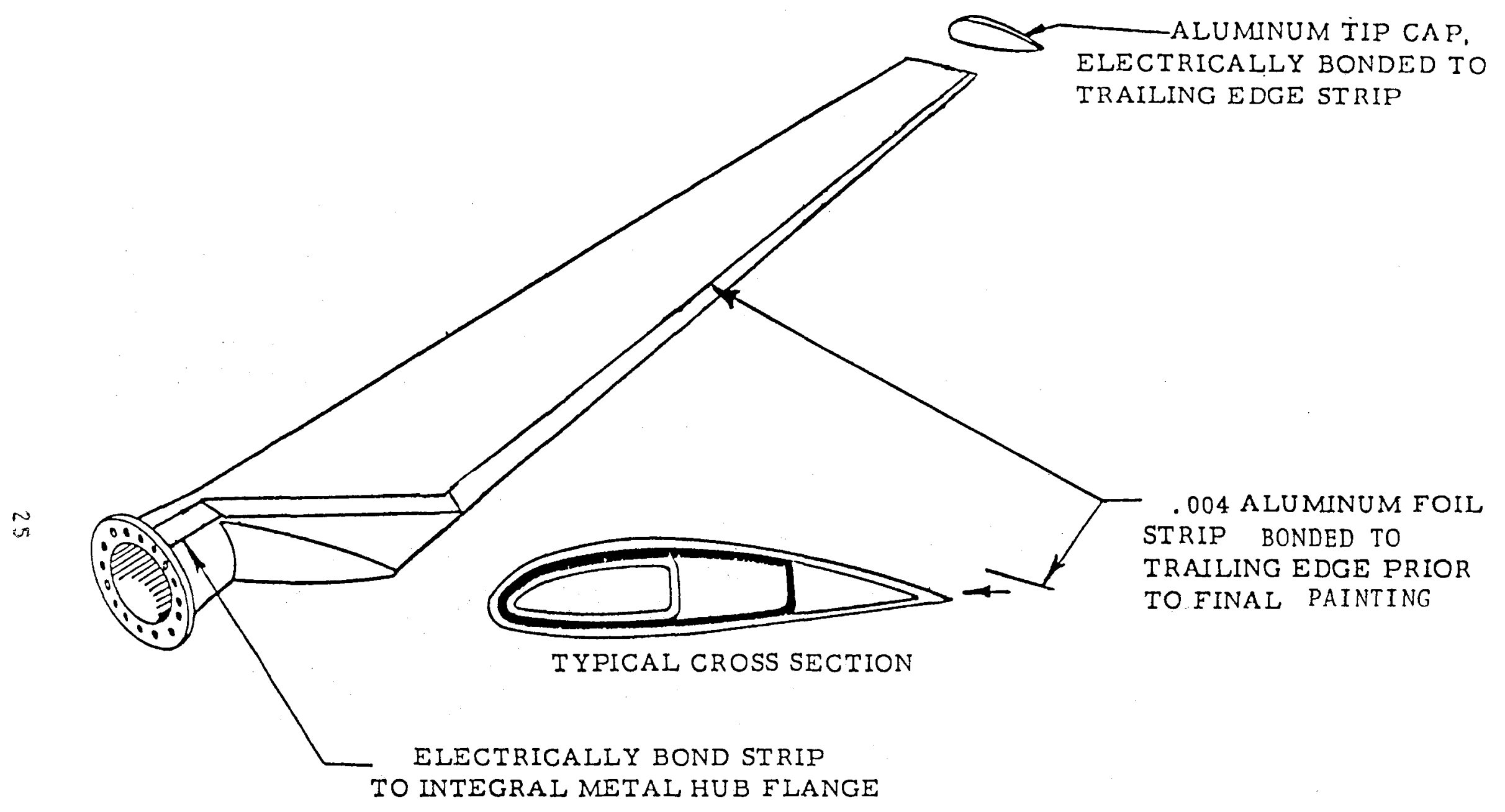

FIGIJRF 11 LIGHTNING PPOTECTICN 


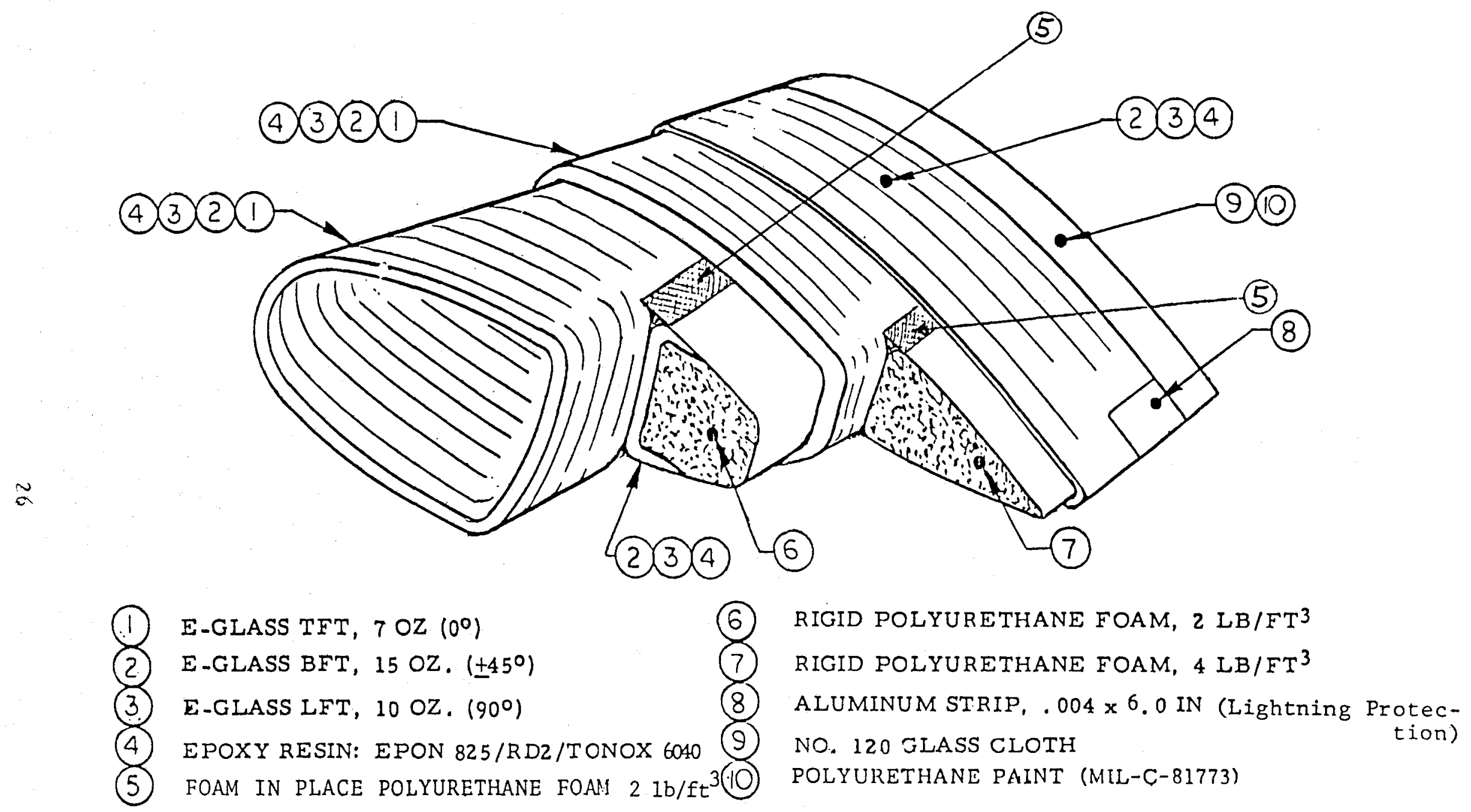


Foam cores are rigid polyurethane foam of 2 and $41 \mathrm{~b} / \mathrm{ft}^{3}$ density. A layer of number $120 \mathrm{glass} / \mathrm{cloth}$ is wound on the blade surface to give a good final finish and to avoid chordwise cracking of the outer hoop windings during blade flexing. The final step is painting the blade. The polyurethane coating used is a MIL-C-81773 - two part - high solids paint which bonds to the epoxy matrix during final blade cure. It serves as a screen against ultra-violet rays (which can degrade the epoxy) and has good abrasion resistance and gloss retention in the outdoor environment.

$\underline{\text { HUB }}$

The hub fitting and hub adapter are made of heat treated 4140 stee1. An epoxy film adhesive and primer system are used to assure a good bond between the composite spar overwrap and the hub fitting.

$4.3 \quad$ DESIGN AND ANALYSIS

4.3.1 DESIGN APPROACH AND CONSIDERATIONS

GENERAL CONDITIONS

Typical large wind turbine blades are characterized by the following requirements:

- Complex (airfoil) shape with twist

- Taper in planform, airfoil thickness and wall thickness

- High structural loads, both steady and cyclic

- Need for low cost

- Must interface with hub structure, usually at the point of maximum loads

- Dynamic requirements, i.e., natural frequency "tuning" and need to avoid flutter

- Need for long life in severe environment

Composite materials are a strong candidate for large wind turbine blade fabrication, as they offer advantages over conventional materials for most of these requirements. 
Composites are generally formed to their final shape during the fabrication of the structure. It is not necessary to rivet or weld together parts made of standard size sheets or plates as with metals. Simple and compound curves are relatively easily formed with composites; as are structures with varying wall thickness. Large structures can be formed in one piece, without joints.

The properties of composite materials can be "tailored" to the requirements of the structure. The strength and stiffness can be varied directionally and local reinforcements and inserts are easily incorporated. Properties can further be varied by the choice of matrix resin and reinforcement fibers. This allows considerable flexibility in structural design, and in cost/performance trade-offs. Composites are relatively inert to the usual environmental conditions. They exhibit reasonable and predictable fatigue strength and low notch sensitivity.

As with conventional materials, composites are available in a variety of raw material costs with a corresponding range of performance and properties. Again, as with conventional materials, higher performance generally means higher raw material costs and more difficult and expensive processing into the final structure. Conventional composites offer high strength to density ratios, and stiffness-to-density ratios which are comparable to conventional materials. The more expensive advanced composites offer even higher stiffness-todensity ratios than metals.

Many different manufacturing processes are used to form structures from composite materials. The processes applicable to large blade structures have been molding and filament-winding (and various combinations of these processes).

FILAMENT WINDING CONSIDERATIONS

Typical filament-wound composite wind turbine blades and spars require high axial stiffness. In addition, structural and aerodynamic considerations require taper in the wall thickness and diameter. Two approaches have been previously advanced to provide the axial reinforcements:

- Low-angle helical windings, which have a large component of strength axially, as used in the NASA MOD-O Composite Blade. (Reference 2)

- Purely axial material, applied in the form of longitudinal tapes or windings. 
Both of these types of reinforcements must be applied in layers of staggered length to achieve the tapered wall thickness. These axial layers may be supplemented by layers of $\pm 45^{\circ}$ helical windings and/or $90^{\circ}$ hoop windings to provide the required transverse and shear properties to the composite.

\section{PROBLEM WITH CONVENTIONAL APPROACHES}

While purely axial plies are more structurally efficient than helical windings, they cannot be applied by conventional filament winding machinery, which normally requires some minimum angle of wrap.

The "dropping off" of layers to form the tapered wall thickness is costly in both 1 abor and wasted materials.

On conventional machinery, low angle helicals or longitudinals must be wound at relatively slow payout speeds. This compromises one of the inherent advantages of the filament winding process, namely high speed deposition of composite. In addition, the windings tend to get thicker as mandrel circumference decreases. This is the reverse of the desired direction of taper, and increases the notch effect of layer termination.

\section{TRANSVERSE FILAMENT TAPE PROCESS}

The transverse filament tape process, shown schematically in Figure 13, alleviates or eliminates the problems listed above. This SCI-developed process was used to fabricate the spar of the $150 \mathrm{ft}$ composite blade (Reference 1). (Note that the $150 \mathrm{ft}$ composite blade was wound using a rotating mandre1. The MOD-OA blades described in this report were wound using a stationary mandrel.)

Transverse filament tape, Figure 14, is a form of unidirectional woven roving. This product is available, in E-glass and other reinforcements, at commercially attractive prices. The tape is woven with approximately 99\% "fill" or "woof" material so that it's major strength is transverse to its length. Hence, the name transverse filament tape or "TFT". Only enough "warp" or longitudinal material is provided to hold the tape together.

This product was developed for a similar use in the commercial filament-wound pipe industry and is manufactured in large quantities on a routine basis. Composite strength and stiffnesses achievable with this type of material are comparable to those of filament wound composites with the same orientation of reinforcements. One method of weaving allows the tape to stretch slightly, thus allowing wrapping a cone without wrinkling. That tape can also distort in a parallelogram fashion so that $0^{\circ}$ alignment of the transverse filaments to the mandrel axis is possible even though the tape is being wound with a helical pitch angle. 


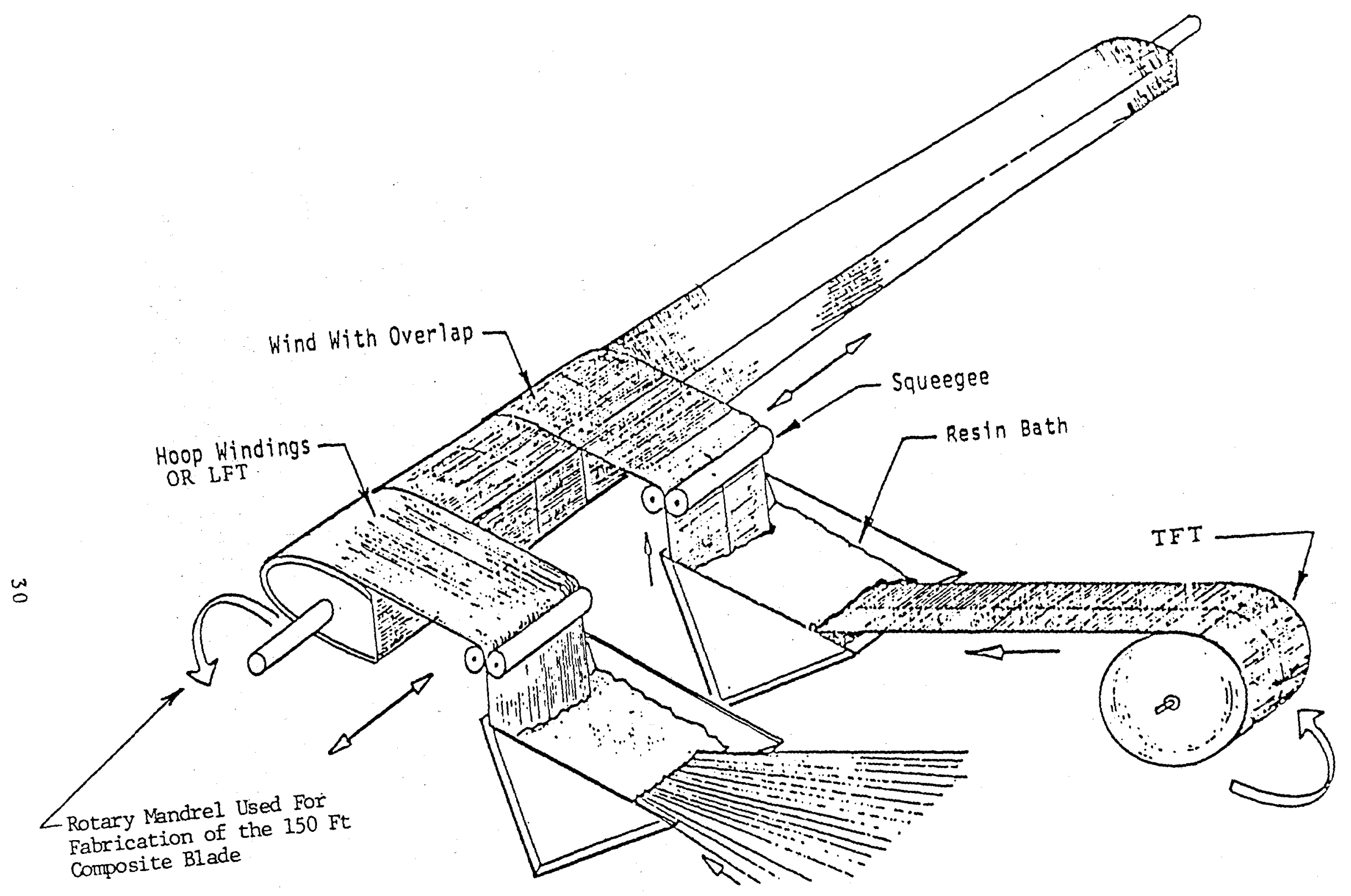

FIGURE 13 THE TFT PROCESS 
11 a $p$ Filaments

l.css Than lo of Height)

Transverse

$F i j a m e n t s$

Pan $=2=$

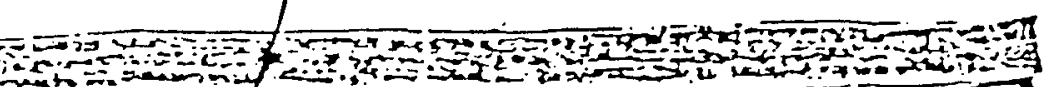
É

-

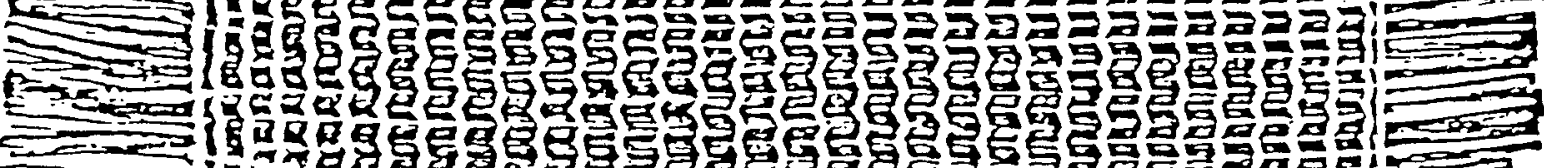

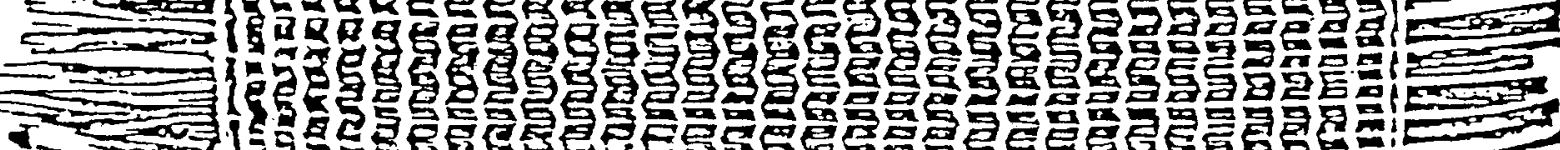

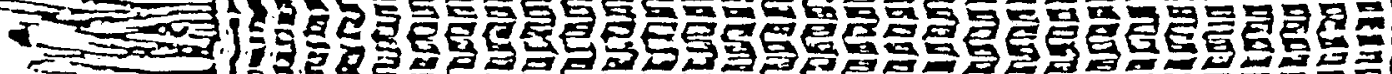

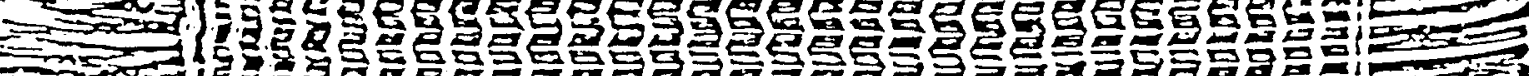

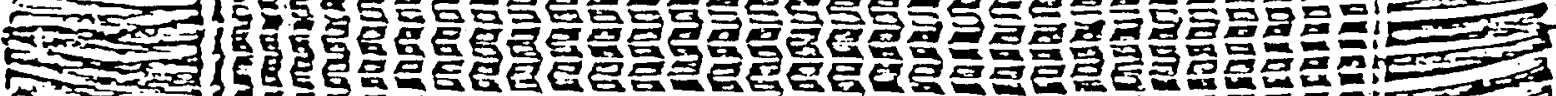

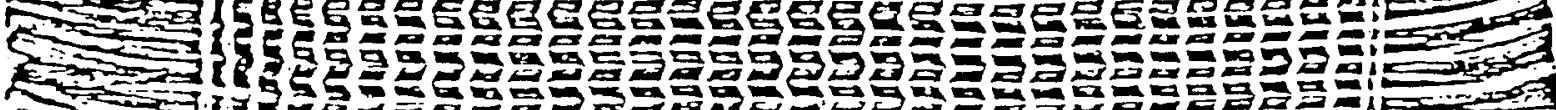

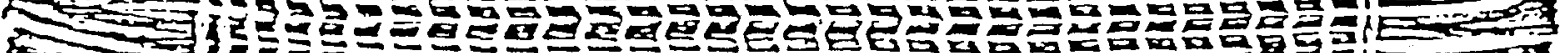

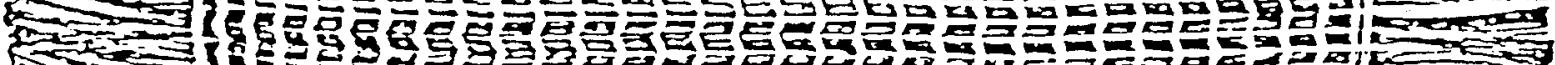

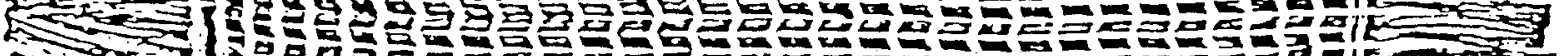

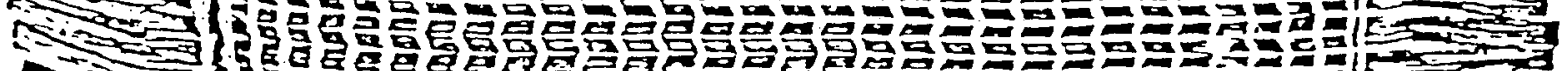

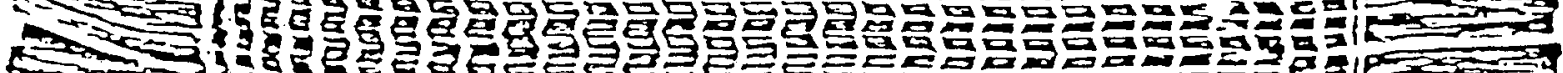

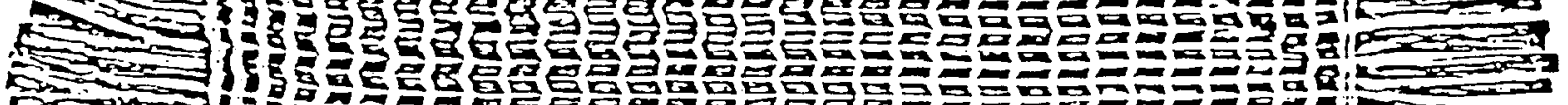

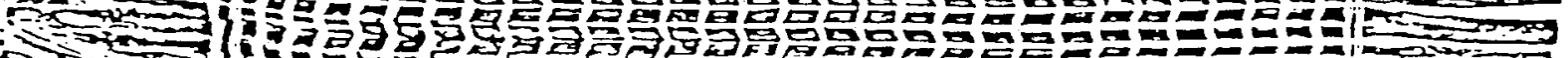

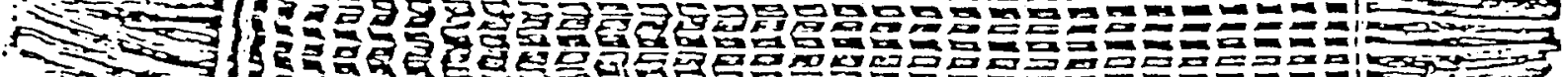

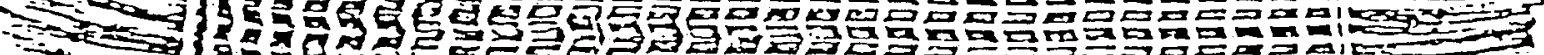

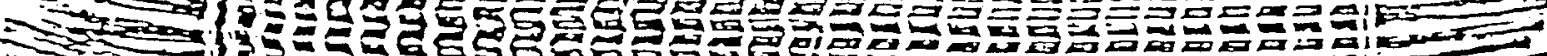

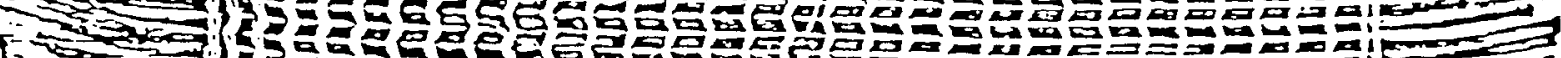

L

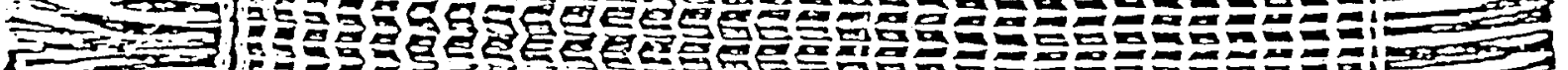

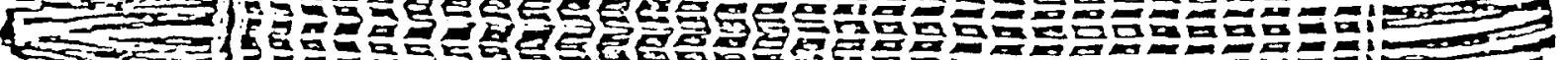

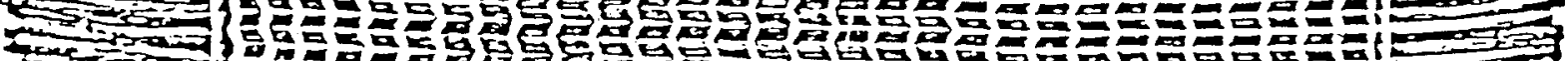

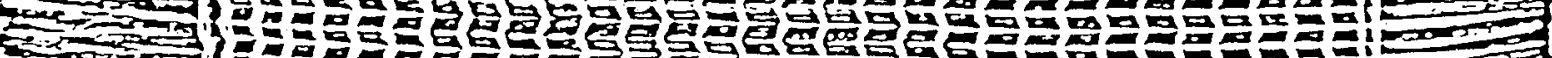

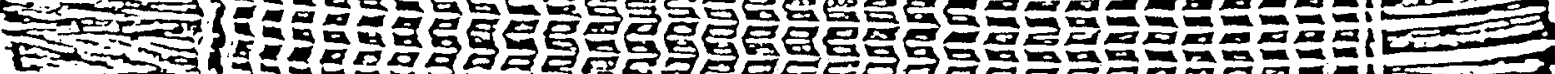

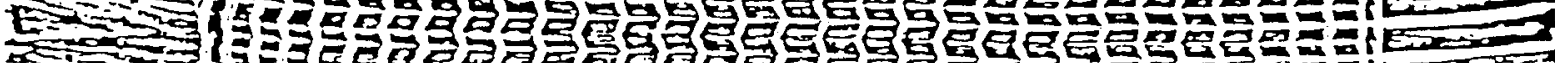

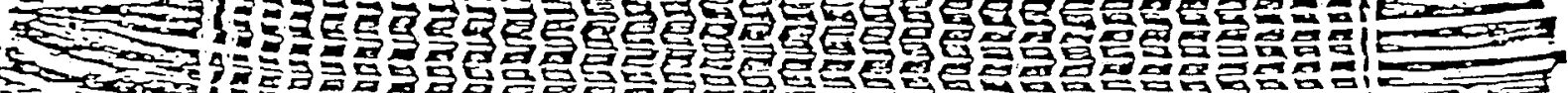

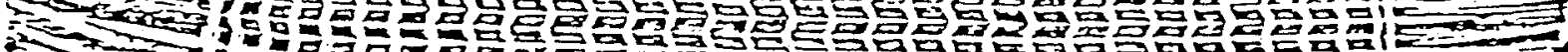

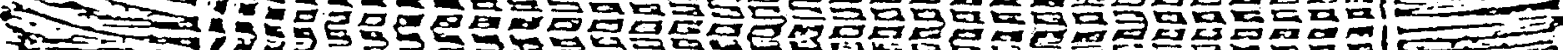

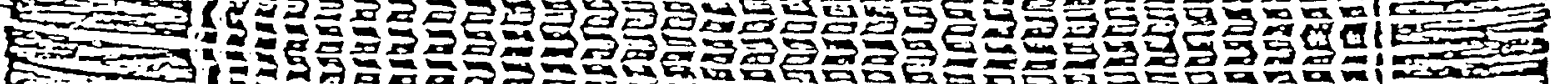

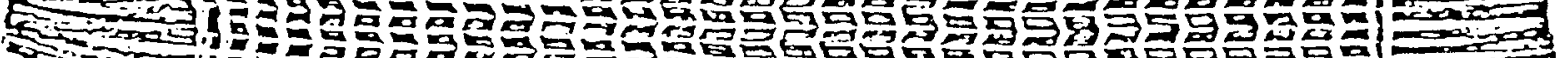

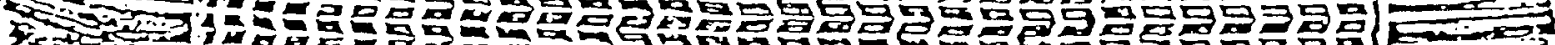

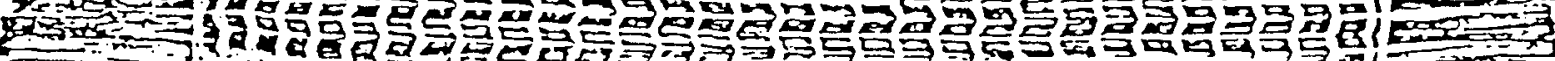

눈

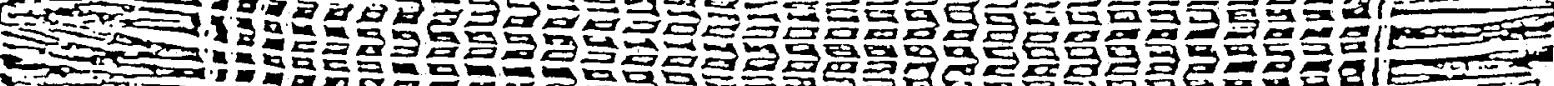

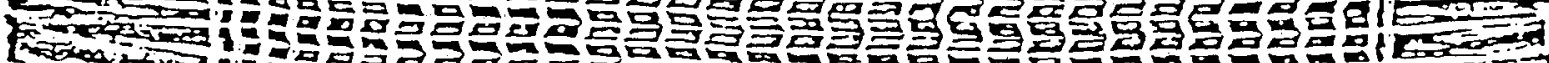

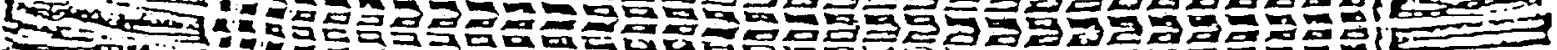

순

Fi二-

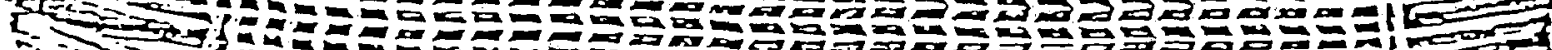

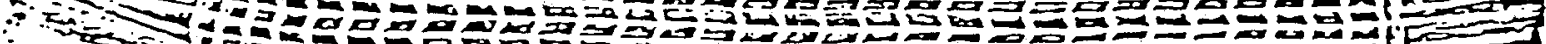

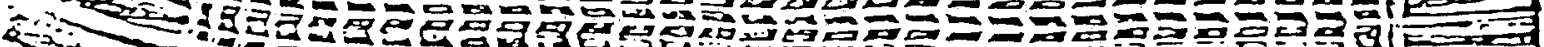

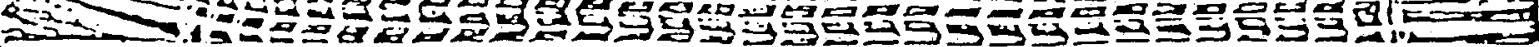

Figure 14

Transverse Filament Tape (TFT) 
As shown in Figure 13 , the TFT tape is wound in the hoop direction, so that the fill reinforcements are essentially axial relative to the spar. Each wrap overlaps the previous one. The tape wraps may be followed by, or interspersed with, $90^{\circ} \mathrm{LFT}$ and/or $\pm 450 \mathrm{BFT}$ to provide compaction, as well as the desired transverse and shear properties.

\section{ADVANTAGES OF THE TFT PROCESS}

- Production Speed

Since the TFT tape is wound in the hoop direction, the winding machine can be run at a constant high rotational speed, with a high payoff rate and slow carriage traverse. This is opposed to low angle helical winding where the mandrei turns very slowly and the carriage must traverse rapidly and must undergo extreme changes in speed and direction at the ends of its stroke. The TFT machine fully covers the mandrel in one carriage pass, while the helical machine must traverse many times for just one layer. Since the hoop windings may be applied simultaneously with the TFT, three or more layers may be applied at once (i.e., one hoop layer and a double overlapped tape layer).

- Ease of Winding Tapered Composite

With the TFT process, it is relatively simple to apply partial layers to achieve a tapered wall thickness from root to tip. The direction of winding may be reversed at any point in the carriage traverse without stopping the winding process. Also one turn of the mandrel produces the same thickness per ply regardless of mandrel circumference.

\section{- Elimination of Wasted Material and Labor}

The transverse filament tape concept does not require "dropping off" of layers as in helical windings, hence no material or labor is wasted in attaching "generating discs" or in trimming the dropped-off plies. In addition, it is possible to wind up to a square edge, so that the "turnaround area" required by helical winding is eliminated. This turnaround area is waste material, normaliy discarded after trimming. With the TFT process, the mandrel may be fitted with end plates which form a finish-molded edge at blade root and tip.

\section{- Ease of Mandrel Removal}

Mandrel removal from a spar wound with the transverse filament tape process is surprisingly easy. This is thought to be due to the fact that the majority of the reinforcement, the TFT, is wound at relatively low tension. Only the LFT windings, which are a small percentage of the total thickness, are wound with normal filament winding tensions. Thus the radial force due to circumferential pre-stress is quite low. Furthermore, the highly axial orientation of the composite allows the application of very high extraction forces if needed, without risk of structural damage to the composite. 
- Ease of Automation-Reliability-Equipment Cost

The machine motions required for the TFT process are simple: Continuous rotation in one direction and slow carriage traverse at a fixed pitch in two directions. This type of motion is easily programmed by simple electro-mechanical devices and does not require complex, computer controlled, servo-hydraulic winding machinery with its concommitant high cost and low reliability. Any simple mechanical 1athe-type machine can wind parts by this process. Machines of this type have proved to be rugged, reliable and "idiot-proof" in high speed mass production of commercial filament-wound pipe and tanks.

- Efficiency of The Reinforcement

With the transverse filament tape construction, less material is required than with helical windings since the reinforcement is aligned with the direction of desired stiffness. DISADVANTAGES OF THE TFT PROCESS

- Cut Filaments

The most questionable aspect of the transverse filament tape approach is the presence of cut filaments in the axial reinforcement at each edge of the tape. In practice, in filament wound pipe, as little as a one inch overlap has been found sufficient to transfer load from tape to tape by shear in a polyester resin matrix. In wind turbine blade or spar winding, where mostly axial material is required, it is possible to program a $50 \%$ or greater overlap of succeeding wraps. Each cut edge is then sandwiched between several uncut layers, so that the amount of cut filaments present at any plane through the spar thickness is insignificant. Additionally, any tapered laminate must contain a certain amount of cut filaments, whatever the process used.

- Laminate Quality

Since the transverse filaments in the tape are wound in a "relaxed" state, without axial tension, they tend to be not as closely packed or as accurately aligned as machine filament windings. However, as stated before, the resultant composite properties compare favorably with filament windings, and especially with low angle helicals wound over large radii of curvature, as would be required in large WTG blades or spars. The use of hoop windings or LFT allows compaction of the tape laminate and also produces a final surface finish where the "lay" of the finish is chordwise, which is desirable from an aerodynamic and aesthetic standpoint. 
Need for TFT Roving Pre-impregnation

The TFT/Ring winder process requires that the fiberglass materials be pre-impregnated with the winding resin prior to winding. This results in increased labor costs over a machine filament winding process that uses wet winding of the roving materials. Because the mandrel does not rotate in the TFT/Ring Winder process, a thickening agent was added to the resin to prevent excessive resin migration to the bottom of the wound structure. The addition of the thickening agent inhibited the displacement of entrained air and excess resin to the wound surface during the winding and curing processes. This requires that a vacuum bag compaction process be used for the fabrication of the low cost blades in order to achieve target blade weights.

\section{- Cost of Raw Material}

The transverse filament tape needed for this process is more costly than the continuous filament roving used for filament winding. On balance, we feel that the 1 abor and waste material savings inherent in this process will compensate the added raw material cost. The large scale requirements expected for WTG production programs will undoubtedly drive the price down closer to that of conventional woven roving, which presently is much lower in cost than TFT, as competition and learning curves come into play.

\section{MANDREL/WINDING MACHINE CONSIDERATIONS}

The slenderness and non-circular cross section of large WTG blades and spars caused problems of mandrel design in previous WTG composite blade programs.

A conventional filament winding machine, such as used on the MOD-O and 150 ft blade program, has a lathe-type arrangement. As shown in Figure 13 , the rotating mandre1 is supported by a headstock and tailstock, while a traversing carriage feeds the winding material onto the carriage at a programmed pitch angle. With round mandrels of low slenderness, such as used for pipe and tanks, this approach works fine, but the slender mandrels of WTG spars are subject to very high deflections due to beam bending, especially when the chord is horizontal. The changing effective section modulus of the mandrel causes it to bend differently as the chordline rotates. Thus the mandrel is subject to high fatigue stresses as it rotates and must be carefully designed and constructed, for cost-effective useful life. One solution to this problem is to use a light-weight breakdown mandrel with a stiff inner shaft; cantilevered at the root end, as in MOD-0 and MOD-1 programs. Problems were encountered with weld and pin joint failures in these programs, which probably can be overcome with careful design, but the mandrel still rotates and bends so useful 1 ife is limited; and the disassembly and reassembly of the mandrel for each blade is time consuming and labor intensive. 
In the $150 \mathrm{ft}$ blade program the successful solution was to use a conservatively designed monolithic mandrel with a movable steady rest to support the center. The deflection was still quite high in the outer half (up to 6 inches) and the use of a steady rest dictates winding the spar in at least two parts with a long, bonded scarf joint in the center. This two-part construction increases cost and reduces reliability of the spar, and the mandrel still has limited life (estimated 10 spars).

Not resolved in these programs was the effect of the constantiy reversing mandrel deflection on the properties of the resulting composite. Since the composite is "working" slightly during winding (and during cure if a rotating cure is used) there is concern about the possibility of reduced strength properties or defects being introduced into the structure by the fabrication process.

Another area of concern is the effect on final straightness of a blade of the constantly changing deflection during winding. The $150 \mathrm{ft}$ spar was supported straight, (chord vertical) during final gel and cure and fit the blade assembly fixture reasonably well, but it did have a slight error in twist.

A further complication with conventional lathe type winding is the change in mandrel rotational center of gravity due to both deflection and the buildup of composite on the non-circular cross section as winding proceeds. This can be minimized by balancing the bare mandrel through the theoretical centroid of the final composite, as was done on the $150 \mathrm{ft}$ spar program. Other approaches involve adjustable counter weights and adjustable shaft locations for the mandrel. At the finish of $150 \mathrm{ft}$ spar winding we were driving an approximately 55,000 Ib unbalanced rotating mass (mandrel, spar and steadyrest rings) and winding had to proceed very slowly (about $2 \mathrm{rpm}$ ).

Note that as the blade becomes more efficient, that is more slender and thinner, these problems are exacerbated.

THE RING WINDER

The SCI ring winder eliminates or alleviates the problems discussed above. The general approach is shown in Figure 15 . The traversing carriage carries a rotating ring which winds the TFT (or conventiona 1) material around a stationary mandrel. The mandrel, being subject to static deflection only, now can be designed for infinite life, and will he lighter and cheaper than a rotating mandrel. The mandrel is positioned with it's chordline vertical, which gives the highest stiffness. Cantilever support and precambering may be used to assure an essentially straight mandrel. Any deflection which does occur can be "designed in", as it will be the same from blade to blade. 


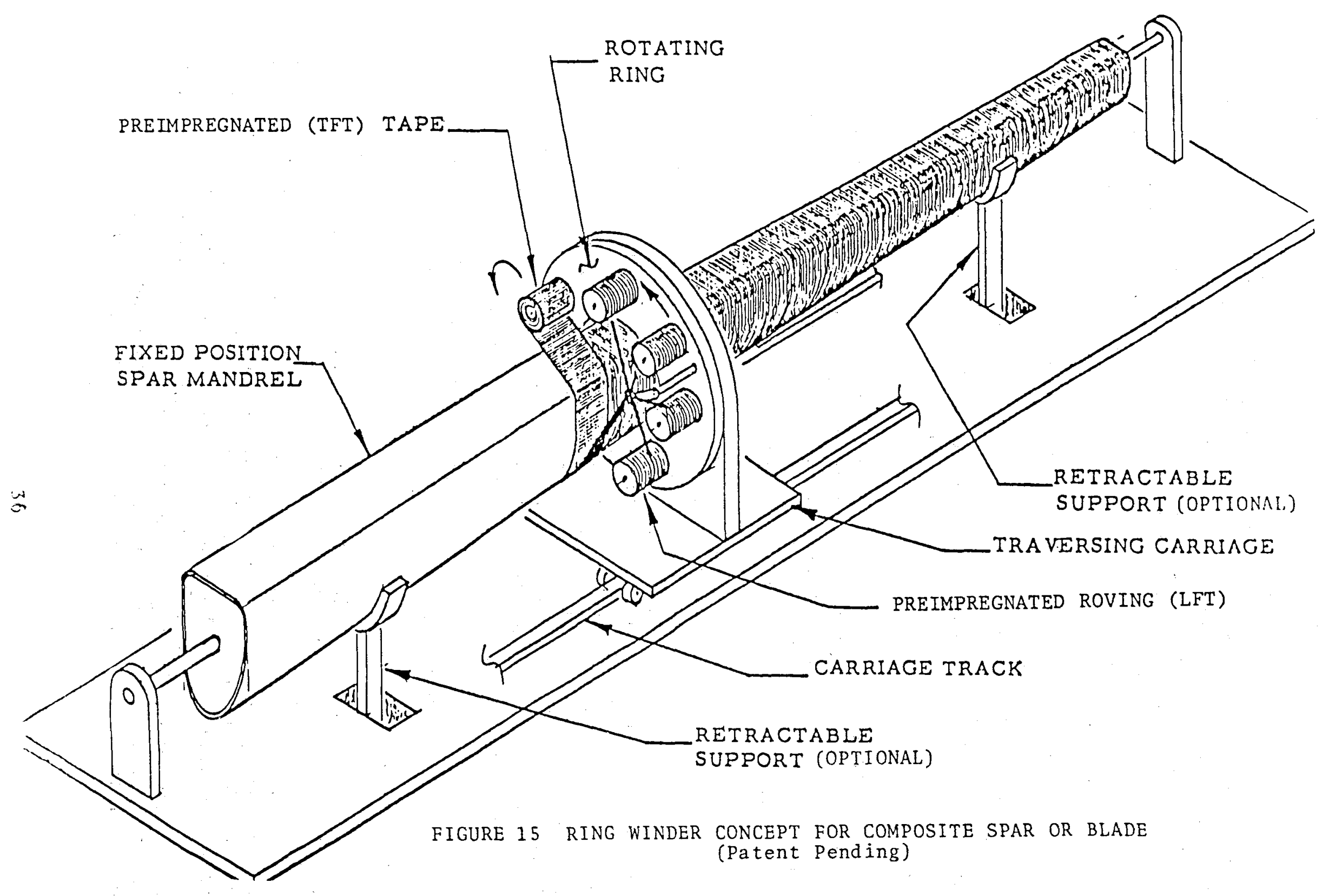


On the ring winder, pre-impregnated winding material is uniformly distributed around the rotating ring; so that balance of the ring is maintained during winding. Note that we are now driving a round, balanced, relatively light-weight ring, instead of the massive unbalanced mandrel, so the winding machine becomes simpler and cheaper, with lower power requirements. The full potential of the TFT process for high speed winding can now be realized.

The use of wet pre-impregnated TFT material (already used on the $150 \mathrm{ft}$ spar) assures thorough wetout of the reinforcement and allows the checking of each roll of material for weight, resin content, cure and gel characteristics and manufacturing defects before it ever gets onto the blade or spar.

\section{CONSTRAINTS AND COMPROMISES}

SCI has conducted design studies for composite blades for the MOD-1, MOD-2, MOD-3 and MOD-5 programs. In these cases the blade, hub and total WTG system were being designed together, with constant trade-offs taking place to optimize the cost of energy.

In this low cost composite blade program, the basic program objectives of low cost with light weight were somewhat compromised by the requirement that these blades be designed to be used on the existing MOD-OA wind turbine. The MOD-OA was initially designed for aluminum blades, which terminate in a steel hub flange of relatively small diameter. In contrast, filament-wound composite blades are usually wound on a D-spar mandrel which must be extracted through a relatively large diameter hub fitting. Thus the hub diameter is interrelated with the winding process, as well as with the blade and hub design. The MOD-OA hub flange diameter is too small to allow extraction of a mandrel of adequate chord width for the structural requirements of the blade D-spar and the winding mandrel itself.

The existing MOD-OA hub design mandated another constraint on low cost composite blade design. Structural capabilities of the existing hub limit the overall blade weight and gravity moments. This dictates a very light, efficient blade structure, which may not necessarily be the most cost-effective design. Due to this limitation, the maximum blade weight was reduced from 4000 to $30001 \mathrm{bs}$ and a maximum gravity moment requirement of $47,000 \mathrm{ft} / 1 \mathrm{bs}$ was added. Other constraints were the need for soft tooling due to budget limitations and certain material and process changes which were made to reduce technical and programmatic risk for the prototypes. 
These constraints resulted in the following design compromises:

(1) The hub diameter of the blade was increased to allow extraction of the D-spar mandrel.

(2) A steel hub adapter was used between the MOD-OA hub and the larger SCI hub flange (the cost and weight of this adapter is considered to be part of the blade).

(3) Since the D-spar chord width was still too small to sustain chordwise blade loads without excessive wall thickness and weight, a structurally efficient 3 -cell blade cross section was designed to extend the chord width of the main blade structure.

(4) The first afterbody mandrel could not be easily extracted because of interference with the hub fitting. The mandrel was therefore fabricated from low density foam and left in place in the blade. This meant a new foam mandrel had to be built for each blade.

(5) The D-spar, no longer the main blade structure, was now relatively thin. It had to be provided with a web doubler, which was applied by hand layup to the first afterbody foam core.

(6) By NASA direction, several material changes were made which increased cost of the prototypes but reduced technical risk. One of these was a change from aluminum to hardened, high strength steel for the hub fitting and root end adapter.

(7) Another NASA directed change was the use of the epoxy resin system from the $150 \mathrm{ft}$ spar program instead of low cost polyester resin originally proposed. The epoxy resin used did not wet the TFT material easily, so vacuum impregnation had to be used. This resin also had a relatively short pot life, which increased the risk of problems with premature resin gel during the winding process. In order to decrease this risk, each of the three major blade winding steps (D-spar, first afterbody and final overwrap) was done as a separate operation. Each of these windings was wrapped in peel ply, vacuum bag compacted, and gelled in the oven. The wound part was prepared for the next operation by removing the pee1 ply to expose an "open" surface for bonding. By this approach the time pressure of resin pot life was reduced. However, labor and material costs for the prototypes were substantially increased compared to a continuous production winding operation.

(8) In order to minimize blade weight, a bleeder p1y and vacuum bag was applied to each of the three winding steps during gel. This held resin content and weight to a minimum, but added material and labor costs, and degraded the blade surface contour and finish.

(9) Due to program tooling cost constraints, the foam mandre1s were precut from slabs of foam rather than being foamed in place in molds. 


\subsubsection{CANDIDATE DESIGNS AND TRADE STUDIES}

A number of candidate blade designs were evaluated during

Phase I. The following blade design elements were examined:

- Solidity and planform

- Cross section details

- Root end cutout and afterbody transition to hub

- Hub attachment

SOLIDITY AND PLANFORM

All of the designs considered were essentially linear taper/ linear twist blades. Figure 16 shows the various planforms considered (Design 1 was the SCI proposal baseline design at the start of Phase I). The Design 1 planform was very similar to the aluminum blades of MOD-OA except for the root end detail. Design 2 had a higher solidity to allow the blade to handle the greater power anticipated for MOD-OAW (a proposed MOD-OA commercial system). This proposed commercial version of the MOD-OA would have up to $500 \mathrm{~kW}$ output as opposed to $200 \mathrm{~kW}$ for MOD-OA. This blade was too heavy for the MOD-OA hub. The final compromise planform of Designs 3 through 8 was essentially constant except for root end cutout and termination details.

\section{CROSS SECTION DETAILS}

All blade cross sections considered were multiple cell designs. Figure 17 shows the cross sections for Designs 1 through 5 . Designs 6, 7 and 8 were shown in Figure 6 . Note that this is similar to Design 3 except for the foam core in the second cell of Designs 6,7 and 8 .

Basically the cross section varied from 2 to 4 cells, the final selection being 3 cells with a web doubler. The 3 -cell design was a good compromise between the lower cost of the 2-cell designs and the lighter weight of the 4-cell designs (for equal planforms). 


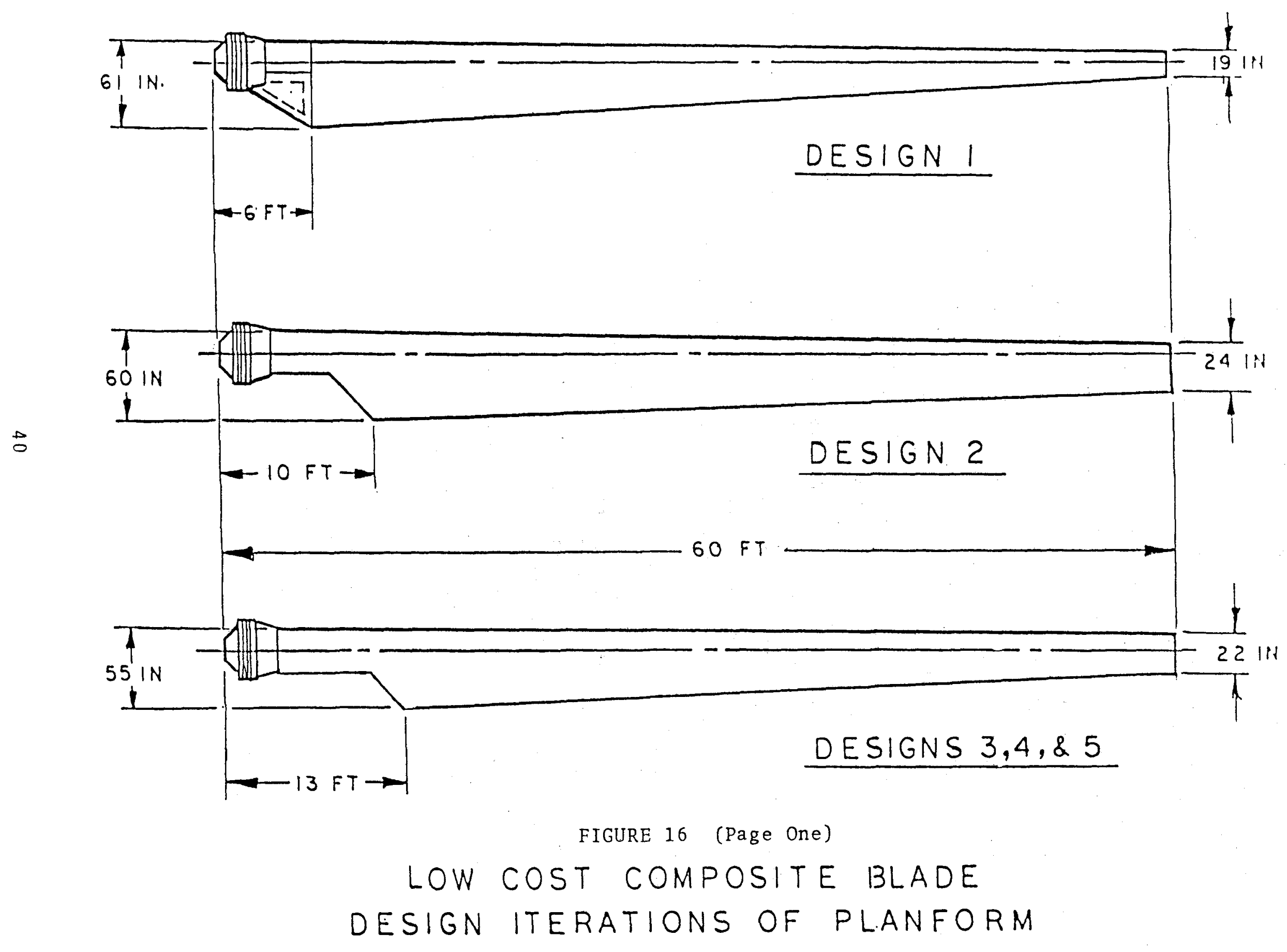



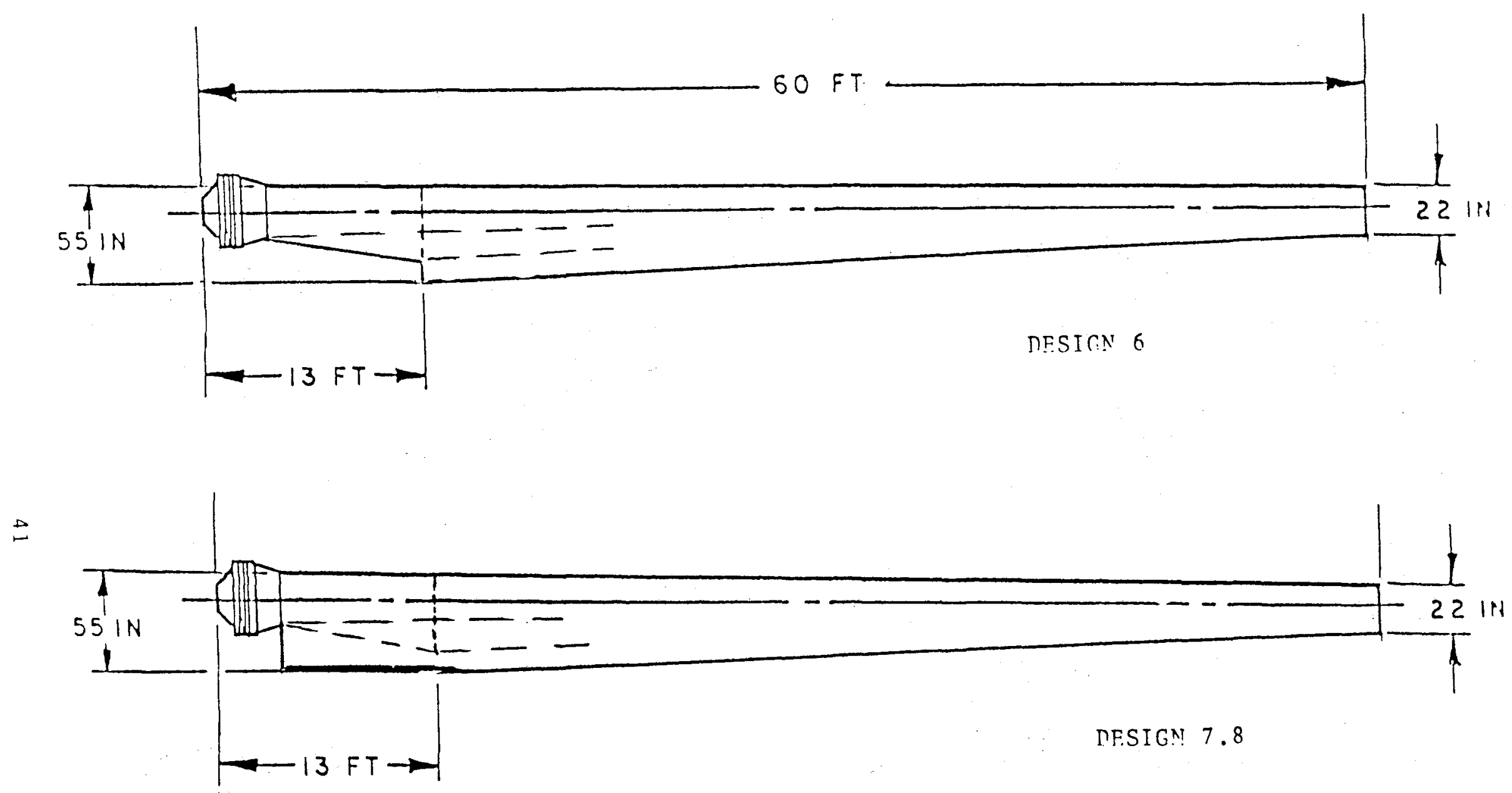

FIGURE 16 (Page Two)

LOW COST COMPOSITE BLADE DESIGN ITERATIONS OF PLANFORM 


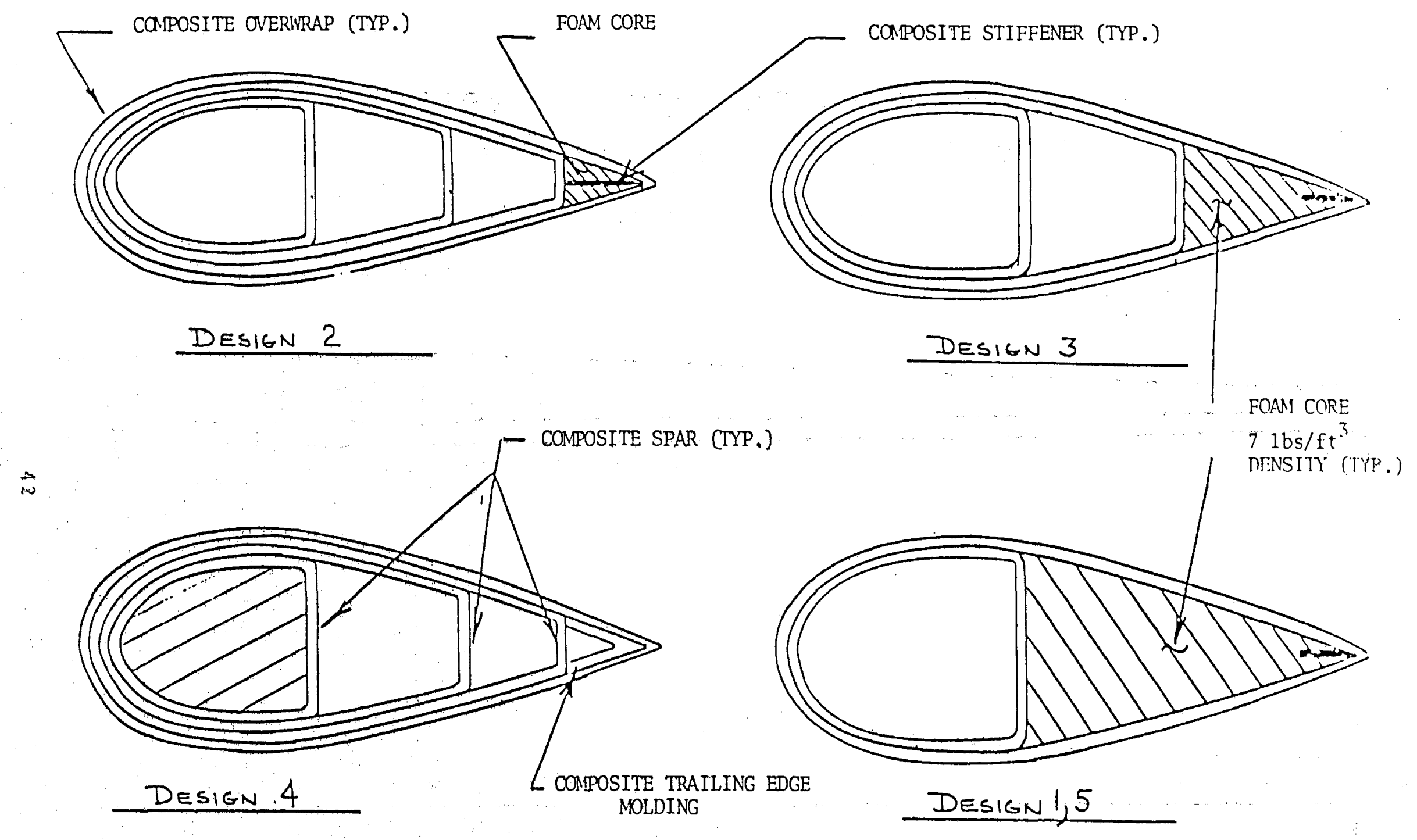

FIGURE 17 LOW COST COMPOSITE BLADE DESIGN ITERATIONS TYPICAL CROSS SECTIONS (NOT TO SCALE) 
The multiple cell designs tend to be 1 ighter because the unsupported chordwise lengths of the skin panels are shorter, hence less susceptible to buckling and thus can be made thinner and 1 ighter.

\section{ROOT END CUTOUT AND AFTERBODY TRANSITION}

Figure 18 shows the details of proposed root end terminations of the afterbody structures for designs 1 through 5 . The termination of the first afterbody was essentially the same for designs 6,7 and 8 except that design 6 had no fairing in that area. A study showed that the drag reduction of the fairing used in design 7 and 8 increased the power output of the rotor. Termination designs 1 through 5 required a secondary bond in a critical load path. Designs 2, 3 and 4 assumed that the first afterbody mandrel could be extracted. Later more refined studies for designs 6,7 and 8 showed that the first afterbody mandrel could not be removed easily due to interference with the hub fitting. Further, the first afterbody was now the primary blade structure and it was desired that it be wound in one continuous piece which gradually transitioned into the hub to minimize kick loads. This ruled out the separately bonded elements of previous designs.

HUB ATTACHMENT

Figures 19 and 20 show the various hub attachment concepts considered for the low cost composite blade.

\section{BASELINE DESIGN}

The baseline hub fitting concept is shown in Figure 7 . A round metal ring forging, or rolled and welded $r$ ing, is machined to the cross section shown. The flange which mates with the MOD-O hub adapter is drilled and tapped to match the adapter bolt circle. Two "shear lug" grooves are provided for positive retention of the TFT composite spar material. Pilot holes may be provided for future drilling of the optional Huck-bolt holes through the TFT composite.

During winding of the spar, each pass of $0^{\circ}$ TFT is pulled down into the appropriate "shear lug" groove by tensioned "hoop" or LFT winding ( $90^{\circ}$ winding). The grooves are filled level with additional $90^{\circ}$ windings. The entire hub fitting area is then overwrapped with additional $90^{\circ}$ windings. This type of fitting retention has been used on rocket motor case thrust rings and other aerospace structures. It presents a number of advantages over the single shear bolted approach used on the $150 \mathrm{ft}$ composite blade. (Figure 19B). 


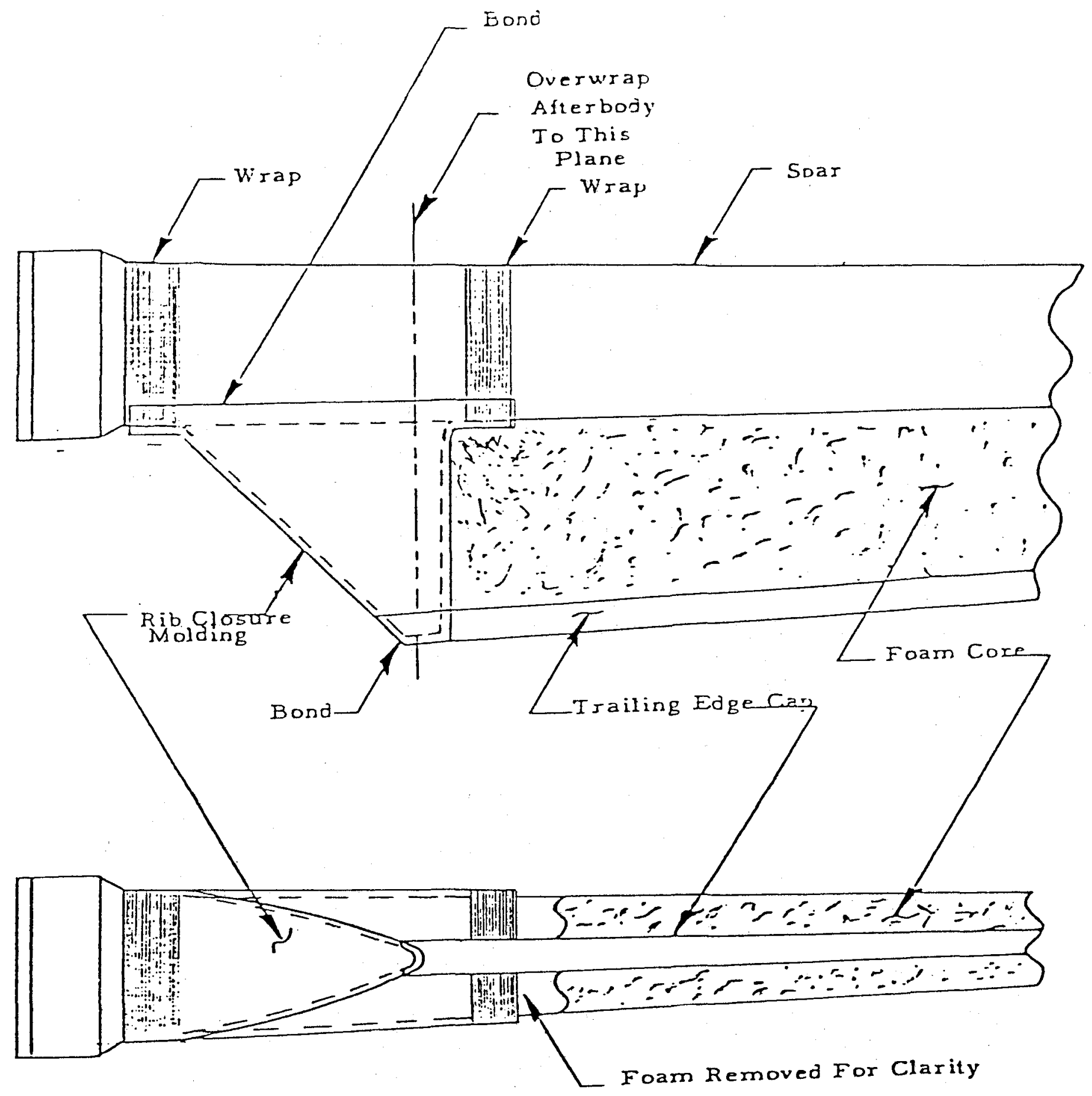

Figure 18 (Page 1)

Root End Closure Concept

Designs 1 and 5 


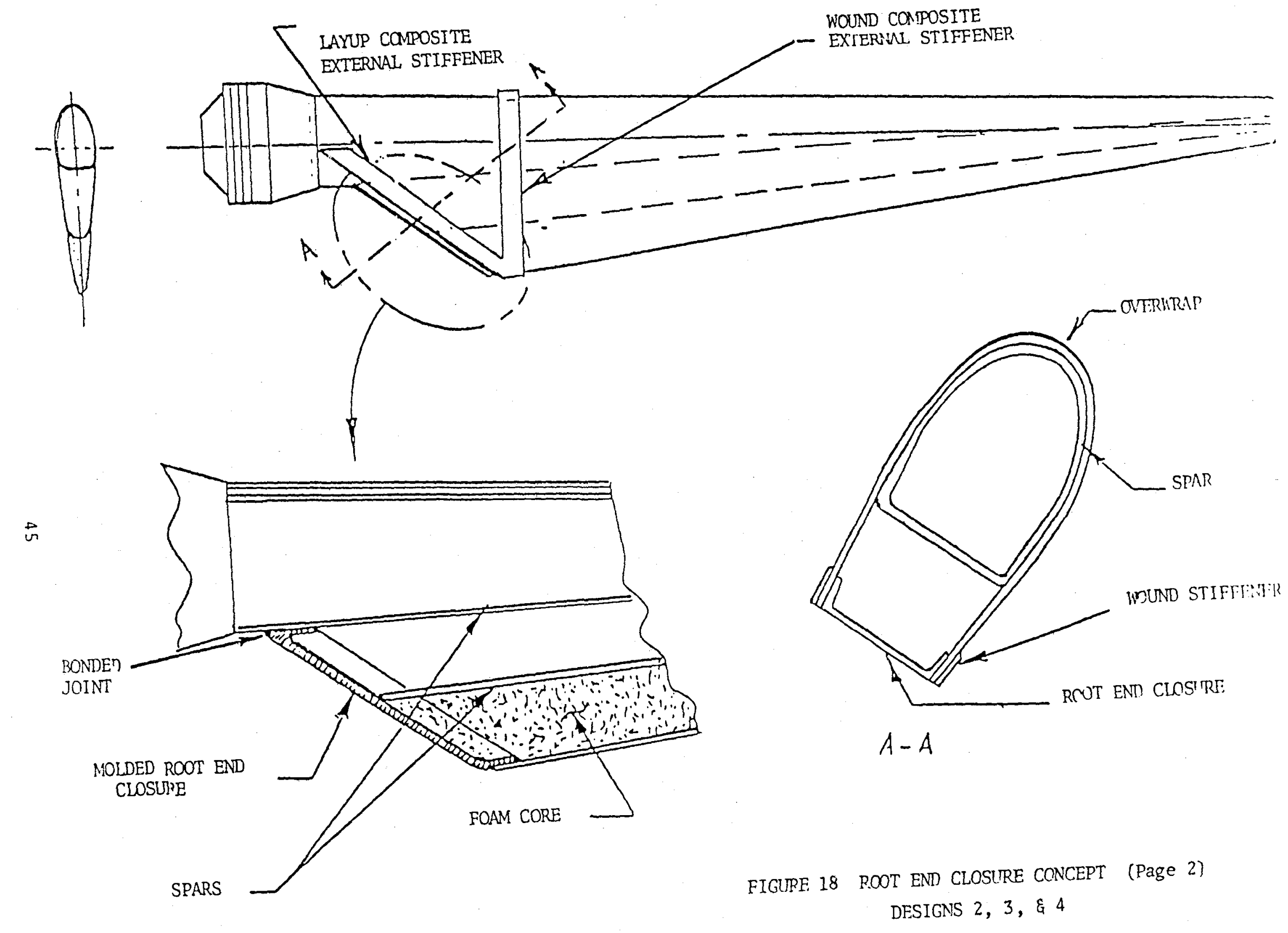



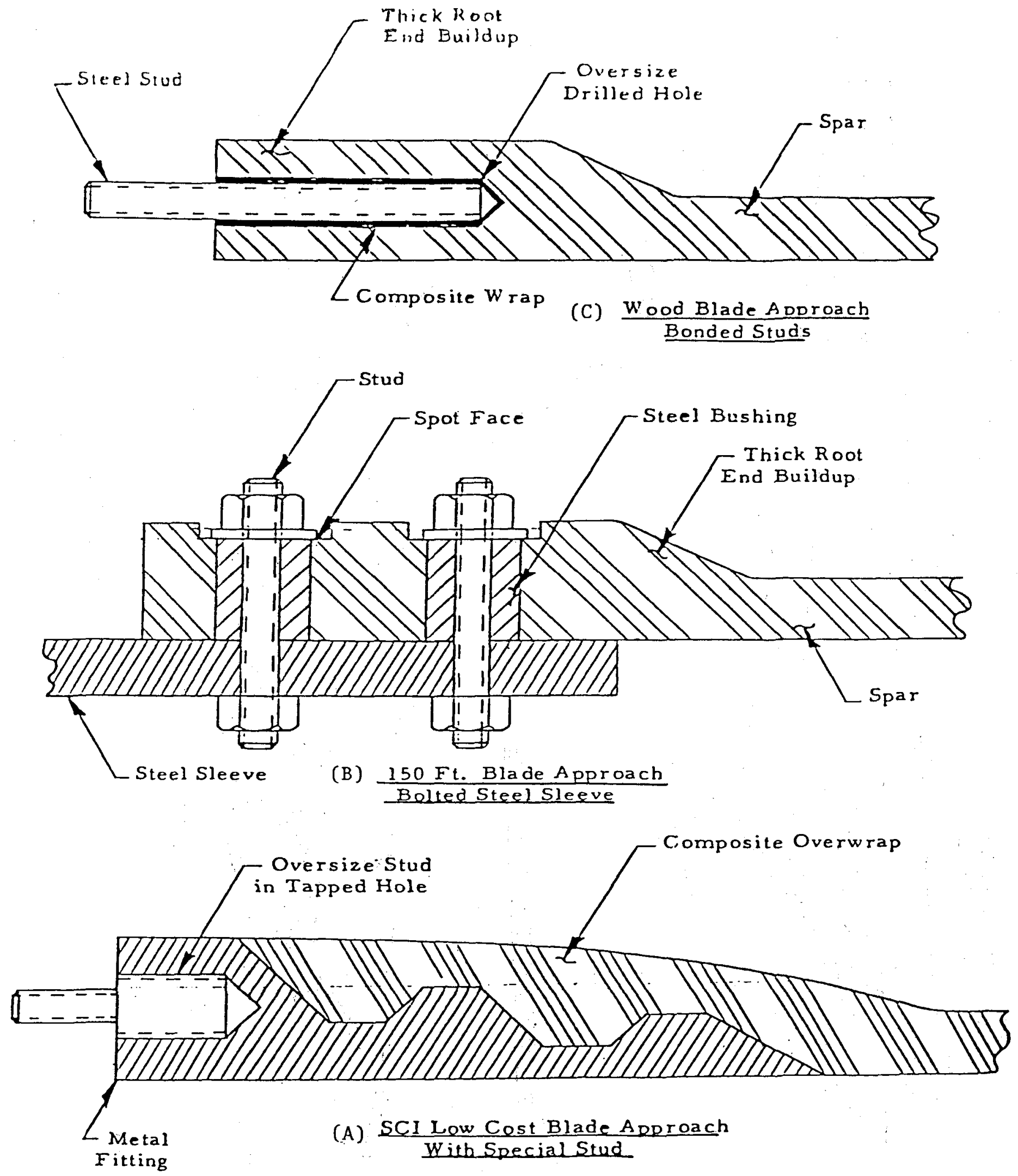

FIGURE 19

Alternate Hub Relention Concepts Low Cost Blade 
The baseline hub fitting is much smaller and lighter than the massive, welded plate " $D$ " shaped transition piece used on the $150 \mathrm{ft}$ blade. In addition, since it is round, it may be lathe-machined from a rolled and welded $r$ ing or ring forging. Only the bolt circle and hub face need to be machined precisely, since the windings will conform to the shape of the "shear lug". Hence there is no fitup problem between the hub fitting and the spar. Proper alignment and perpendicularity of the hub fitting is assured, since it fits over a machined cylindrical area on the mandrel and is bolted to the perpendicular mandrel bucking ring.

The axial TFT filaments must be broken in cross laminar shear to pull this hub fitting out of the spar. (Cross laminar shear strengths in tests run at SCI averaged better than 50,000 psi). Thus the joint retention does not depend on interlaminar shear or bolt bearing properties of the composite. To make a redundant joint, we designed the hub fitting with sufficient bond area to take the applied loads. For further redundancy, Huck bolts were added to clamp the composite to the hub fitting. These bolts also positively prevent rotation between spar and hub fitting.

The proposed joint design is wound net, so no laborious trimming of the thick root end spar composite is required. (The ability to wind up to a square finished edge is a unique feature of the TFT process).

\section{ALTERNATE DESIGN APPROACHES}

\section{HUB FITTING}

The wound in place round hub fitting was favored by SCI as the potentially lowest cost, most reliable approach. However, several variations were considered. Figures 19B and 19C show alternates being used on other NASA/DOE blade programs.

The NASA MOD-OA wood composite blades use studs which are bonded into holes drilled in the wood blade root. These studs are now serving on several MOD-OA wind turbines. This bonded stud approach would also be applicable to a composite blade, but it would require a thick root end buildup and the drilling of many large diameter, deep holes in this buildup, not an easy task with fiberglass composite. Further, the drilling and bonding of these studs require careful jigging and fixturing for accurate alignment. The quality of bond achieved will be difficult to evaluate, as it is in a

"blind" hole. In the SCI spar concept, where the spar must be large enough in diameter at the hub to allow mandrel extraction, the stud approach would still require a hub adapter. The studs will be difficult to replace if damaged or broken. 
The bolted sleeve adapter used on the $150 \mathrm{ft}$ blade and MOD-1 composite blade is another candidate for the composite low cost blade. Typical designs require welding across the principle load paths, with consequent problems of weld quality control and fatigue sensitivity. Like the bonded studs, the sleeve approach requires a thick root end buildup on the spar, and drilling of large bolt holes (with spot facing to a precision depth). There is a fitup problem in between the sleeve and the spar, requiring hand working to achieve a good fit. The bolts are in single shear and require large bushings due to the low allowables for bolt bearing in a composite.

One way to ease the fitup problem with this type of sleeve is to use a round sleeve fitting into a round end on the composite spar. The whole sleeve adapter is now round at any cross section, so 1athe-type machining is possible for accurate fitup and squaring of the hub flange bolting face. The sleeve can also be shorter and lighter, with the composite spar taking care of the transition from "D" to round cross section. This transition is easy to manufacture with a wound TFT composite, which will merely follow the shape of the mandrel. This approach was followed on the MOD-1 composite blade.

The primary advantage of the sleeve is that it is replaceable. The SCI wound-in fitting is not replaceable. If the tapped bolt holes are damaged they might be renewed by inserts (like helicoils), but this is a vulnerable area. One way to reduce vulnerability would be the use of special removable studs, Figure 19A. Another is the use of a drilled flange, Figure 20A with standard nut and bolts. This approach would require a somewhat heavier, larger and more expensive fitting. It has the advantages of easy pretensioning of the flange bolts, easy replacement of bolts or nuts, and visibility of the whole bolted joint at any time. This was the design finally chosen for the prototype blades.

HUB ADAPTER

Because of the small size of the MOD-O hub flange, the SCI low cost blade requires a hub adapter. This adapter is priced in the estimates. The hub adapter shown in Figure $20 \mathrm{~A}$ is the most efficient design, but since weight near the hub is not as critical as weight farther out on the blade, we considered the heavier, less efficient, and cheaper adapter of Figure 20B. This is an adapter flange, similar to those used on pipe, which is machined out of a "round", flame cut from heavy plate. It requires no forging or complex machining. 


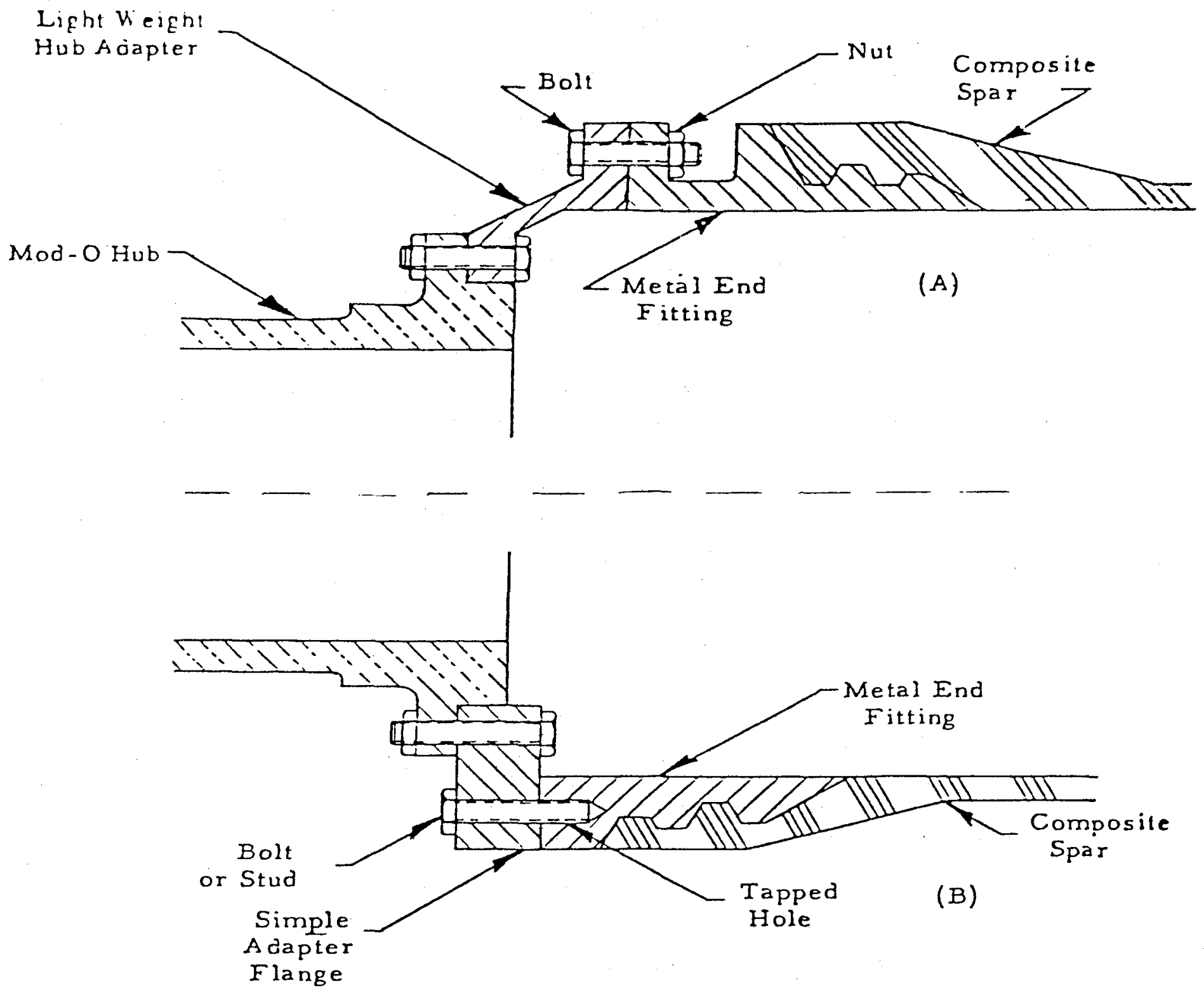

Figure 20

Alternate Hub Adapters

Low Cost Blade 


\section{3 .3 STRUCTURAL ANALYSIS}

This section presents the results of the structural design and analysis. Material property characteristics of the blade are presented together with design allowables used to assess structural integrity. The structural performance of the blade is then evaluated by presenting the results of a detailed structural analysis of the blade design. The analysis approach utilized both computerized and hand calculations to evaluate the structural integrity of the blade. Computer math models of the blade, hub joint and mandrel were developed and analyzed for stress response and internal load distribution. Hand calculations were then performed to evaluate critical design components based on the internal load distributions. Minimum margins of safety computed for major structural components of the blade are summarized in Table 1.

These results and other data presented in this report demonstrate that the blade design configuration is structurally adequate and satisfies the requirements of the NASA design specification.

\subsubsection{MATERIALS SELECTION AND PROPERTIES (See Table 2 For Nomenclature)}

The material properties used for the blade design are summarized in the following paragraphs.

METAL

The material selected for all metallic components of the blade was heat treated AISI 4140 steel. Properties of this material, obtained from Reference 8 are 1 isted below:

Modulus of Elasticity, E......................

Coefficient of Expansion, $\alpha \ldots \ldots \ldots \ldots 6.3 \times 10^{6} \mathrm{in} / \mathrm{in} /{ }^{\circ} \mathrm{F}$

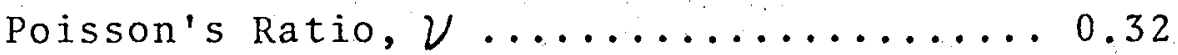

Ultimate Tensile Strength, $\sigma_{t} \ldots \ldots \ldots \ldots 150,000$ psi

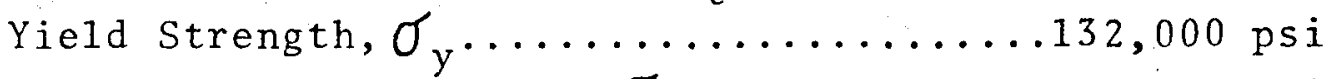

Ultimate Shear Strength, $\tau_{u} \ldots \ldots \ldots \ldots \ldots 90,000$ psi

Density, $\rho \ldots \ldots \ldots \ldots \ldots \ldots \ldots \ldots \ldots .2831 \mathrm{~b} / \mathrm{cu}$ in. 
TABLE 1

CRITICAL LOAD CONDITIONS AND MARGINS OF SAFETY

Component $\begin{gathered}\text { Critical Load } \\ \text { Condition }\end{gathered}$

Blade Tip Shutdown

D-Spar

D-Spar

D-Spar

D-Spar

Trailing

Edge

Bub Joint

Fitting

Hub Joint

Spar

Hub Joint

Adhesive

Hub Joint

Hoops

Hub

Adapter

Root End

Closure

Ribs

Survival wind
Operation
Operation
Operation

Survival Wind

Operation

Operation

Operation

Operation

Operation

Survival

Operation
Failure Mode

M. S.

Impact With Tower

0.06

Buckling

0.14

Flatwise Fatigue

0.38

Edgewise Fatigue

1.67

Combined Fatigue 0.17

Buckling

0.46

Tensile

0.14

Fatigue

0.17

Fatigue

0.25

Fatigue

1.32

Tensile

1.93

Buckling

1.83

Fatigue

2.35 
TARLE 2

GENERAL NOMENCLATURE FOR STRUCTURAL ANALYSIS

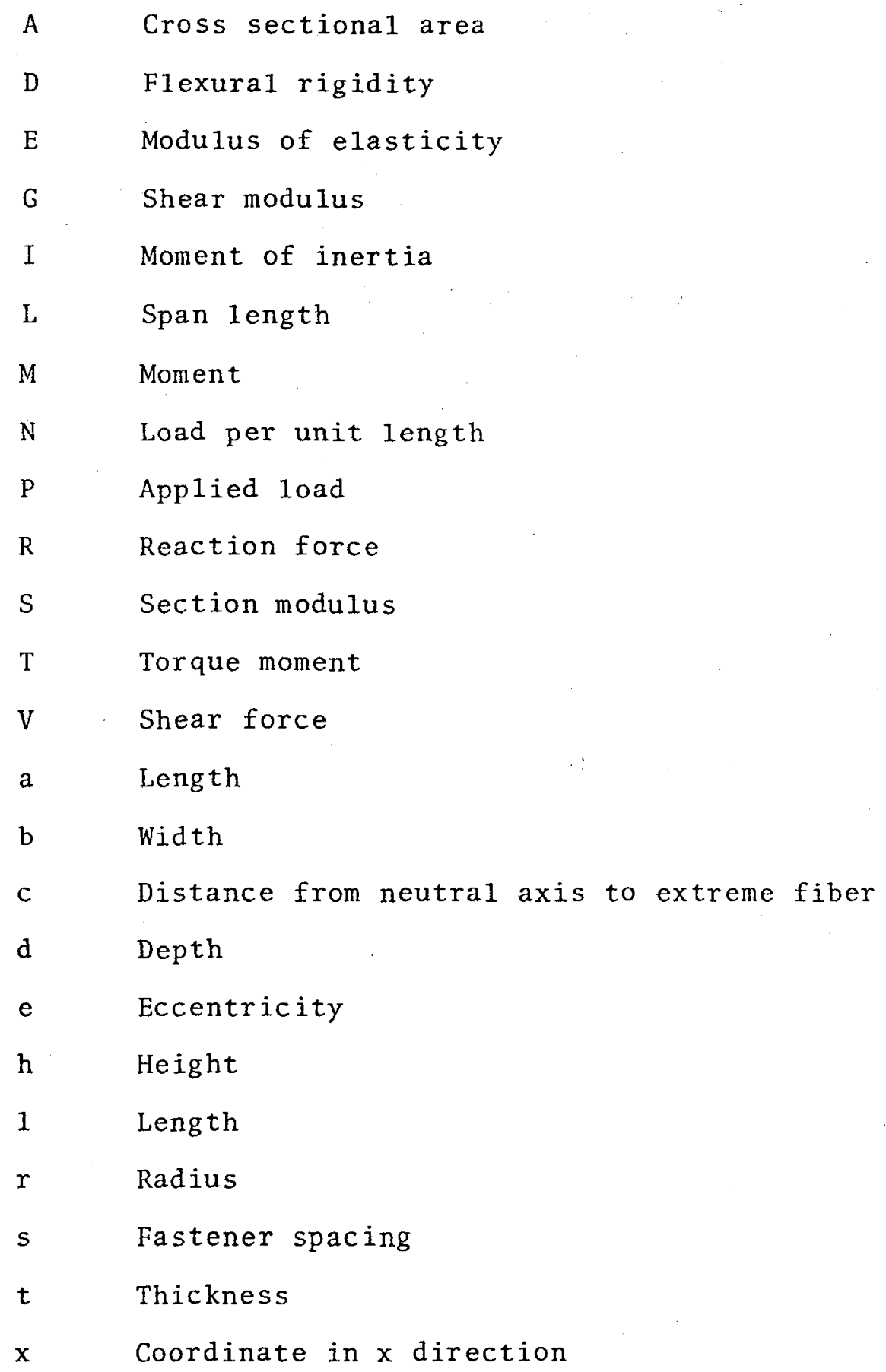




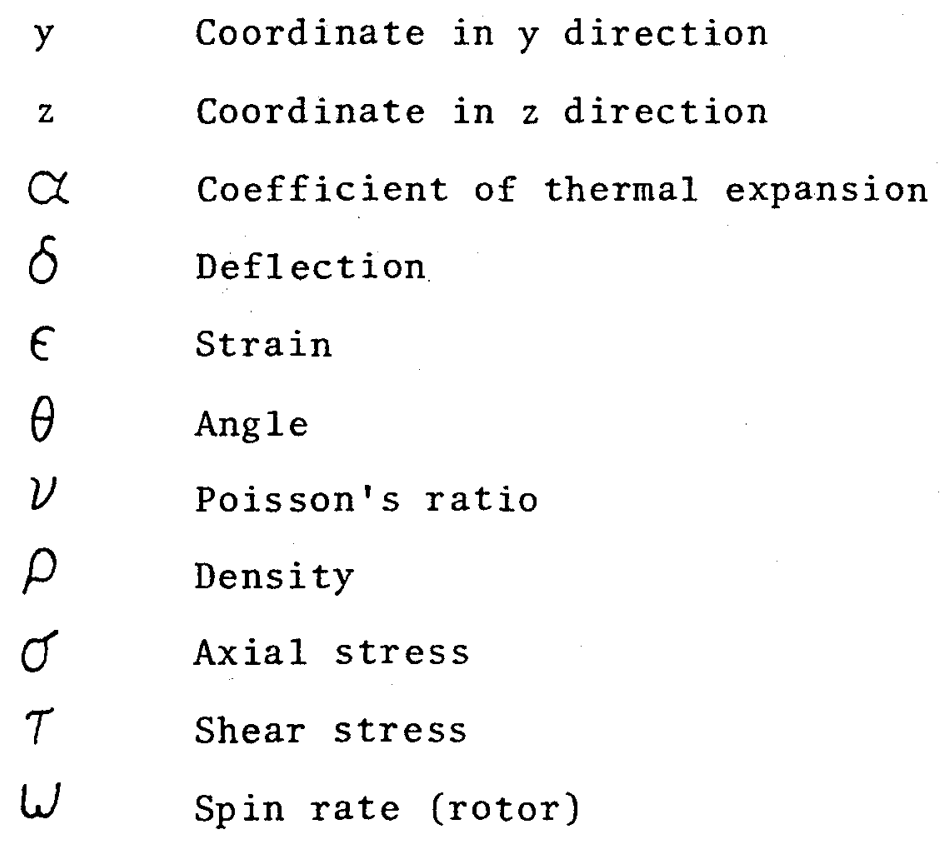




\section{TFT COMPOSITE SPAR}

The material used for the composite spar of the blade consists of volume percentage of $16 \%$ longitudinal filament tape (LFT), $72.6 \%$ transverse filament tape (TFT) and $11.4 \% \pm 45^{\circ}$ double bias tape. The properties for the combination of this material were obtained from SCI'S SQ5 laminate analysis and are 1 isted below:

Modulus of Elasticity, $E_{L} \ldots \ldots \ldots \ldots \ldots \ldots .82 \times 10^{6}$ psi Modulus of Elasticity, $E_{T} \ldots \ldots \ldots \ldots \ldots 1.89 \times 10^{6}$ psi Shear Modulus, $G_{\text {LT }} \ldots \ldots \ldots \ldots \ldots \ldots \ldots \ldots .58 \times 10^{6}$ psi Major Poisson's Ratio $V_{L T} \ldots \ldots \ldots \ldots \ldots \ldots .26$

Coefficient of Expansion, $\alpha_{L} \ldots \ldots \ldots \ldots 6.1 \times 10^{-6} \mathrm{in} / \mathrm{in} /{ }^{\circ} \mathrm{F}$

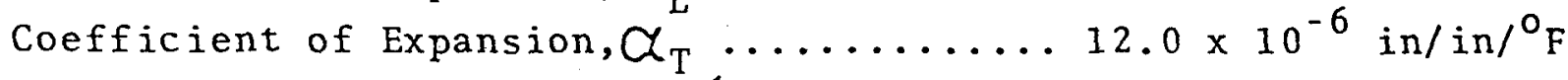
U1timate Long Tensile/Comp. $\sigma_{\mathrm{L}} \ldots \ldots \ldots \ldots 20,000 \mathrm{psi}$ U1timate Trans. Tensile/Comp. $\sigma_{\mathrm{T}} \ldots \ldots \ldots 10,000$ psi Strength

Ultimate In-Plane-Shear Strength, $\tau_{u} \ldots \ldots .3,500$ psi Weight Density, $\rho \ldots \ldots \ldots \ldots \ldots \ldots \ldots .0 .07 \mathrm{lb} / \mathrm{cu}$ in.

HOOPS

The layup for the hoops consists of $100 \%$ LFT material. The properties for this material were obtained from Reference 9 and are 1 isted below:

Modulus of Elasticity - Long, $\mathrm{E}_{\mathrm{L}} \ldots \ldots \ldots 5.68 \times 10^{6} \mathrm{psi}$

Modulus of Elasticity - Trans, $\mathrm{E}_{\mathrm{T}} \ldots \ldots \ldots 1.46 \times 10^{6} \mathrm{psi}$

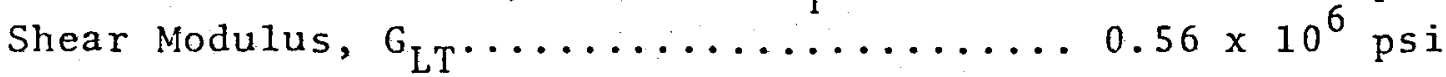

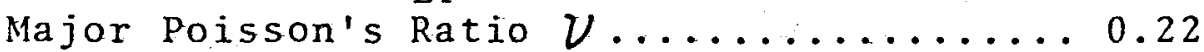

Coefficient of Expansion-Long $\alpha_{L} \ldots \ldots \ldots 5.0 \times 10^{-6} \mathrm{in} / \mathrm{in} /{ }^{\circ} \mathrm{F}$

Coefficient of Expansion-Trans $\alpha_{\mathrm{T}} \ldots \ldots \ldots \ldots 18.0 \times 10^{-6}$ in $/$ in $/{ }^{\circ} \mathrm{F}$

Ultimate Long. Tensile Strength $\sigma_{\mathrm{LT}} \ldots \ldots \ldots 75,200$ psi

Ultimate Long. Compressive $\sigma_{\text {Lc }} \ldots \ldots \ldots \ldots 41,400$ psi Strength

U1timate Trans. Tensile Strength, $\sigma_{\mathrm{Tt}} \ldots \ldots 1,200 \mathrm{psi}$

U1timate Trans. Compressive $\sigma_{\text {Tc }} \ldots \ldots \ldots \ldots \ldots 7,000$ psi

Strength

Ultimate in Plane Shear Strength $\tau_{\mathrm{u}} \ldots \ldots \ldots 3,200 \mathrm{psi}$

Weight Density $\rho \ldots \ldots \ldots \ldots \ldots \ldots \ldots . . . .67 \mathrm{lb} / \mathrm{cu}$ in. 
Due to design restraints, where extraction of metal mandrels was not practical, rigid polyurethane foam mandrels were employed and remained as part of the structure of the blade. The first afterbody consists of $21 \mathrm{bs} / \mathrm{ft} 3$ foam and the second afterbody has a density of $4 \mathrm{lbs} / \mathrm{ft}^{3}$. Typical foam properties for $7 \mathrm{lb} / \mathrm{ft}^{3}$ material found in Reference 9 , are listed below:

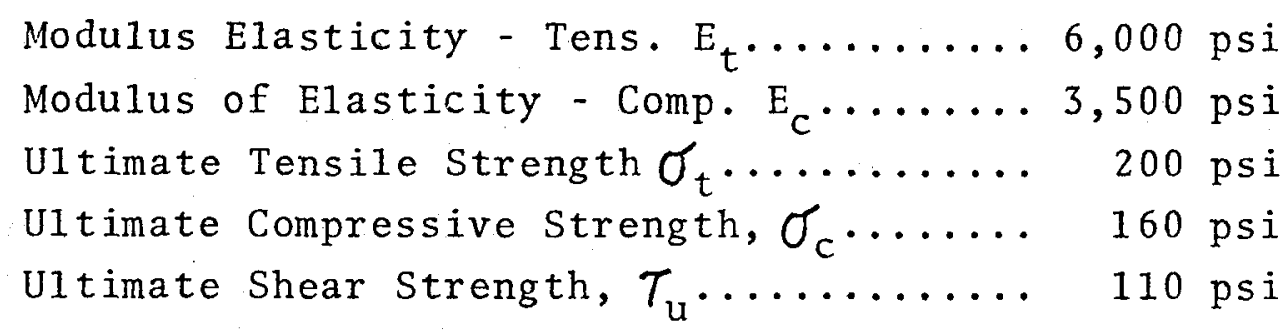
EPOXY PHENOLIC ADHESIVE

To bond the metal fitting to the composite material an epoxy Phenolic Adhesive film was selected. This adhesive was chosen to give a predictable glue-line thickness, and excellent bond strength to metal substrate and bondline corrosion resistance. It is also resilient to allow differences in the coefficient of thermal expansion and to withstand the required fatigue loading. The properties were obtained from References 9 , 10 and 11 and are 1 isted below:

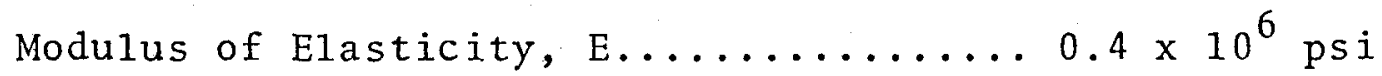

Poisson's Ratio $\nu \ldots \ldots \ldots \ldots \ldots \ldots \ldots . . . \ldots \ldots$

U1timate Shear Strength $T_{u} \ldots \ldots \ldots \ldots \ldots 5330$ psi

Design U1timate Shear Strength $T_{\text {ud }} \ldots \ldots 4000$ psi

Yield Shear Strength $\tau_{p} \ldots \ldots \ldots \ldots \ldots \ldots 3200$ psi

Shear Fatigue Strength $\tau_{e} \ldots \ldots \ldots \ldots \ldots 1280$ psi

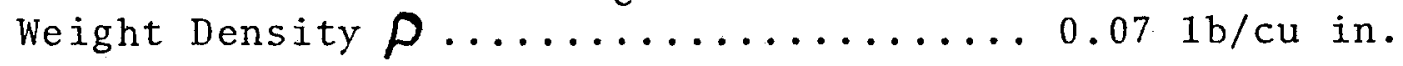

Design Ultimate Tensile Strength $\sigma_{\text {ud }} \ldots .1920$ psi

Ultimate Tensile Strength $\sigma_{u} \ldots \ldots \ldots \ldots 2560$ psi 


\section{STRENGTH}

The strength allowables used in the analysis are the minimum yield and ultimate strength values known for the materials listed above. In the case of the composite TFT and hoop (LFT) material and the adhesive, the yield strength was taken to be $80 \%$ of the static ultimate strength of the material. For the adhesive a knockdown factor of 0.75 was applied to the average ultimate strength of the adhesive as reported in the literature for bonded scarf joints to develop the design ultimate strength. This was done to account for different adherends in the test data relative to the LCCB application. In the case of TFT composite spar material, the strength data were derived on the basis of maximum lamina strain theory using a laminate analysis computer program (Reference 12). The resultant failure envelope for the spar material is shown in Figure 21 .

\section{BUCKLING}

The allowable buckling stresses for the blade were computed according to the expression

$$
\begin{aligned}
& \sigma_{\mathrm{Ca} 1 \mathrm{c} .}=0.314\left[\frac{2-(\mathrm{b} / \mathrm{a})^{2}}{(\mathrm{~b} / \mathrm{a})^{2}}\right]^{0.12} \cdot \frac{\mathrm{E}_{\mathrm{e}}}{1-\nu_{12} \nu 21}\left(\frac{\mathrm{t}}{\overline{\mathrm{r}}}\right)^{-} \cdot \ldots
\end{aligned}
$$

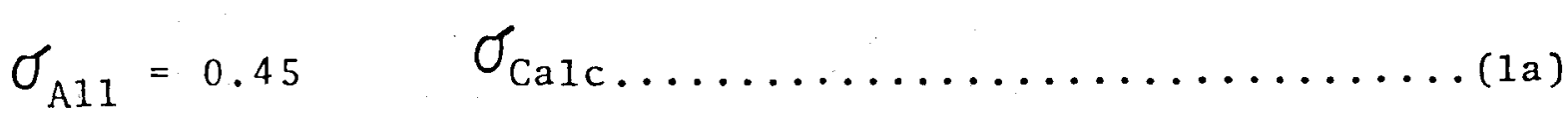

where, $(\mathrm{b} / \mathrm{a})=$ Blade Aspect Ratio

$$
\begin{aligned}
T / F & =\text { Thickness to Critical Radius of Curvature Ratio } \\
\nu & =\text { Poisson's Ratio } \\
\mathrm{E}_{\mathrm{e}} & =\frac{1}{2} \sqrt{\mathrm{E}_{11} \mathrm{E}_{22}}+\frac{1}{2} \nu_{12} \mathrm{E}_{22}+\left(1-\nu_{12} \nu_{21}\right) \mathrm{G}_{12}
\end{aligned}
$$

Equation (1) was developed by SCI to provide a physically-based, analytical means to determine the buckling stress of orthotropic, tapered D-section shells in flatwise bending.

A knockdown factor of 0.45 was applied to Equation (1) to provide design allowable buckling stresses. This knockdown factor was selected by SCI based on data correlating test results with theoretical predictions. 


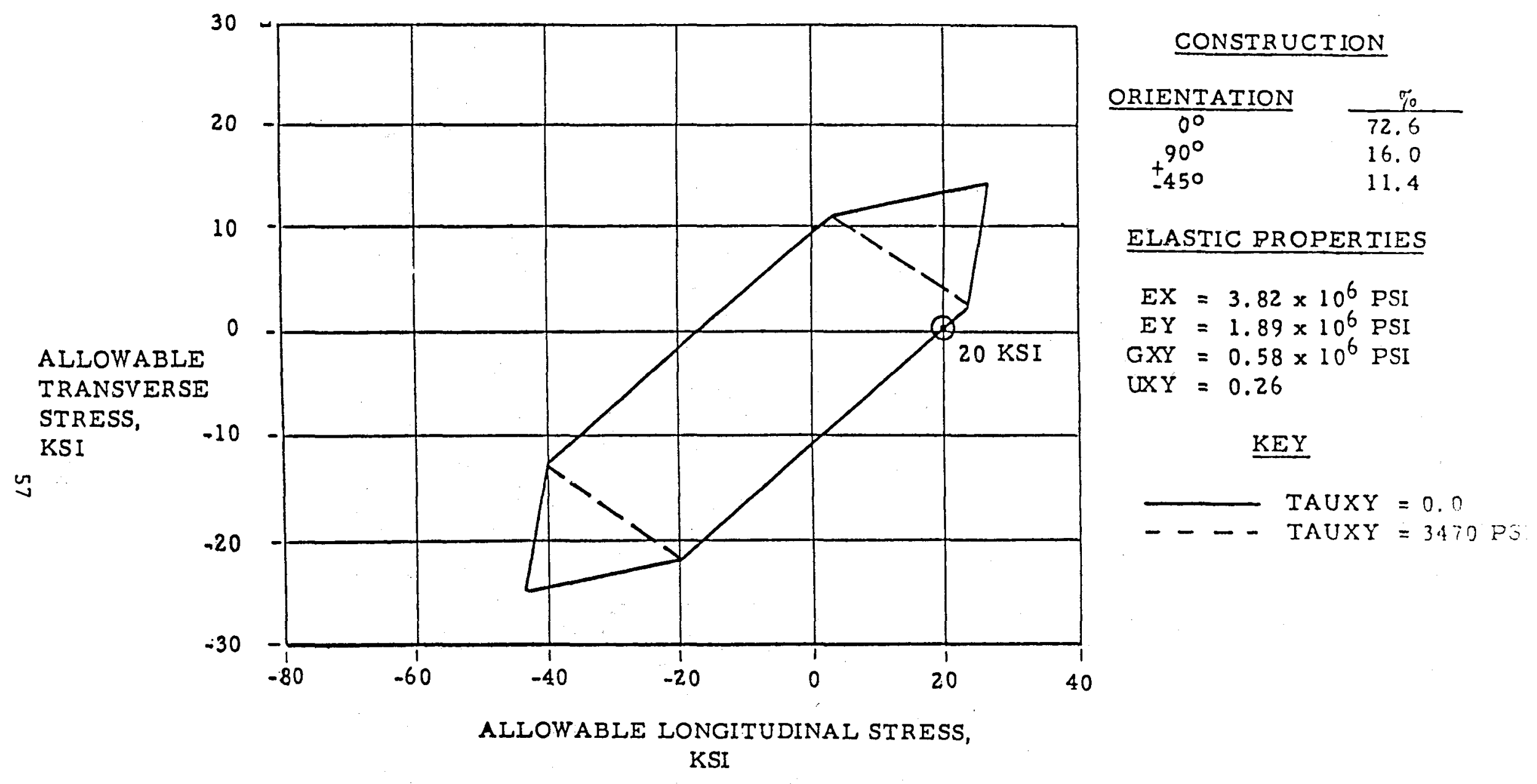

FIGURE 21 COMBINED STRESS ALLOWABLES - TYPICAL SPAR COMPOSITE 
The fatigue allowable for the metal is the minimum endurance limit for notched fatigue strength taken from the literature (Reference 8 ). This value has been experimentally characterized over a large specimen population and can confidently be used in the blade application.

The fatigue allowables for the TFT composite blade material were determined from the expression

$$
\begin{aligned}
S_{\text {MAX }} & =\frac{6.20}{1-.690 R} \ldots \ldots \ldots \ldots \ldots \ldots \\
S_{\text {MAX }} & =\text { Allowable Maximum Stress } \\
R & =\sigma_{\text {MIN } /} \sigma_{\text {MAX }} \\
\sigma_{\text {MIN }} & =\text { Applied Minimum Stress } \\
\sigma_{\text {MAX }} & =\text { Applied Maximum Stress }
\end{aligned}
$$

Equation (2) is based on the regression analysis of data from $150 \mathrm{ft}$ spar tests at NASA. A modified Goodman diagram is shown in Figure 22.

The shear fatigue strength of the adhesive is based on a review of experimental fatigue data on adhesives given in the literature (Reference 9). The value of $1280 \mathrm{psi}$ represents approximately $40 \%$ of the yield shear strength of the adhesive. Fatigue endurance limits of this magnitude appear characteristic of single lap shear joint behavior under cyclic loading.

\subsubsection{BLADE STRUCTURAL PROPERTIES}

\section{STIFFNESS DISTRIBUTIONS}

The flexural stiffness distributions of the blade in the flatwise and edgewise directions are shown in Figures 23 and 24 respectively. The torsional stiffness distribution is shown in Figure 25. The flexural stiffness of the second afterbody trailing edge laminate was neglected in the calculations since this laminate represents a soft (low modulus), non-load bearing skin in the primary bending directions. 


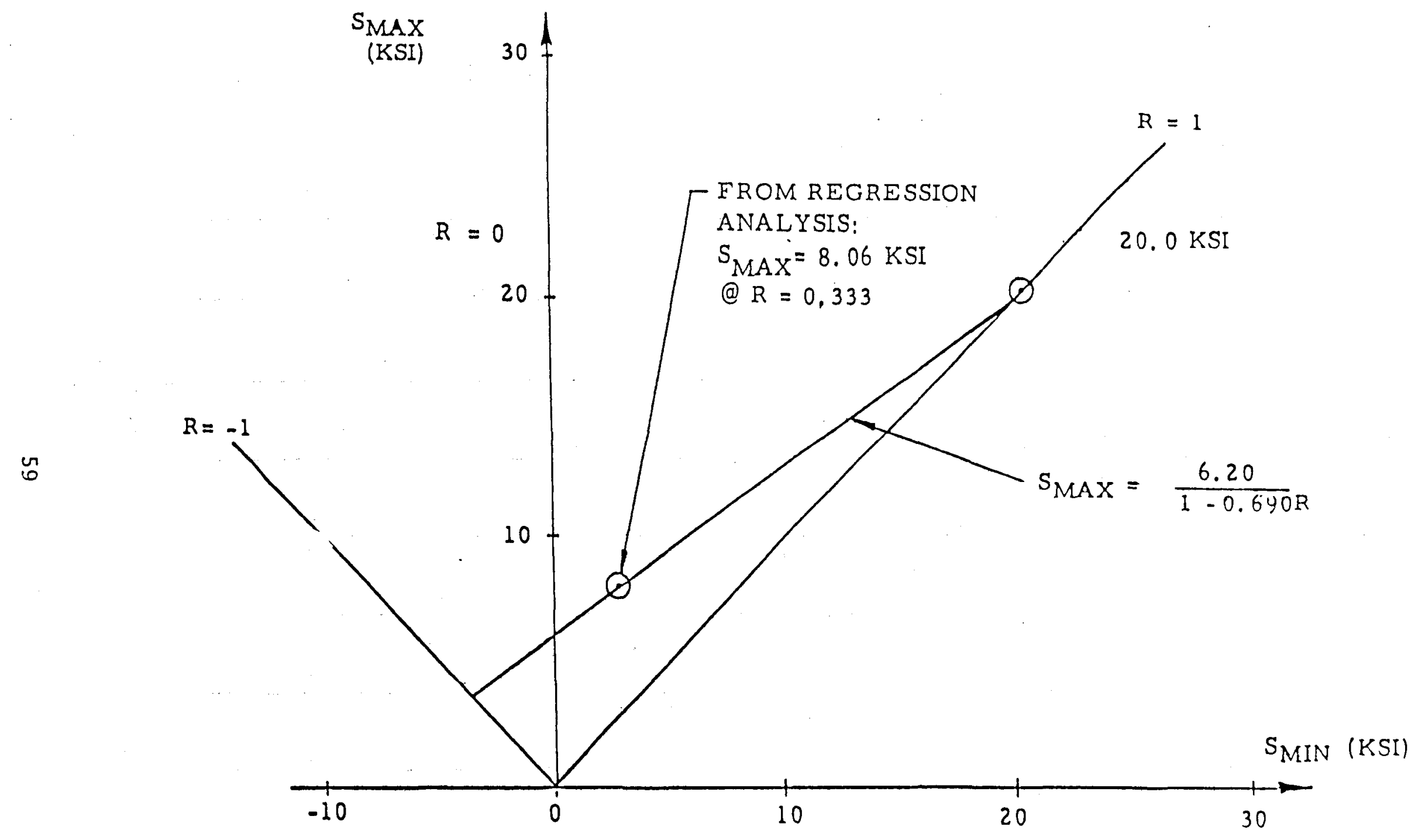

FIGURE 22 COMPOSITE FATIGUE ALLOWABLES FOR $4 \times 10^{8}$ CYCLES 


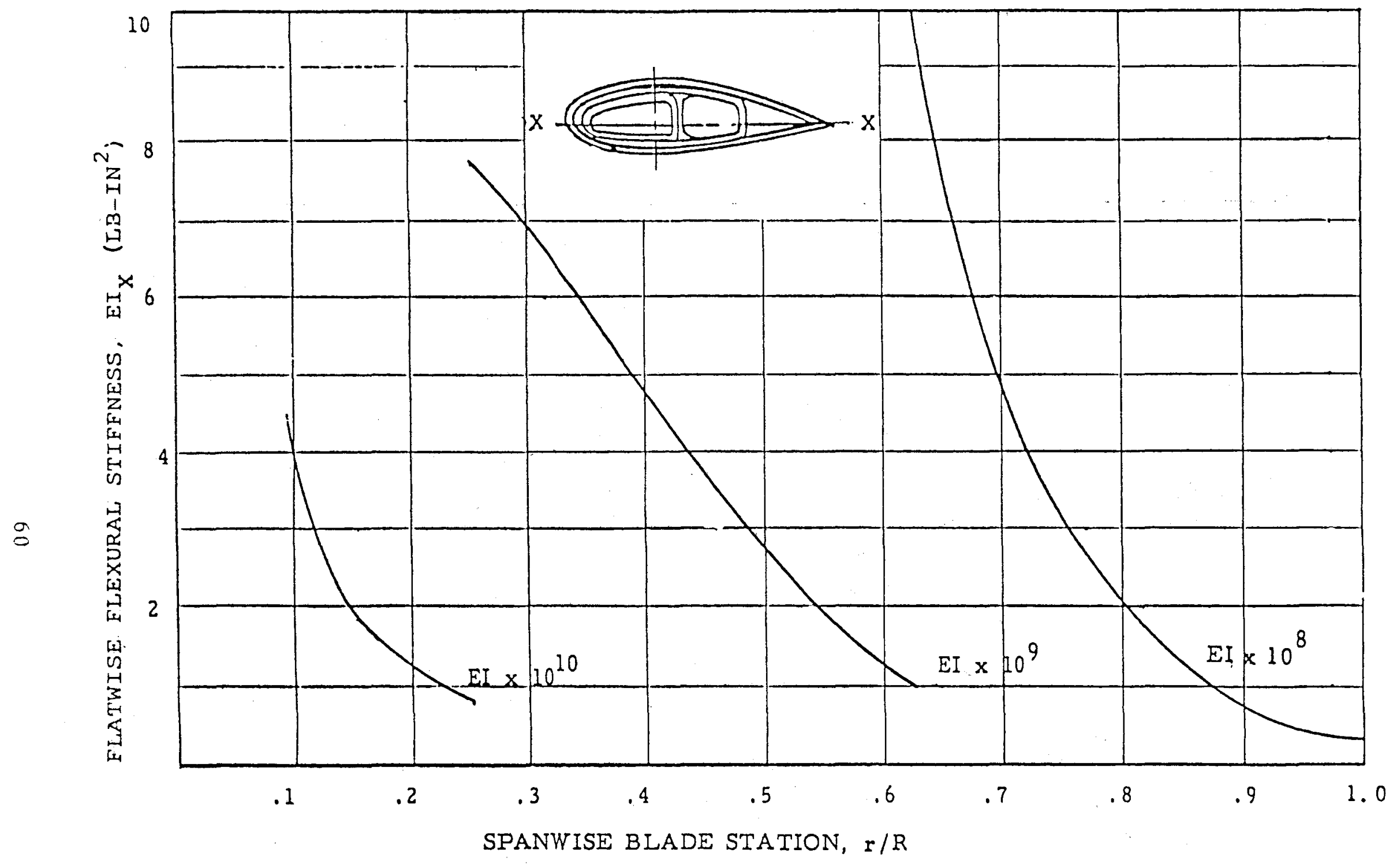

FIGURE 23 BLADE FLATIISE FLEXURAL STIFFNESS 


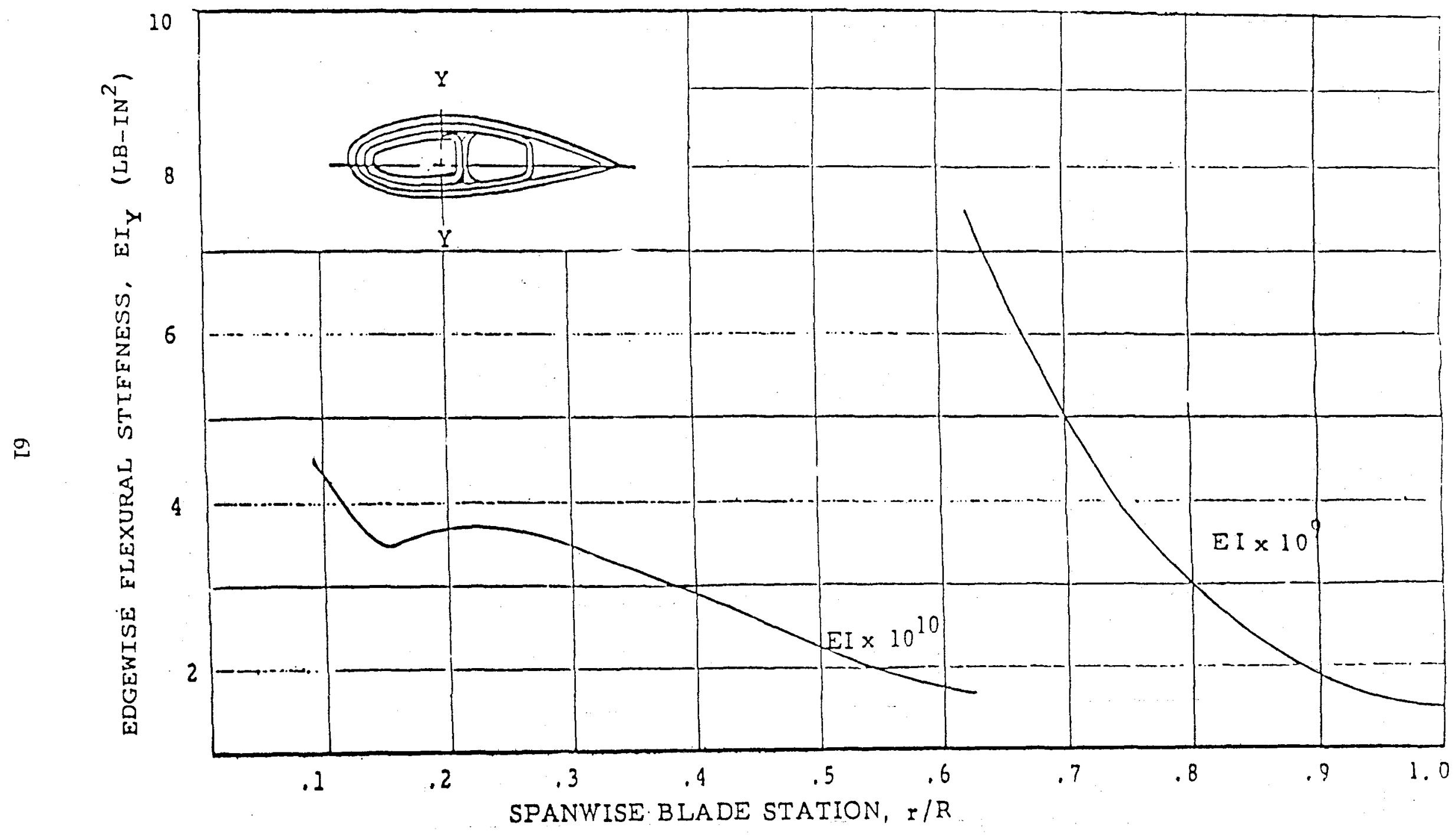

FIGURE 24 BLADE EDGEWISE FLEXURAL STIFFNESS 


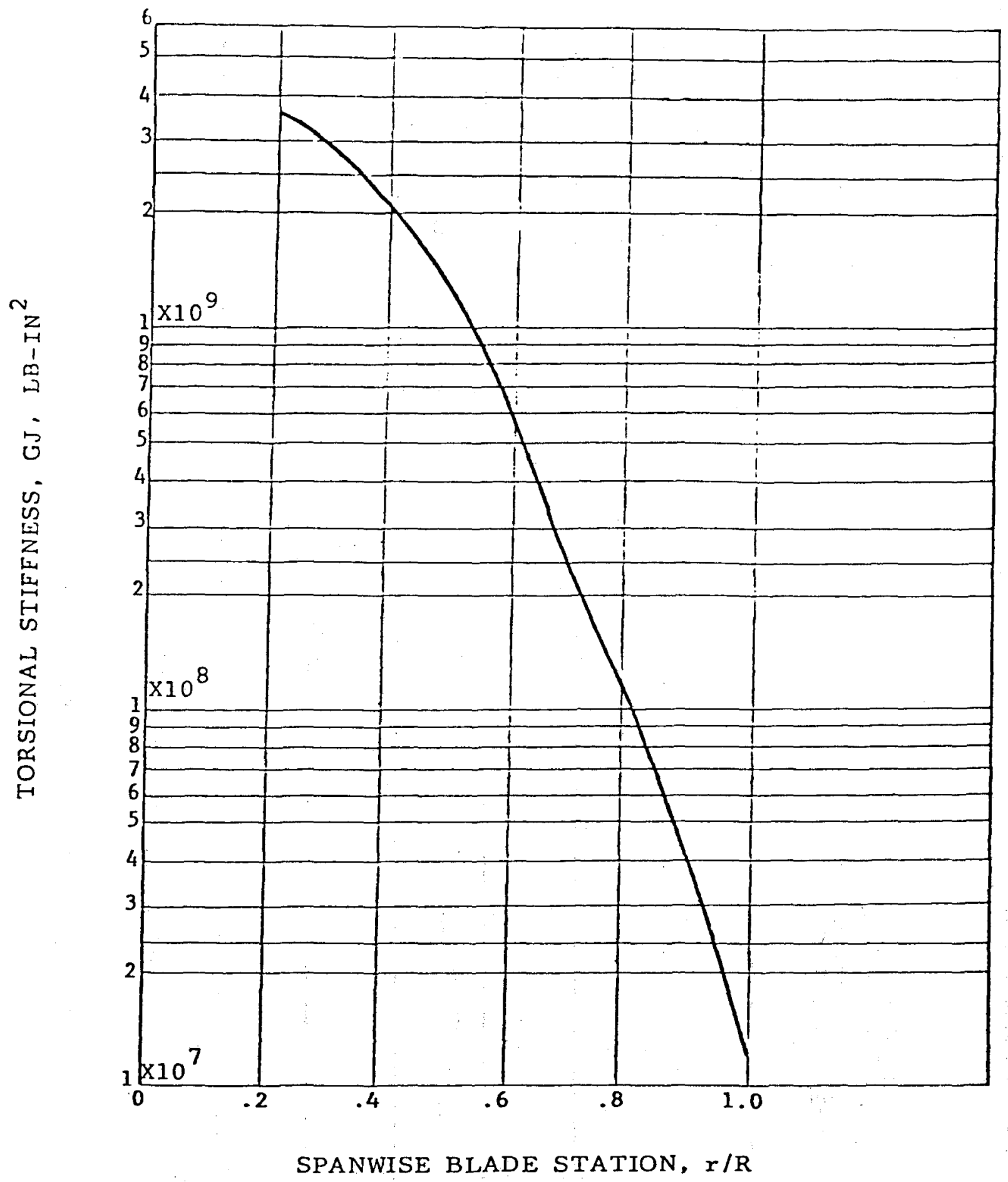

FIGURE 25 BLADE TORSIONAL STIFFNESS 
The specific section properties used to calculate the flexural stiffness (i.e., the moments of inertia and cross sectional areas) are summarized in Table 3 . These properties were determined by approximating full scale blade sections at several stations along the blade with sets of 1 inear elements. Section properties were then computed using conventional area and moment of inertia calculating procedures and the thicknesses summarized in Table 4.

The torsional moment of inertia, $J$, was computed by applying St. Venant's principle for the torsional stiffness of hollow sections according to the relation

$$
J=\frac{4 A^{2}}{(1 / t)} \ldots
$$

where

$$
\begin{aligned}
& A=\text { Total cross sectional area of blade } \\
& 1=\text { Length of mean blade perimeter } \\
& t=\text { Thickness of blade section }
\end{aligned}
$$

The longitudinal elastic modulus, $E_{L}$, of $3.82 \times 10^{6} \mathrm{psi}$ was used to represent the 1 inear, elastic material of the blade model. This was done since the primary bending and curvature effects of the blade are governed by this modulus. This modulus and the other elastic constants for the composite materials, were computed using the SQ5 computer program (Reference 13) for a laminate construction of $72.6 \%$ at 0 o (longitudina 1 ), $16.0 \%$ at $90^{\circ}$ (transverse) and $11.4 \%$ at $\pm 45^{\circ}$. This laminate construction was essentially constant for both the leading edge and midchord locations of the blade cross section as illustrated by the data below:

ding
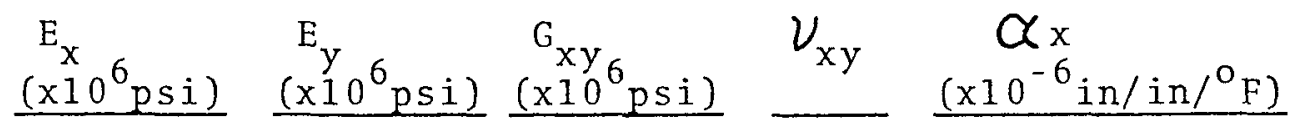

\begin{tabular}{l}
$C_{y}$ \\
$\left(x 10^{-6}\right.$ in $/$ in $\left.^{\circ} F\right)$ \\
\hline
\end{tabular}

Edge

Midchord

3.83

1.88

0.57

0.266

6.1

12.1

$$
3.67
$$

1.94

0.61

0.275

6.2

11.6

Also, the elastic constants were found to be essentially the same along the span length of the blade. 
TABLE 3 SECTION PROPEPTIES OF BLADE

\begin{tabular}{lrrrr}
$S T A(r / R)$ & $A\left(i n^{2}\right)$ & $I_{X}\left(i n^{4}\right)$ & $I_{y}\left(i n^{4}\right)$ & $\left.J_{(i n}^{4}\right)$ \\
\cline { 2 - 3 } .025 & 133.0 & 16568 & 16568 & 33136 \\
.075 & 133.0 & 12345 & 12345 & 24690 \\
.15 & 58.5 & 4800 & 6450 & 6897 \\
.25 & 56.2 & 2030 & 7264 & 5793 \\
.35 & 50.0 & 1516 & 5723 & 4483 \\
.45 & 41.7 & 978 & 4073 & 2931 \\
.55 & 29.4 & 452 & 2167 & 1552 \\
.65 & 19.9 & 226 & 1507 & 655 \\
.75 & 17.2 & 83 & 763 & 259 \\
.85 & 11.1 & 37 & 377 & 117 \\
.95 & 8.3 & 14 & 192 & 47
\end{tabular}




$$
\begin{gathered}
\text { Local (3) } \\
\text { Bwist Angle } \\
\text { (Degrees) }
\end{gathered}
$$

Cross Section Thicknesses (inches)

STA. DISTANCE FROM

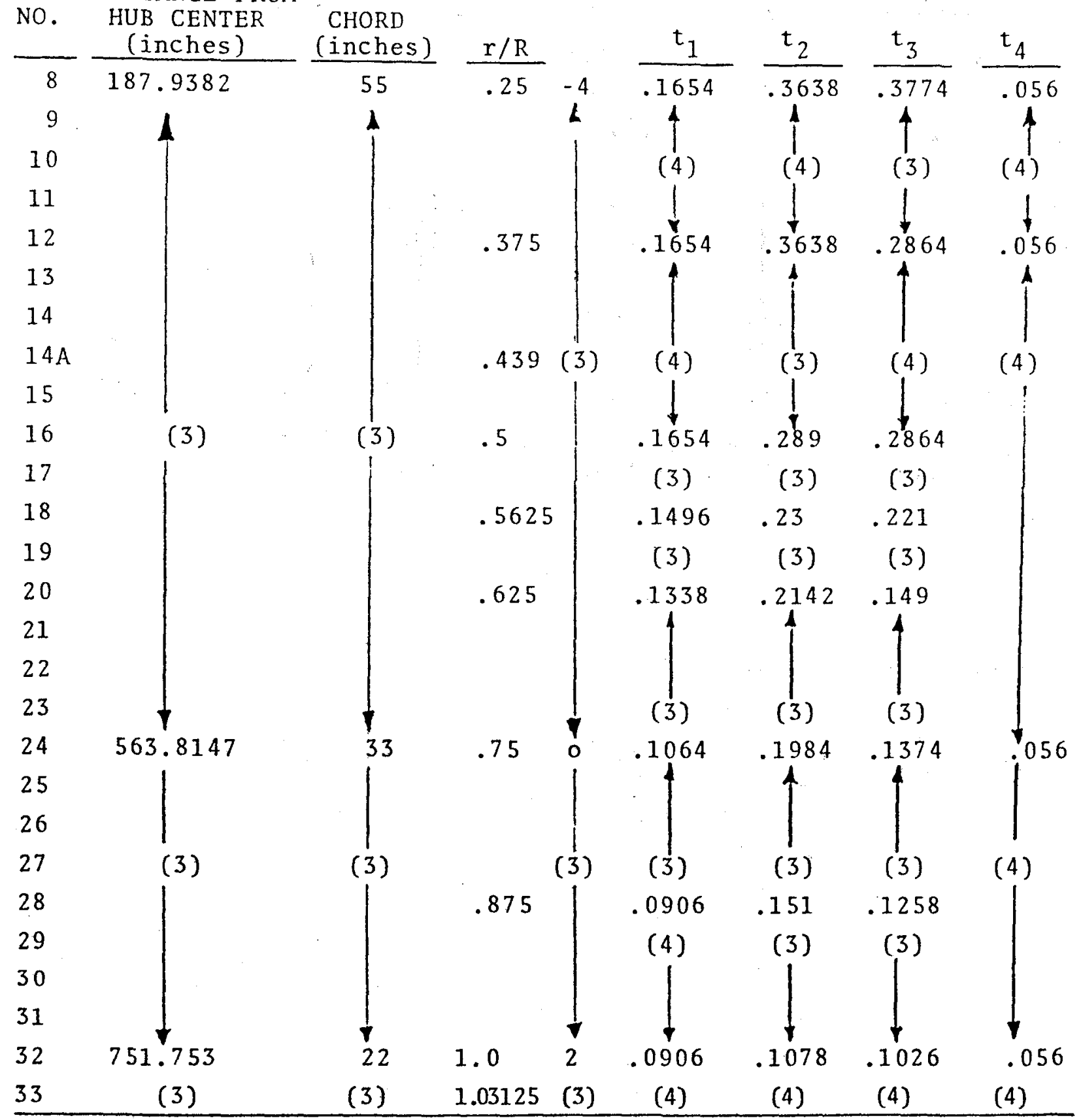

(1) All stations located at intervals of $N R / 32$; where $R=751.753$ and $N=1,2,3 \ldots, 32$

(2) Zero twist reference station is at $r / R=0.75(N=24)$

(3) Straight line element blend between stations

(4) Constant values 


$\begin{array}{ccc}\text { Local } & \text { Cross Section } \\ \text { Bwist Angle } & \text { (Degrees) } & \text { Thicknesses } \\ \text { (inches) }\end{array}$
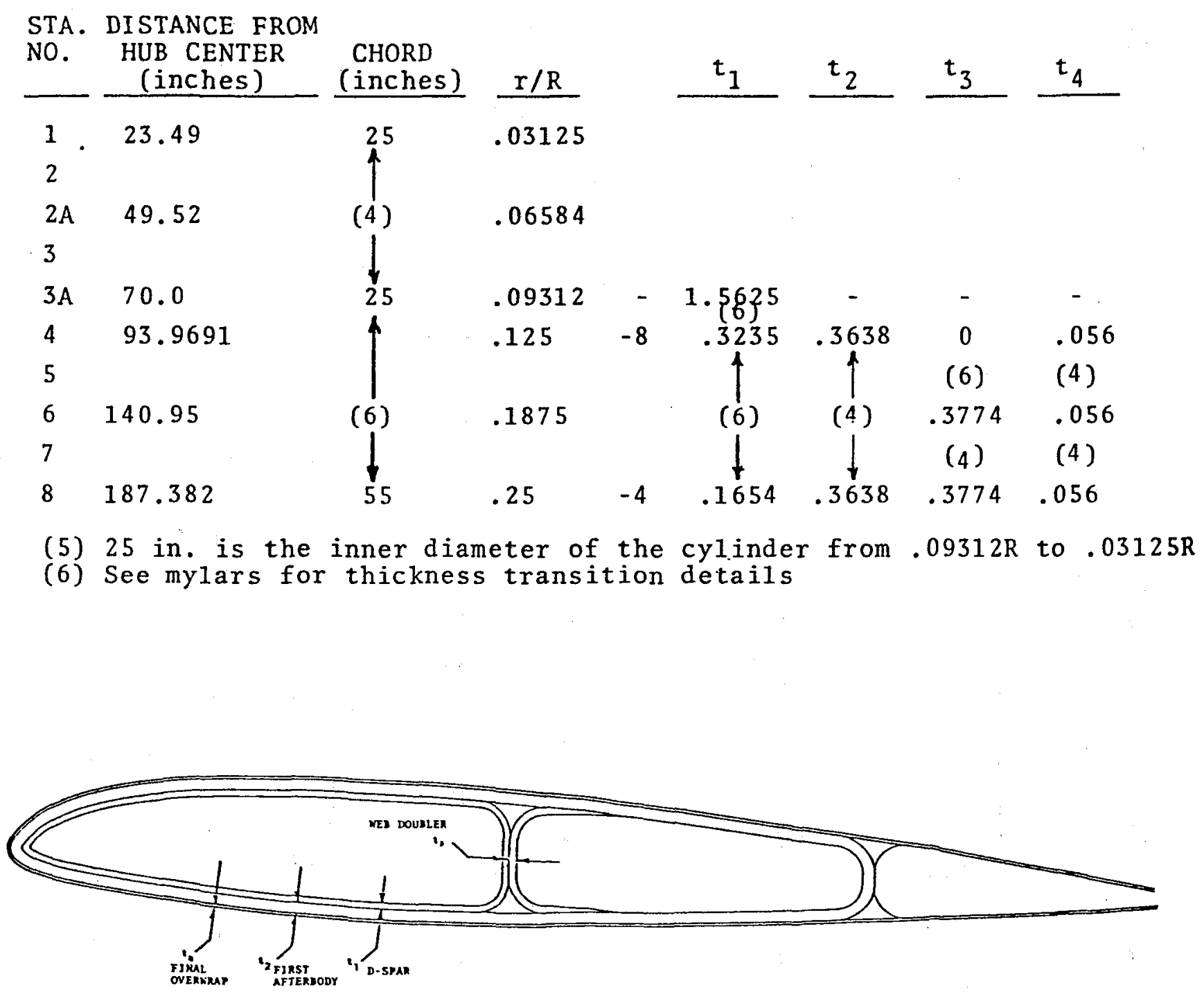
The total predicted weight of the final blade design for

structural analysis is 2,582 lbs. A breakdown of this weight is as follows:

\begin{tabular}{lc} 
Item & Wt. (1bs) \\
\cline { 2 - 2 } Composite & 1742 \\
Root End Fitting & 265 \\
Adapter & 373 \\
Miscellaneous Total & $\frac{472}{2852}$
\end{tabular}

The spanwise distribution of this predicted weight is shown in Figure 26. The center of gravity of the blade is located at STA $(r / R)=.302$. The gravity bending moment of the blade about STA 40 in. is $44,400 \mathrm{ft} / 1 \mathrm{bs}$. The mass moments of inertia about the spanwise axis of the blade were computed at various station locations from the relation

$$
I_{p}=\frac{w}{g} \quad\left[\frac{\left(I_{x}+I_{y}\right)}{A}+d^{2}\right] \ldots(4)
$$

where

$$
\begin{aligned}
\mathrm{w}= & \text { Blade weight per foot at the station under consideration } \\
\mathrm{g}= & \text { Gravity constant } \\
\mathrm{I}_{\mathrm{x}}= & \text { Flatwise moment of inertia } \\
\mathrm{I}_{\mathrm{y}}= & \text { Edgewise moment of inertia } \\
\mathrm{A}= & \text { Total cross sectional area of the blade } \\
\mathrm{d}= & \text { Distance from the neutral axis to the elastic } \\
& \text { axis of the blade cross section }
\end{aligned}
$$




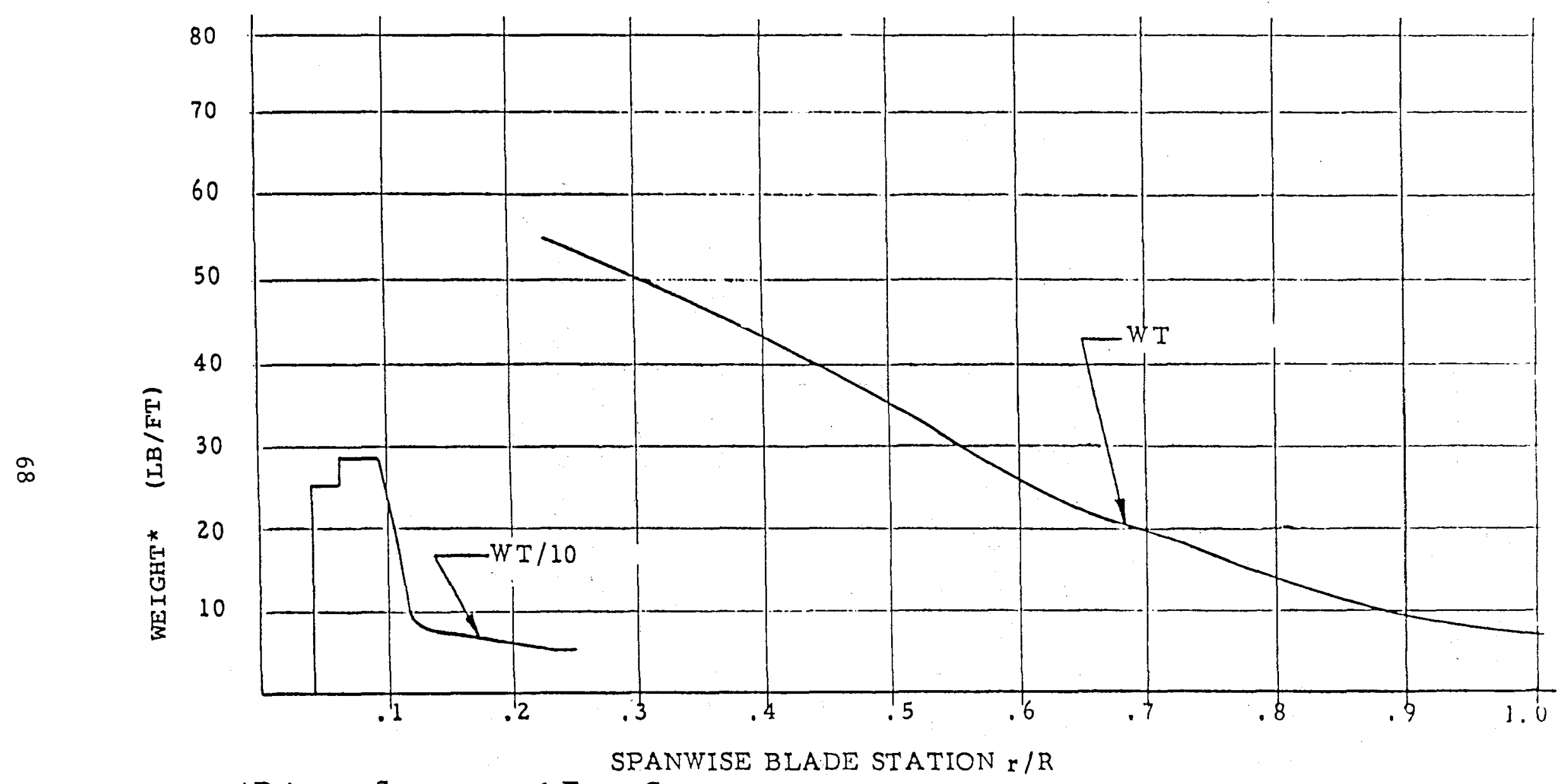

*Primary Structure and Foam Core日

FIGURE 26 BLADE WEIGHT DISTRIBUTION 
Using the section properties of the blade given in Table 3 and the weight distribution, $w$, shown in Figure 26 , the mass moments of inertia, I , were calculated according to Equation (4) and are as follows:

\begin{tabular}{lll} 
STA $(\mathrm{r} / \mathrm{R})$ & $\mathrm{d}(\mathrm{in})$ & $\mathrm{I}_{\mathrm{p}}\left(\frac{\mathrm{s} \text { lug-ft }}{\mathrm{ft}}\right)$ \\
\hline 0.25 & 2.1 & 2.32 \\
0.375 & 2.0 & 1.68 \\
0.500 & 1.4 & 0.97 \\
0.625 & 1.6 & 0.49 \\
0.750 & 0.7 & 0.21 \\
0.875 & 0.7 & 0.08
\end{tabular}

Values of the distance, d, used in Equation (4) are also 1 isted. It should be noted that the mass moments of inertia, Iisted above, contain a factor of 1.44 times the Equation (4) calculated value to account for the increase in mass moment of inertia due to the non-structural trailing edge laminate and the afterbody foam. This factor was determined from a detailed analysis of the blade cross section at STA 0.25 and applied uniformly to all other blade cross sections.

\subsubsection{BLADE DESIGN ANALYSIS}

The final blade configuration shown in Figure 5 was analyzed for stress and deflection response under survival wind simulated shutdown and cyclic fatigue loadings as specified in Section 4.1 In addition, a modal analysis of the blade was performed to determine the two lowest natural frequencies and associated mode shapes of the blade. This analysis was necessary for comparison of the blade predicted natural frequencies with the tuning requirements given in Section 4.1 .

SIMULATED SHUTDOWN CONDITION

The blade response under simulated shutdown and the modal characteristics of the blade were determined by developing and analyzing a finite element beam model of the blade. 
The model used to conduct these analyses is shown in Figure 27 It is a finite element cantilevered beam model consisting of 11 elements and 12 lumped masses. The mode1 includes a $7^{\circ}$ cone taper of the blade relative to the spin plane and is fixed at the base of the rotor (node 1). Two equally spaced elements were used to represent the adapter and hub region $0 \leq(r / R) \leq 0.1$. The remaining 9 elements were equaliy spaced to simulate the blade region $0.1 \leq(\mathrm{r} / \mathrm{R}) \leq 1.0$. Both flat and edgewise bending stiffness as shown in Figures 23 and 24 respectively, were included in the model.

\section{APPLIED LOADS}

The model was analyzed for static tip deflection under the simulated shutdown load condition using

the SPAR computer program. The blade was assumed to spin about the $Y$ axis of the model at 45 RPM. A set of initial centrifugal loads were developed to represent the centrifugal force acting in the $X$ direction at each nodal point of the model.

The loads were determined from the relation

$$
F_{C}=\frac{w_{i}}{g} \quad r_{i} \omega^{2} \quad \ldots \ldots(5)
$$

where

$$
\begin{aligned}
W_{i} & =\text { Weight of blade at } i^{\text {th }} \text { node } \\
r_{\dot{i}} & =\text { Spin radius along } x \text { axis at } i^{\text {th }} \text { node } \\
\omega & =\text { Blade rotational speed }(\mathrm{rad} / \mathrm{sec}) \\
g & =\text { Gravity constant }
\end{aligned}
$$

In addition to the centrifugal forces, the dead weight of the blade was included in the initial analysis by adding the weight of the blade at each node, $W_{i}$, to the centrifugal force at the corresponding nodal location. This represents the worse case loading condition where the centrifugal forces were combined with the gravity loads acting in the $x$ direction. 


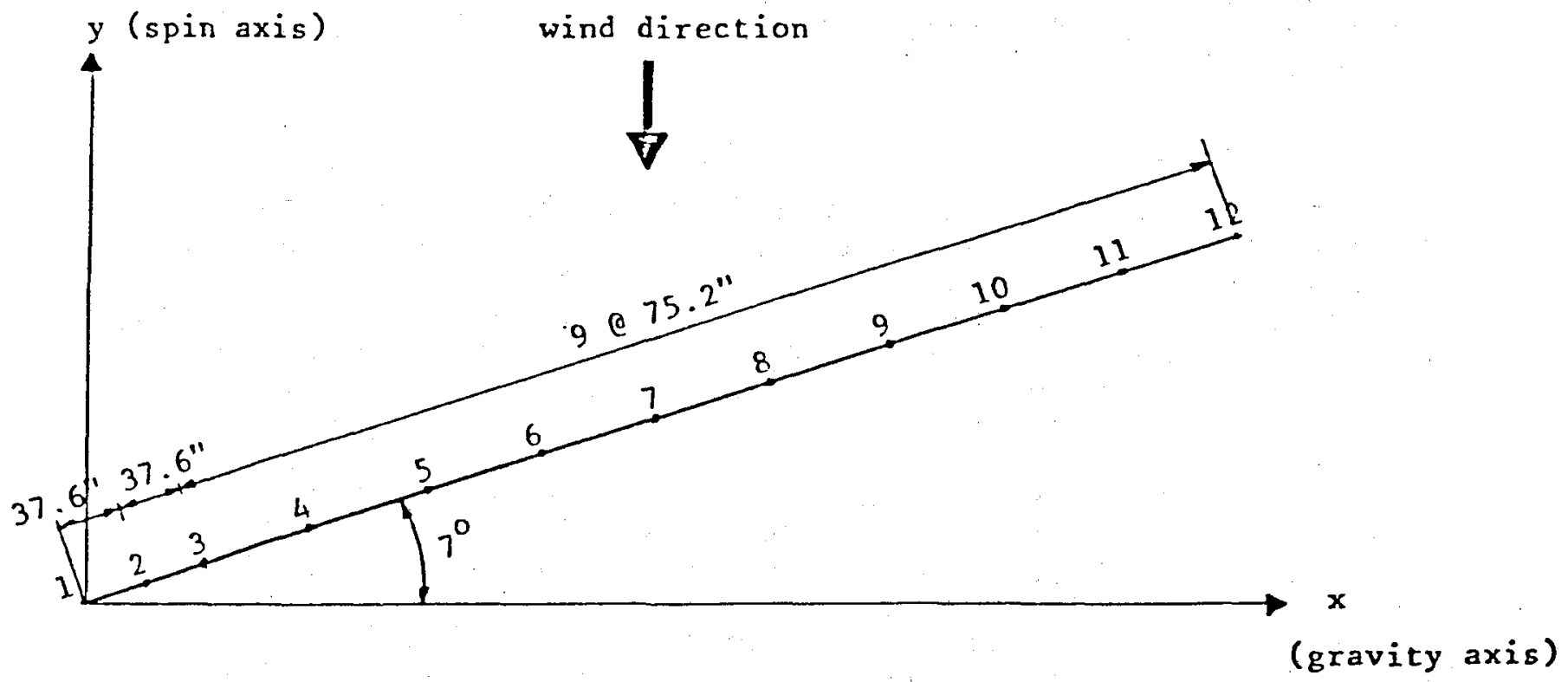

FIGURE 27 MODEL OF BLADE CONFIGURATION 
Finally, the aerodynamic loading was combined with the centrifugal and gravity loads to form the complete set of loads for the initial loading condition. The aerodynamic load was approximated at a 50 psf pressure loading acting on the flatwise profile of the blade in the direction shown in Figure 27 The pressure loading was applied as a nodal point loading having been developed on the basis of the product of the wind pressure and the appropriate projected blade area at the nodal point under consideration. A summary of the initial blade loads is given in Table 5.

\section{TIP DEFLECTION}

The loads of Table 5 were applied to the blade model shown in Figure 27 to calculate the first deflected shape of the blade in flatwise bending and the associated stress response. For the second and subsequent blade analysis, the deflected shape of the previous analysis was used as the undeformed blade configuration and only the centrifugal loads were applied to the blade configuration. Furthermore, only the transverse component of the centrifugal force at each node was applied to the undeformed shape since the axial component was considered in the initial blade analysis." This was necessary to avoid cumulative summation of axial loading during the iterative analysis procedure. A total of 4 static blade analyses were conducted using the sequential loading procedure described above. The deflected blade shape resulting from each analysis is shown as shape $1,2,3$, and 4 respectively, in Figure 28. Shape $\phi$ represents the original undeformed blade configuration.

Based on the last two analysis cases, it can be seen, that the maximum tip displacement of the blade lies between 97 in. (point $A$ ) and 21 in. (point B) relative to the original undeformed shape of the blade. Using the maximum tip displacement of 97 in., and recognizing that the allowable tip deflection is 103 in., the minimum margin of safety against impact of the blade tip against the tower is

$$
\text { M.S. }=\frac{103}{97}-1=\quad+0.06
$$

Convergence to a final deflected blade shape was not attempted since it was considered technically unnecessary and would be costly to do so. 
TABLE 5 SIMULATED SHUTDOWN LOADING CONDITION

\begin{tabular}{ccrc} 
Node & $\begin{array}{r}\text { Dead Wt. } \\
(1 \mathrm{bs})\end{array}$ & $\begin{array}{r}\text { Centrifugal } \\
(1 \mathrm{bs})\end{array}$ & $\begin{array}{c}\text { Force, } F_{c} \\
(1 \mathrm{bs})\end{array}$ \\
\hline 1 & - & - & - \\
2 & 375 & 857 & 324 \\
3 & 541 & 2337 & 931 \\
4 & 235 & 2025 & 1481 \\
5 & 365 & 4800 & 1367 \\
6 & 340 & 5825 & 1253 \\
7 & 265 & 5575 & 1139 \\
8 & 195 & 4975 & 1025 \\
9 & 150 & 4500 & 911 \\
10 & 112 & 3825 & 797 \\
11 & 76 & 2950 & 683 \\
12 & 45 & 2025 & 313
\end{tabular}




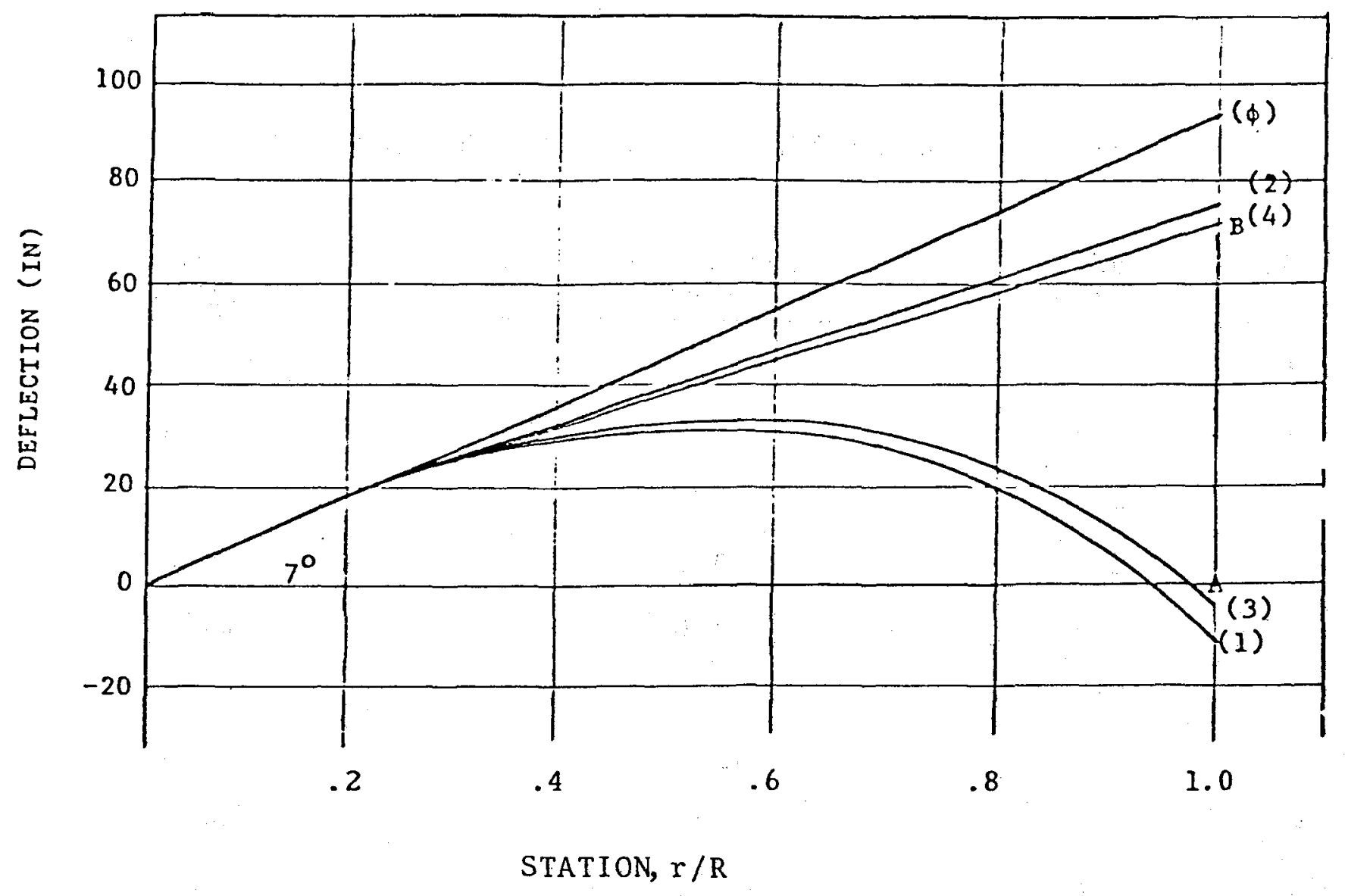

FIGURE 28 BLADE RESPONSE TO SIMULATED SHUTDOWN CONDITION 
The stability of the blade was investigated to ensure structural integrity of the blade design against a buckling failure under the survival wind loading. Using Equation (1), the TFT spar elastic moduli previously given in Section 4.3.3.1 and the blade cross sectional thickness given in Table 4 , the allowable buckling stresses at various stations along the blade were computed. These allowables were used in conjunction with the stress response values shown in Figure 28 to compute the associated margins of safety against stability failure of the blade. The results are given in Table 6.

The 1 imit load stresses given in Table 6 were computed at the critical buckling location of the cross section. It should be noted that the buckling allowables given in Table 6 contain a knockdown factor of 0.45 to account for such factors as blade eccentricity and material defects.

\section{OPERATING CONDITIONS}

The applied loads under operational conditions were supplied by NASA after several iterations of blade sectional properties. The computer code MOSTAB generated the fatigue bending moment requirements for flatwise and edgewise blade loads as shown in Figures 2 and 3 respectively. The blade stresses were then calculated for both flatwise and edgewise loading plus a combined loading condition which provided the margins of safety at various spanwise stations along the blade.

\section{FATIGUE STRESSES}

The blade was analyzed at 8 locations along its span, (i.e., $125 \mathrm{R}, .25 \mathrm{R}, .375 \mathrm{R}, .5 \mathrm{R}, .625 \mathrm{R}, .75 \mathrm{R}, .875 \mathrm{R}$, and $1.0 \mathrm{R})$. Each station was subjected to a flatwise and edgewise load with both steady and cyclic components. Using the cross sectional moments of inertia and calculating the effective length on which the loads are applied, minimum and maximum stress values were obtained. 
TABLE 6 BLADE BUCKLING ALLOWABLES AND MARGINS OF SAFETY

\begin{tabular}{cccc}
$\mathrm{r} / \mathrm{R}$ & $\begin{array}{c}\text { Limit Load* } \\
(\mathrm{ksi})\end{array}$ & $\begin{array}{c}\text { Allowable } \\
(\mathrm{ksi})\end{array}$ & M.S \\
\hline .250 & 7.79 & 11.01 & 0.41 \\
.375 & 6.95 & 10.55 & 0.52 \\
.500 & 7.17 & 10.10 & 0.41 \\
.625 & 7.25 & 8.31 & 0.15 \\
.750 & 6.79 & 7.75 & 0.14 \\
.875 & 3.63 & 6.75 & 0.58
\end{tabular}

*Due to 50 psf wind load 
The $R$ value was then determined as the minimum stress divided by the maximum stress. The fatigue allowables rational for the composite material are found in Section 4.3.3.2 and Figure 22 . Margins of safety were calculated in the flatwise and edgewise direction and results are shown in Tables 7 and 8 , respectively. Fatigue stresses due to the combined loading condition were also calculated. The same approach as above was used with the exception that both the steady and cyclic flatwise and edgewise loads were combined prior to calculation of the actual stresses and margins of safety. The results are summarized in Table 9.

MODAL ANALYSIS

The blade model shown in Figure 27 was analyzed for natural resonant frequencies and associated mode shapes using the SPAR computer program. The analysis was performed for the minimum blade rotational velocity of $40 \mathrm{RPM}$.

The analysis results indicated that the fundamental (flatwise) natural frequency of the spinning blade is $1.66 \mathrm{~Hz}$ and the second (chordwise) natural frequency is $2.47 \mathrm{~Hz}$. These frequencies correspond to a blade vibration frequency of approximately 2.49 and 3.70 cycles/blade revolution, respectively. The associated mode shapes are flatwise and edgewise blade bending as shown in Figure 29. The results of the modal analysis indicate that the blade design satisfies the tuning requirements given in Section 4.1 as shown below:

$$
\begin{aligned}
& 1.50 \leq f_{0}=1.66 \mathrm{~Hz} \leq 1.85 \\
& 2.15 \leq f_{1}=2.47 \mathrm{~Hz} \leq 2.55
\end{aligned}
$$

TRAILING EDGE ANALYSIS

The trailing edge laminate was analyzed for structural integrity under the survival wind loading condition. Although the trailing edge is considered non-structural in primary flatwise and edgewise blade bending, it must be structurally adequate to transmit local edgewise bending loads to the blade afterbody cell. Thus, the trailing edge was analyzed for flexural strength and $s^{4}$ ability under the survival wind pressure loading of 50 psf.

For analysis purposes the trailing edge was considered to be a triangular sandwich cantilevered beam as shown in Figure 30 A unit spanwise length of beam at STA 0.25 was considered since this section represents the critical bending region of the trailing edge. This criticality derives from the fact that the thickness of the trailing edge laminate is constant along the span of the blade and the cantilevered length of the trailing edge is largest at STA 0.25 . 


\section{Table 7 Flatwise Fatigue Stress Margins of Safety}

$\infty$

$r / R$

.250

.375

.500

.625

.750

$\therefore 875$
MAX

APPLIED

STRESS

(KSI)

4.03

3.99

4.04

4.34

4.12

2.49

$$
\begin{gathered}
R \text { VALUE } \\
\left(S_{\min }^{/ S_{\text {max }}}\right)
\end{gathered}
$$

$-.171$

$-.143$

$-.109$

$-.023$

$+.063$

$+.173$
ALLOWABLE

MAXIMUM

STRESS

(KSI)

5.55

5.64

5.77

6.10

6.48

7.04
MARGIN

OF

SAFETY

0.38

0.41

0.43

0.41

0.57

1.83 


\section{Table 8 Edgewise Fatigue stress Margins of safety}

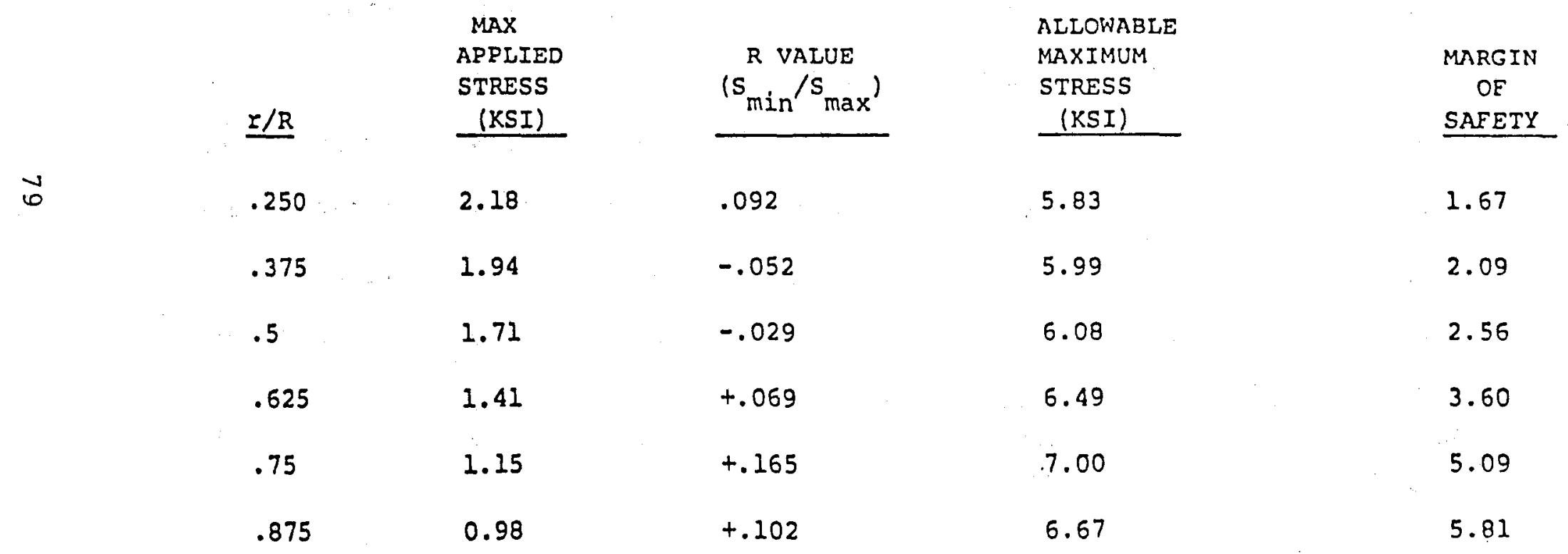


Table 9 Combined stress Due To

Flatwise and Edgewise Moments

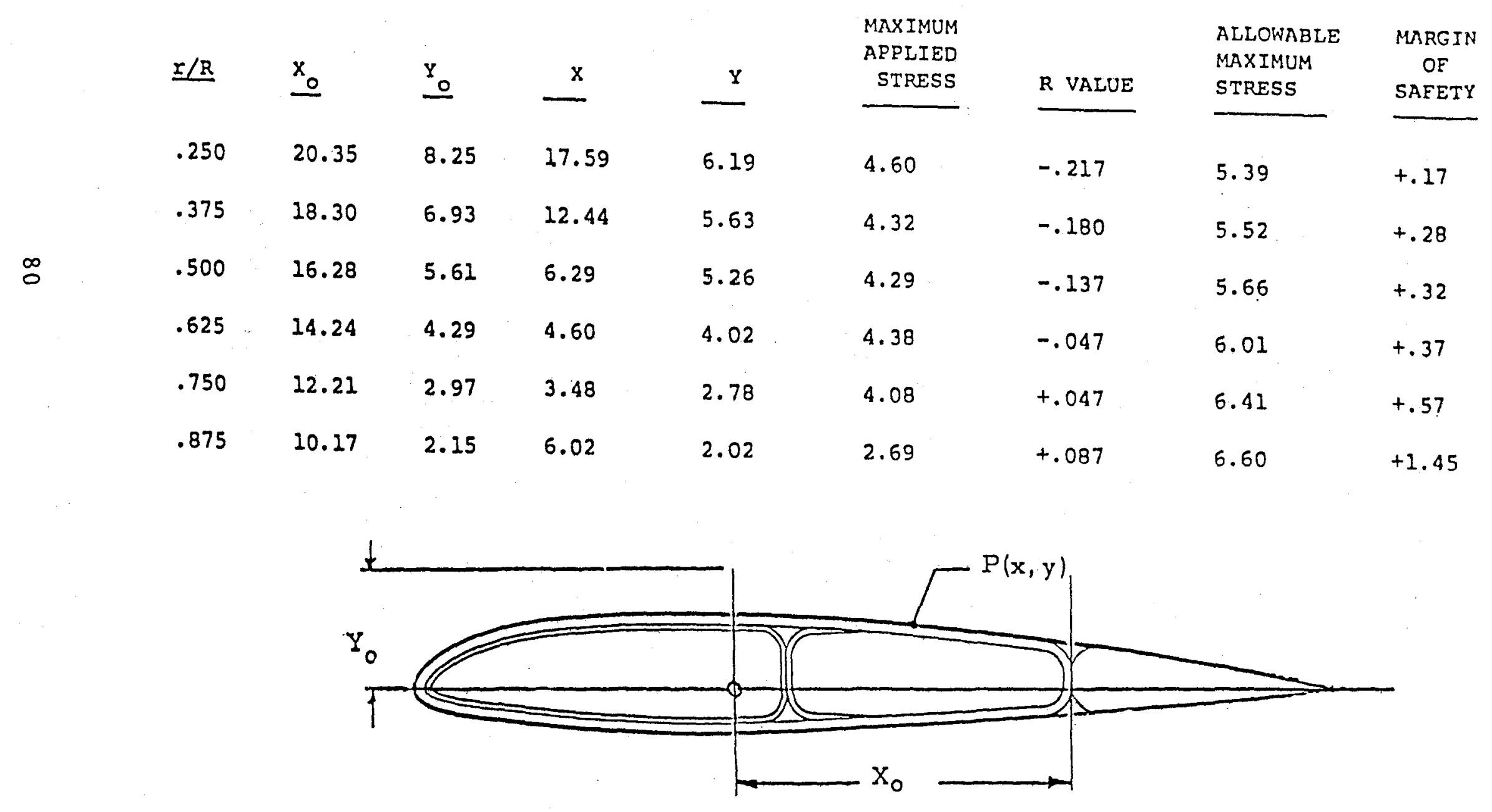




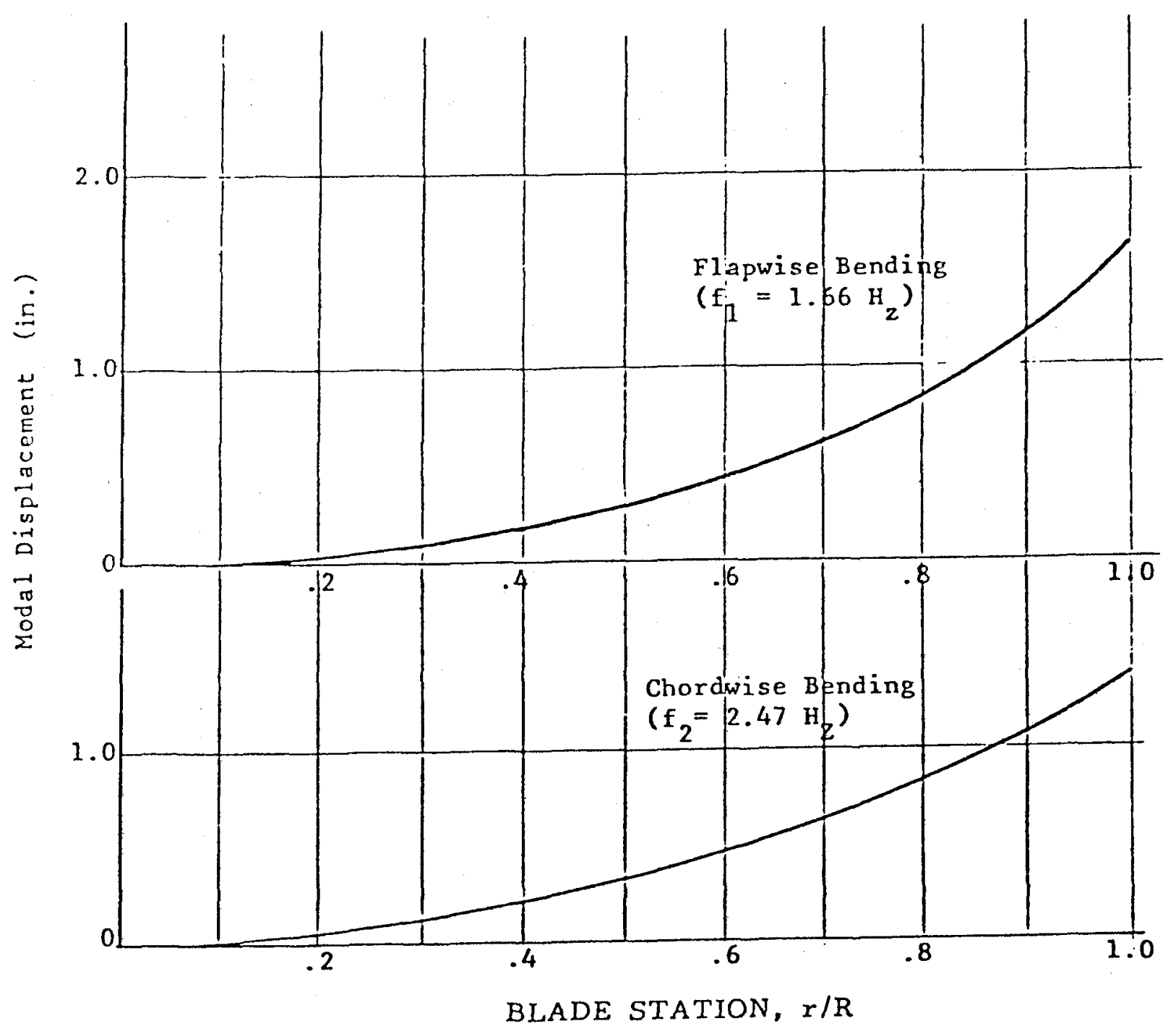

FIGURE 29 BLADE VIBRATIONAL MODE SHAPES 

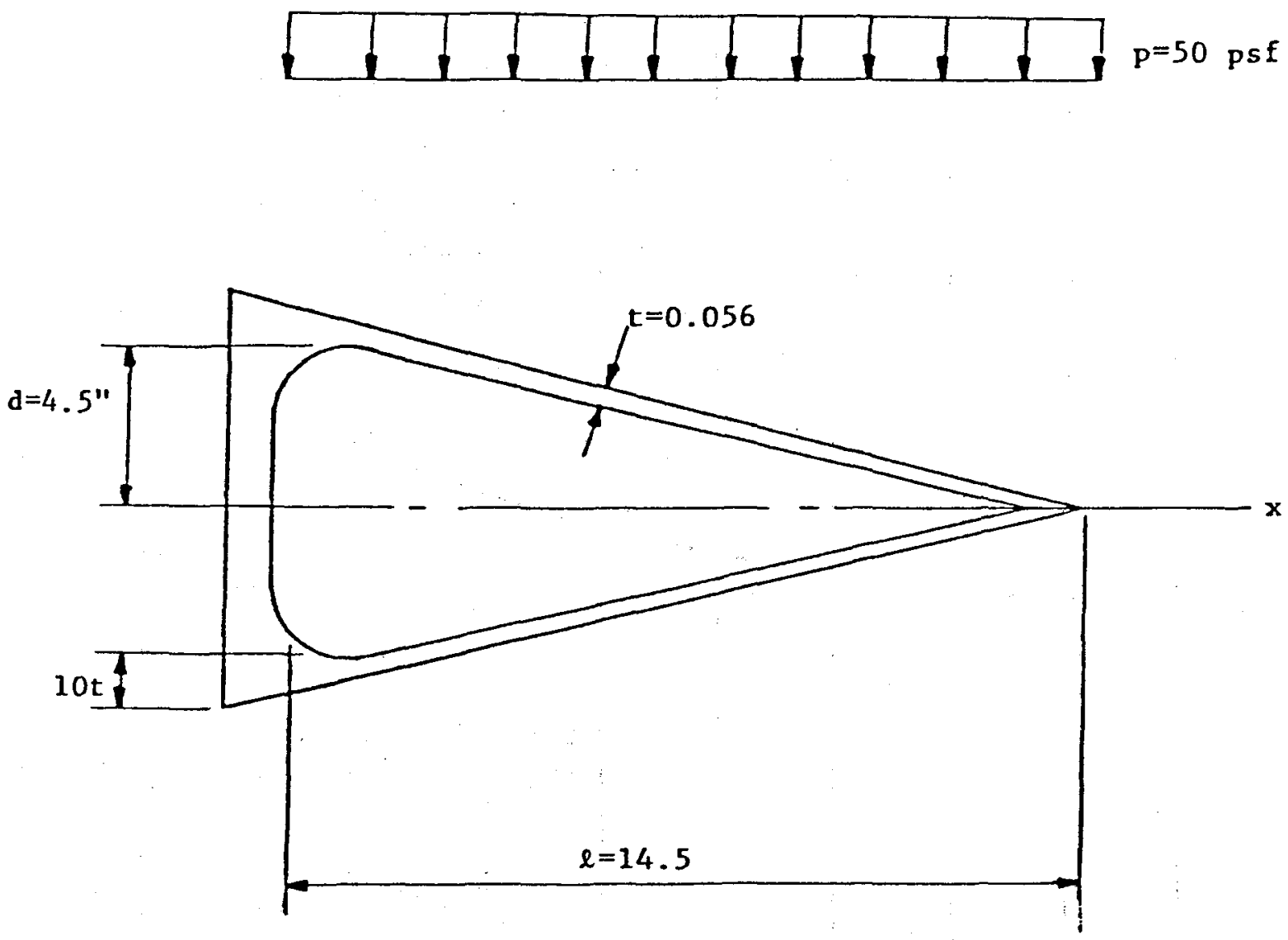

FIGURE 30 TRAILING EDGE AT STA. 0.25 
The effective cantilever length was considered to be 14.5 inches having been measured from the fixed end at which the root thickness is ten (10) times the laminate thickness to the tip.

The laminate properties and strength characteristics of the trailing edge laminate were determined using the same laminate analysis computer code (Reference 12 ) as was used for the TFT composite blade. The laminate consists of $58.9 \%$ fibers \pm 450 and $41.1 \%$ at $0^{\circ}$ relative to the edgewise direction of the trailing edge. The elastic constants and strength envelope of the laminate are shown in Figure 31.

For the beam model shown in Figure 30 , the maximum bending stress in the face sheets occurs at the base of the cantilever. This stress is given by the relation

$$
\begin{aligned}
& \sigma_{\text {MAX }}=\frac{M c}{I}=\frac{M}{Z t d} \quad \ldots(6) \\
& \sigma_{\text {MAX }}=\frac{36.50}{2(.056)(4.5)}=72 \mathrm{psi}
\end{aligned}
$$

From Figure 31 , the maximum allowable stress in unidirectional bending is $11,000 \mathrm{psi}$. Thus, the margin of safety against at strength failure of the trailing edge is

$$
\text { M.S. }=\frac{11,000}{72}-1=\underline{\underline{\text { High }}}
$$

For stability of the face sheets under compressive loading, both column buckling of the unit width strip and local buckling of the plate were investigated. In each case the lateral stability improvement afforded by the flatwise tensile connection of the face sheet to the foam was neglected. The column buckling allowable stress, $\sigma_{c r}$ was determined from the
relation

$$
\sigma_{\mathrm{cr}}=\frac{4 \pi^{2} \mathrm{E}_{\mathrm{e}} \mathrm{I}}{\mathrm{AL}^{2}} \quad \ldots(7)
$$


AVERAGE LAMINATE ELASTIC CONSTANTS BEY

$$
\begin{aligned}
& E X \quad=2.91 \times 10^{6} \mathrm{psi}-\text { TAUXY }=0 \\
& E Y=1.60 \times 10^{6} \mathrm{psi}-1-\text { TAUXY }=6026 \mathrm{psi} \\
& U X=0.506 \\
& G X Y=9.98 \times 10^{5} \mathrm{psi}
\end{aligned}
$$

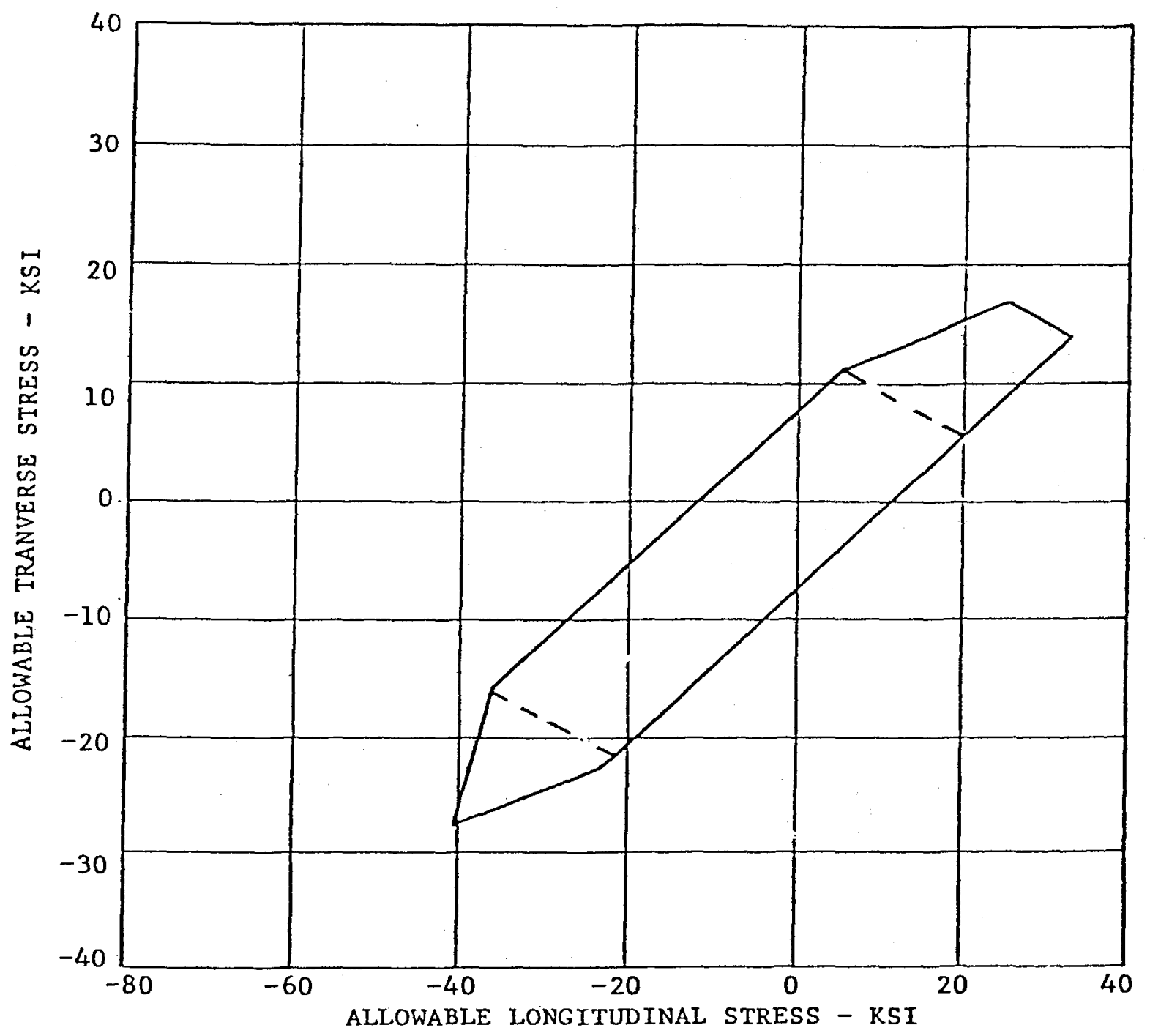

FIGURE 31

LAMINATE PROPERTIES AND STRENGTH

ENVELOP OF TRAILING EDGE 
where the effective modulus, $E_{e}$, is given in Equation (1). For this case, using the data given in Figure 31. $\mathrm{E}_{\mathrm{e}}=2.34 \times 10^{6} \mathrm{psi}$. Thus, Equation (7) yields

$$
\begin{aligned}
& \sigma_{c r}=\frac{4 \pi^{2}\left(2.34 \times 10^{6}\right) \frac{1}{12}(1)(0.056)^{3}}{(1 \times .056)\left(14.5 / \cos 17.25^{\circ}\right)^{2}} \\
& \sigma_{c r}=105 \mathrm{psi}
\end{aligned}
$$

The margin of safety against column buckling is then

$$
\text { M.S. }=\frac{105}{72}-1=\quad+0.46
$$

For local plate buckling of the face sheets, the allowable stress $\sigma_{b}$ is given by the relation

$$
\sigma_{b}=3.6 \mathrm{E}_{\mathrm{e}}\left(\frac{t}{\mathrm{~L}}\right)^{2}
$$

For this case

$$
\begin{aligned}
& \sigma_{b}=3.6\left(2.34 \times 10^{6}\right) \cdot\left(\frac{0.056}{14.5 / \cos 17.25}\right)^{2} \\
& \sigma_{b}=115 \mathrm{psi}
\end{aligned}
$$

Thus the margin of safety against local buckling of the face sheets is

$$
\text { M.S. }=\frac{115}{72}-1=\quad+0.60
$$

\subsubsection{HUB JOINT DESIGN ANALYSIS}

A detailed analysis of the blade hub joint consisting of the spar, end fitting and adapter transition to the NASA hub was performed. The purpose of this analysis was to demonstrate the structural integrity of the blade hub joint to adequately transfer blade loads to the NASA hub section of the rotor. 
The general design philosophy adapted for the hub joint design was to ensure a smooth transition of blade loads to the NASA hub fitting. This was interpreted structurally to require a hub joint design which minimized stress discontinuities and concentrations through gradual geometric shape transition of components. Accordingly, this interpretation resulted in the requirement for a scarf joint configuration for the end fitting and a relatively long, shallow-angle conical adapter for the transition from the blade end fitting to the NASA hub.

END FITTING

Several design criteria were established for the scarf joint configuration of the end fitting. The scarf joint was to be designed to exhibit constant stiffness (Et) along the effective load transfer of the joint. Such a design would provide for constant joint strain and minimize thermal mismatch of the adherends. In addition, the scarf angles of the adherends were to be sized to prevent premature tip failures and reduce peel stresses during joint loading. Finally, the scarf angle was to be as small as possible to facilitate winding of the spar composite material on the end fitting.

\section{ADAPTER}

The design criteria for the conical adapter were established as follows. The length of the adapter was to be designed to minimize kick loads developed at the fitting/adapter interface. Also, the line of action of the conical forces in the adapter was to be directed through the centroid of the NASA hub fitting bolts to minimize bolt bending effects. Finally, the flange bending stiffness of both the adapter and the end fitting at the adapter/fitting interface was to be the same for each component to minimize bolt loads in joining the components.

\section{DESIGN APPROACH}

Hand calculations followed by a preliminary computer math model analysis of the hub joint were used to develop initial joint design configurations.

The analysis results were useful in providing engineering insight toward the development of the final joint design configuration. The computer model analysis was particularly useful in establishing the final joint design analysis procedure. 
The final hub joint design configuration is shown schematically in Figure 7A. The joint consists of a TFT composite spar overwrapped on a steel end fitting. The end fitting, in turn, is bolted to the steel adapter, shown schematically in Figure 8 to form the final field joint installation.

MODEL DESCRIPTION

A detailed finite elementmodel of the hub joint design was developed and analyzed to demonstrate structural integrity of the final design configuration. The model consists of 425 nodes, 336 axisymmetric ring elements and 4 material types. The model was developed for analysis using the ANSYS computer code. The model represents a detailed simulation of the hub joint from STA 97.73 inch to STA 52.62 inch, including a section of the NASA hub fitting to provide a physically relevant boundary condition for the model.

\section{LOADING CONDITIONS}

The hub joint design was analyzed under static limit and cyclic operational loads. 6 The static limit load was represented by a moment of $4.0 \times 10^{6}$ in.-1bs applied at STA 97.73 inch of the hub joint model. This moment was derived from the survival wind load condition shown in Figure 1 and is conservative since it represents the maximum bending moment occuring on the blade.

The cyclic operational load was represented by a moment of $1.5 \times 10^{6}$ in.-1bs at a stress ratio, $R$, of -0.37 applied at STA 97.73 inch of the hub joint mode. This moment and stress ratio were developed from the NASA loading curves for flatwise and edgewise bending previously presented as Figures 2 and 3 , respectively. The moment represents a combined flatwise and edgewise bending moment which was developed by adding the RSS values of the steady and cyclic load components at the $8 \mathrm{ft}$ station (STA 0.13) of both loading curves. The stress ratio was developed from the relation

$$
\mathrm{R}=\frac{\sigma_{\min }}{\sigma_{\max }}=\frac{\mathrm{M}_{\min }}{\mathrm{M}_{\max }} \ldots(9)
$$


The hub joint was analyzed under 1 imit and operational loads with and without a superimposed temperature loading. The temperature load was represented as a bulk temperature differential loading of $-280^{\circ} \mathrm{F}$ applied to the hub joint model. This loading conservatively assessed stresses developed in the joint as a result of cool down during blade cure $\left(+250^{\circ} \mathrm{F}\right)$ to the minimum operating temperature $\left(-30^{\circ} \mathrm{F}\right)$.

\section{ALLOWABLE STRESSES}

The allowable stresses for the limit load analysis were taken as the yield strength of the materials. This is consistent with the design requirement of Section 4.1. The yield design allowables are given in Section 4.3.3.2. The allowable stresses for the operational loads analysis were determined as follows:

\section{STEEL}

The Goodman diagram for AISI 4140 (F - $150 \mathrm{ksi}$ ) alloy steel given in Reference 8 was used to develop the design allowable stress. Using the notched fatigue data $\left(K_{+}=3.3\right)$ at $10^{7}$ cycles, a maximum allowable stress of $44,000 \mathrm{psi}$ was determined for the stress ratio, $R-0.37$. This was done by adding the mean and alternating components of the cyclic stress.

\section{TFT COMPOSITE}

The design allowable stress for the TFT composite was developed from Equation (2). Using $R=-0.37$, the maximum allowable stress was determined to be 4,900 psi.

\section{ADHESIVE}

Based on the bonded scarf joint data given in Reference 9 , the ratio of the minimum cyclic fatigue stress (at $10^{7}$ cycles) to the static ultimate strength of the adhesive was found to be 0.4 . Thus, the fatigue of the adhesive was determined as

$$
\begin{aligned}
& \sigma_{\max }=0.4 \quad \sigma_{U 1 t}=0.4(32.00) \\
& \sigma_{\max }=1,280 \mathrm{psi}
\end{aligned}
$$

$\underline{\text { HOOPS }}$

By extending the Goodman Diagram shown in Figure 22 to be consistent with a static ultimate strength of the composite of 75,200 psi at $R=1$, the maximum allowable stress of the hoops was determined to be $18,570 \mathrm{psi}$. This stress corresponds to a stress ratio of $R=0.37$. 
The hub joint was analyzed under operational and 1 imit loads in both the adhesively bonded and unbonded configuration. The specific cases analyzed on the computer were:

$$
\begin{aligned}
& \text { a. Bonded }\left(M=4.0 \times 10^{6} \text { in. }-1 \mathrm{bs}, \Delta T=0\right) \\
& \text { b. Bonded }\left(M=0, \Delta T=280^{\circ} \mathrm{F}\right) \\
& \text { c. Unbonded }\left(M=4.0 \times 10^{6} \text { in. }-1 \mathrm{bs}, \Delta T=0\right)
\end{aligned}
$$

The hub joint response to the operational moment loading condition was derived by scaling the limit load moment response data by the ratio of $M_{\text {operational }}$ to $M_{1 \text { imit }}(i . e ., 1.5 / 4.0=0.375$ ). Such scaling is permissable since in all cases the hub joint stress response was found to be within the elastic limits of the materials. Where applicable, the $\Delta T=280^{\circ} \mathrm{F}$ stress response data were added to the moment response data to form the combined $M=\Delta T$ response analysis data.

\section{ANALYSIS RESULTS}

As a result of the computerized structural analysis, detailed stress distribution in the hub joint for the several loading conditions was obtained. A nearly uniform stress state was developed for the steel fitting and adapter in order to optimize the design of these components for minimum blade weight.

A critical analysis of the computer results was also made to determine margins of safety against structural failure of the hub joint. The results of this analysis for the operational and limit load conditions are given in Tables 10 and 11, respectively. These tables present the minimum margins of safety developed for each of the components of the joint.

The data given in Tables 10 and 11 indicate that positive margins of safety exist for every structural component of the joint for every loading condition. For the critical high stress tip area of the steel fitting, the results given in Table 11 for the unbonded scarf joint configuration show that the minimum margins of safety against failure of the fitting is 0.28 . Also, the analysis results for the operational loading condition indicate that the margin of safety against failure of the adhesive under cyclic loading is 0.25 . 


\section{TABLE 10 \\ HUB JOINT \\ ANALYSIS SUMMARY \\ OPERATIONAL LOADS}

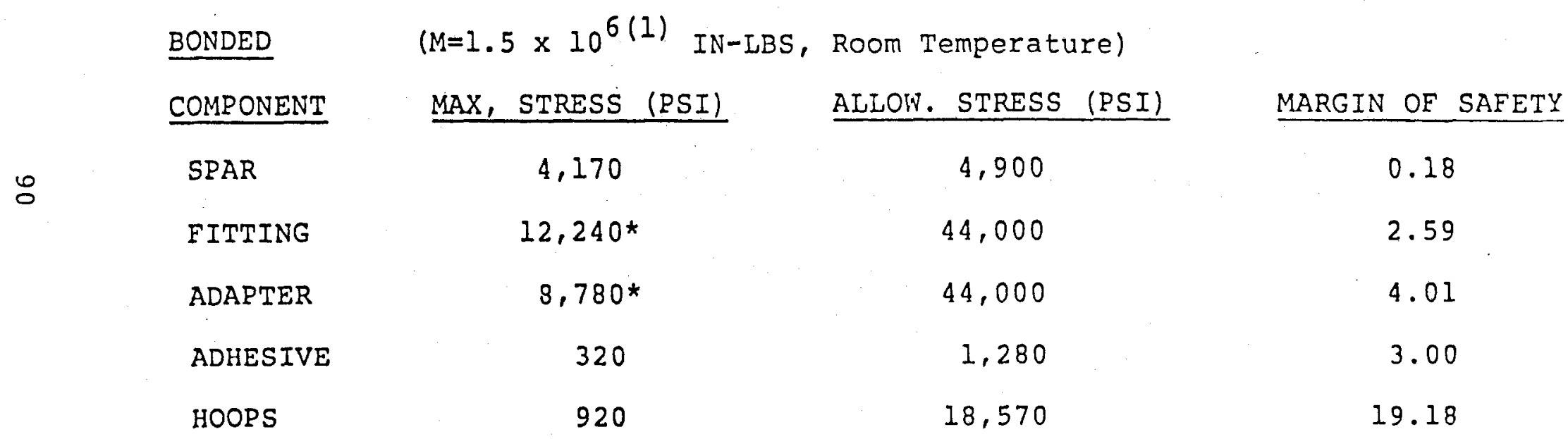

\section{(*PRINCIPAL STRESS VALUE)}

(1) Combined Fatigue Moment Value with $R=.37$ 


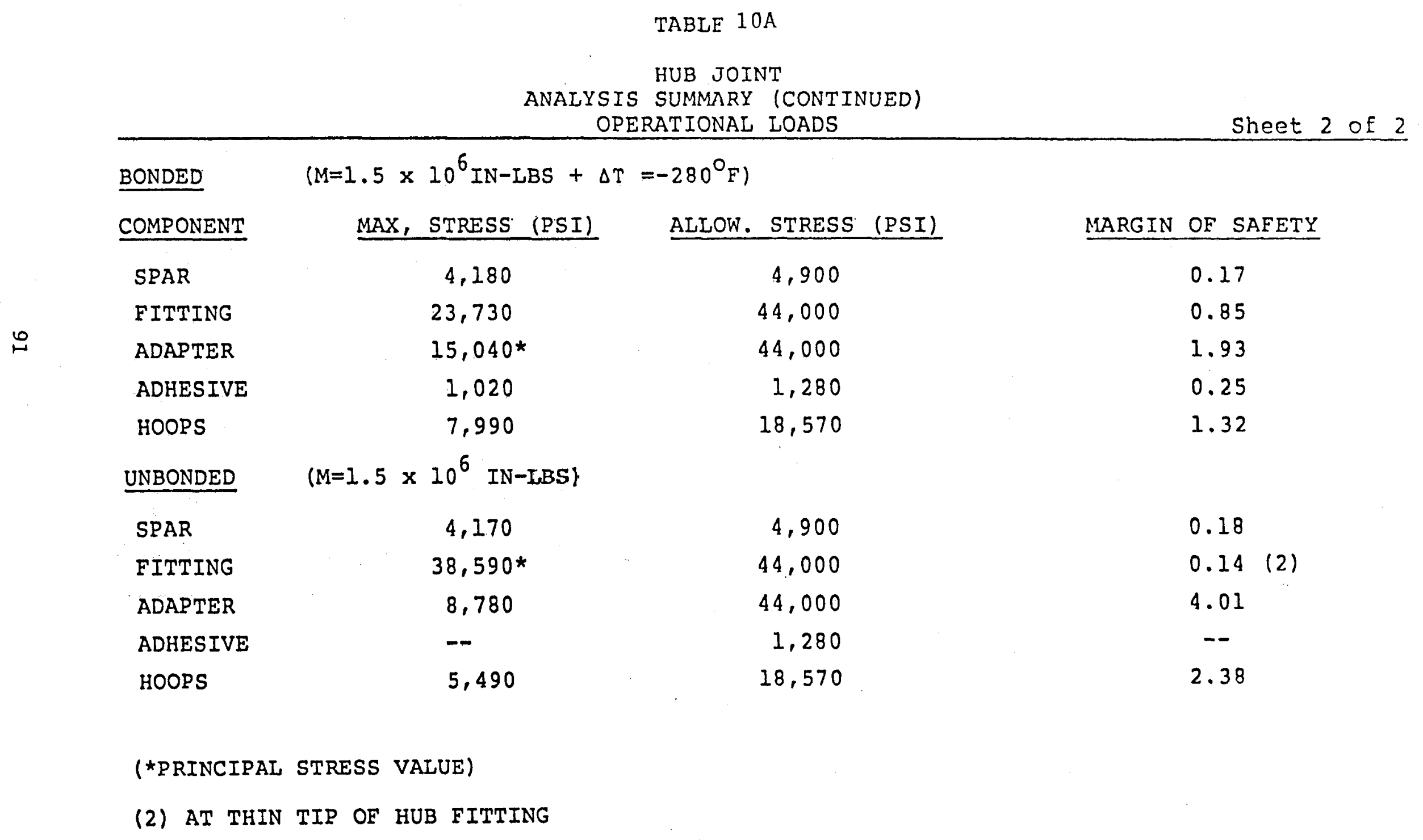


TABLE 11

HUB JOINT

ANALYSIS SUMMARY

IIMIT LOADS

Sheet 1 of ' 1

BONDED (M=4 $\times 10^{6}$ IN-LBS (1), ROOM TEMPERATURE)

COMPONENT

SPAR

FITTING

$\stackrel{\omega}{N}$

MAX. STRESS (PSI)
$\begin{array}{r}11,120 \\ 32,650 * \\ 23,400 * \\ 860 \\ -2,440\end{array}$

ADHESIVE

$-2,440$

$\left(\mathrm{T}=-280^{\circ} \mathrm{F}\right)$

BONDED

SPAR

FITTING

ADAPTER

ADHESIVE

HOOPS

(*PRINCIPAI STRESS VALUE)

(1) 50 PSF WIND LOAD PLUS BLADE WEIGHT

\begin{tabular}{rc} 
ALLOW. STRESS (PSI) & MARGIN OF SAFETY \\
\hline 16,000 & 0.44 \\
123,000 & 3.04 \\
132,000 & 4.64 \\
2,560 & 1.98 \\
60,000 & 23.59
\end{tabular}

16,000

6.69

132,000

5.79

132,000

18.70

2,560

0.96

8.63 
TABLE 11A

HUB JOINT

ANALYSIS SUMMARY

LIMIT LOADS

Sheet 2 or?

BONDED $\quad\left(M=4 \times 10^{6} \mathrm{IN}-\mathrm{LBS}+\Delta \mathrm{T}=-280^{\cup} \mathrm{F}\right)$

COMPONENT

SPAR

FITTING

ADAPTER

ADHESIVE

HOOPS

UNBONDED

SPAR

FITTING

ADAPTER

ADHESIVE

HOOPS
MAX. STRESS (PSI)

11,120

21,160 *

29,650 *

$-8,670$

$\left(M=4 \times 10^{6} \mathrm{IN}-\mathrm{LBS}\right)$

11,120

$102,920 *$

23,410 *

$-$

14,640
1,690
ALLOW. STRESS (PSI)

16,000

123,000

132,000

2,560

$60 ; 000$

16,000

132,000

132,000

2,560

60,000

\section{MARGIN OF SAFETY}

0.44

5.24

3.45

0.51

5.92

0.44

$0.28(2)$

4.63

3.10

(*PRINCIPAL STRESS VALUE)

(2) AT THIN TIP OF HUB FITTING 
The "shrink fit" radial stress distribution at the bond joint was analyzed. These results indicate that the steel fitting and the adhesive are in compression and the hoops in tension almost completely along the length of the scarf region of the joint due to the $\triangle \mathrm{T}$ shrinkage of the composite material relative to the fitting. Localized areas of radial tension relative to the fitting and adhesive are evident, however, in the aft 1 and areas of the fitting. These tensile stresses arise due to the difference in joint stiffness, Et, of the adherends in these areas.

In the critical adhesive layer of the joint, it was found that the maximum radial tensile stress in the aft land area is approximately 900 psi. This compares with flatwise tensile design allowable of approximately 1900 psi (See Section 4.3.3.2) thereby yielding a margin of safety of 1.11 against tensile failure of the adhesive.

\section{3 .3 .7 ROOT END CLOSURE ANALYSIS}

A set of hand calculations were performed to analyze the structural integrity of the root end closure transition from the blade spar to the hub joint fitting. The purpose of this analysis was to demonstrate the structural integrity of the root end closure to adequately transfer blade kick loads to the hub joint fitting.

\section{DESIGN ANALYSIS APPROACH}

In order to conservatively demonstrate the structural integrity of the closure design, the root end closure shell was considered to be plate type construction consisting of a kick load panel between the afterbody cell and the hub joint fitting and two triangular side plates. Thus, the additional strength and stiffness design improvement provided by the curvature of the actual shell construction was neglected. Furthermore, the plate type construction was sized such that either the kick plate or the side plates could individually react all the kick load forces.

\section{LOADING CONDITIONS}

The critical loading condition is edgewise blade bending at STA 0.25. For this condition, the maximum static 1 imit bending moment (Figure 3 ) is $0.61 \times 10^{6}$ in.-1bs. This load is based on the sum of both the steady and cyclic components of the moment. 
Since the root end closure is a TFT composite laminate, only the 1 imit load condition need be investigated for static response. The ultimate loading condition will yield the same margins of safety as the $1 \mathrm{imit}$ load condition since $\mathrm{M}_{U 1 \mathrm{t}}=$ $1.25 \mathrm{M}_{\mathrm{Lim}}$ and $\sigma_{\mathrm{y}}=0.8 \sigma_{\mathrm{U}}$ or, conversely,

$$
\sigma_{\mathrm{U} 1 \mathrm{t}}=1.25 \sigma_{\mathrm{y}} \text {. }
$$

The maximum fatigue bending moment (Figure 3 ) is $0.43 \times 10^{6}$ in. -1 bs This load represents the cyclic component of the edgewise loading condition.

\section{DESIGN DESCRIPTION}

The closure design was analyzed for strength, stability and fatigue under the design loading conditions. The kick load panel ( $A C)$, side plates $(A B C)$ and ribs ( $B C$ and $B F$ ) as shown in Figure 32 were investigated.

KICK LOAD PANEL

The kick load panel was considered to be a TFT composite laminated plate simply supported at ends $A$ and $C$. The plate thickness $(0.364$ in.) and width (9.0 in.) were taken from the afterbody thickness and nominal cell web width, respectively, at STA 0.25. For the limit load static bending moment condition, the maximum stress at the extreme fiber of the afterbody cell is

$$
\sigma=\frac{0.61 \times 10^{6}(38-18.6)}{7264}=1,630 \mathrm{psi}
$$

Then, for strain compatibility at the panel/web joint and for equal component thicknesses, the induced panel stress is

$$
\sigma_{\mathrm{KP}}=\frac{1630}{\cos 10^{\circ}}=1,660 \mathrm{psi}
$$

Thus, the margin of safety against a strength failure of the panel is

$$
\text { M.S. }=\frac{0.8(20,000)}{1,660}-1=\underline{+8.64}
$$

For panel buckling the allowable stress, $\sigma_{b}$, is given by

$$
\sigma_{b}=3.6 \mathrm{E}_{\mathrm{e}}\left(\frac{\mathrm{t}}{\mathrm{b}}\right)^{2}
$$




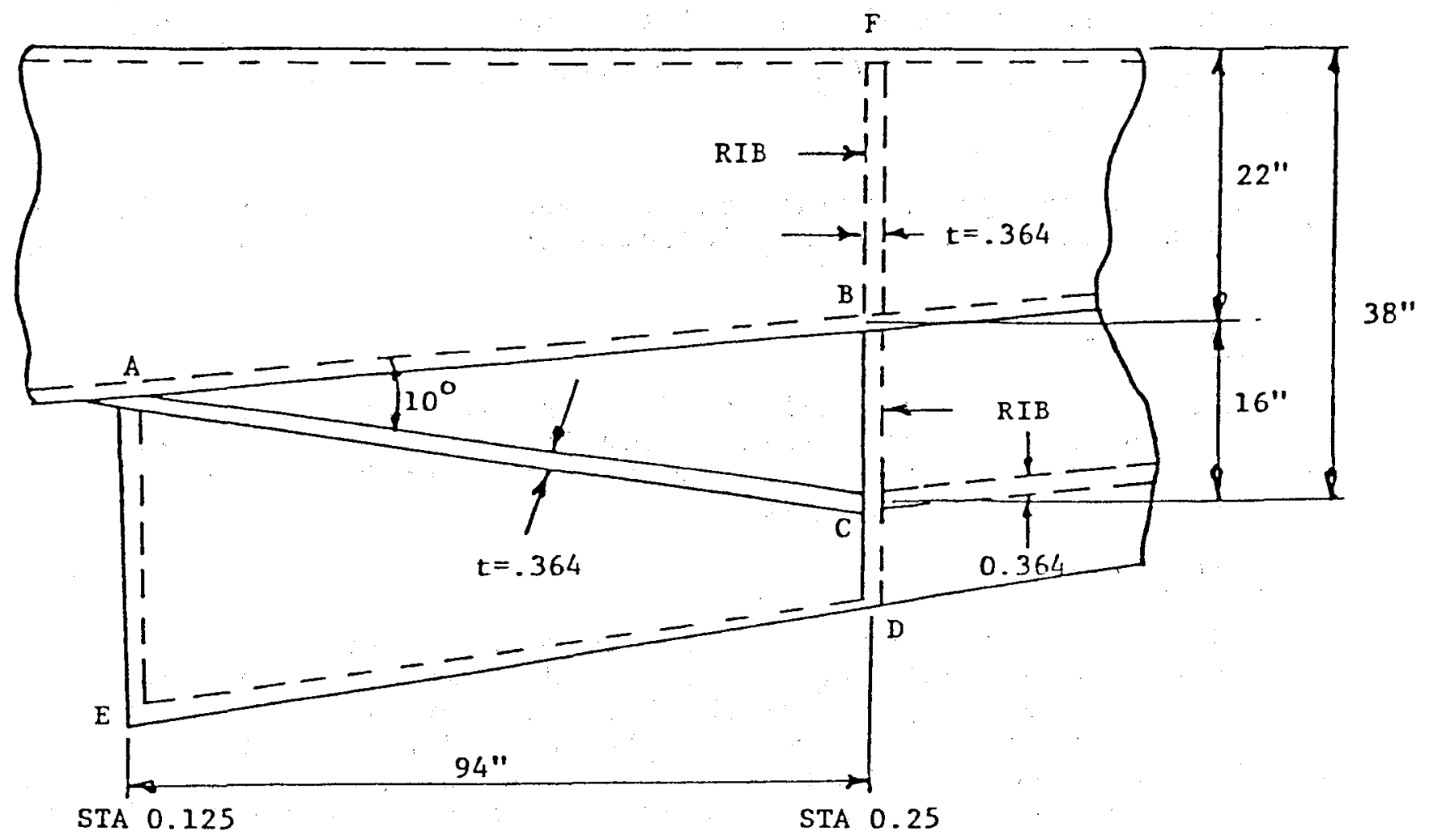

FIGURE 32 SCHEMATIC OF ROOT END CLOSURE DESIGN 
For this case

$$
\begin{aligned}
& \sigma_{b}=3.6\left(2.20 \times 10^{6}\right) \quad\left(\frac{0.364}{9.0}\right) \\
& \sigma_{b}=12,950 \mathrm{psi}
\end{aligned}
$$

Thus, the margin of safety against a stability failure of the panel is

$$
\text { M.S. }=\frac{12,950}{1,660}-1=\underline{+6.80}
$$

For the fatigue loading condition, the stress in the panel is

$$
\sigma_{f_{K P}}=\frac{0.43 \times 10^{6}(19.4)}{7264 \cos 10^{\circ}}=1,170 \mathrm{psi}
$$

Using a TFT fatigue allowable stress of 4,900 psi (See Section 4.3.3.2) results in the following margin of safety against a fatigue failure of the panel

$$
\text { M.S. }=\frac{4,900}{1,170}-1=\underline{+3.19}
$$

SIDE PLATES

Each of the side plates was considered as a triangular gusset plate fixed along the sides $A B$ and $B C$ and free along the diagonal side, $A C$. Loading was developed along the side $B C$ with a linear stress distribution occuring in the plate at that location as a result of the applied moment at STA 0.25 . For this case

$$
\sigma_{\mathrm{SP}}=1,630 \mathrm{psi}
$$

Thus, the margin of safety against a strength failure of the side plate is

$$
\text { M.S. }=\frac{16,000}{1,630}-1=+8.82
$$

The stability of the gusset plate can be investigated using the procedures of Reference 9 . For the side plate configuration shown in Figure 32 , the maximum allowable stress is given by

$$
\sigma_{\mathrm{A} 11}=\frac{\mathrm{R}}{\mathrm{bt} \cos ^{2} \alpha} 1+\frac{6 \mathrm{e}}{\mathrm{b}}
$$


For this case

$$
\begin{aligned}
\mathrm{R} & =\frac{1}{2}(16) \quad(1630)=13,040 \mathrm{bs} \\
\mathrm{b} & =16 \mathrm{in} . \\
\mathrm{t} & =0.364 \mathrm{in} . \\
\mathrm{e} & =\frac{2}{3}(16)-\frac{1}{2}(16)=2.67 \mathrm{in} . \\
\alpha & =10^{\circ}
\end{aligned}
$$

Thus, Equation (11) yields

$$
\begin{aligned}
& \sigma_{\mathrm{A} 11}^{\prime}=\frac{13,040}{16(0.364) \cos ^{2}\left(10^{\circ}\right)}\left(1+\frac{6 \times 2.67}{16}\right) \\
& \sigma_{\mathrm{A} 11}=4,620 \mathrm{psi}
\end{aligned}
$$

Therefore, the margin of safety against a stability failure of the side panel is

$$
\text { M.S. }=\frac{4620}{1630}-1=+\underline{+1.83}
$$

For the cyclic fatigue loading, the stress in the side plate is

$$
\sigma_{f p}=\frac{0.43 \times 10^{6}(19.4)}{7264}=1,150 \mathrm{psi}
$$

Thus, the margin of safety against a fatigue failure of the gusset is

$$
\text { M.S. }=\frac{4,900}{1,150}-1 \quad+3.26
$$

$\underline{\text { RIBS }}$

Owing to minimum cross sectional area, the maximum compressive kick load stress occurs in rib, BC. By resolving forces at joint $\mathrm{C}$ of Figure 32 , the rib kick load stress can be determined as

$$
\sigma_{R}=\frac{F_{R}}{A_{R}}=\frac{F_{K P} \sin \theta}{A_{R}}=\frac{\sigma_{K P} A_{K P} \sin \theta}{A_{R}} \ldots(12)
$$

then, by conservatively considering the cross sectional area, $A_{R}$, of the $\mathrm{rib}$ to be constant along the $\mathrm{rib}$ length and equal to the cross sectional area, $A_{K P}$, of the kick load panel 


$$
\begin{aligned}
& \sigma_{\mathrm{R}}=\sigma_{\mathrm{KP}} \mathrm{sin}=1660 \sin 10^{\circ} \\
& \sigma_{\mathrm{R}}=290 \mathrm{psi}
\end{aligned}
$$

Thus, the margin of safety against a compressive stress failure of the $\mathrm{rib}$ is

$$
\text { M.S. }=\frac{16000}{290}-1=\quad+54.2
$$

For the fatigue loading condition, the stress in the rib is

$$
\sigma_{\mathrm{FR}}=1,170 \mathrm{sin} 10^{\circ}=200 \mathrm{psi}
$$

Thus, the margin of safety against fatigue failure of the rib is

$$
\text { M.S. }=\frac{4900}{200}-1=+23.5
$$

\subsubsection{COMPARISON TO NASA SPECIFICATIONS}

Table 12 summarizes the actual versus NASA specified characteristics of the final SCI low cost blade design. The only parameter which is out of the specified range is the chordwise center of gravity, which is $38 \%$ from the leading edge, against a specified maximum of $32 \%$. NASA analyzed the SCI design for flutter and pitch control forces and determined that the $38 \%$ location was acceptable for this particular design.

\subsection{MANUFACTURING CONSIDERATIONS}

The interactions between generalized composite blade design and manufacturing considerations have already been discussed at some length in Section 4.3.1. In this section we will discuss manufacturing considerations for the final SCI design.

\subsubsection{FABRICATION PROCEDURES}

Figure 33 is an overall flow diagram for the SCI blade. PREPARATION

Figures 34 and 35 illustrate the process used to vacuumimpregnate the TFT material. The dry tape is unwound into baskets which are placed into a tank for vacuum impregnation. The wet impregnated material is then rewound onto spools which fit the ring winder. The BFT and LFT did not require the vacuum impregnation step, but were wound from the supply spool through a resin bath, and directly onto the ring winder spools. 


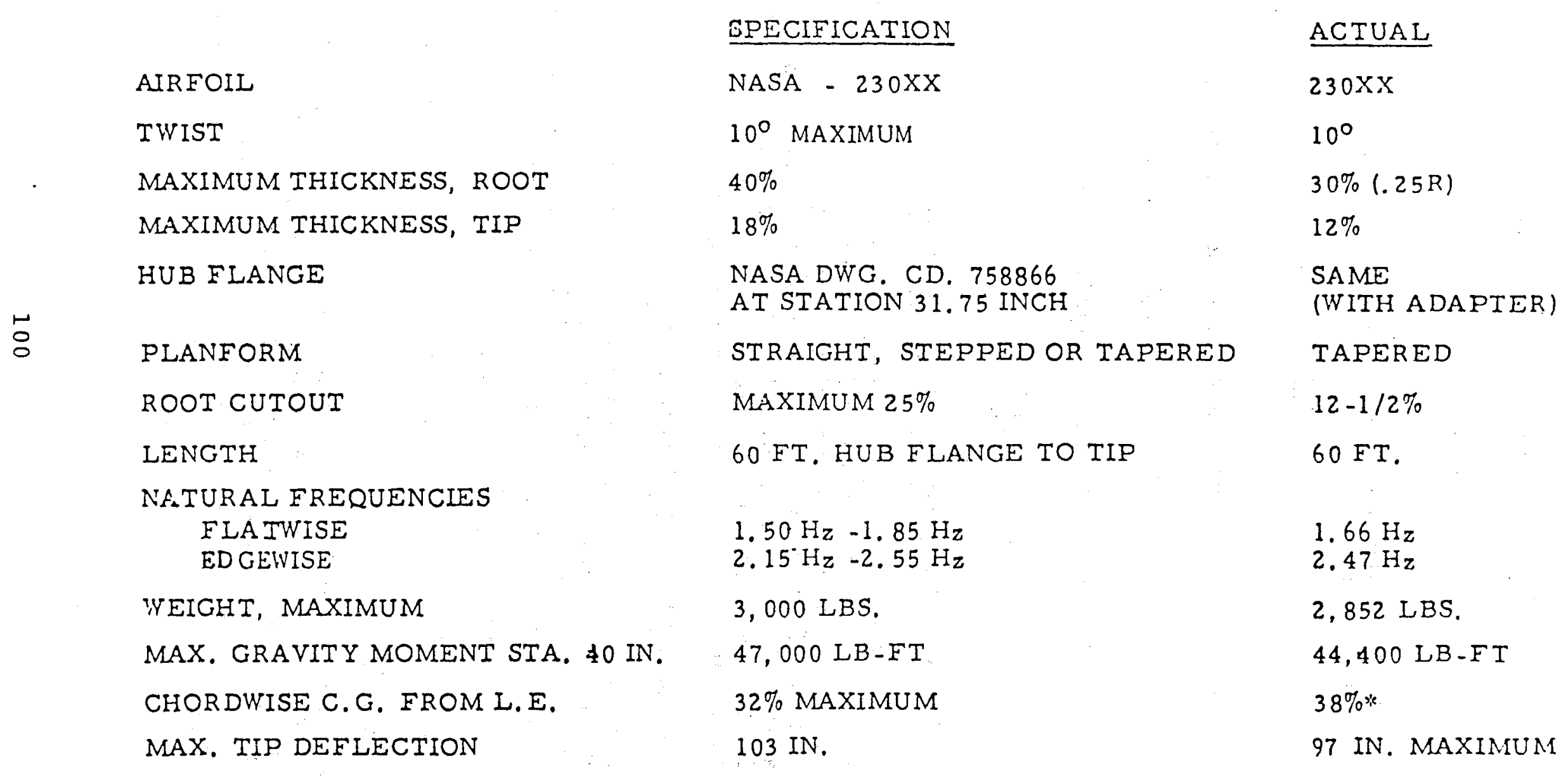

* ACCEPTABLE BY NASA ANALYSIS 


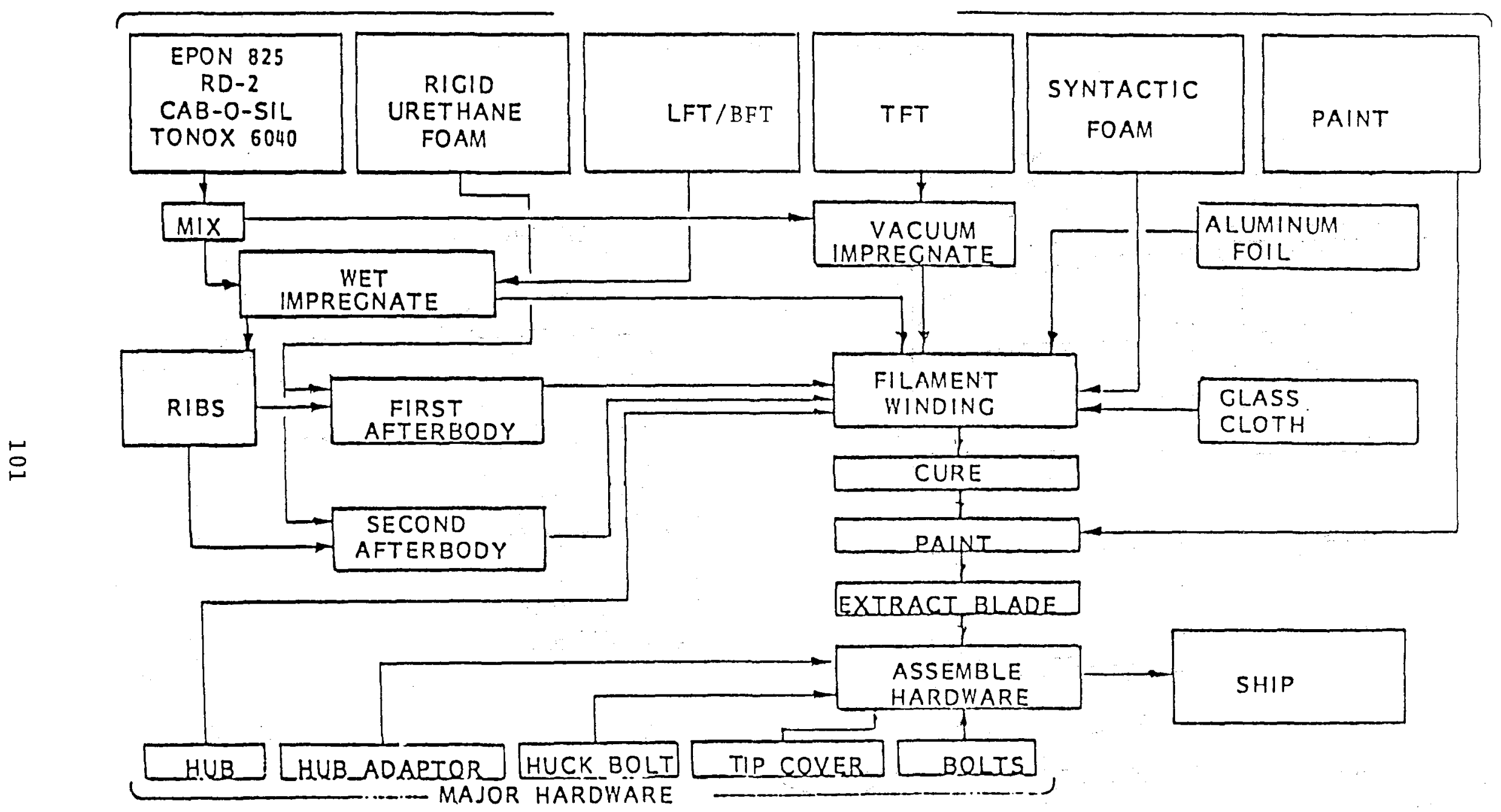

FIGURE 33 FABRICATION PROCFDURE (PROTOTYPE) 


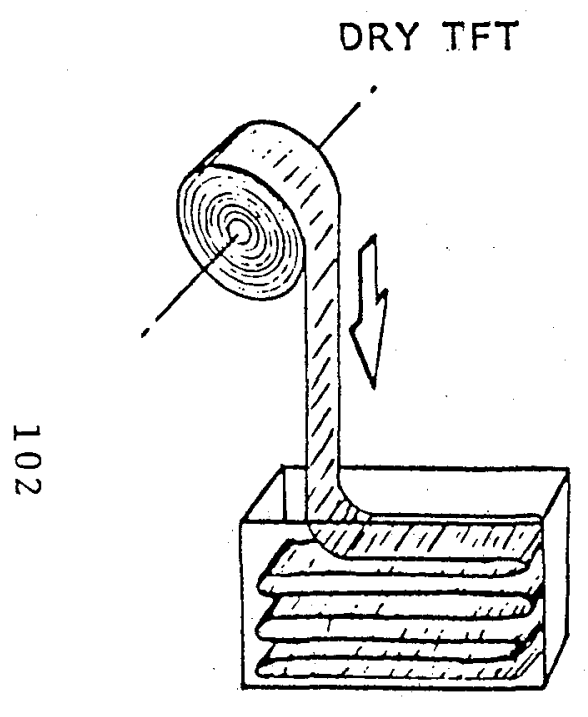

IMPRECNATION BASKET

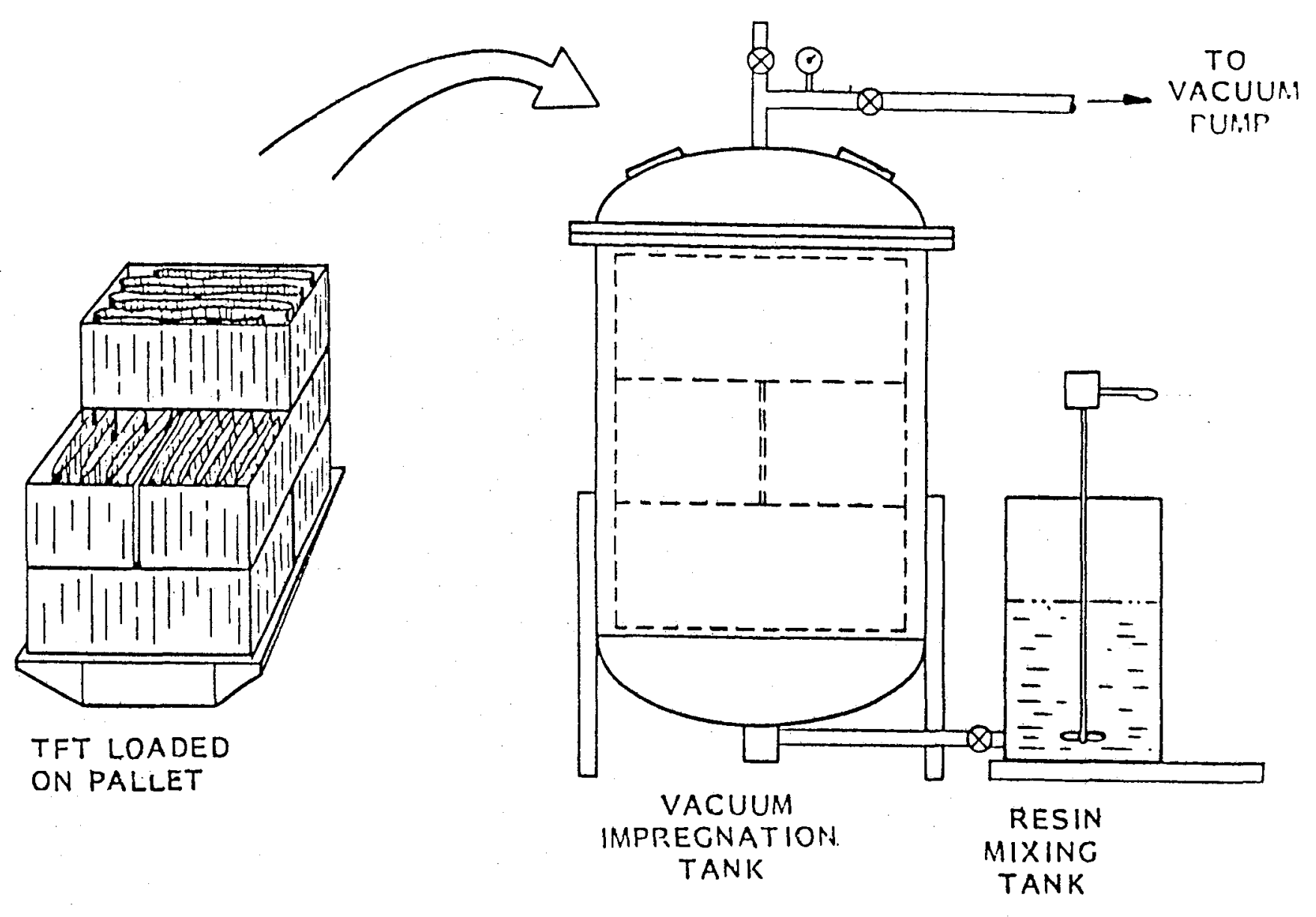

FIGURE 34 TFT VACUUM IMPREGNATION 

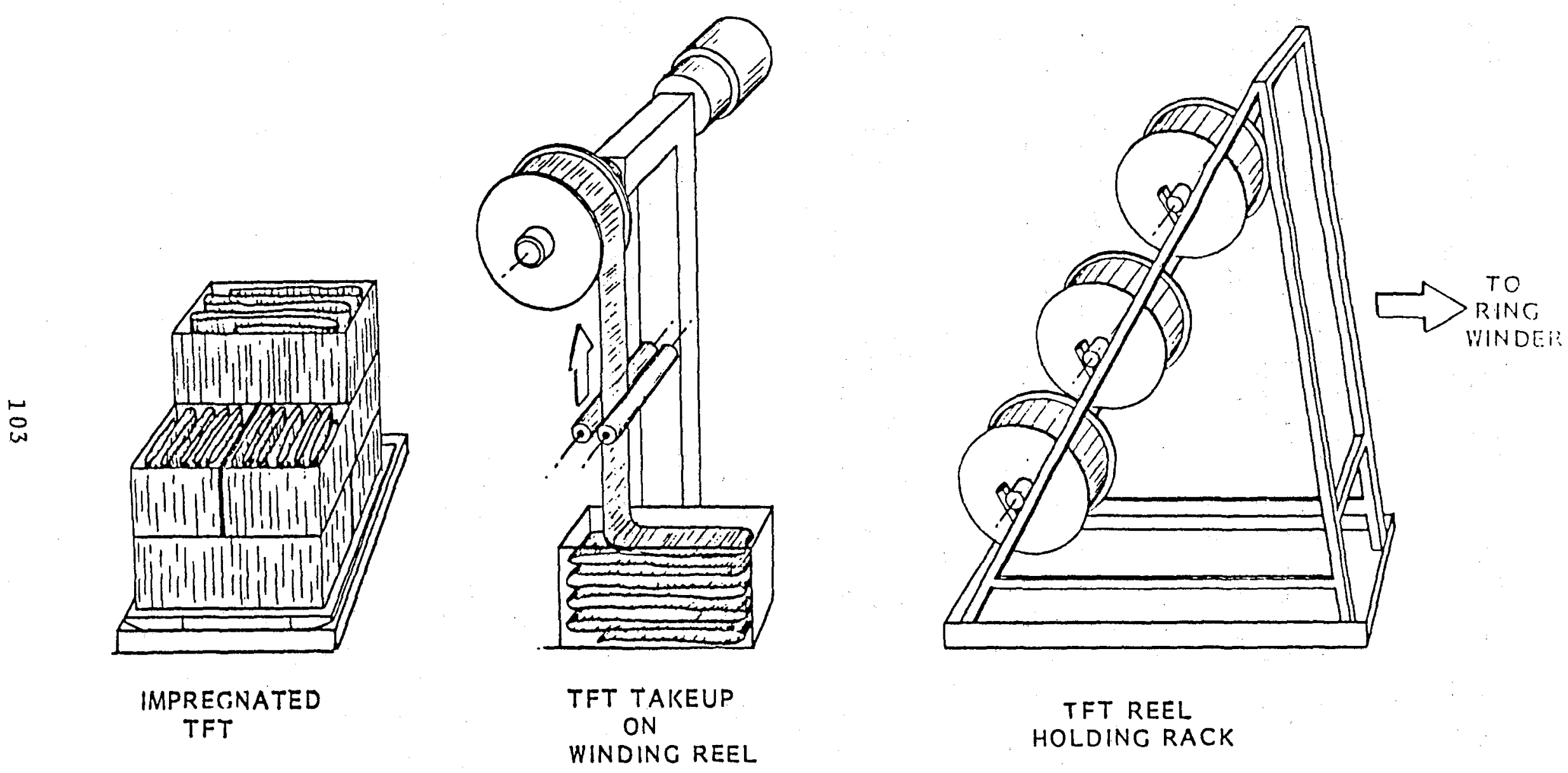

FIGURE 35 RESPOOLING IMPREGNATED TFT 
Other preparation included; precutting of the foam cores and the various plies of the web doubler layup; surface preparation and application of release agent to the mandrel.

\section{BLADE WINDING}

Figure 36 shows the overal1 winding arrangement for the blades. The water-filled headstock and tailstock support the D-spar mandrel in a fixed position while the traversing ring winder wraps the tape to form the composite. Figures 37 and 38 show how the foam cores are added in succession to form the afterbody and trailing edge.

CURING AND EXTRACTION

Figure 39 illustrates the blade curing arrangement. The cure oven is rolled over the wound blade from its parked position at the headstock end. A $200 \mathrm{~kW}$ electric hot air blower is used to heat the oven. The ring winder is parked under the tailstock overhang during cure.

Figure 40 shows the mandrel extraction concept. The tailstock is removed. Four 50 ton hydraulic jaws, driven by a common hydraulic power supply, push against the bucking $r$ ing to free the blade from the mandrel. The freed blade, supported by two cranes, is then moved clear of the mandrel while temporary blocks are positioned under the mandrel to support it until the tailstock is replaced.

FINAL FINTSHING AND ASSEMBLY

As shown in Figure 37 , the finished blade is painted in the winding machine prior to final cure. The lightning protection strip is applied prior to painting. After extraction, balancing tubes, D-spar $r i b$, ice detector and tip cap are installed to complete the blade.

\subsubsection{QUALITY ASSURANCE}

The overall quality assurance flow chart for the low cost composite blade is presented in Figure 41. Receiving inspection, in-process inspection and final inspection steps are detailed in Tables 13,14 and 15 , respective1y.

\subsubsection{TOOLING DESIGN AND FABRICATION}

Tooling designed for the low cost composite blade included the winding mandrel and its supports, the tape impregnation equipment and $j i g s$, fixtures and templates for alignment of the blade components during fabrication. The most critical item of tooling was the D-spar mandrel, which is the "backbone" upon which the blade is built. 


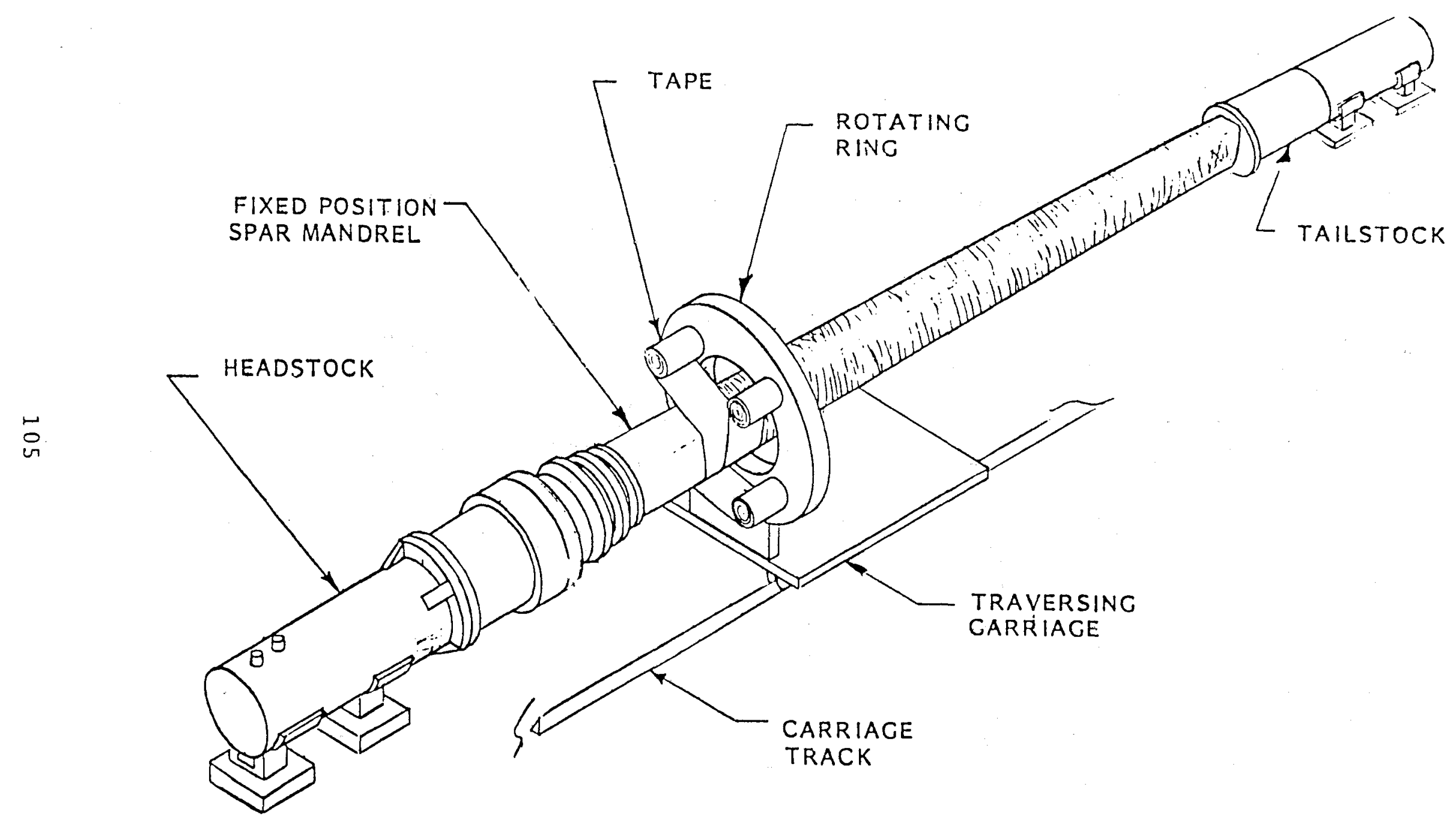

FIGIRE 36 OVERALL WIMIING ARRANGEMANT 


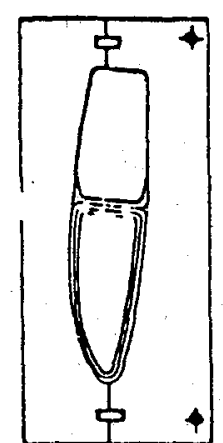

1) nenove BetL Rer ol Lay-ue wre stirrenian

el posipion Ist rom
NTI.xMJuY vith TLMploatr.s d) arri,r intactic

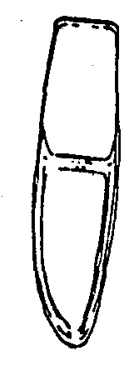

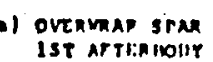
) aspi.y ir.el rly e) nuon trmpenatume
eun? itace pate.

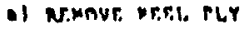

- Cosition ino rom Artriklour
riatiatiss

el appl.y snitactic

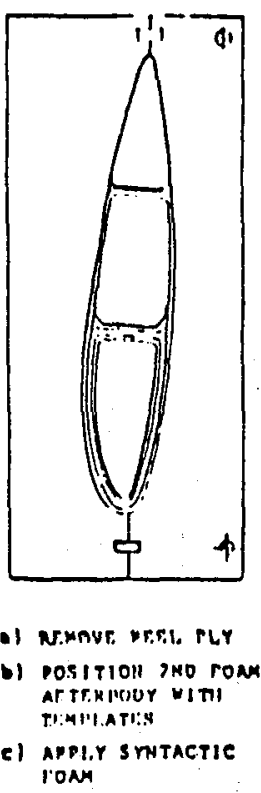

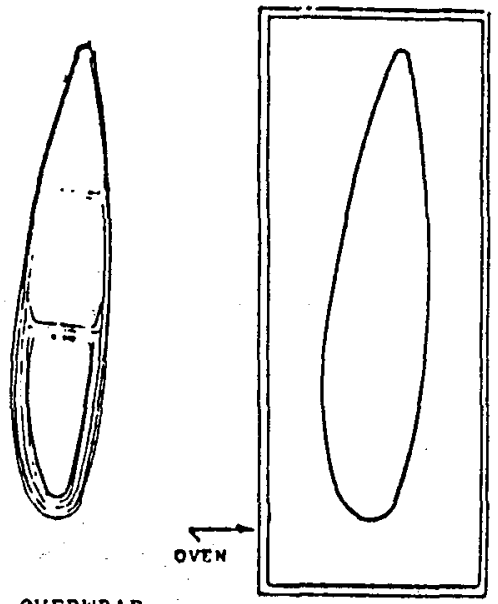

2) GEL BLADE

b) REMOVE FROM OVEN

c) LIGHTNING PROTECTION

d) PEEL, PLY c) RENOVE PEFL PLY

d) SURFACE CIIECK

il cune

el exmace ospan

rurune

d) Aтtacy

iuruvane

1 Pinal.
insercetion

(I) ship

NOTE: Vacuum Bag Compaction Was Used in Conjunction With Peel.Ply Layers. 


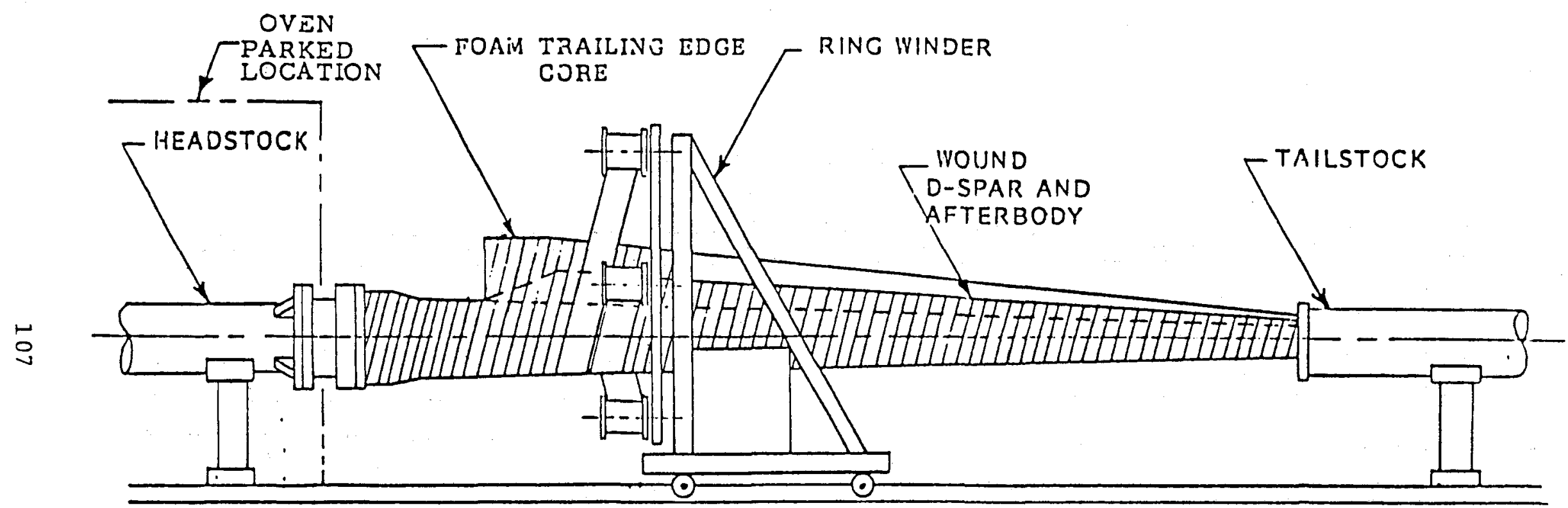

FIGURE 38 MANUFACTUP ING APPROACH 


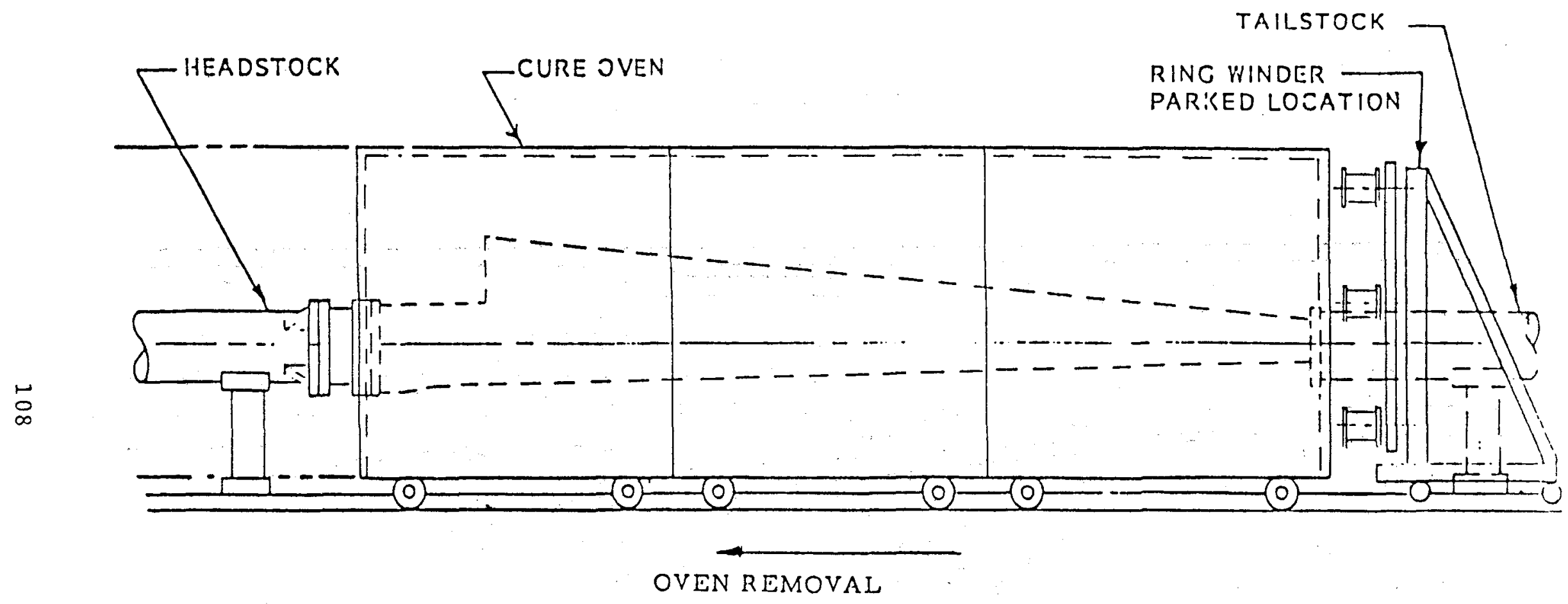

FIGIRE 39 BLADF CURING ARRANGEN'FNT 


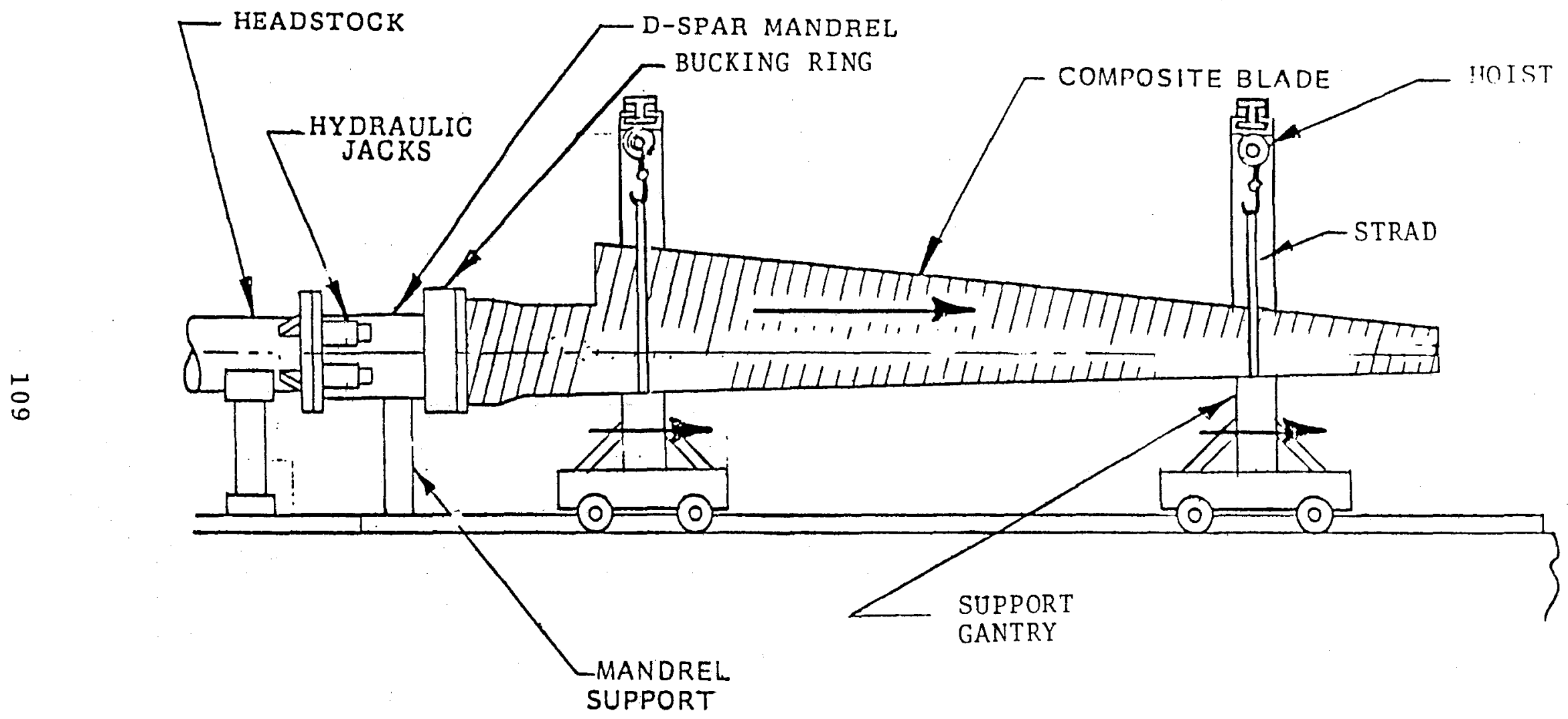

FIGIIPE 40 MANDRFL EXTRACTION 


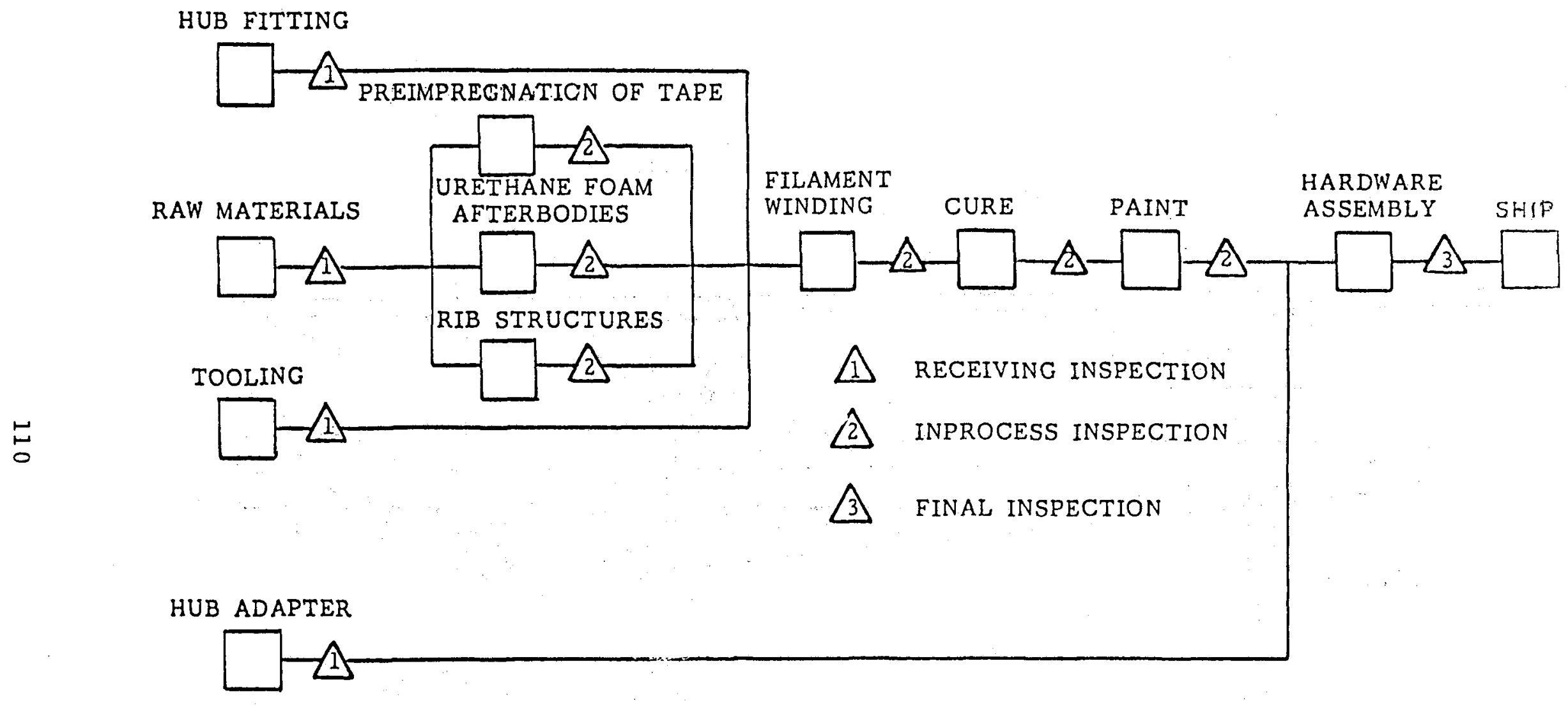

FIGURE 41 OIALITY ASSIRANCE PLAN FLOW CUART 
TABLE 13 RECEIVING INSPECTION

$\stackrel{\mapsto}{\rightleftarrows}$

$$
\begin{aligned}
& \text { 1. VISCOSITY } \\
& \text { 2. GEL TIME } \\
& \text { 3. BARCOL HARDNESS }
\end{aligned}
$$

\section{RESIN SYSTEM COMPONENTS}

4. SPECIFIC GRAVITY

5. CERTIFICATION (VENDOR)

WOVEN MATERIALS

1. YIELD $\left(W T / Y D^{2}\right)$

3. VISUAL \& DIMENSIONAL

2. TENSILE STRENGTH

4. CERTIFICATION (VENDOR)

FOAMS

1. VENDOR CERTIFICATION 2. DENSITY 3. COMPRESSIVE STRENGTH 
TABLE 13A PECEIVING INSPECTION

\section{HARDWARE}

1. VISUAL

2. DIMENSIONAL

3. WELDMENTS

a. SUBMERGED ARC WELD FE AWS A5.17-69

b. 100\% RADIOGRAPHIC INSPECTION

c. QUALIFICATION PLATES

4. VENDOR CERTIFICATION OF HEAT TREATMENT

a. RUALIFICATION PLATE

5. DYE PENETRANT

6. SURFACE FINISH 
TABLF 14 IN-PROCESS INSPFCTION

\section{PREIMPREGNATED TAPE}

\begin{abstract}
1. TENSION
2. VISUAL
\end{abstract}

VISUAL
岕

1. WEIGHT OF COMPONENTS

2. GEL TIME

WINDING PATTERN

1. PITCH

2. LAYER COUNT

1. OVEN TEMPERATURE VS. TIME

2. PART TEMPERATURE VS. TIME

MIXED RESIN

CURE
3. RESIN CONTENT

4. WEIGHT

3. RETAINED SAMPLES (CASTINGS)

3. PLACEMENT

4. VISUAL

3. MANDREL SURFACE TEMPERATURE,

4. TEST PANEL

5. BARCOL HARDNESS 
TABLE 15 FINAL INSPECTION

1. VISUAL

2. DIMENSIONAL

3. PAPERWORK COMPLETE

4. WEIGHT, AND C.G. DETERMINATION 
Blade contours were generated for SCI by Teledyne-Ryan Aeronautical Corporation of San Diego, California using the IBM developed GEOM program. A full blade cross section was generated mathematically, at each $1 / 32 \mathrm{R}$ station along the span, by a digital computer. (Approximately every two feet). The computer-generated geometry was used with an X-Y plotter to produce full sized cross section negatives on mylar. Positive contact prints on mylar were furnished to SCI for tooling fabrication. These mylars (Figure 42) were used for mandrel fabrication as we1l as foam core cutting templates and blade assembly jigs and fixtures. Each mylar contains optical tooling alignment points and a reference plane.

MANDREL FABRICATION CONCEPT

The welded steel mandrel was built by Rettig Machine Shop of Redlands, California, who also built the mandrels for the $150 \mathrm{ft}$ blade and the $100 \mathrm{ft}$ MOD-1 blades. The same general procedure was used in fabricating all of these mandrels. Steel plate ribs were cut by an automatic frame cutting machine which follows the mylar with an electric eye. The ribs are set up on a central shaft and aligned with optical tooling telescopes. Steel stringers and skins are added to complete the mandrel. A lathe-turned cylindrical section is used at the root end of the LCCB mandrel where the round hub fitting and bucking ring are located. (See Figure 43)

The internal construction of the steel winding mandrel design is shown schematically in Figure 44 . The welded skin construction forming the final design surface of the mandrel is shown in Figure 45. The mandrel is assembled between headstock and tailstock supports as shown in Figure 46. Each of these supports is composed of a 24 in. diameter steel pipe which is designed to accept a water-fill ballast to control end rotations of the mandrel for minimum overall deflection. 


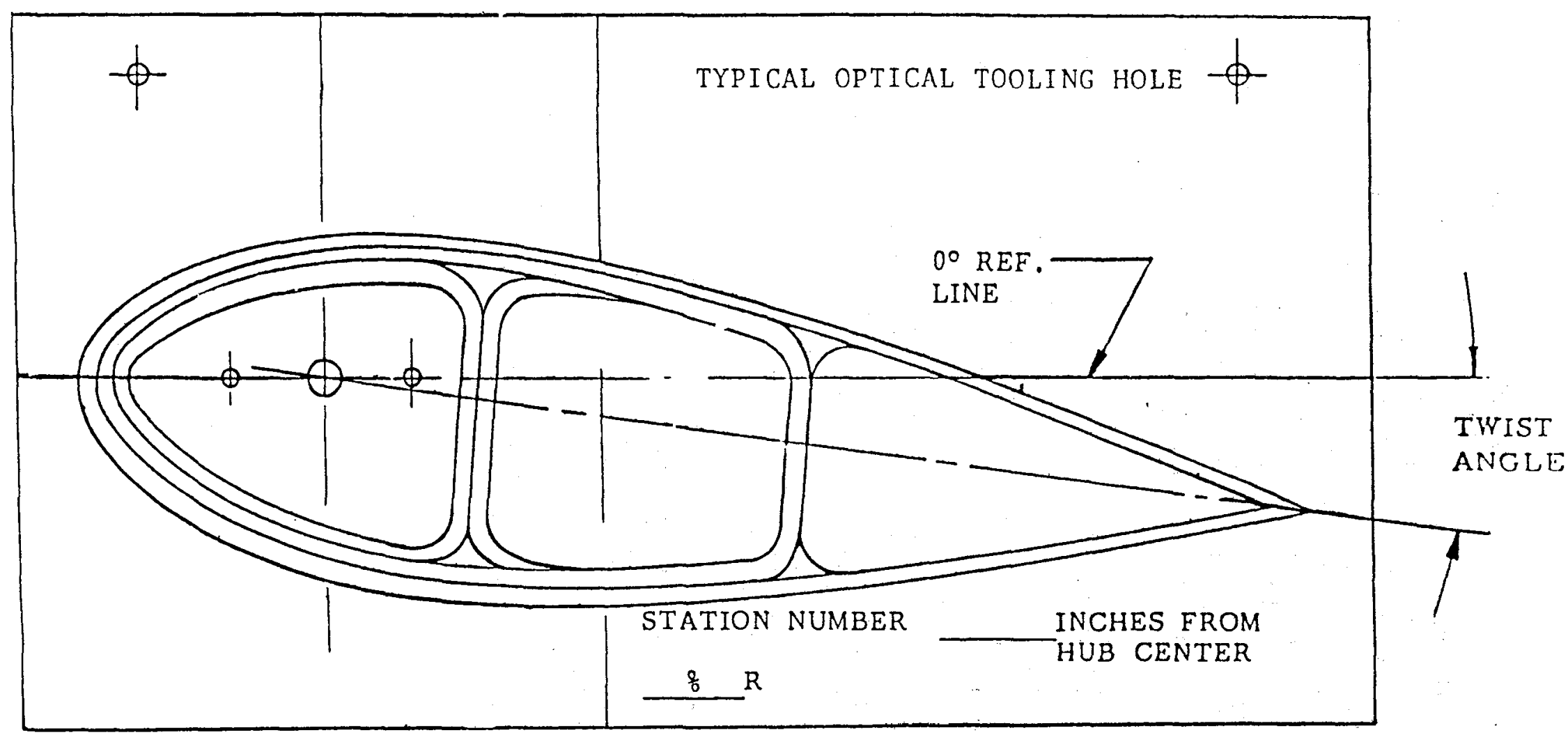

FIGURE 42 TYPICAL MYLAR 


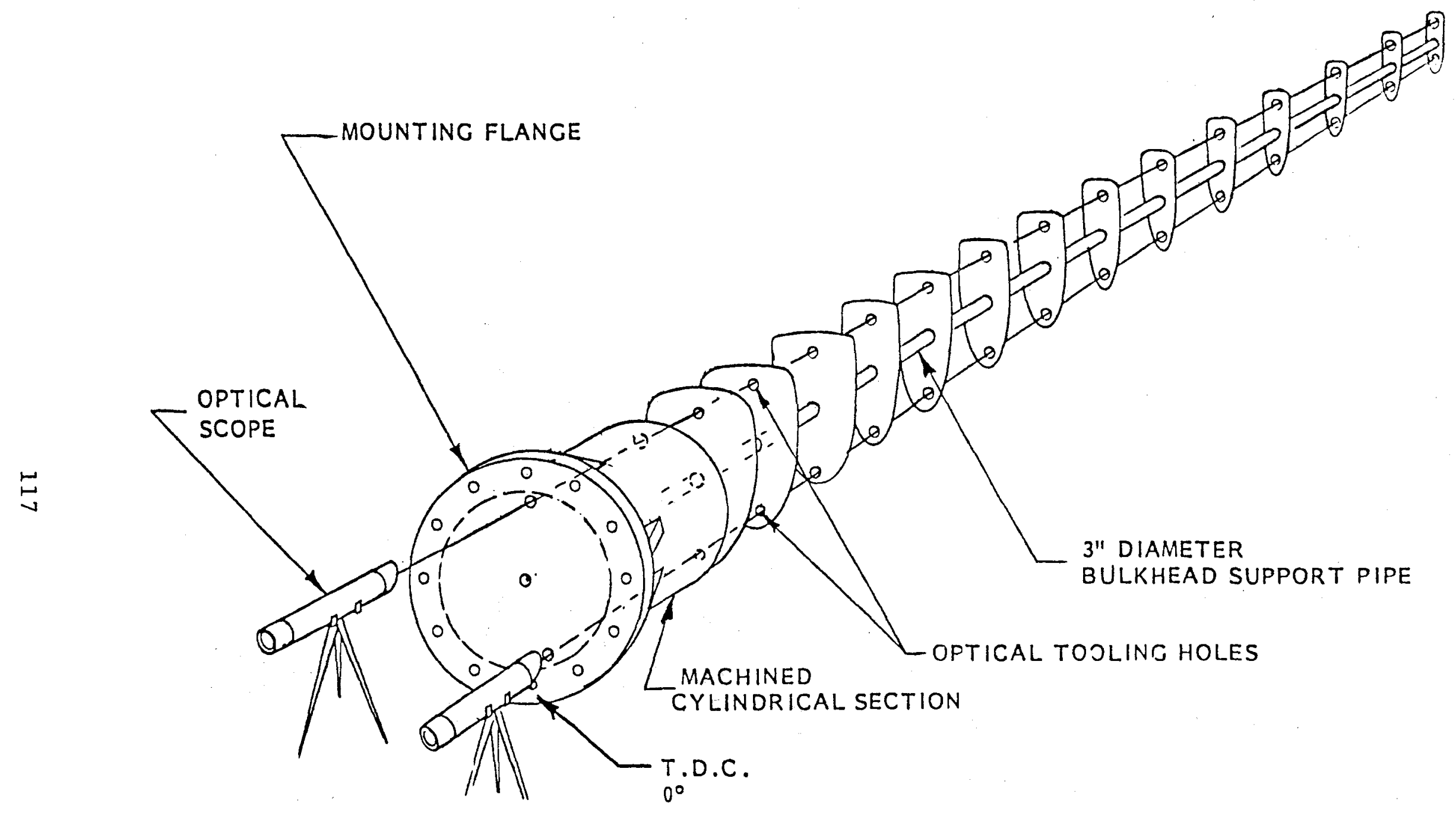

FIGURE 43 SPAR MANDREL RIB ASSFMBLY 


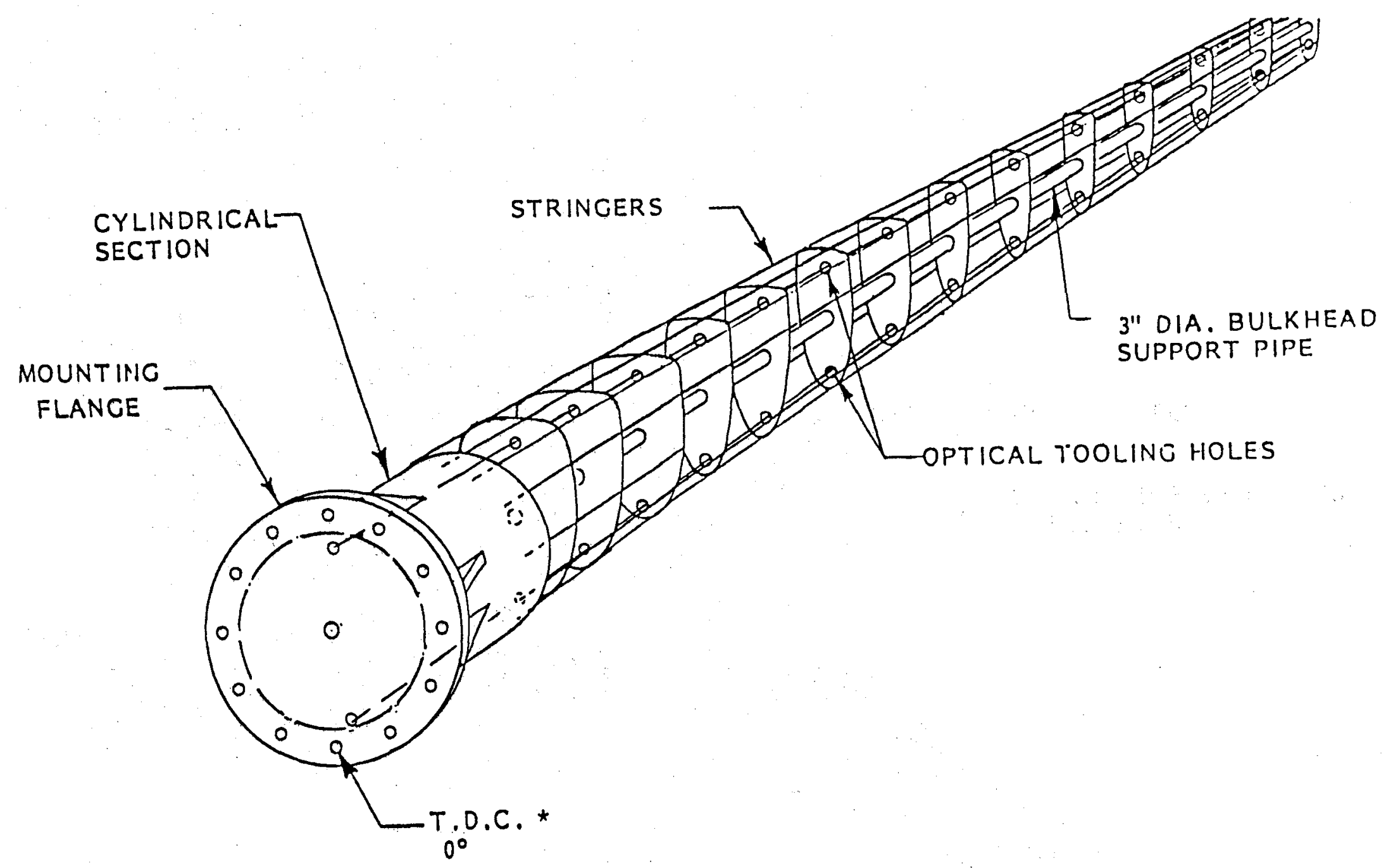

*Tooling Aide for blade orientation 


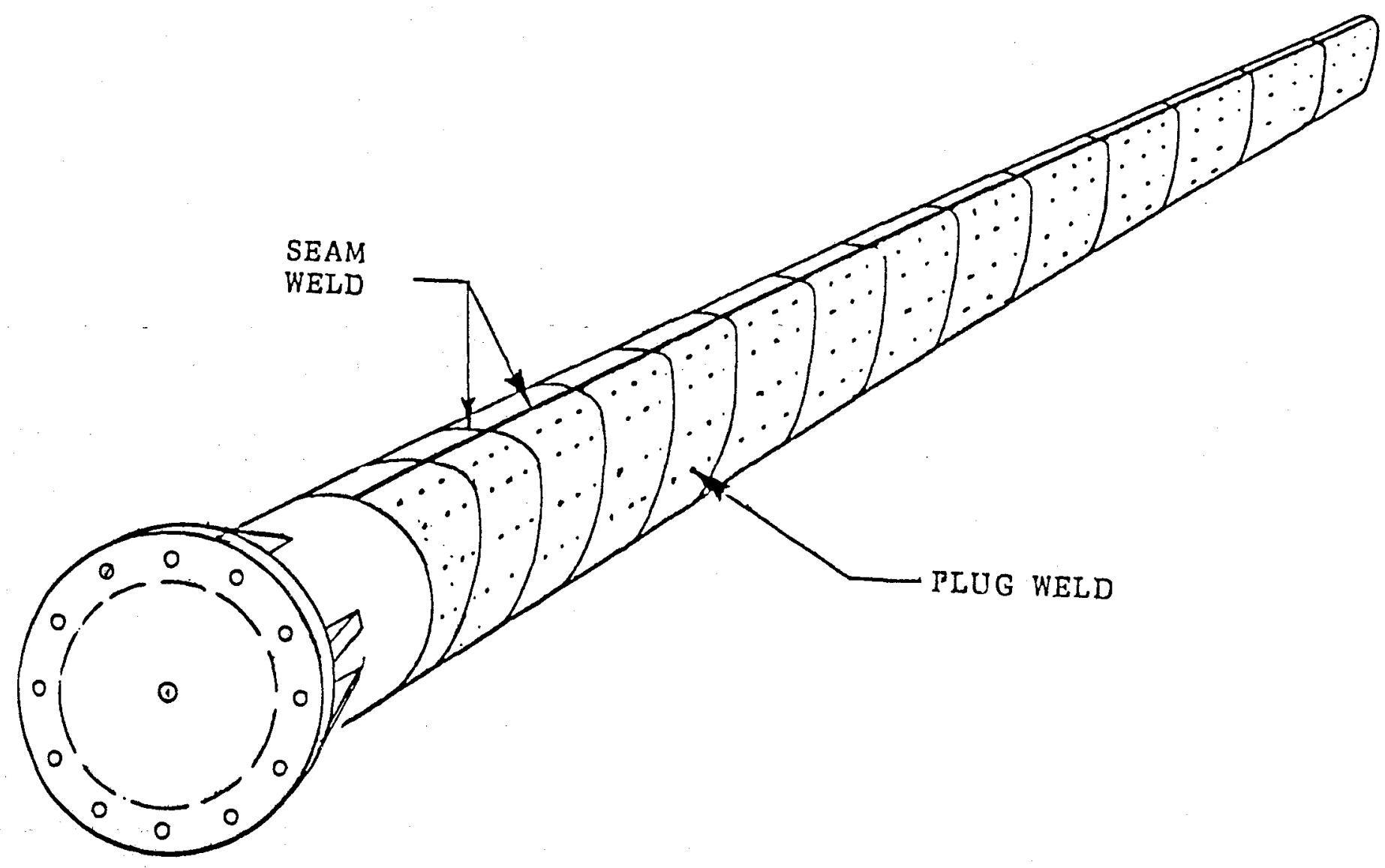

FIGURE 45 WELDED SKIN INSTALIATION 


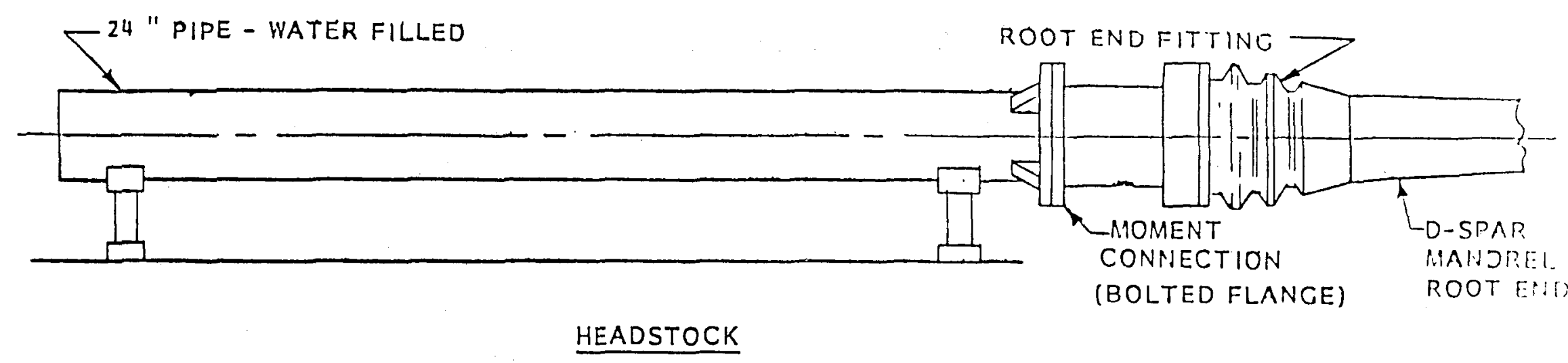

$\stackrel{N}{0}$

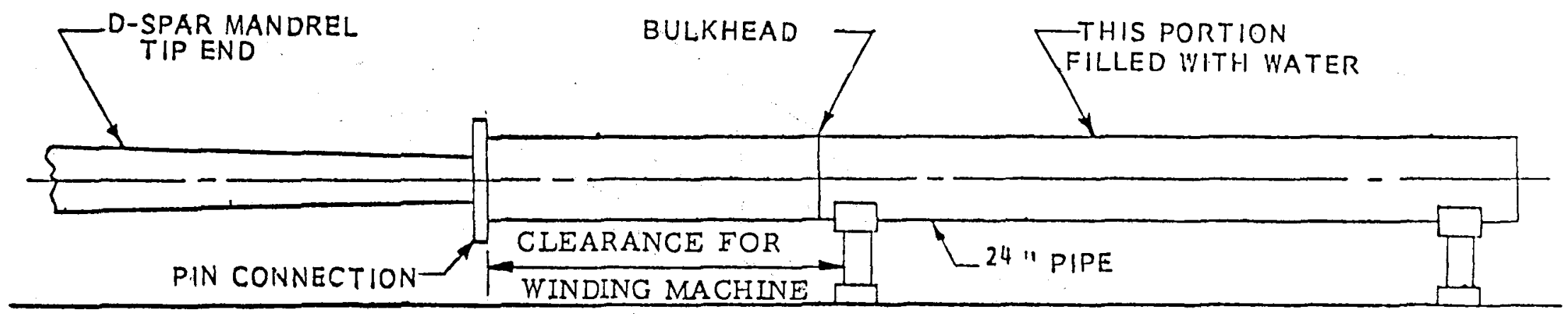

\section{TAILSTOCK}

FIGURE 46 HEADSTOCK AND TAILSTDCK 
MODEL DESCRIPTION

The structural design of the mandrel was evaluated by first developing and analyzing a computer math model of the mandrel for stress, deflection and internal load distribution. Then a detailed stress analysis of critical components of the mandrel was performed using hand calculations based on the internal load distribution.

The computer math model of the mandrel design is shown schematically in Figure 47 . The model is a finite element continuous beam model consisting of thirteen (13) Iinear elements and fourteen (14) lumped mass node points. Ten (10) of the elements were used to represent the spar mandrel and three (3) elements were used to simulate the headstock assembly. Simple support boundary conditions were used at each end of the headstock segment of the model and at the end of the spar segment to simulate the tailstock support.

The model simulation characteristics used to represent the stiffness and load distribution of the mandrel design are summarized in Table 16. The moment of inertia, I, in the spar segment consists of both the mandrel skin and stringers. The distributed weight loading consists of the skin, stringers, ribs and central pipe of the mandrel plus the TFT composite blade wrap weight.

MODEL ANALYSIS

The model was analyzed for stress and deflection response and internal load distribution using the SPAR computer code.

ANALYSIS RESULTS

The results of this analysis are presented graphically in Figures 48 through 51 which present the deflection, shear, moment and stress distribution, respectively, for the mandrel design. Key results are summarized below:

Item

Deflection

Reaction

Moment

Stress
Response (Max. Va1ue)

0.96 in. $14,6001 \mathrm{bs}$ $0.98 \times 10^{6}$ in. $-1 \mathrm{bs}$ 5,400 psi 


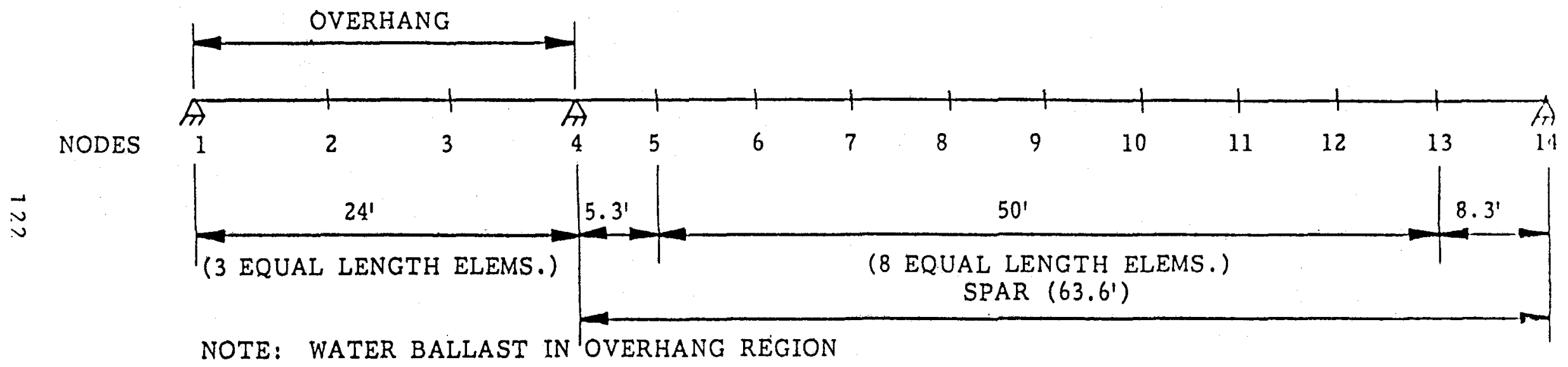

FIGURE 47 LCB MANDREL SCHEMATIC 
TABLE 16

MANDREL STRUCTURAL PROPERTIES AND LOADING

\begin{tabular}{|c|c|c|c|c|}
\hline Node* & $\left(\right.$ in $\left.^{I^{4}}\right)$ & $\begin{array}{c}\text { Outer Fiber, } \\
\text { (in) }\end{array}$ & Distributed $w t . \quad(1 b / f t)$ & Concentrated wt. (1b) \\
\hline 1 & 3346 & 12.0 & 329 & \\
\hline 2 & 3346 & 12.0 & 329 & \\
\hline 3 & 3346 & 12.0 & 329 & \\
\hline 4 & 3346 & 12.0 & 329 & 1170 \\
\hline 5 & 1485 & 12.5 & 250 & 720 \\
\hline 6 & 1380 & 12.2 & 158 & \\
\hline 7 & 1170 & 11.5 & 140 & \\
\hline 8 & 790 & 10.8 & 124 & \\
\hline 9 & 590 & 10.0 & 107 & \\
\hline 10 & 420 & 8.6 & 94 & \\
\hline 11 & 300 & 7.0 & 75 & \\
\hline 12 & 200 & 5.9 & 55 & \\
\hline 13 & 120 & 5.2 & 43 & \\
\hline 14 & 40 & 4.7 & 28 & \\
\hline
\end{tabular}




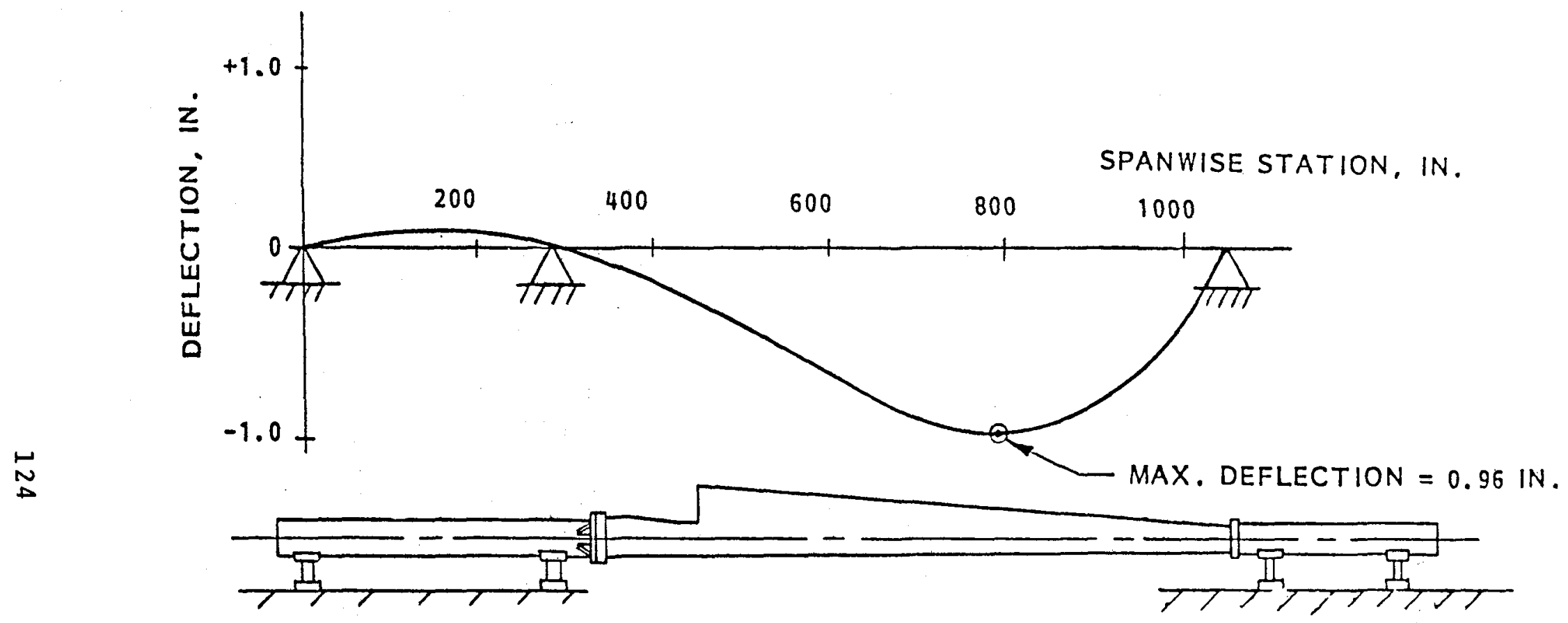

FIGUPE 48 MANDREL DEFLECTION 


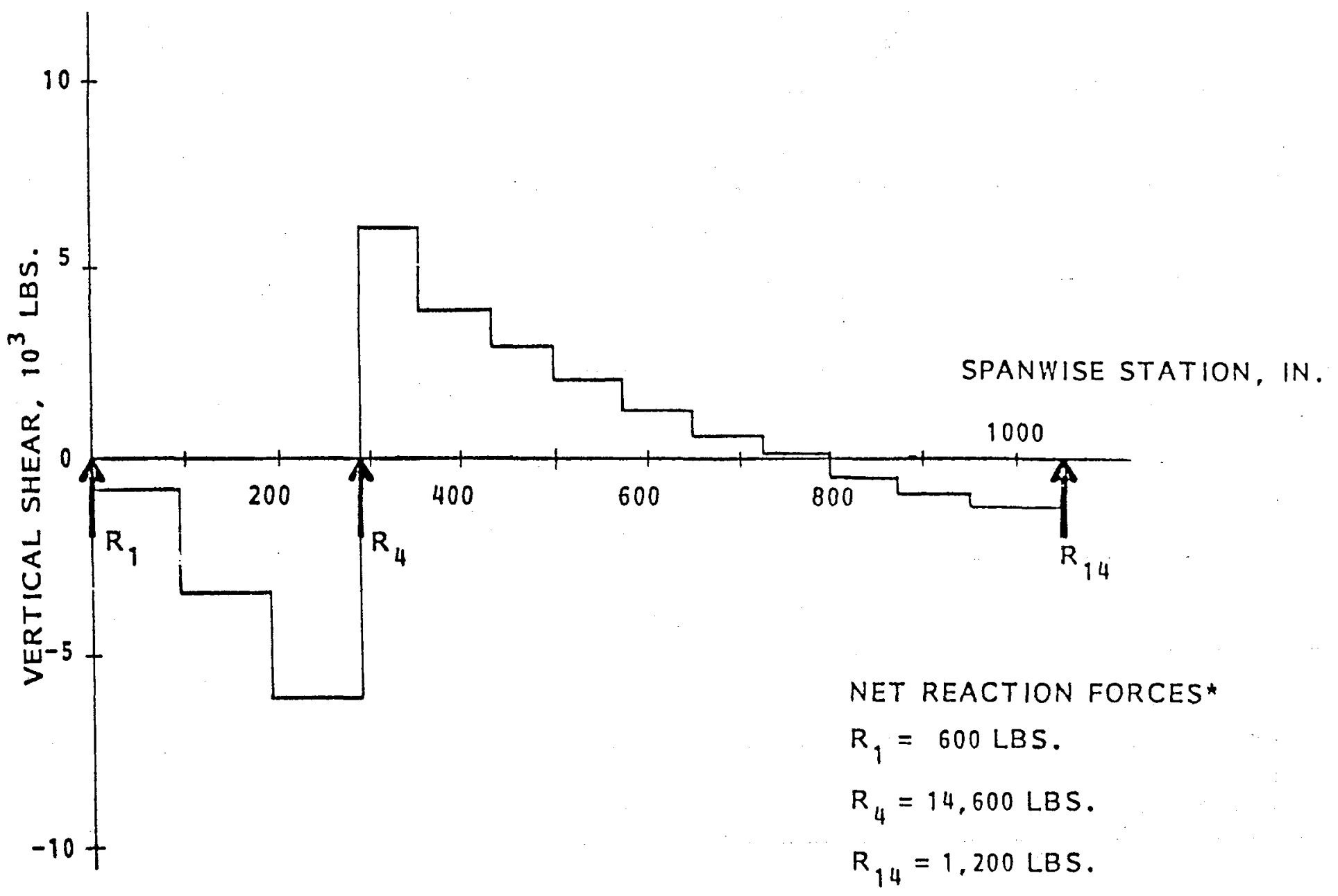

* includes COMPONENT Of deAd weight acting at nOde.

FIGURE 49 MANDREL SHEAR DISTRIBUTION 


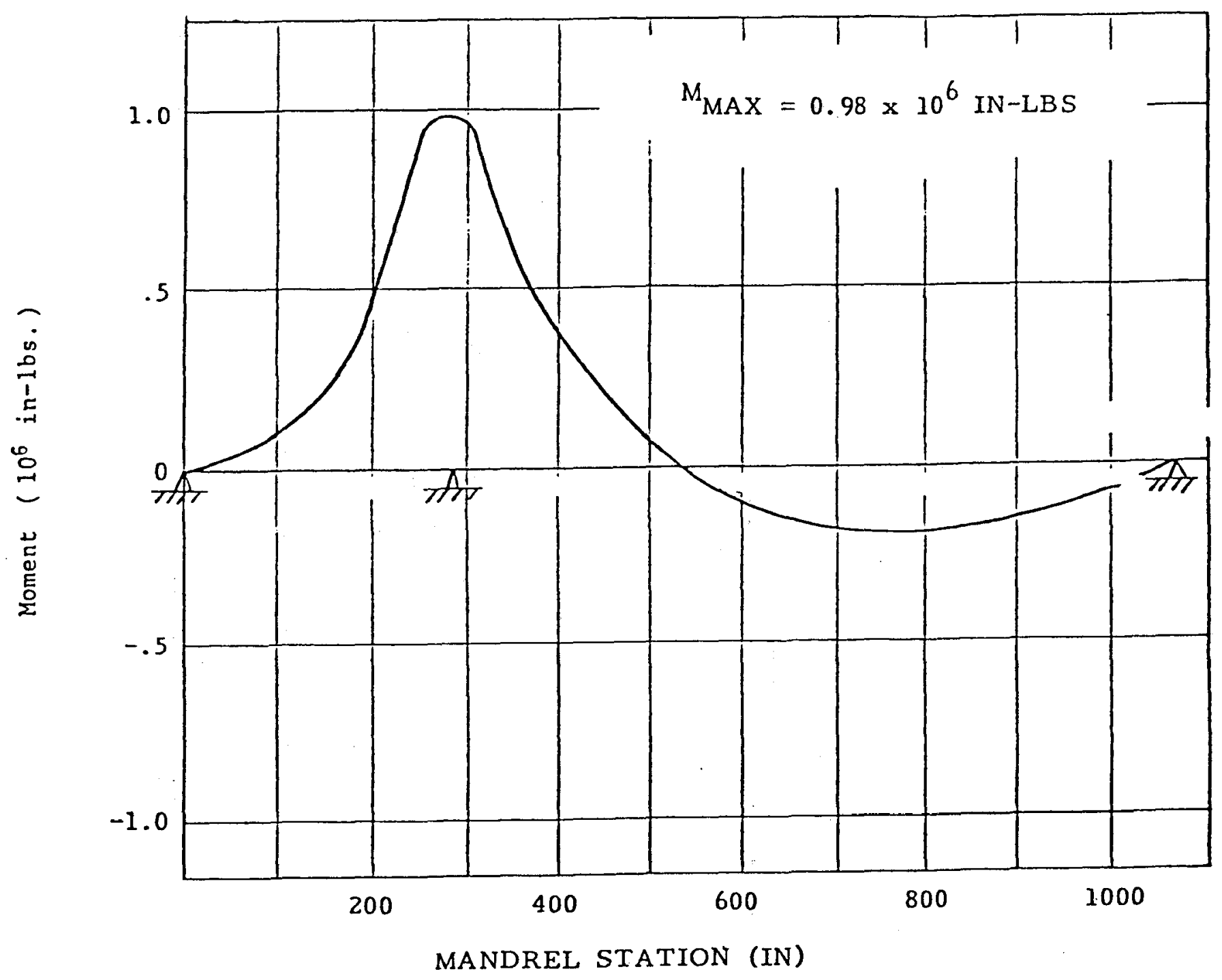

FIGURE 50 MANDREL BENDING MOMENT 


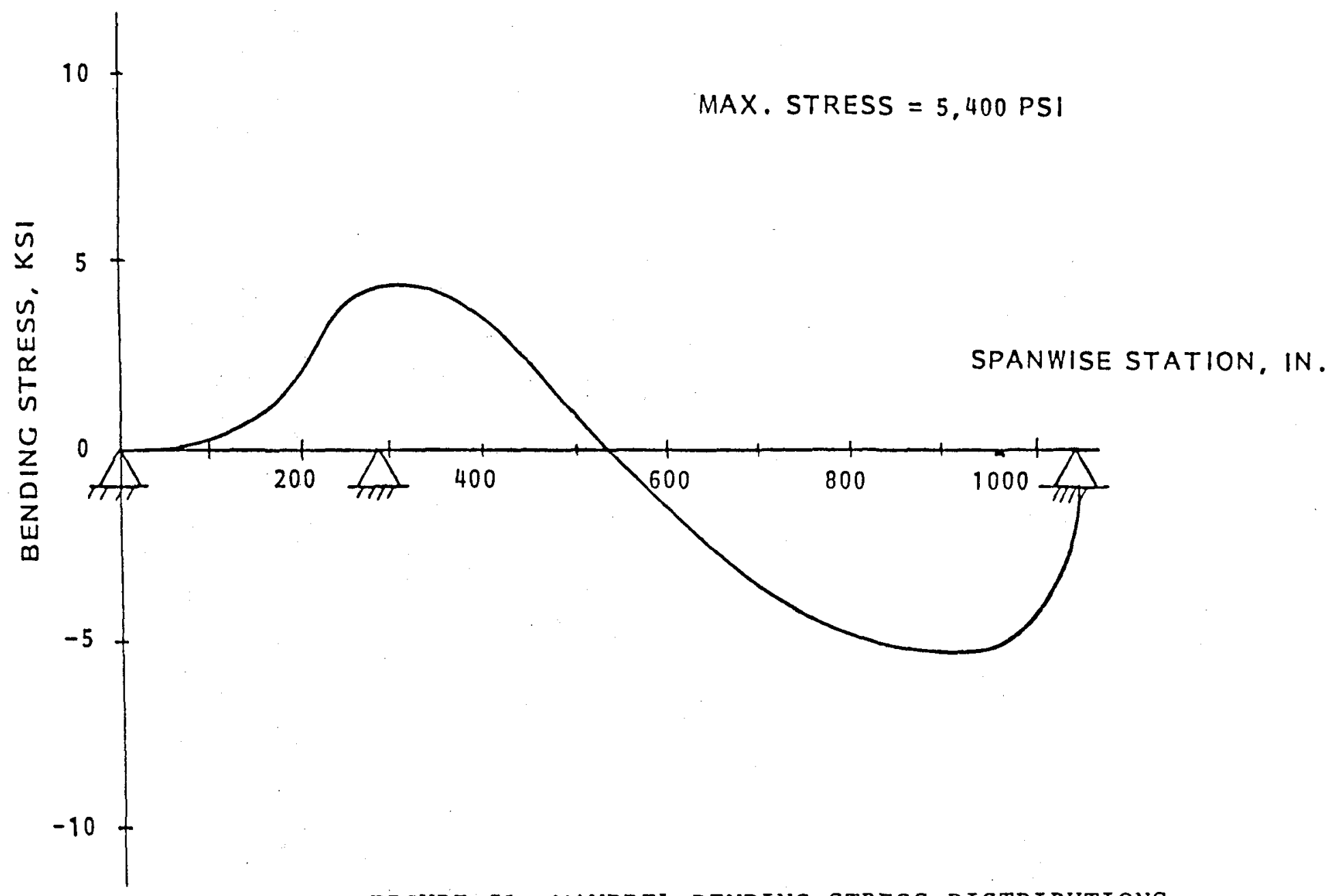

FIGURE 51 MANDREL BENDING STRESS DISTRIRITINNS 
As can be seen, the maximum predicted deflection of the mandrel is less than 1 inch implying good blade dimensional control and relatively easy mandrel extraction. Also, the maximum skin stress was found to be approximately $5400 \mathrm{psi}$ which is well below the yield stress of the AISI 1020 steel material.

In addition to the overall mandrel analysis a detailed stress analysis was performed on critical components of the design. A factor of safety of 1.25 was applied to the loads derived from the computer model analysis to yield the ultimate design analysis load conditions. In addition, yield strength allowables were used in the margin of safety throughout the analysis in which multiple load paths contributing to greater design strength were ignored. A summary description of the detailed analysis and margins of safety is given in Table 17 .

\subsubsection{HANDLING AND SHIPPING}

The handling and shipping concept is shown in Figures 52 and 53 . The blades are supported on a $60 \mathrm{ft}$ extendible bed truck. The root end fitting is used to support the heavy root end and to take axial addeleration loads. Blades can be 1 ifted with the same supports or by a pair of straps centered on the CG.

APPLICABILITY TO OTHER SIZES $(15-200 \mathrm{ft})$

No constraint was found in applicability of the low cost composite blade (LCCB) design and fabrication techniques to other sizes. As shown in Table 18, similar blades have been proposed, studied, designed or built on several other programs in lengths from 15.5 to $250 \mathrm{ft}$. The filament winding process is not limited to any particular size. It is only necessary to provide a large enough winding machine and mandrel(s). Since the composite is being fabricated by the winding process, there is no 1 imitation such as size of available plates or sheets of material. The rovings and tapes used in filament winding are continuous and of practically infinite length.

In the smaller size blades, such as the SCI blades designed for the $4 \mathrm{~kW}$ SWECS program, it might be cost-effective to mold the outside surface to final contour after winding. This method is used on helicopter rotor blades. It results in a better contour and surface finish, a denser laminate, and fast cure cycle. 
TABLE 17

DETAILED STRESS ANALYSIS SUMMARY FOR LCB MANDREL

$\begin{array}{lll}\text { Item } & \text { Failure Mode } & \text { M.S. } \\ \text { Spar gussets } & \text { Weld shear* } & 0.15 \\ \text { Headstock gussets } & \text { Weld shear* } & 0.15 \\ \text { Spar/headstock bolts } & \text { Bolt tension } & 0.29 \\ \text { Skin/pipe joint } & \text { Weld tension } & 0.59 \\ \text { Spar gusset } & \text { Weld tension* } & 0.90 \\ \text { Headstock gusset } & \text { Plate compression* } & 1.06 \\ \text { Buckling ring } & \text { Ring tension* } & 1.25 \\ \text { Mounting plates } & \text { Local bending* } & 1.89 \\ \text { Headstock cradle } & \text { Flange bending } & 2.61 \\ \text { Mounting plate } & \text { Flange bending } & 96.60\end{array}$

*Based on 50 ton hydraulic jack load on each of four jacks 


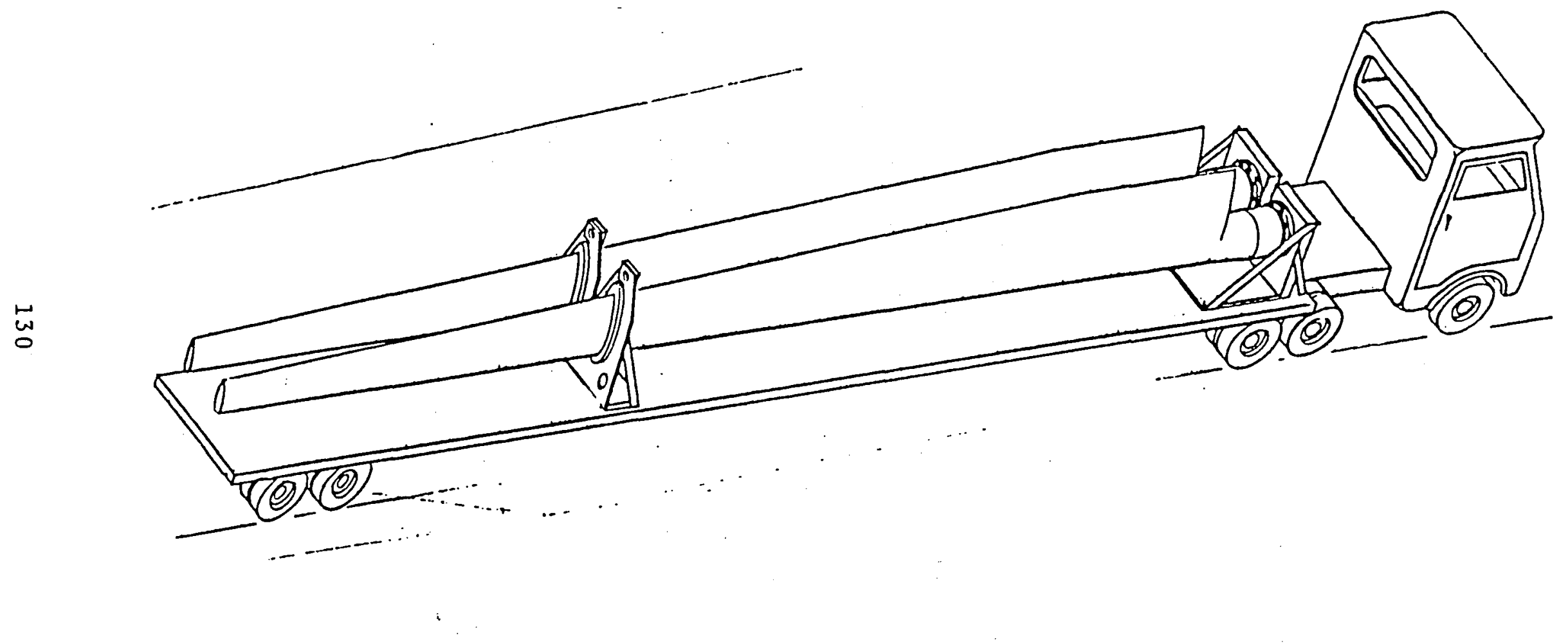

FIGURE 52 SHIPPING PROCEDURE 


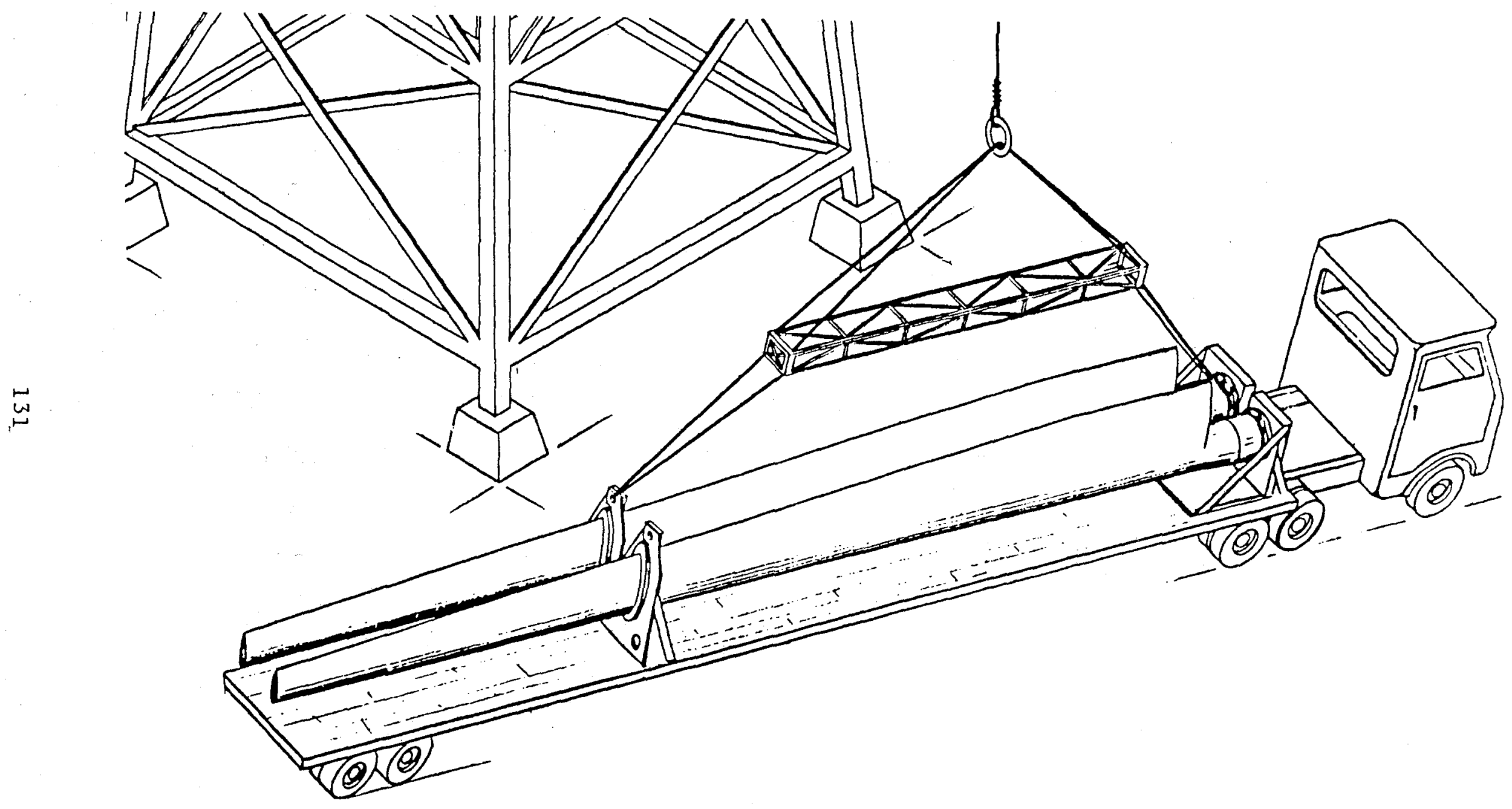

FIGURE 53 HANDLING CONCEPT 
$\begin{array}{lll}\text { TABLE } 18 & \text { APPLICABILITY OF THE DESIGN AND } & \text { FABRICATION } \\ & \text { PROCEDURE TO BLADES } 15-200 \text { FEET } & \text { LONG }\end{array}$

OTHER USE OR STUDIES OF SIMILAR PROCESSES OR DESIGNS

KAMAN/SCI

KAMAN

KAMAN

HAMILTON-STANDARD

HAMILTON-STANDARD

$\mathrm{SCI} / \mathrm{BEC}$

$S C I / G E$

$S C I / G E$

DANISH GOVERNMENT

SCI
150 FT. COMPOSITE BLADE

MOD-1 BLADE (100 FT.)

$40 \mathrm{~kW}$ BLADE (32 FT.)

$60 \mathrm{FT}$. COMPOSITE BIADE

SWEDISH PROGRAM (138 FT)

MOD-2 COMPOSITE BLADE STUDY

NIAGARA MOHAWK STUDY (138 FT.)

MOD -5

NIBE WINDMILLS (55 FT.)

$4 \mathrm{~kW}$ BLADES AND TOWER

(15.5 FT, AND $50 \mathrm{FT}$.)

CONCLUSION: DESIGN AND PROCESS ARE APPLICABLE OVER THE RANGE OF 15-200 FT. 


\subsection{COST AND WEIGHT ANALYSIS}

\section{WEIGHT SUMMARY}

The projected weights for the LCCB are 1 isted in Table 19.

The $28521 \mathrm{~b}$ weight is well below the $30001 \mathrm{~b}$ 1imit

for MOD-OA.

\section{PRODUCTION COSTS}

Table 20 shows production materials costs projected for a blade built in quantities of $100 /$ year with polyester resin and a mild steel hub fitting. In Table 21 the costs for quantities of 2 through 1000 production blades are estimated. The assumptions made for these estimates include (1) the use of foam in place cores for the afterbody and trailing edge, (2) a web doubler wound into the D-spar, (3) continuous winding with only one cure cycle and no vacuum bags or peel ply. This modified sequence (Figure 54) reduces labor substantially since the cutting, bonding and fairing of the foam cores and the hand layup and positioning of the web doublers on the prototype blades were very labor-intensive, as were the multiple cures, vacuum bags and peel plies.

\section{DESIGN FEATURES THAT CONTRIBUTE TO LOW COST}

The blade design, as was mentioned in Section 4.3.1, dictated by the existing MOD-OA is not the ultimate LCCB design. Table 22 lists some of the features which will contribute to low cost of the production blades.

\section{COMPARISON TO NASA SPECIFICATION}

Figure 4 shows the NASA weight cost envelope with the production version of the SCI LCCB plotted. At $\$ 11,745$ and $2,8521 \mathrm{~b}$, it is well within the envelope.

\subsection{SUBELEMENT AND SUBSCALE TESTS}

In support of the design and evaluation work of Phase I, a number of laboratory scale subelement tests and subscale blade tests were performed to confirm the allowables and the materials and process selections and certain design features of the LCCB. 
TABLE 19 BLADE WFIGHT SUMMARY (PROTOTYPE)

MATERIAL

TOTAL

BLADE WT (LBS)

STEEL HUB FITTING

265

COMPOSITE

1742

2-LB FOAM

67

4-LB FOAM

87

SYNTACTIC FOAM

118

ADDITIONAL HARDWARE, PAINT, MISC 200

TOTAL

2479

HUB ADAPTER

373

GRAND TOTAL

2852 
TABLE 20. MATER.IALS COST SIJMMARY
100 PRODUCTION BLADES/YFAR

ITEM

RESIN

E-GLASS REINFORCEMENT

FOAM (2 LB/ET $\left.{ }^{3}\right)$

FOAM $\left(4 L B / F T^{3}\right)$

HUB FITTING

PAINT, HARDWARE MISC.

TOTAL MATERIALS COST*

ROOT END ADAPTER WITH BOLTS

GRAND TOTAL

*WITH MODIFIED POLYESTER RESIN, 100
$\operatorname{cosT*}$

391

903

162

210

1375

250

3291

1697

4988

BIADES, 1978 DOLLARS 


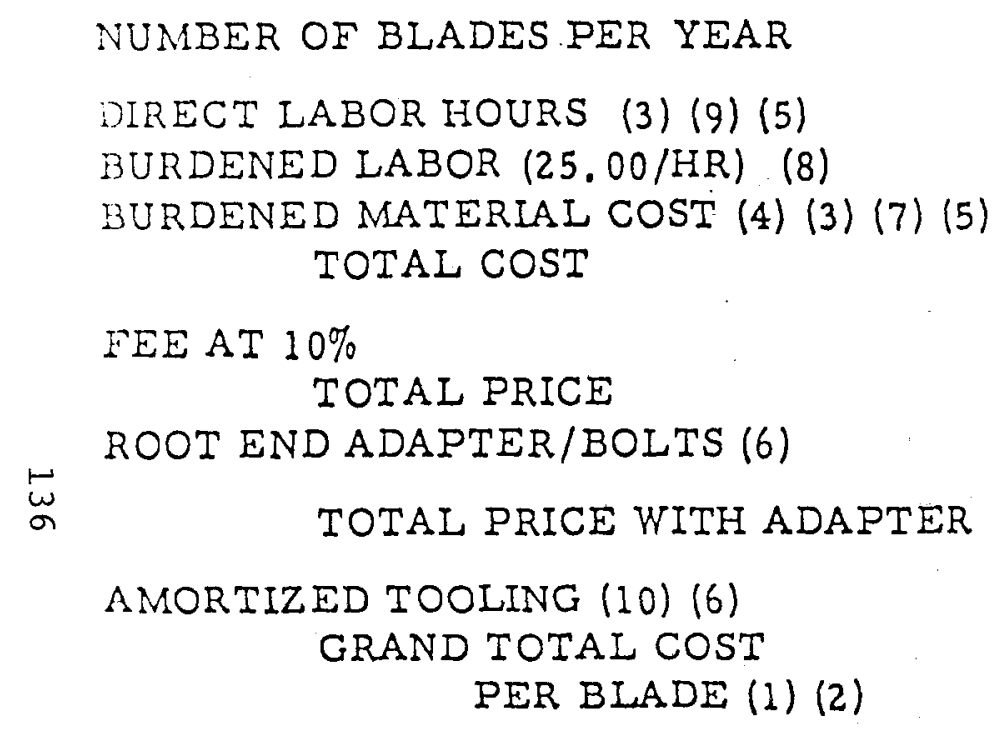

\begin{tabular}{|c|c|c|c|}
\hline 2 & 10 & 100 & 1000 \\
\hline 201 & 178 & 251 & 127 \\
\hline 5,025 & 4,450 & 3,775 & 3,175 \\
\hline 5,708 & 5,065 & 4,272 & 3,605 \\
\hline 10,733 & 9,515 & 8,047 & 6,780 \\
\hline 1,073 & $\begin{array}{r}952 \\
\end{array}$ & 805 & 678 \\
\hline 11,806 & 10,467 & 8,852 & 7,458 \\
\hline 2,943 & 2,612 & 2,203 & 1,859 \\
\hline 14,749 & 13,079 & 11,055 & 9,317 \\
\hline 34,520 & 6.904 & 690 & 69 \\
\hline 49,269 & 19,983 & 11,745 & 9,386 \\
\hline
\end{tabular}




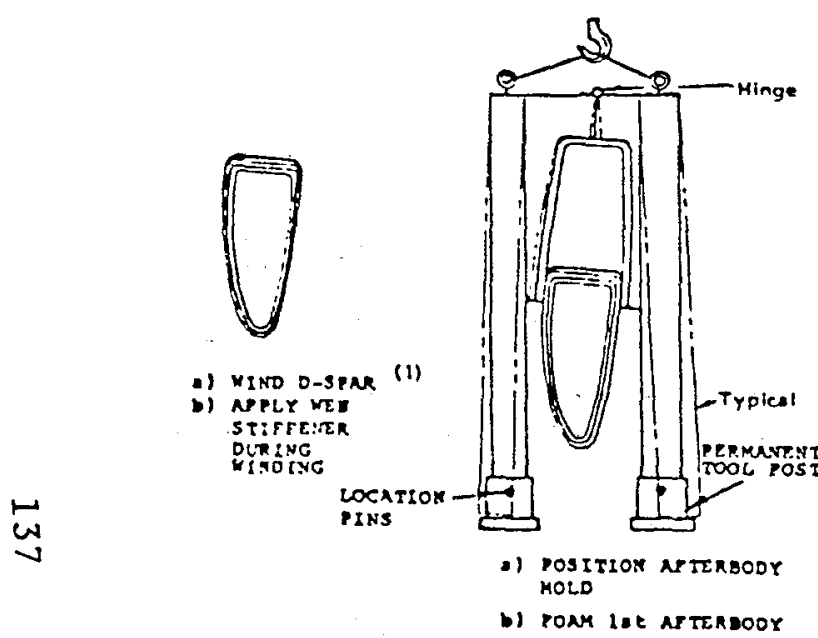

(1) POLYESTER RESIN

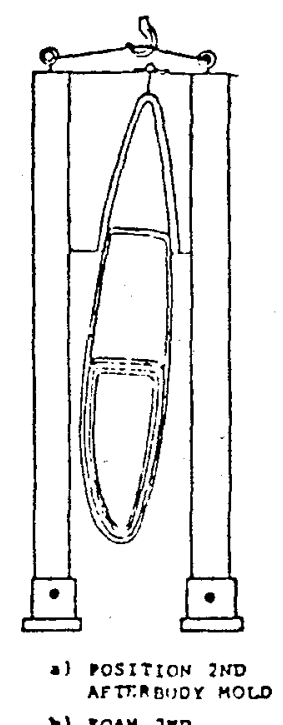

i) ronar 2no

APTER POOO

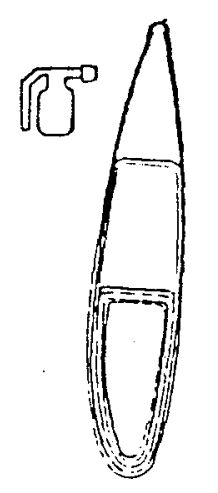

11 armove $2 \mathrm{NO}$ i) OVEPHAN ILADE

c) LICHTIING
PRUTECTION

d) $120 \mathrm{CLOTH}$

-) PAINT

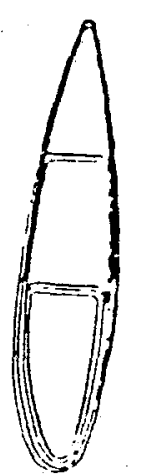

i expaci onpax

D) attacti inevare

e) PINac inspretron

a) suI 
FILAMENT WINDING

TFT PROCESS

COMPOSITE CONSTRUCTION

WOUND IN PLACE

HUB FITTING

RING WINDER

FOAM IN PLACE AFTERBODY CORES
FOR AUTOMATED FABRICATION, LOW LABOR INTENSITY, REPEATABILITY

ALLOWS NON-STOP WINDING OF TAPERED WALL ON TAPERED MANDREL - REDUCED LABOR AND MATERIAL WASTE - NO DUMMY HEADS - WIND NET - HIGH AXIAL ORIENTATION FOR LOW WEIGHT

FOR LOW PARTS COUNT, FEW JOINTS

NO DRILLING, MACHINING OR TRIMMING OF ROOT END OF BLADE NO BOLTING OR BONDING OF STUDS

EASY AND FAST STACKUP OF MANDRELS FOR MULTIPLE CELL BLADE WINDING. NO MANDREL FLIP-FLOP SO HIGHER WINDING SPEEDS, LONGER TOOL LIFE

NO SEPARATE MOLDING, SHAPING, FITTING OR BONDING OF FOAM CORES. NO SEPARATE PARTS FOR ROOT END TRANSITION OF FIRST AFTERBODY TO HUB. 


\subsubsection{SUBELEMENT TESTS}

These tests consisted of characterization of the basic materials of construction, including the epoxy resin system, glass reinforcements, adhesives and rigid polyurethane foams.

RESIN MIX EVALUATION

SUMMARY

The epoxy resin mix selected for the blade fabrication was modified with Cab-0-Sil, a fumed silica thixotropic additive, at concentrations of $1,1 \frac{1}{2}$, and $2 \%$ by weight to determine and establish the effectiveness of the additive to control resin migration from the stationary mandrel.

The resin mixes were characterized for basic resin properties of viscosity, gel time, pot 1 ife and density to relate with material processability. The resin mixes were evaluated by impregnating the TFT material to observe for fiber wet-out and making layups to observe for control of resin migration. The resin mix with $1 \frac{1}{2} \%$ Cab-0-Sil was determined to be optimum based on overall performance, but the $1 \%$ concentration was an acceptable lower level.

Figure 55 illustrates the resin apparent viscosity versus temperature and Cab-0-Sil content. In Figure 56 we have plotted the short beam shear strength of composites fabricated with various percentages of Cab-O-Sil and either vacuum impregnated or hand impregnated. The vacuum impregnated specimens exhibited essentially constant short beam shear strength up to 1.5\% Cab-0-Sil. In Table 23 the effect on resin migration and void content is shown. Note the obvious drainage without any additive. The overall findings of this study are summarized in Table 24.

REINFORCEMENT EVALUATION

Three types of woven roving fabric - TFT, LFT and BFT - were examined for weight/unit area, woven thread content and tape width. The inspection of TFT material showed uniformity of the product within rolls but varied in tape width between rolls.

Strand tensile strength of specimens prepared from short length rovings pulled out of TFT material averaged 279,170 psi. This was essentially the same as the reported value by the manufacturer of E-glass roving. Table 25 shows the results of the tests. Note that the weight per unit area was not near the nominal for the LFT and DBT. 


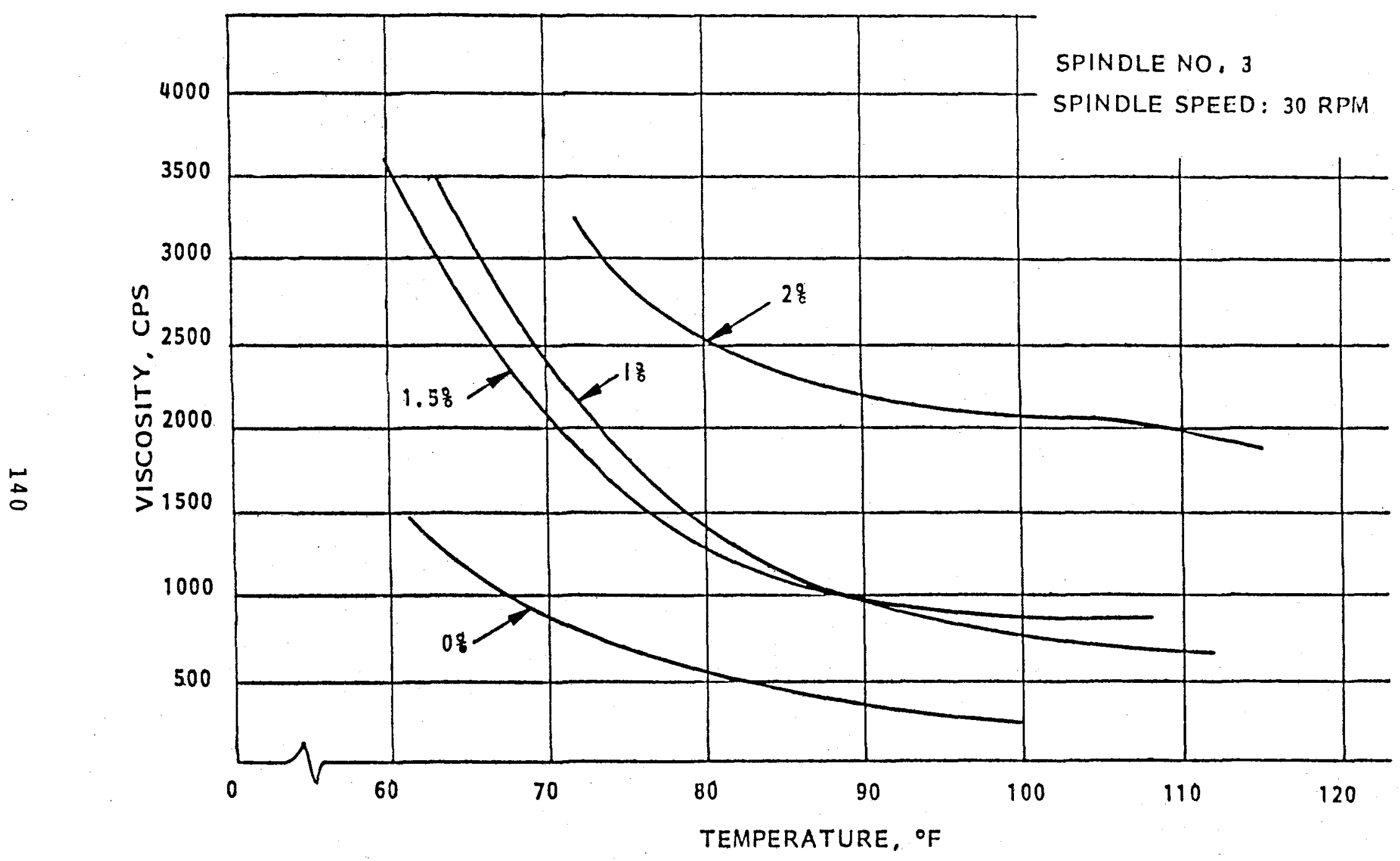

FIGURE 55 VISCOSITY AS A FUNCTION OF CAB-O-SIL CONCENTRATION AND TEMPERATURE 


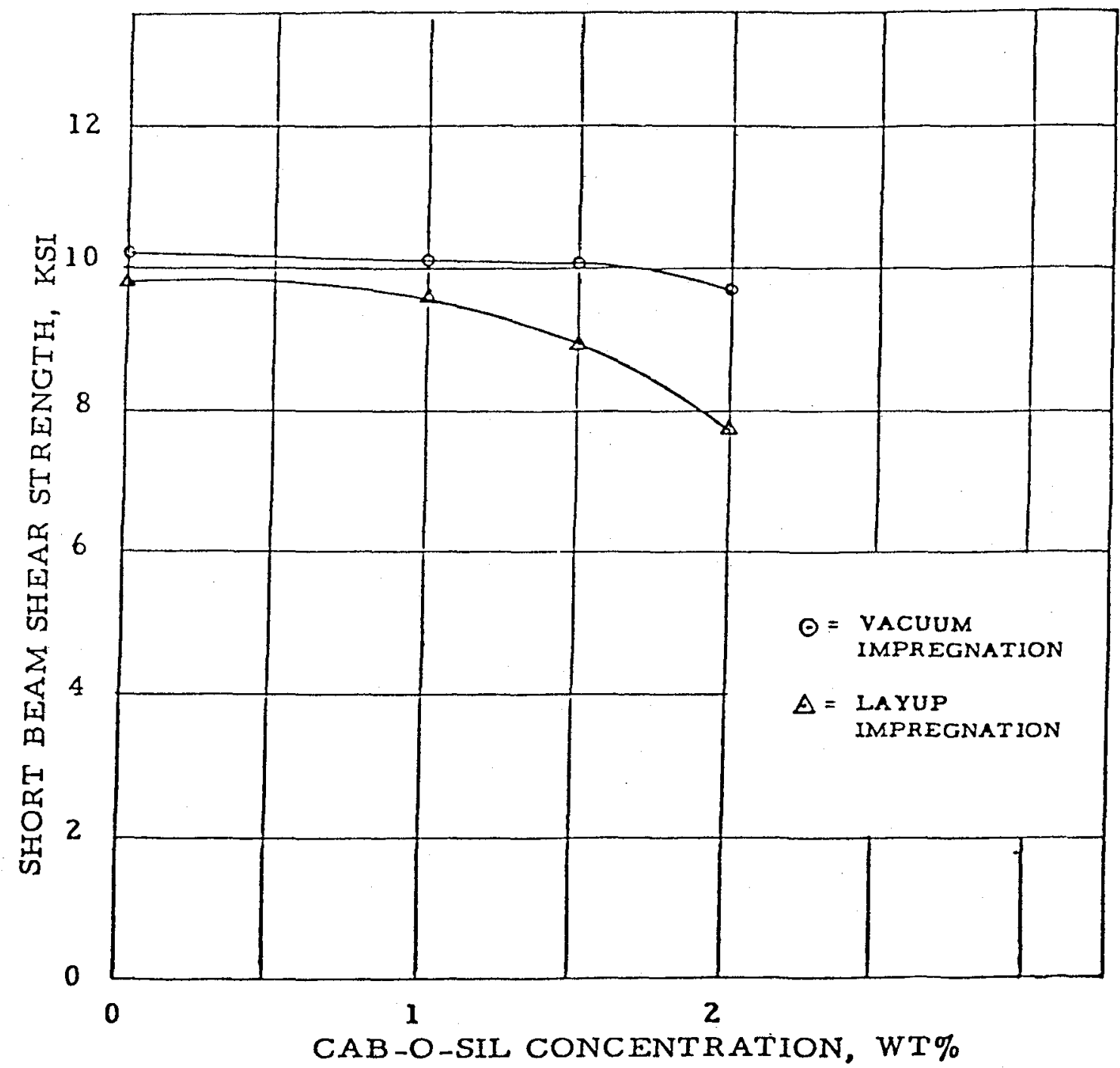

Figure 56 Effect of CAB-O-SIL on Composite Shear Strength 
Table 23

EFFECT OF CAB-O-SIL ON RESIN MIGRATION AND COMPOSITE PROPERTIES

Cab-O-Sil

Concentration

Wt. o

0

1.0

1.5

2.0
Sample

Location

Top

Middle

Bottom

Top

Middle

Bottom

Top

Middle

Bottom

Top

Middle

Bottom
COMPOSITE (1) PROPERTIES

\begin{tabular}{lll}
\hline $\begin{array}{c}\text { Resin } \\
\begin{array}{c}\text { Content } \\
\text { Wt. }\end{array}\end{array}$ & $\begin{array}{c}\text { Density } \\
\text { g/cc }\end{array}$ & $\begin{array}{c}\text { Voids } \\
\text { Vol. 8 }\end{array}$ \\
27.9 & 1.77 & 9.4 \\
31.1 & 1.73 & 9.3 \\
40.6 & 1.72 & 2.5 \\
43.6 & 1.69 & 2.1 \\
45.5 & 1.67 & 1.6 \\
46.3 & 1.66 & 1.8 \\
40.1 & & \\
39.9 & 1.73 & 2.3 \\
40.5 & 1.74 & 1.2 \\
46.8 & 1.75 & 1 \\
45.2 & & 1 \\
44.6 & 1.68 & 1
\end{tabular}

(1) Vacuum impregnated TFT laid up on vertical surface, 9-ply thick 
Table 24

FIBER WET-OUT AND RESIN MIGRATION CONTROL

BY MODIFICATION WITH CAB-O-SIL

\section{O\& CAB-O-SIL}

Good fiber wet-out

Much resin flow and drainage from vertical layup

Gradual air diffusion into layup from standing

\section{$1.5 \% \mathrm{CAB}-0-\mathrm{SIL}$}

Slow fiber wet-out by spreading resin, clarity improved from standing

Good fiber wet-out by vacuum impregnation

Minor resin flow from excess surface resin

\section{$1 \% \mathrm{CAB}-\mathrm{O}-\mathrm{SIL}$}

Slow fiber wet-out by spreading resin

Good fiber wet-out by vacuum impregnation

Some resin flow and drainage from vertical layup

No air diffusion into layup

\section{$2 \frac{8}{0} \mathrm{CAB}-\mathrm{O}-\mathrm{SIL}$}

Very slow fiber wet-out by spreading resin Good fiber wet-out by vacuum impregnation Essentially no resin drainage

Some surface resin-rich areas 
Table 25

CHARACTERIZATION DATA OF GLASS REINFORCEMENTS

\begin{tabular}{|c|c|c|c|c|c|c|c|c|}
\hline & Nominal & & & ple $W_{t}$. & 6 -in. len & , g & Density & $1 y d^{2}$ \\
\hline $\begin{array}{l}\text { Material } \\
\text { Sty:le } \\
\end{array}$ & $0 z / y^{2}{ }^{2}$ & in. & Total & Glass & Thread & o Thread & Total & Glass \\
\hline $\operatorname{TFT}^{(1)}$ & 18 & 6.75 & 93.49 & 91.91 & 1.58 & 1.69 & 17.58 & 17.26 \\
\hline TFT & 7 & $\begin{array}{l}7.00 \\
7.00 \\
7.12 \\
6.62\end{array}$ & $\begin{array}{l}38.83 \\
37.30 \\
38.70 \\
35.81\end{array}$ & $\begin{array}{l}37.72 \\
36.29 \\
37.16 \\
34.33\end{array}$ & $\begin{array}{l}1.11 \\
1.01 \\
1.54 \\
1.48\end{array}$ & $\begin{array}{l}2.86 \\
2.70 \\
3.98 \\
4.32\end{array}$ & $\begin{array}{l}7.04 \\
6.76 \\
6.86 \\
6.86\end{array}$ & $\begin{array}{l}6.84 \\
6.58 \\
6.59 \\
6.56\end{array}$ \\
\hline LFT & 8 & $\begin{array}{l}2.9 \\
3.0\end{array}$ & $\begin{array}{l}23.58 \\
23.44\end{array}$ & $\begin{array}{l}23.21 \\
22.65\end{array}$ & $\begin{array}{l}0.36 \\
0.79\end{array}$ & $\begin{array}{l}1.55 \\
3.37\end{array}$ & $\begin{array}{r}10.32 \\
9.91\end{array}$ & $\begin{array}{r}10.16 \\
9.58\end{array}$ \\
\hline LFT & 8 & 3.65 & 30.17 & 28.85 & 1.32 & 4.40 & 10.50 & 10.03 \\
\hline$D B$ & 18 & $\begin{array}{l}7.00 \\
7.00\end{array}$ & $\begin{array}{l}81.22 \\
81.67\end{array}$ & $\begin{array}{l}77.06 \\
77.52\end{array}$ & $\begin{array}{l}4.16 \\
4.15\end{array}$ & $\begin{array}{l}5.12 \\
5.08\end{array}$ & $\begin{array}{l}14.72 \\
14.80\end{array}$ & $\begin{array}{l}13.97 \\
14.05\end{array}$ \\
\hline
\end{tabular}

(1) Strand tensile strength determined from roving samples taken from TFT

$$
\begin{array}{ll}
\text { Sample Length: } & 6.75 \mathrm{in} . \\
\text { Strand Weight: } & 0.1890 \mathrm{~g} \\
\text { (Yield: } 454 \mathrm{yd} / \mathrm{lb} \text { ) } \\
\text { Fiber Density: } & 2.578 \mathrm{~g} / \mathrm{cc} \\
\text { Test Specimen } \\
\text { Resin Content: }
\end{array}
$$

(average of 10 specimens) 
Characterization of the $7-1 \mathrm{~b} / \mathrm{ft}^{3}$ density rigid polyurethane foam originally planned for Designs $1-5$ was performed including determination of density, flatwise compressive strength and flatwise tensile strength. The strength properties determined were within typical reported values for 7 -to $8-1 \mathrm{~b} / \mathrm{ft}^{3}$ density foam. $2-1 b / f^{3}$ and $4-1 b / f^{3}$ density polyurethane foams replaced the $7-1 \mathrm{~b} / \mathrm{ft}^{3}$ density foam original1y in Designs 6-8. These low density foams were evaluated to determine their capability to resist, and means of reinforcing the materials to resist, deformation from compressive forces applied from LFT overwrap and heat exposure during cure. The results showed that $2-1 \mathrm{~b}$ density foam can be used as the first afterbody mandrel without significant permanent deformation. The bare 4-1b density foam was marginally acceptable for the trailing edge core but was adequately strengthened by surface resin coat application. Glass skin facing improved the properties substantially, but with a weight penalty.

Table 26 summarizes the $7-1 \mathrm{~b} / \mathrm{ft}^{3}$ foam tests and Table 27 summarizes the tests on the nominal 2 and $4-1 \mathrm{~b} / \mathrm{ft}^{3}$ foam samples. Figure 57 shows the test winding setup for core evaluation.

\section{ADHESIVE EVALUATIONS}

Two film adhesives, Hysol EA-9652 and Narmco Met1bond M-1113, were evaluated for bonding the metal root end fitting to "wet" TFT overwrap. Hysol EA-9652 was determined to be a superior material based on a comparative performance in tensile lap-shear strength and strength retention at $-30^{\circ}$ and $120^{\circ} \mathrm{F}$. See Table 28 . Adhesive primer was determined to be an essential part of the bonding system for both adhesives on Type 1020 and 4140 steel substrates used in the test. Two room-temperature-cure paste epoxy adhesives, Hysol EA-9410 and Reliabond R-10, were evaluated for bonding composite-to-composite and composite-to-metal applications. Hysol EA-9410 produced consistently higher and more reproducible bond strength from batch-to-batch mixes than Reliabond R-10 adhesive. (Table 29 and 30 )

The evaluation of Nylon peel ply to provide sound bonding surfaces showed no significant difference in tensile lap-shear strength as compared with the strength obtained from untreated surfaces. (Table 31) The advantage of the Nylon peel ply is that it eliminates the need for sanding or grinding any excess surface resin and resin beads that may be formed from resin bleedout during the winding operation. 


\section{RIGID POLYURETHANE FOAM ${ }^{(1)}$ PROPERTIES}

Test Sample

1. Load Parallel with Rise Direction
2. Load Perpendicular to Rise Direction.

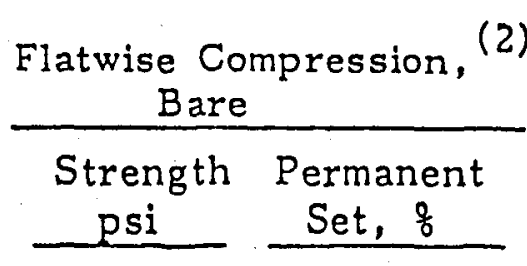

\begin{tabular}{|c|c|c|}
\hline & $\begin{array}{l}253 \\
245 \\
243 \\
241 \\
243\end{array}$ & $\begin{array}{l}0.9 \\
0.9 \\
1.4 \\
1.5 \\
1.5\end{array}$ \\
\hline verage & 243 & 1.2 \\
\hline
\end{tabular}

167

165

164

141

113

150

\section{7}

2.1

2.4

2.7

2.0

3.6

\begin{tabular}{l}
$\begin{array}{c}\text { Flatwise Tensile } \\
\text { Strength, psi }\end{array}$ \\
$\begin{array}{c}\text { No Resin Resin } \\
\text { Coat } \quad \text { Coat }\end{array}$ \\
\hline
\end{tabular}

81

92

177

162

162

167

117

(1) Polyurethane foam, Type PDL 801-7 (Polymer Development Laboratory), nominal 7-1b/cu. ft density

(2) Tested per ASTM Method C365

(3) Tested per ASTM Method C297

(4) Resin Coat (Epon 925/RD+2/Tonox 6040/1.5\% Cab-O-Sil) applied on both foam surfaces prior to layup of resinimpregnated TFT skins and cured at $250^{\circ} \mathrm{F}$ 
Table 27

DIMENSIONAL STABILITY TEST RESULTS OF

RIGID POLYURETHANE FOAMS

Test Sample

A. Foam Density, Ib/cu ft

B. LFT Overwind (1) (2)

1. Wedge

$$
\begin{aligned}
& \text { Bare } \\
& \text { Resin Coat } \\
& \text { Glass Skin }
\end{aligned}
$$

2. Block

$\stackrel{\varpi}{ \pm}$

Dimensional Change in Sample

$\begin{array}{lllll}2-6 & \frac{2-5}{2.20} & \frac{4-9}{3.02} & \frac{4-4}{3.48} & \frac{4-5}{4.63}\end{array}$

$\begin{array}{lll}.168 & .092 & .045 \\ .018 & .032 & .025 \\ .020 & .023 & .018\end{array}$

$\begin{array}{lllll}.031 & .051 & .027 & .023 & .019 \\ .029 & .021 & .022 & .020 & .018 \\ .024 & .009 & .014 & .014 & .004\end{array}$

C. Vacuum Bag (2)

1. Wedge

$$
\begin{aligned}
& \text { Bare } \\
& \text { Resin Coat } \\
& \text { Glass Skin }
\end{aligned}
$$

2. Block

Bare
Resin Coat
Glass Skin

3. Slab

Bare
Resin Coat
Glass Skin

(3)

$\begin{array}{ll}.014 & .001 \\ .012 & .004 \\ .007 & .002\end{array}$

$\begin{array}{lllll}.377 & .077 & .059 & .023 & .022 \\ .072 & .043 & .37 & .025 & .024 \\ .025 & .016 & .012 & .010 & .018\end{array}$

(1) Overwind with 3-in LFT at $33 \mathrm{lb}$ tension; 2 layers for wedge samples and 5 layers for block samples.

(2) Both LFT overwind and vacuum-bag assemblies subjected to heat at $250^{\circ} \mathrm{F}$ for 2 hours.

(3) No test performed. 


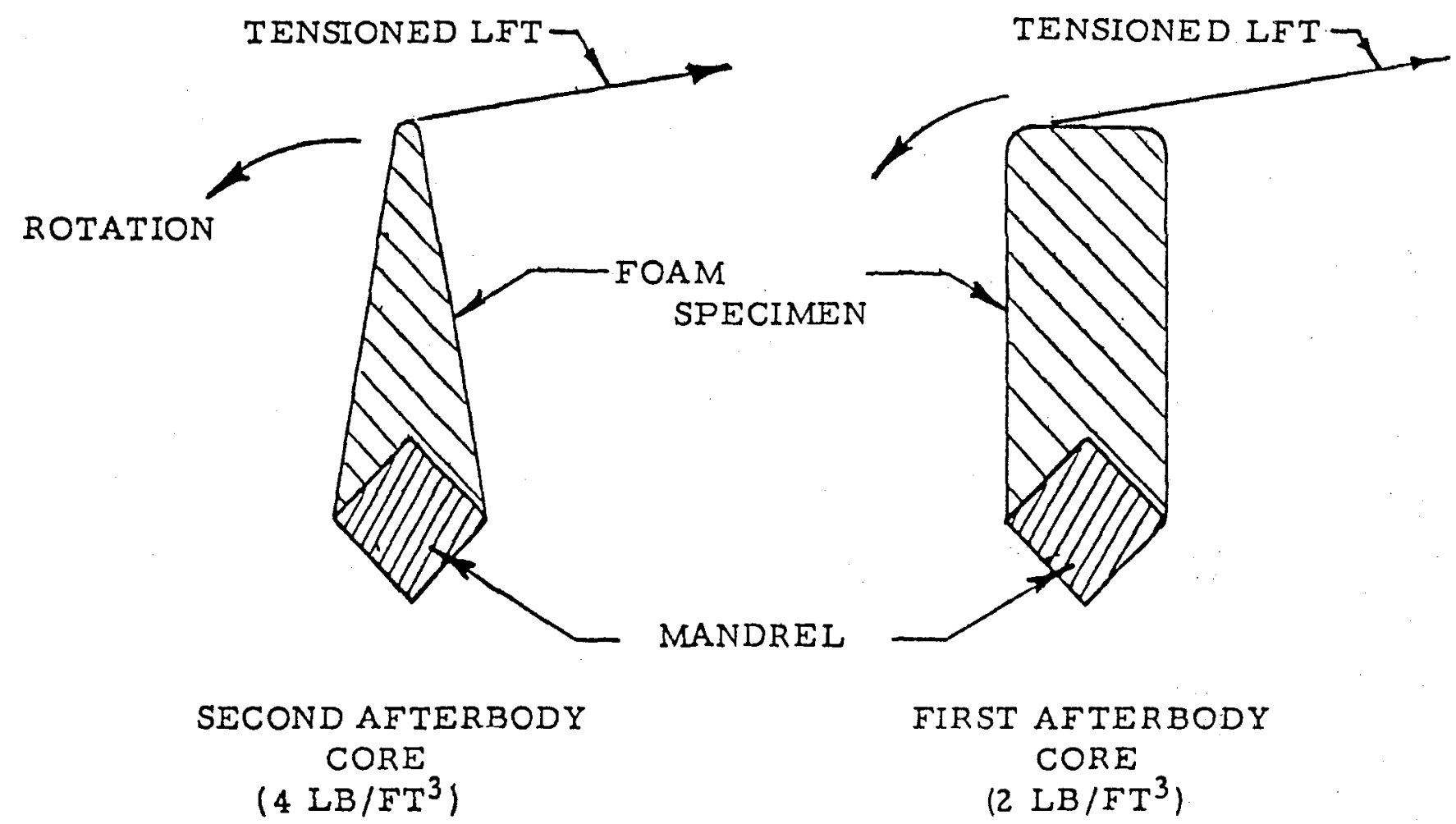

FIGURE 57 FOAM WINDING TESTS 
Table 28

ADHESIVE TEST RESULTS OF METAL-TO -

"WET" TFT BONDING

Tensile Lap-Shear Strength ${ }^{(1)}$, psi

Test

Temp

$\frac{O F}{75}$

$\stackrel{\leftrightarrow}{6}$

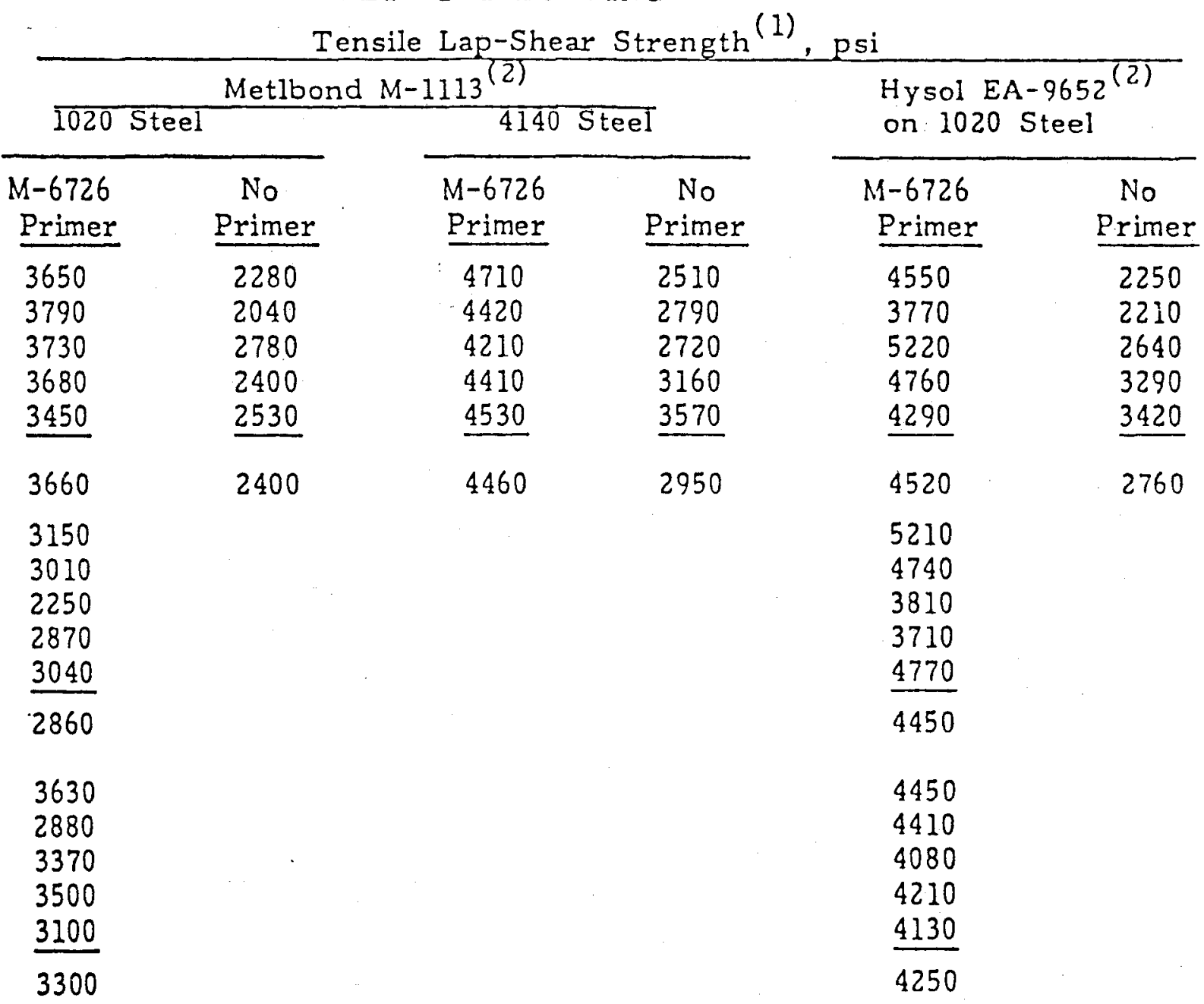

(1) Test method per Federal Specification MMM-A-132; tensile shear strength requirement per $M M M-A-132$, Type I $\left(-67\right.$ to $\left.180^{\circ} \mathrm{F}\right)$ is 2500 psi at $75^{\circ} \mathrm{F}$, 1250 psi @ $180^{\circ} \mathrm{F}$, and 2500 psi @ $-67^{\circ} \mathrm{F}$.

(2) Nominal weight of $0.08 \mathrm{lb} / \mathrm{ft}^{2}$ or 0.013 -in thickness. 
Table 29

ADHESIVE TEST RESULTS OF COMPOSITE-TO-

COMPOSITE BONDING

Tensile Lap-Shear Strength ${ }^{(1)}$; psi

Test

Temp

OF

75

जั

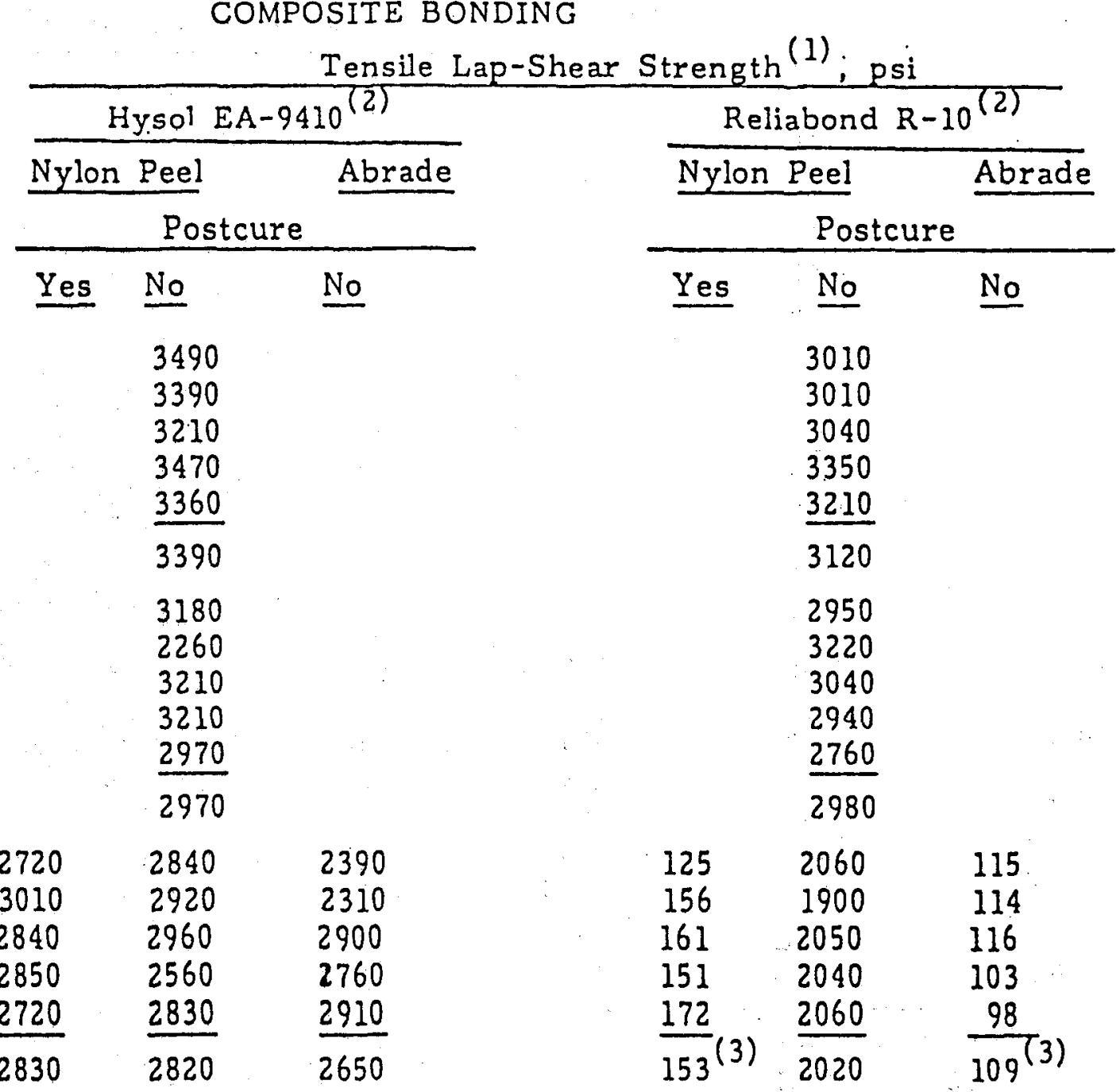

(1) Test method per Federal Specification MMM-A-132

(2) Two-part, room-temperature cure epoxy adhesive

(3) Second batch of ahdesive mix prepared from the same kit did not cure to hard mass 
ADHESIVE TEST RESULTS OF COMPOSITE-TO-

METAL BONDING

Test Temp

75

$\stackrel{\leftrightarrow}{\uplus}$

\begin{tabular}{|c|c|c|c|c|}
\hline \multirow[b]{3}{*}{$\begin{array}{c}\text { Test Temp } \\
\text { of } \\
\end{array}$} & \multicolumn{4}{|c|}{ Tensile Lap-Shear Strength ${ }^{(1)}$, psi } \\
\hline & \multicolumn{2}{|c|}{ Hysol EA-9410 } & \multicolumn{2}{|c|}{ Reliabond $\mathrm{R}-10^{(2)}$} \\
\hline & Postcure & $\begin{array}{c}\text { No } \\
\text { Postcure } \\
\end{array}$ & Postcure & $\begin{array}{c}\text { No } \\
\text { Postcure } \\
\end{array}$ \\
\hline 75 & $\begin{array}{l}3400 \\
3650 \\
2560 \\
2480 \text { (3) } \\
2100^{(3)}\end{array}$ & $\begin{array}{l}3040 \\
2360 \\
1910 \\
3160 \\
3310 \\
\end{array}$ & $\begin{array}{l}1220 \\
1130 \\
1110 \\
1120 \\
1070 \\
\end{array}$ & $\begin{array}{l}370 \\
620 \\
760 \\
640 \\
640 \\
\end{array}$ \\
\hline Average & 3020 & 2970 & 1130 & 610 \\
\hline-30 & & $\begin{array}{l}2470 \\
2840 \\
3010 \\
1430 \\
2130 \\
\end{array}$ & & \\
\hline Average & & 2610 & & \\
\hline 120 & & $\begin{array}{r}1130 \\
1200 \\
980 \\
\end{array}$ & & \\
\hline Average & & 1100 & & \\
\hline
\end{tabular}

(1) Test method per Federal Specification MMM-A-132

(2) Two-part room-temperature cure epoxy adhesive

(3) Poor test due to unbonded atea up to 50\%; data not included in the average 
\begin{tabular}{c} 
Test Temp \\
OF \\
\hline
\end{tabular}

75

120

Table 31

RESULTS OF SURFACE PREPARATION ON LAMINATE BOND STRENGTH

\begin{tabular}{lr}
$\begin{array}{c}\text { Tensile Lap-Shear Strength } \\
\text { Nylon }\end{array}$, psi \\
$\begin{array}{c}\text { Peel } \\
\text { Ply }\end{array}$ & $\begin{array}{r}\text { Surface } \\
\text { Abrasion }\end{array}$ \\
\cline { 2 - 2 } 2810 & 2700 \\
2760 & 2900 \\
2990 & 2970 \\
3020 & 2920 \\
3080 & $\underline{2980}$ \\
2930 & 2890 \\
& \\
2980 & \\
2760 & 2810 \\
2790 & 2730 \\
2720 & 2630 \\
2810 & 2470 \\
& 2660
\end{tabular}

(1) Test method per Federal Specification MMM-A-132 
A number of flat laminate panels were prepared to: (1) evaluate the static strength of the basic TFT material and to attempt to improve allowables to reduce blade weight, (2) develop methods to reduce void and resin content in the wound blade for lighter weight and better laminate quality, and, (3) provide fatigue test panels to NASA for testing, on another contract, to confirm the fatigue allowables.

\section{STRENGTH EVALUATION}

The evaluation was conducted by fabrication of flat laminates and determination of tensile properties, as well as gravimetric analysis of each laminate fabricated. The material and processing parameters evaluated included TFT materials of different areal weight density (oz/yd $\left.{ }^{2}\right)$, resin content, layup pattern and impregnation method. Eleven laminates were

fabricated to evaluate three weight variations of TFT materials including nominal 7,10 and $18 \mathrm{oz} / \mathrm{yd}^{2}$ materials and four variations of layup patterns. The laminates were constructed by maintaining approximately $90 \%$ longitudinal (TFT) fiber to $10 \%$ circumferential (LFT) fiber ratio by weight to simulate the planned blade construction. Three test coupons were prepared from each laminate and tested at ambient temperature for determination of ultimate tensile properties.

The most significant parameter affecting the composite and fiber tensile strengths was the TFT areal weight (oz/yd2); lower weight material yielded significantly higher strength. The fiber strength of $7-0 z$ TFT was nearly $70 \%$ higher $(215 \mathrm{ksi}$ vs $127 \mathrm{ksi}$ than the strength of 18 -oz material, with the $10-0 \mathrm{z}$ material between the two values.

Variations in layup patterns showed essentially no effect on fiber tensile strength determined for the 7-oz TFT material. The variations included the amount of overlap of 7 -in. wide tape (to simulate winding pitch) and distribution of overlapped tape ends within the structure (to simulate winding with one or two rolls simultaneously on a ring winder). Fiber strength translation of discontinuous fiber construction for $7-0 z / \mathrm{yd}^{2}$ material showed high efficiency with more than $90 \%$ strength retention when compared with continuous fiber strength value of the 10-oz material. Figure 58 summarizes the results of this test series. 


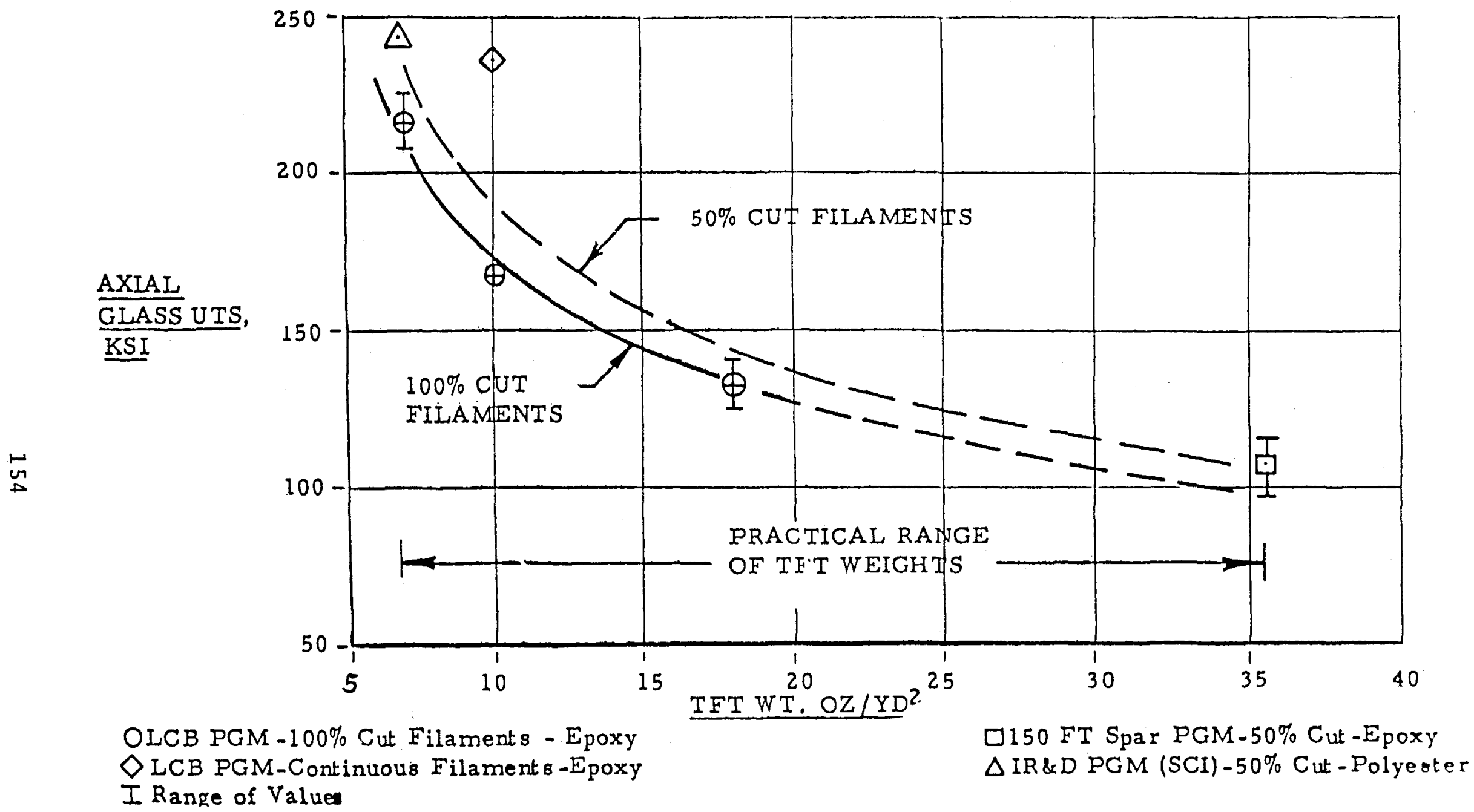

FIGURE 58 GLASS ULTIMATE TENSILE STRESS VS TRANSVERSF FILAMENT TAPE WEIGHT 
A number of small panels, D-spars and cylinders were wound to evaluate methods of controlling resin and void content on TFT wound areas of large radius of curvature.

Data was scattered and somewhat inconclusive because the resin staging time, an important variable, was not initially controlled. The use of a vacuum bag, with a bleeder ply and peel ply, later was found to give good weight, void and resin content control provided the resin was allowed to stage (partially polymerize) prior to the application of vacuum. If vacuum was applied too soon, too much resin would be drawn from the composite by the vacuum and bleeder ply, resulting in high void content.

\section{FATIGUE TEST PANELS}

Fatigue panels were fabricated with two variations of laminate construction using the material system selected for the blade manufacture. The laminates were wound on a flat aluminum mandrel and compressed down to stops of predetermined thickness between a cover plate. The panels were shipped to NASA-LeRC for fatigue property determination of test coupons to be prepared from these panels. Tables 32 and 33 detail the construction used for the panels and Figure 59 shows the winding setup. The results of testing of these panels is reported elsewhere, but the assumptions used to design the LCCB were not changed by these tests.

\subsubsection{SUBSCALE TESTS}

Subscale testing consisted of (1) the winding of two half scale spar stubs for fatigue testing of the root end joint, (2) six foot long subscale blade and D-spar cross sections for process demonstration and confirmation.

\section{HALF SCALE FATIGUE SPECIMENS}

The purpose of this task was to fabricate two fatigue test specimens, each featuring the double lug type metal/composite joint of the low cost blade root end. The root end portion of these specimens was scaled to half the size of the low cost blade spar and root end fitting. The tip section contained an adapter for a fatigue test machine. Total length was 156 inches $(13 \mathrm{ft}-0$ in.). One specimen, S/N 001 , utilized an adhesive to bond the composite to the respective fittings. The other specimen, S/N 002 , featured a "released" root end fitting, simulating a total adhesive failure. Figure 60 shows a half scale spar being wound in the ring winder. 
TABLE 32

FATIGUE PANEL WRAP PATTERN AND CONSTRUCTION

A.

PATTERN 1

CONSTRUCTION:

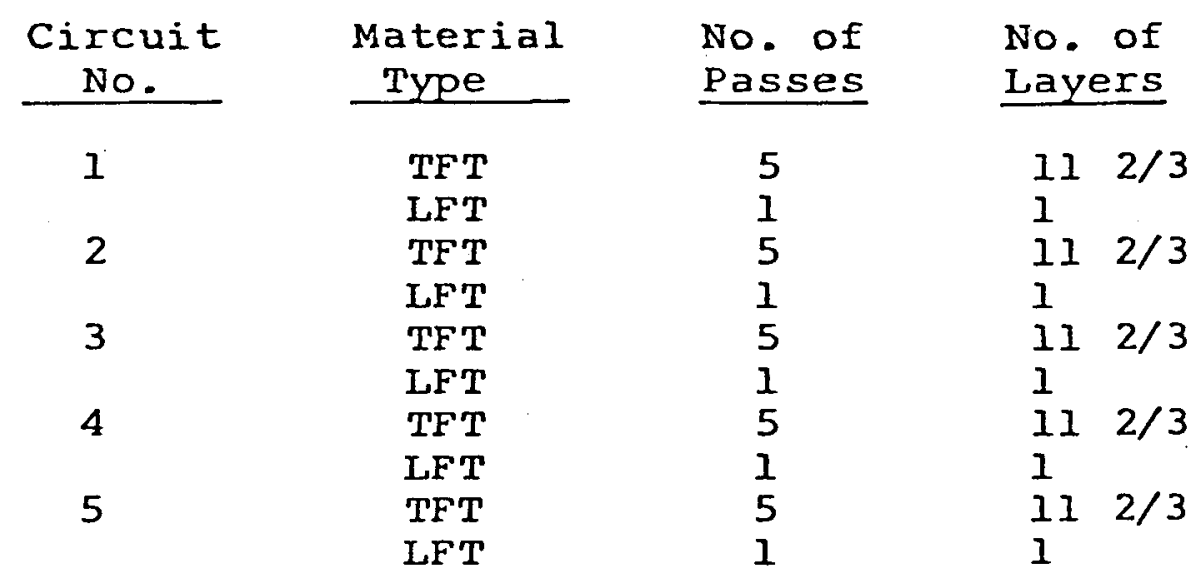

MATERIALS: TFT, $7 \mathrm{oz} / \mathrm{yd}^{2}, 7$-in.-wide LFT, $10 \mathrm{oz} / \mathrm{yd}^{2}, 3$-in.-wide

WINDING PITCH: 3-in.-pitch; wind from one direction only

WINDING TENSION: TFT @ 5-1b tension

LFT @ 33-1b tension 
TABLE 33

FATIGUE PANEL WRAP PATTERN AND CONSTRUCTION

B. PATTERN 2

CONSTRUCTION:

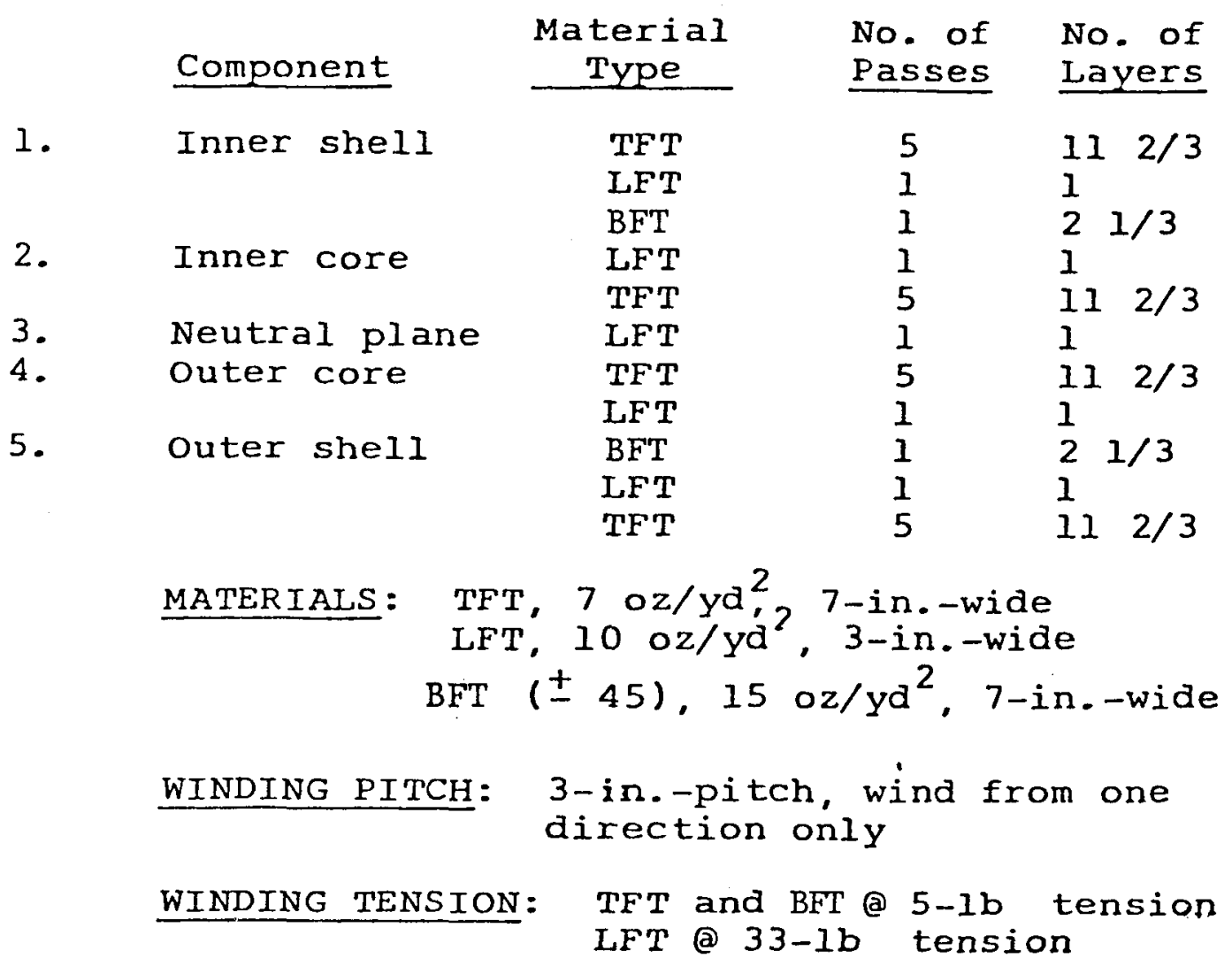


FABRICATION OF FOUR FLAT PANELS - SCI SPECIMEN PREPARATION - NASA LERC TESTING

|TTR I

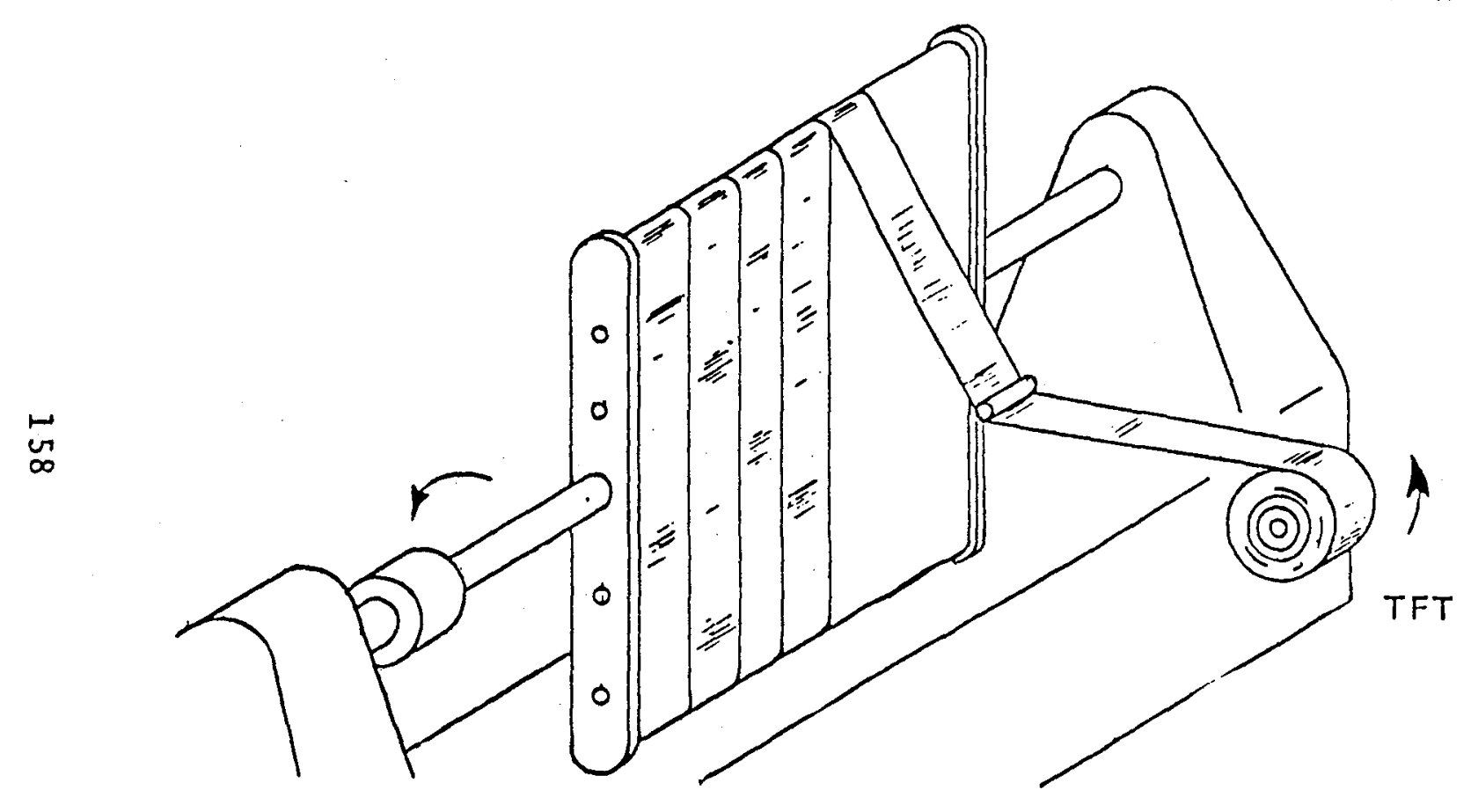

FIGURE 59 FLAT SPECIMEN WINDING FATIGUE TEST PANELS 


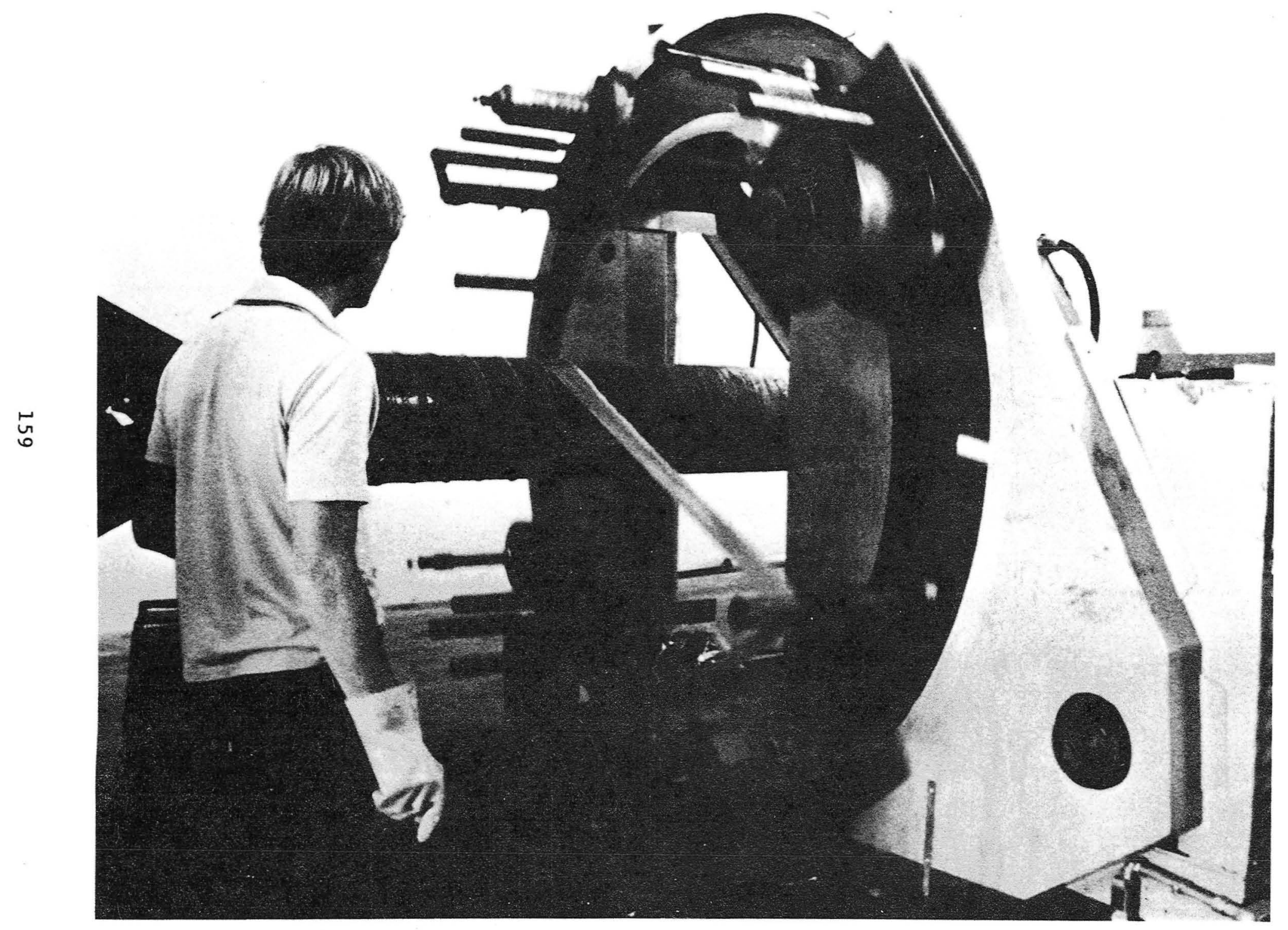

FIGURE 60 WINDING HALF SCALE SPAR 
A preliminary trial wind was used to develop the fitting winding technique. This wind consisted of a short section wound on the half scale spar mandrel using a dummy mild steel fitting. Machinery materials and processes used for the half scale spar were representative of those planned for the full size blades. Figure 61 shows the overall specimen configuration and Figure 62 an actual half scale spar.

Both half scale spars were shipped to NASA for fatigue testing. At this writing, both the bonded and unbonded fittings had been tested to well beyond the planned test region without any failures in the composite-to-metal fitting joint.

Detailed results of this testing will be reported elsewhere, but none of the assumptions or allowables used in LCCB design were changed by these test results.

\section{FT LONG SUBSCALE BLADE SECTIONS}

Several subscale D-spars and a full blade cross section were built using the setup shown in Figure 63 . Figure 64 is an actual cross section of the subscale blade. Figure 65 shows the effect of resin content on composite thickness. Figure 66 shows the variation in composite thickness with local radius of curvature. This data was used to develop the relation $\mathrm{T} / \mathrm{T}=0.091 \mathrm{nR}+0.9$ which was used in plotting the mylar cross seclions for blade tooling. 
吕

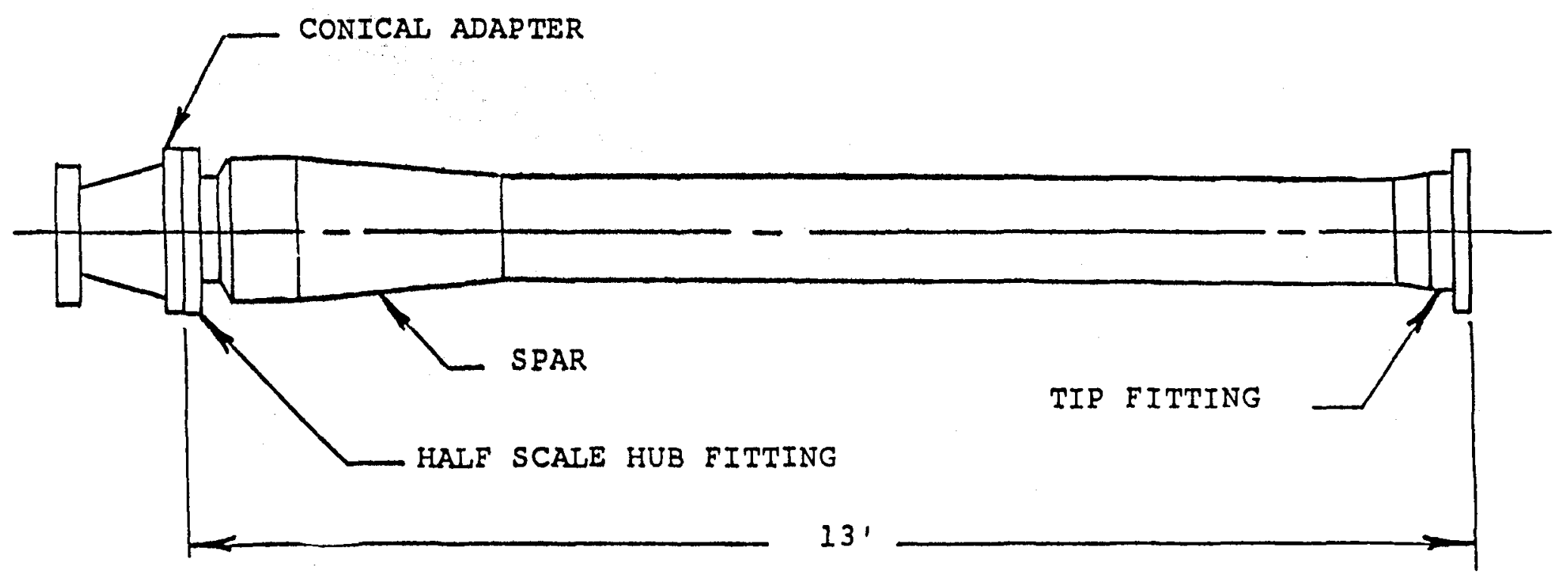

FIGURE 61 HALF SCALE HUB JOINT FATIGUE TEST SPECIMEN 


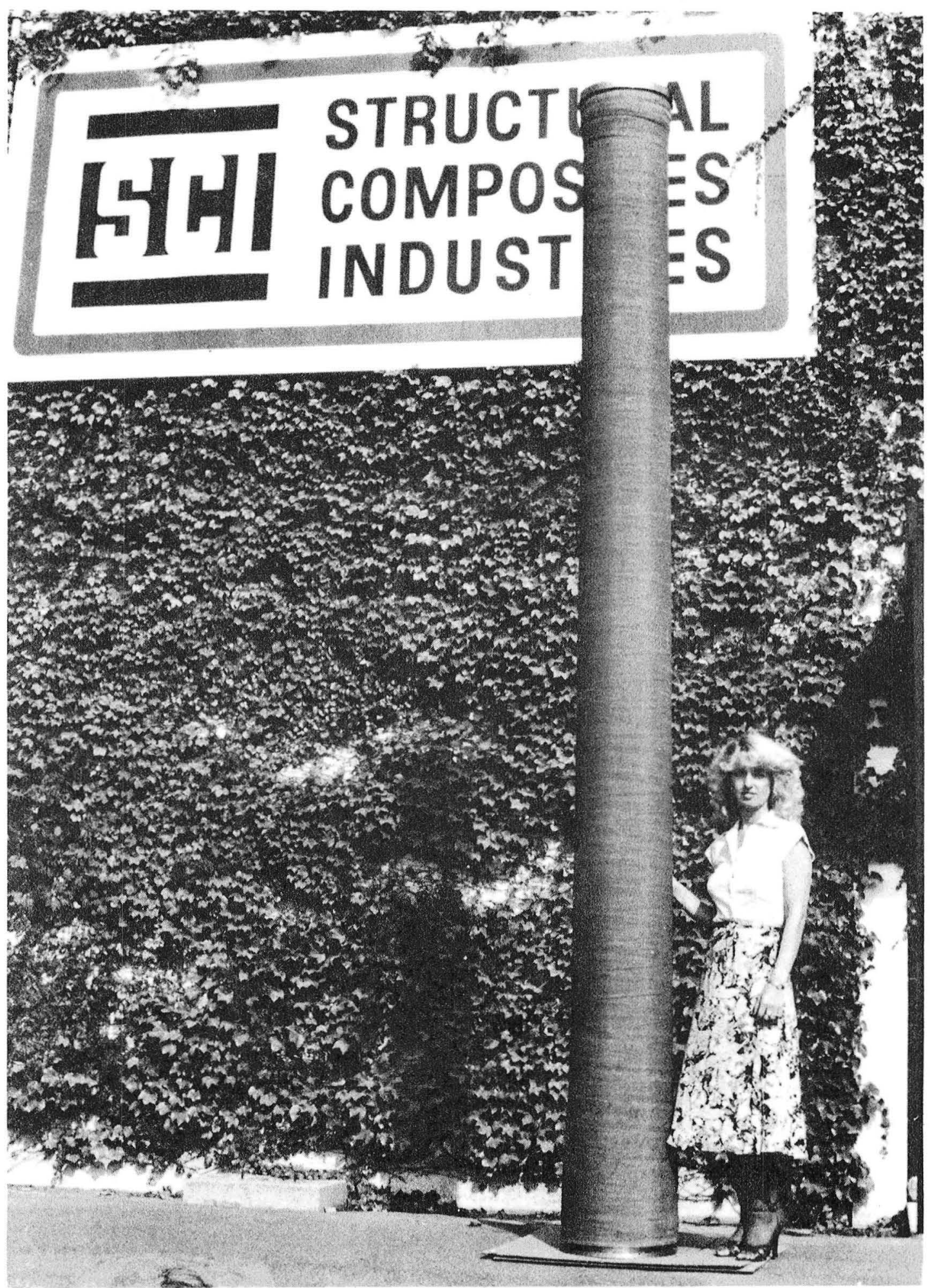

FIGURE 62 FINISHED HALF SCALE SPAR 


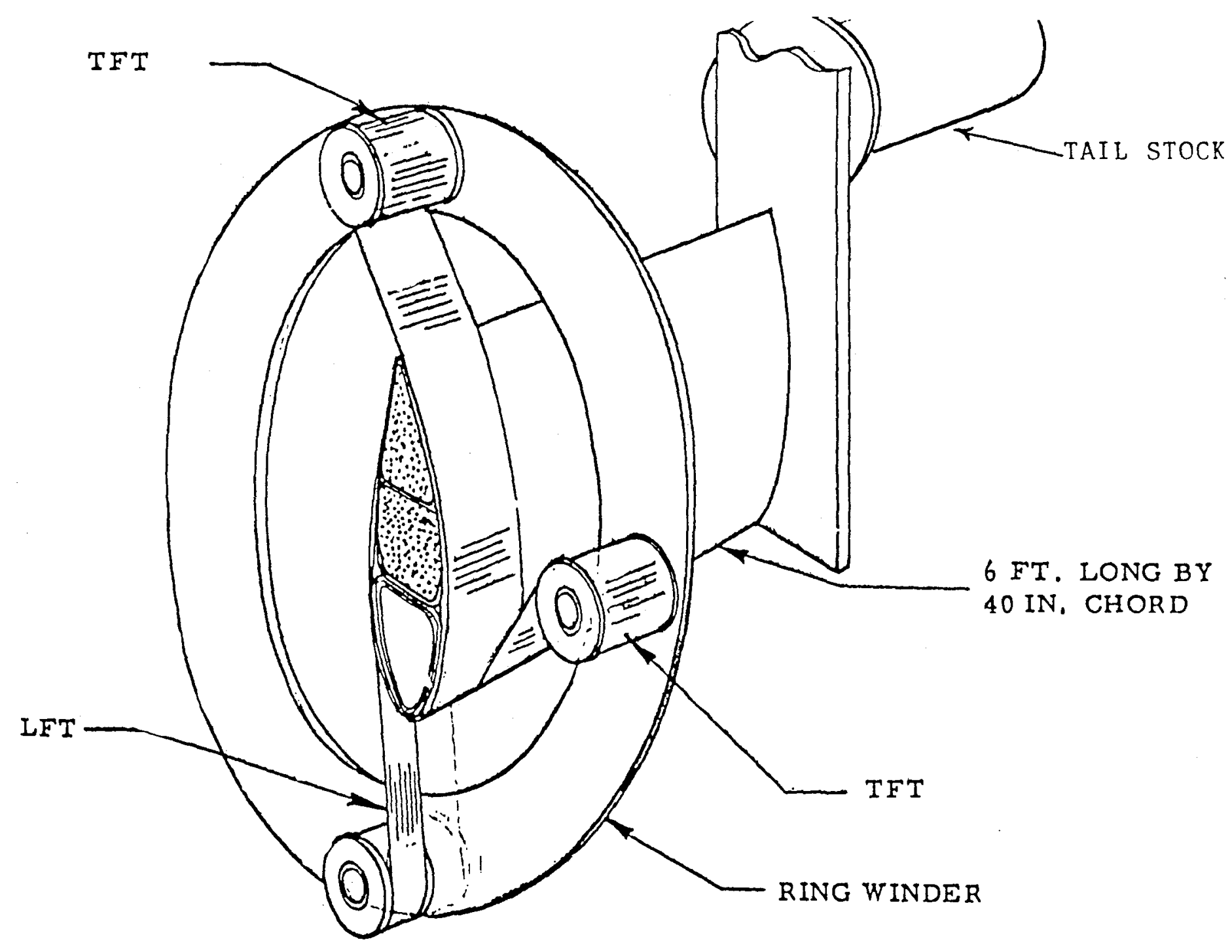

FIGURE 63 WINDING SETUP FOR 6 FT SUBSCALE BLADF SECTION 


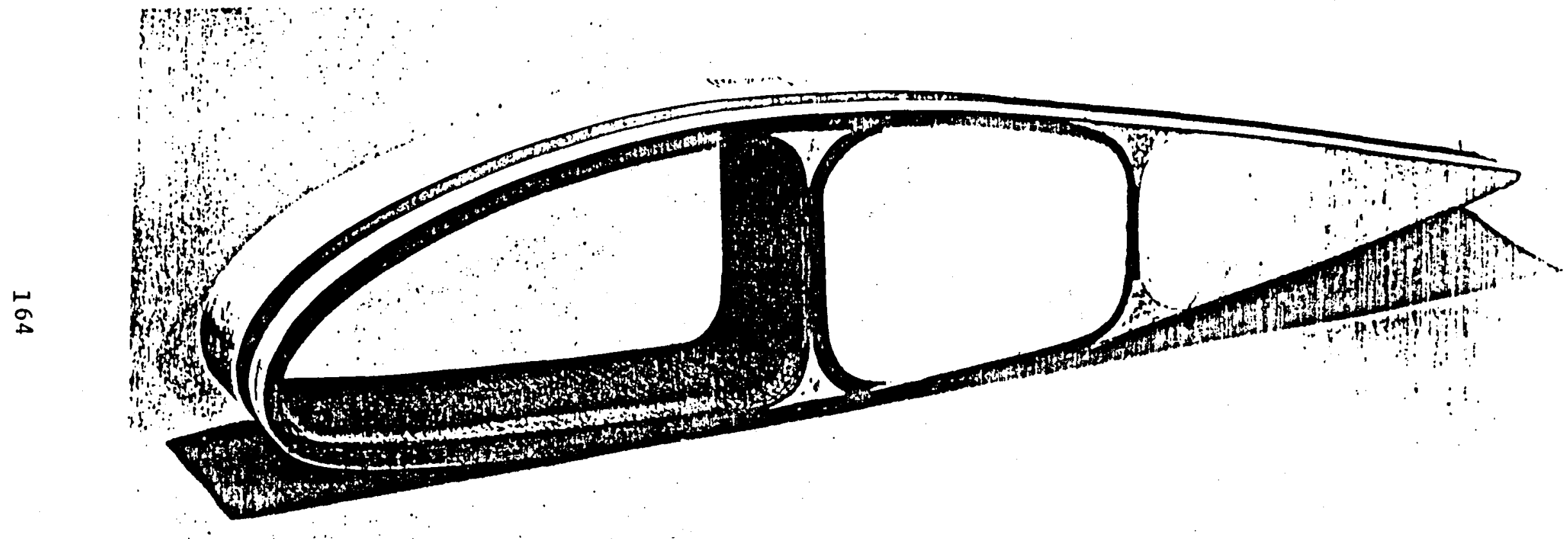

FIGURE $64 \quad 6$ FT SUBSCALE BLADE CROSS SECTION 


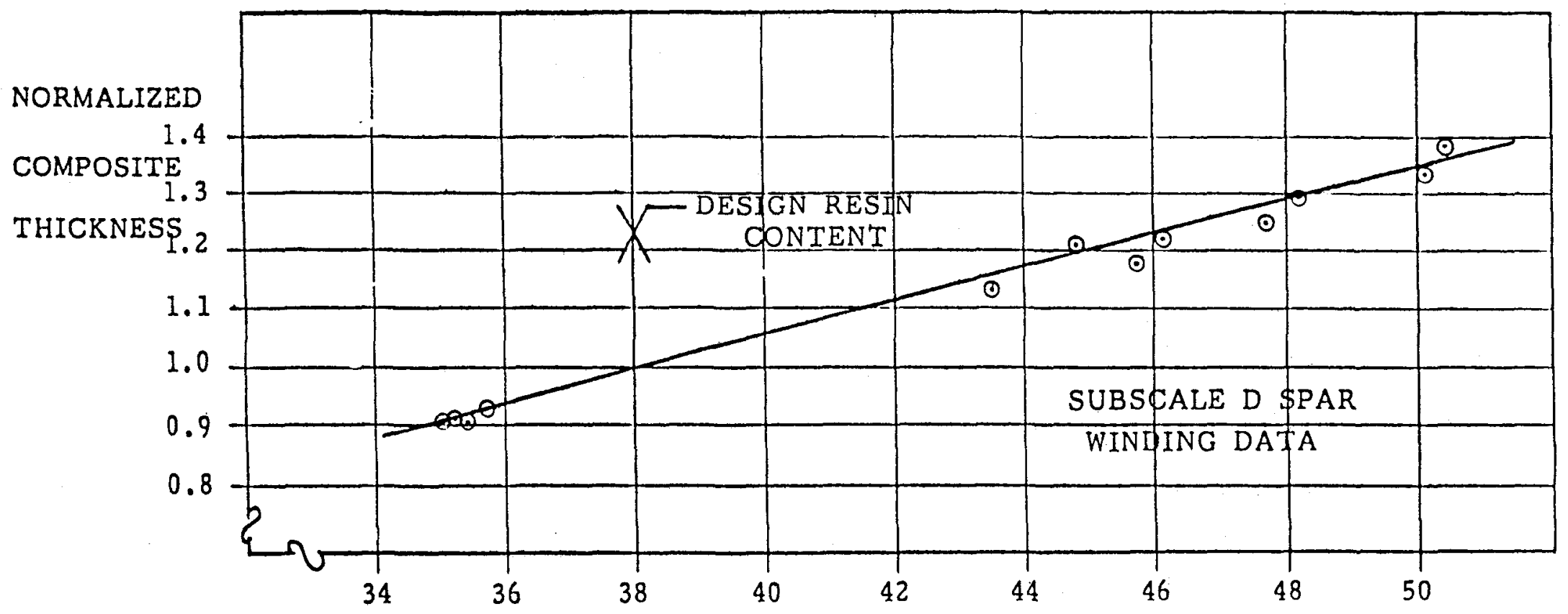

PERCENT RESIN BY WEIGHT

FIGURE 65 EFFECT OF RESIN CONTENT ON COMPOSITE THICKNESS, 6 FT SIIBSCALF BLADF 


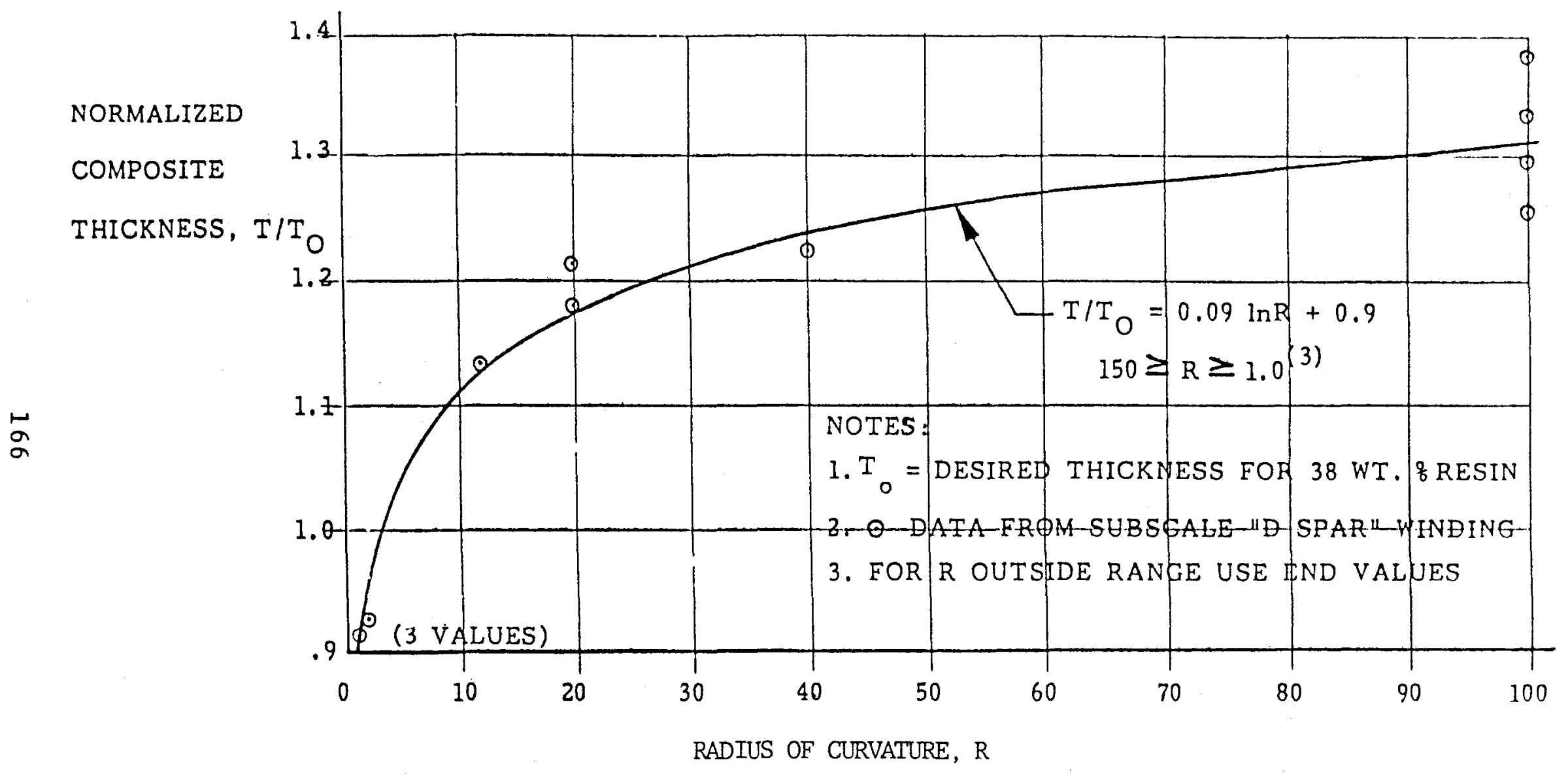

FIGURE 66 RADIUS OF CURVATURE EFFECT ON COMPOSITE THICKNFSS, 6 FT SIBSCALE RIADF, 
In Phase II of the program, the tooling and equipment necessary for blade fabrication was built and debugged. A tool tryout blade and two deliverable blades were fabricated and shipped to NASA. Cost, weight and quality control records for the prototype blades were evaluated in order to provide cost projections and recommendations for improvements for production blades.

\subsection{TOOLING AND EQUIPMENT FABRICATION}

Tooling and equipment for the LCCB fabrication included the SCI-furnished winding machine and facility; The D-spar winding mandrel and it's supports, equipment for impregnation and tensioning the TFT, curing extraction and handing equipment and $j i g s$ and fixtures.

\section{1 .1 WINDING MACHINE AND FACILITY}

The ring winding machine discussed in Section 4.3.1 was designed and built, using private funding, for the LCCB program. The machine concept was shown in Figure 15, and a picture of the actual winding machine is Figure 60. As built, the machine has a $90 \mathrm{ft}$ length and 65 inch chord capability, however it was designed to be easily convertible to $15 \mathrm{ft}$ or more chord for MOD-2 or MOD-5 blades. Length capability is limited only by the size of the building in which the machine is housed. otherwise, it is virtually unlimited. The machine also has the capability of winding large curved blades, such as might be used on very large vertical axis wind turbines.

\section{1 .2 D-SPAR MANDREL AND SUPPORTS}

The mandrel design concept and structural analysis were discussed in Section 4.4. Figure 67 shows the completed mandrel installed in the winding machine.

\section{1 .3 TFT IMPREGNATION AND TENSIONAL EQUIPMENT}

This equipment, discussed in Section 4.4 , consists of winding, dipping and vacuum impregnation units, with associated hoists, spools and racks. Tape tensioning was accomplished on the ring winder by four CTC units. (Compensating Tension Controls, Inc.) Figure 68 is an overall view of the impregnation area. 


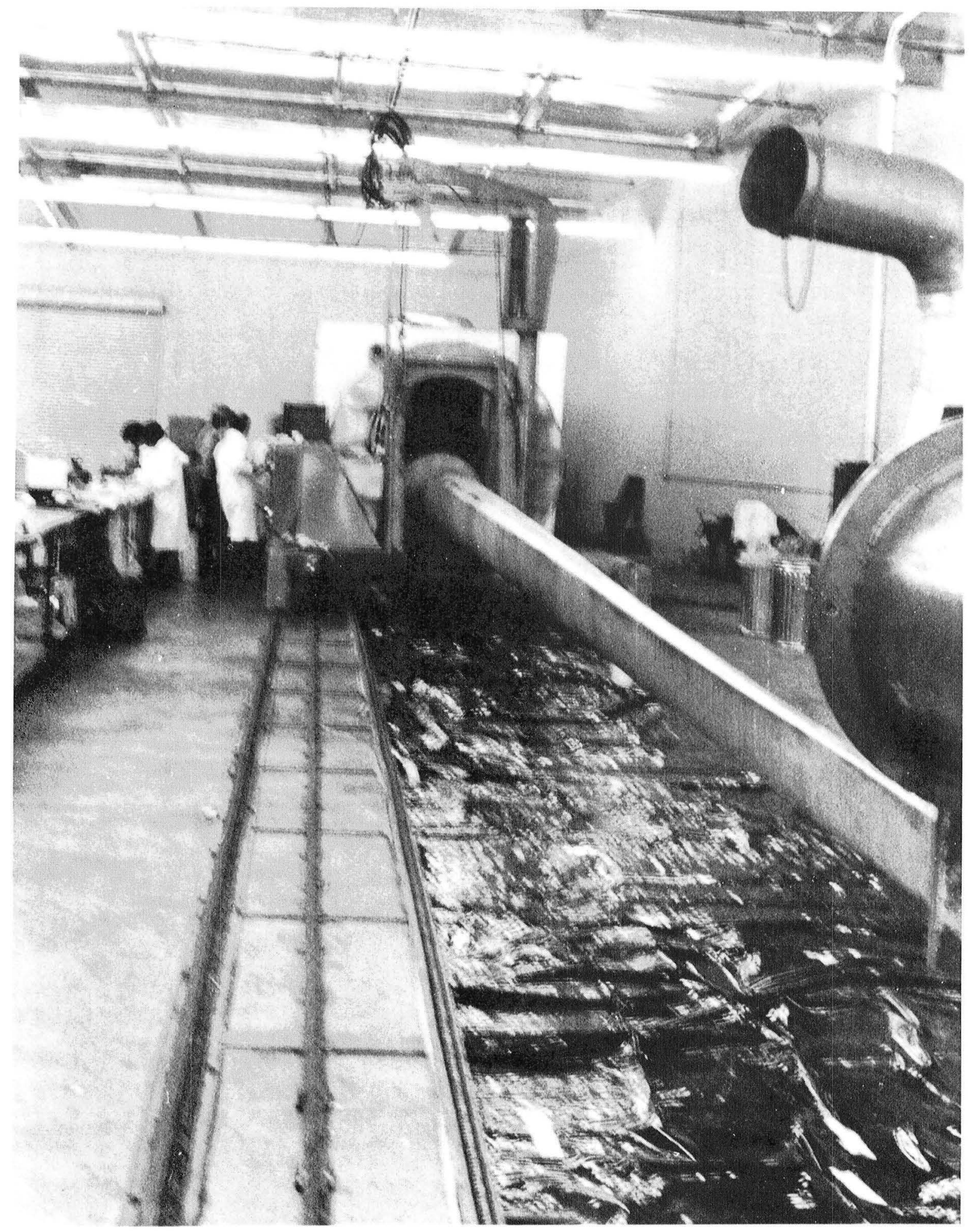

FIGURE 67 D-SPAR MANDREL IN WINDING MACHINE 


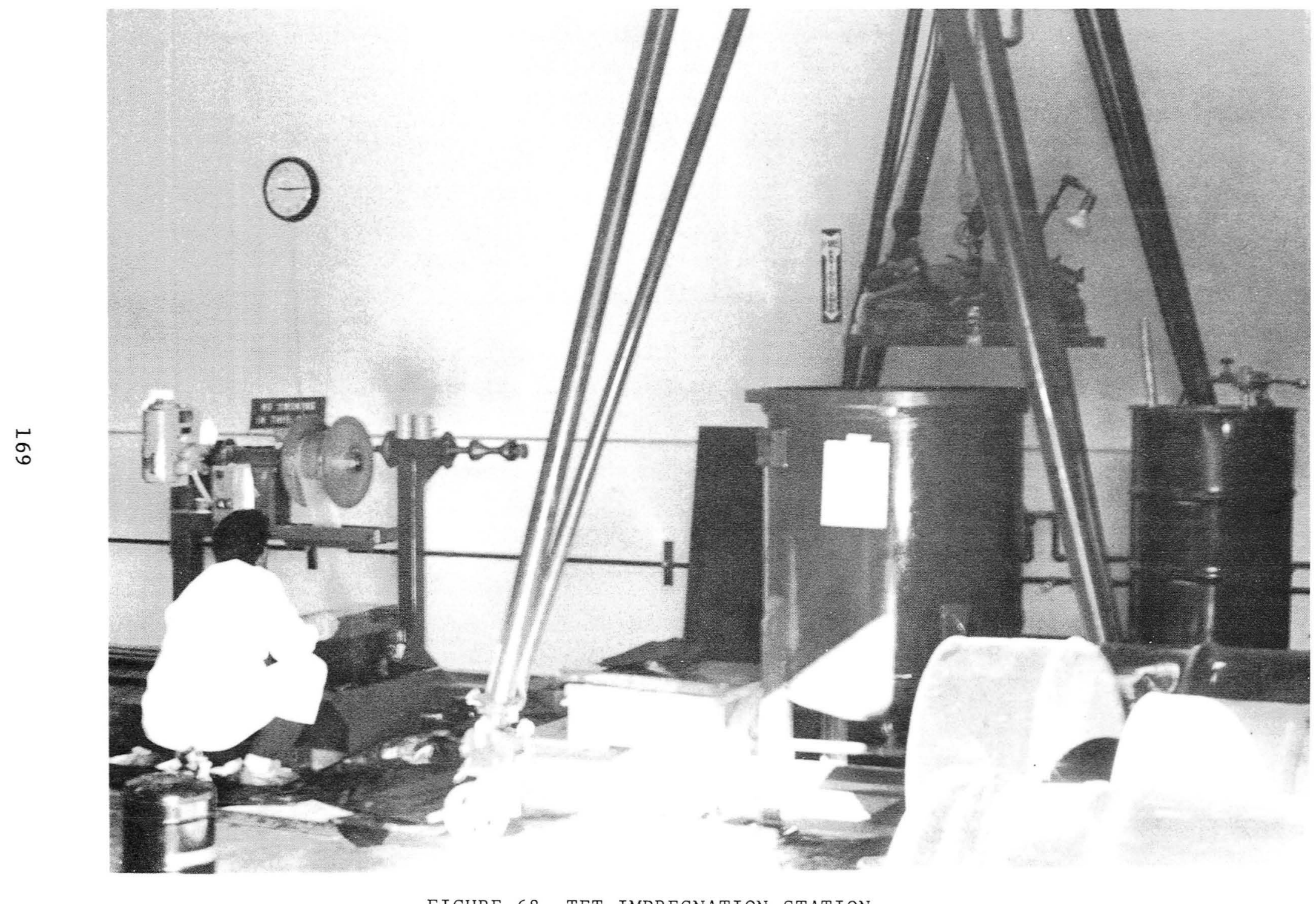

FIGURE 68 TFT IMPREGNATION STATION

DIP AND WIND MACHINE ON LEFT

VACUUM IMPREGNATION TANK ON RIGHT 
As discussed in Section 4.4, the cure oven is a $60 \mathrm{ft}$ by $9 \mathrm{ft}$ by $9 \mathrm{ft}$ insulated enclosure which is rolled on tracks over the wound blade mandrel. The oven and its $200 \mathrm{~kW}$ heater are shown in Figure 69.

The bucking ring and extraction jacks are shown in Figure 70 . Handling equipment was limited to standard slings, hoists, forklifts and gantries.

\section{1 .5 FIXTURES}

Some of these fixtures were used for aligning the mandrel and foam cores. Other fixtures were used to drill the root end fittings and to shape the foam cores. Figure 71 shows the alignment fixtures.

\subsection{BLADE FABRICATION}

In order to evaluate the proposed fabrication process in full scale, a part length tool tryout blade was built. Two deliverable blades were then fabricated and delivered to NASA for instrumentation, testing and eventual installation on a MOD-OA wind turbine.

\section{2 .1 TOOL TRYOUT BLADE}

The tool tryout blade consisted of the root end, the full D-spar and the first $16 \mathrm{ft}$ of the airfoil portion of the blade. The D-spar was wound full length to evaluate mandrel extraction. NASA plans to use this D-spar for buckling tests to confirm the equations used for blade design.

Using the data from this test, a final weight prediction, shown in Table 34 was made for the two deliverable blades. During the final design study, the gravitymoment for the estimated weight of $2852 \mathrm{lbs}$ was $44,400 \mathrm{ft} / 1 \mathrm{bs}$. (Table 19) For the new estimated weight of $2731 \mathrm{lbs}$, the gravity moment was $42,516 \mathrm{ft} / 1 \mathrm{bs}$.

\section{2 .2 FABRICATION OF PROTOTYPE BLADES}

The two deliverable prototype LCCB's were fabricated at SCI's Azusa, California facility during February and March 1981. Figures 72 through 79 show typical steps during blade fabrication. 


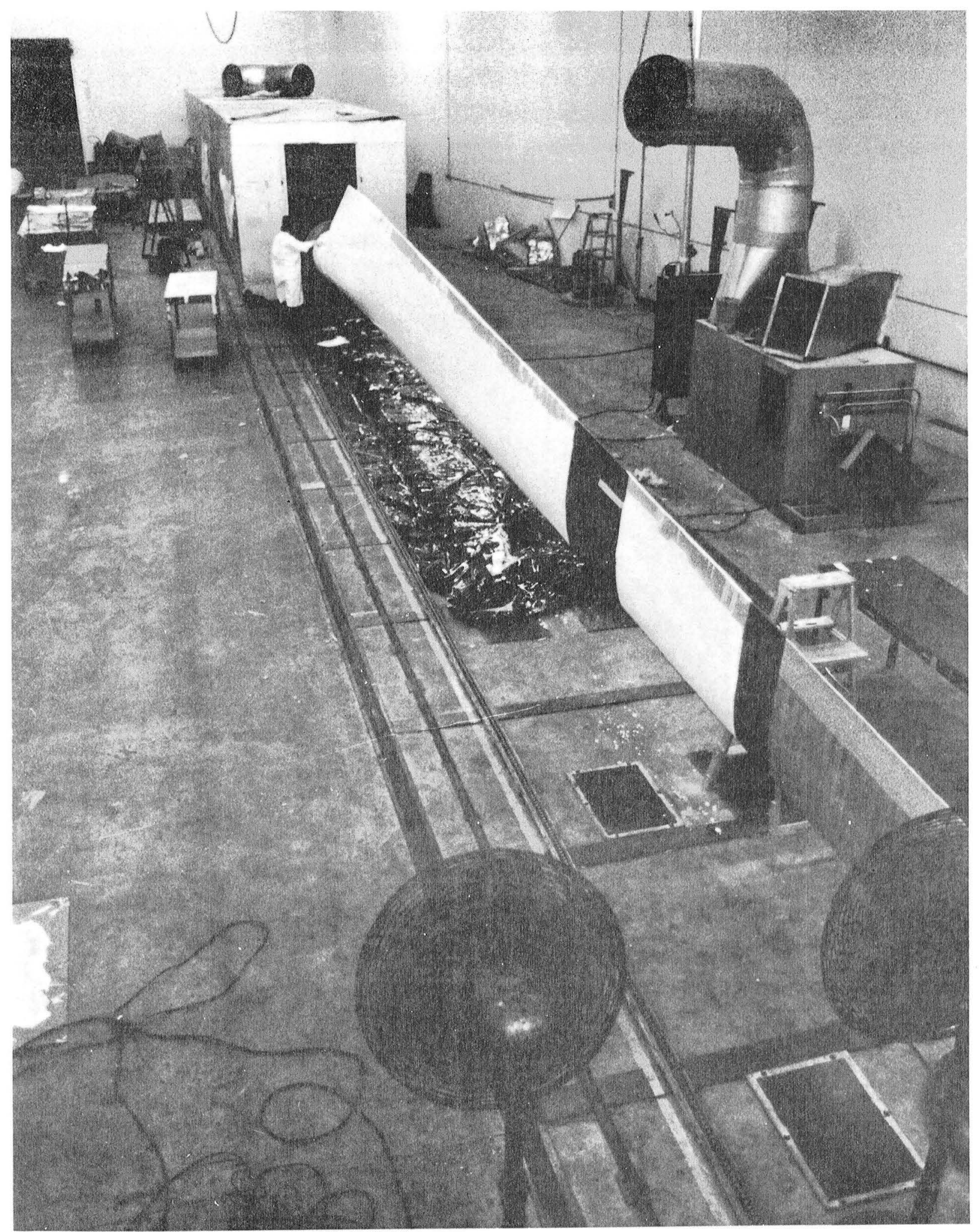

FIGURE 69 OVEN AND HEATER

OVEN - LEFT BACKGROUND

HEATER - RIGHT BACKGROUND 


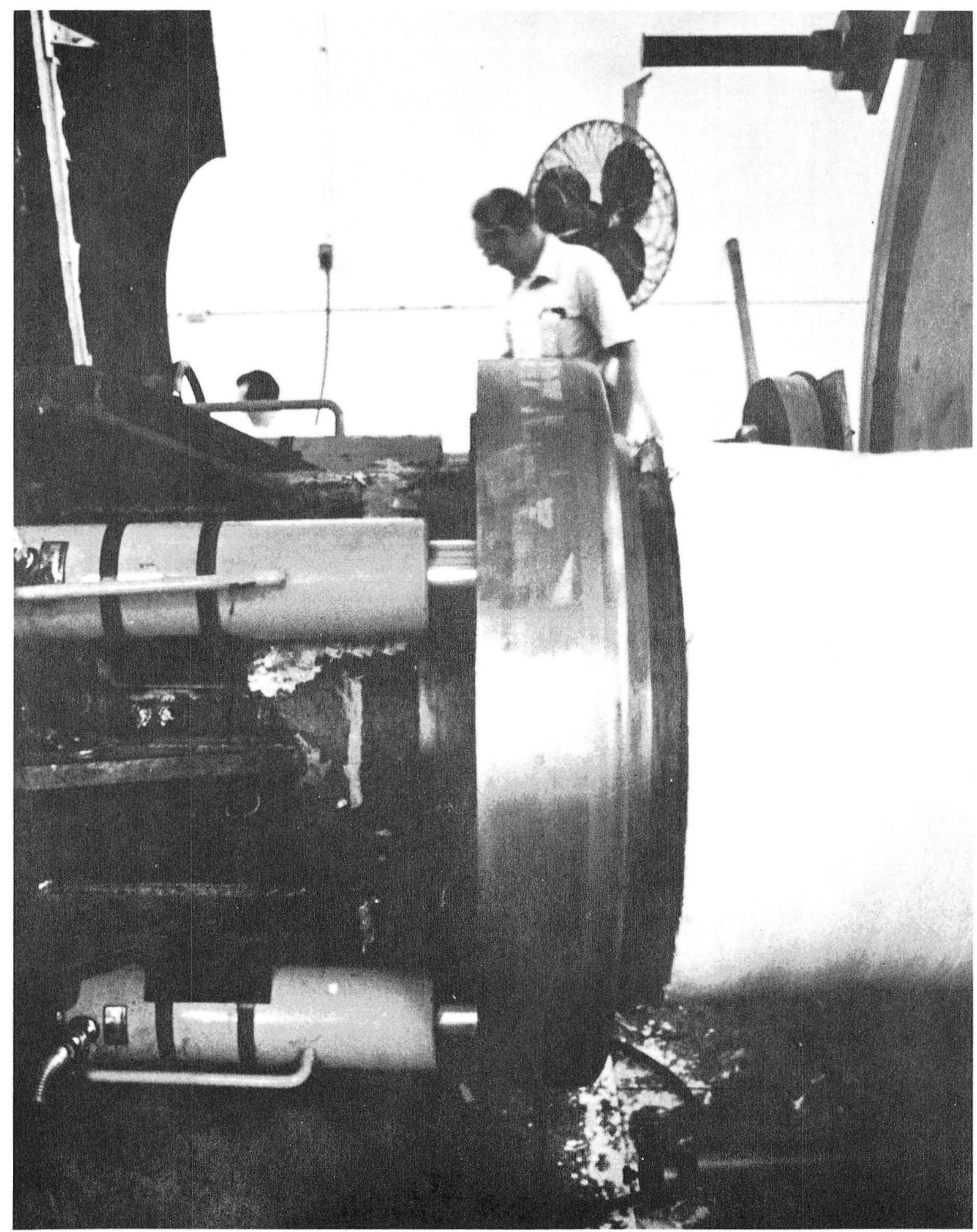

FIGURE 70 BUCKING RING AND EXTRACTION JACKS 


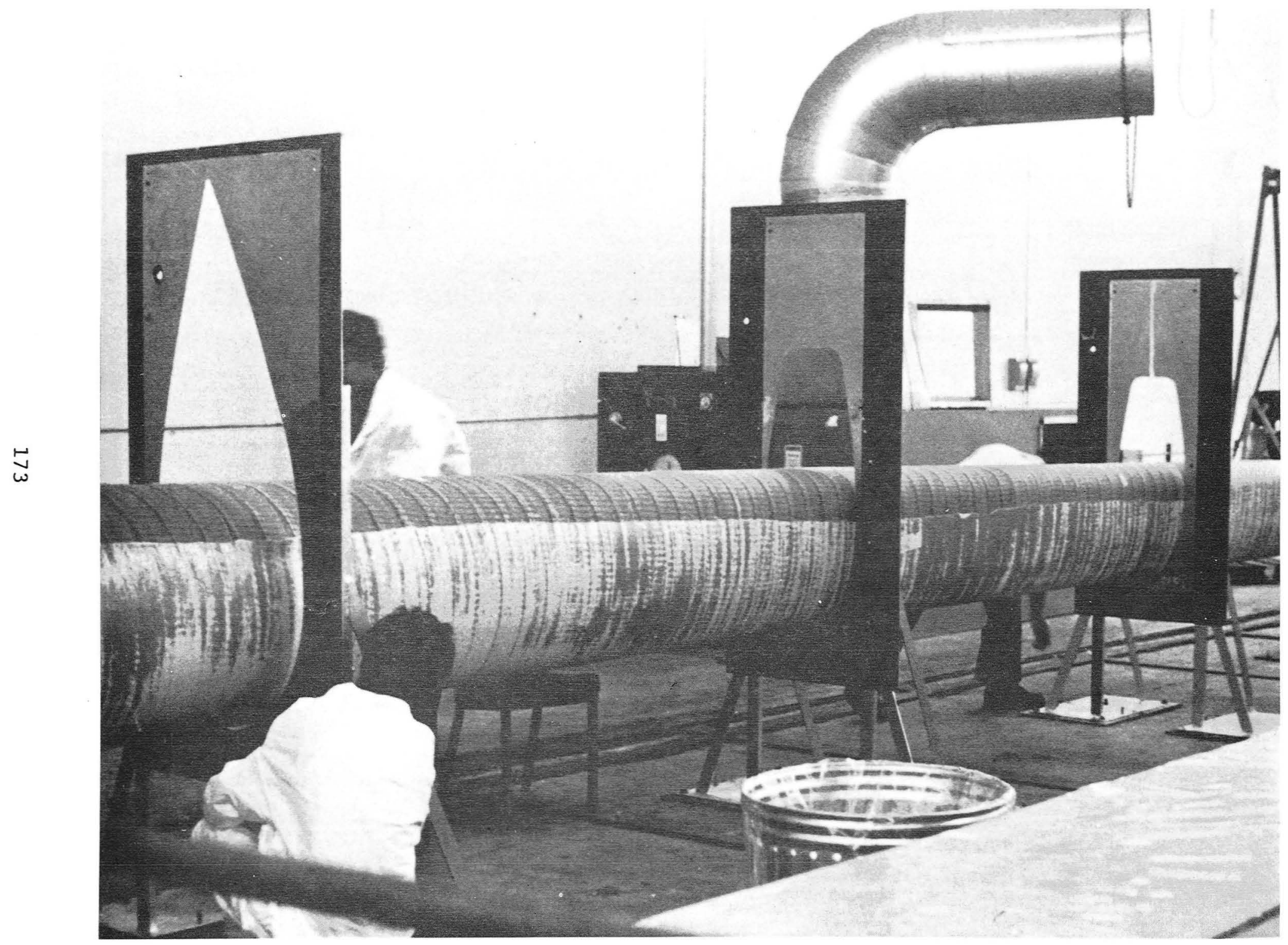

FIGURE 71 BLADE ALIGNMENT FIXTURES 
TABLE 34

WEIGHT COMPARISONS

MATERIAL

STEEL HUB FITTING

COMPOSITE

$2-L B$. FOAM

$4-L B$. FOAM

FOAM FILLER

ADDITIONAL HARDWARE, PAINT, MISC.

TOTAL

HUB ADAPTER

GRAND TOTAL
TOTAL BLADE WEIGHT (LBS)

\begin{tabular}{|c|c|c|}
\hline FINAL DESIGN & AFTER TOOL TRYOUT & ACTUAI, BHA:P: \\
\hline 265 & 273 & \\
\hline 1742 & 1808 & \\
\hline 67 & 58 & \\
\hline 87 & 93 & \\
\hline 118 & 21 & \\
\hline 200 & 105 & \\
\hline 2479 & 2358 & 2180 \\
\hline 373 & 373 & 395 \\
\hline 2852 & 2731 & 2575 \\
\hline
\end{tabular}


In Figure 72, the D-spar is being wound. Figure 73 shows application of the first afterbody core. In Figure 74, the first afterbody winding is being applied. Figure 75 shows application of the trailing edge core and Figure 76 is a view of the final cross section. (Tool tryout)

The painting of the blades, Figure 77, was followed by final cure, Figure 69. After trimming and installation of details such as ice detector, balance weights and tip caps, Figure 78 , the blades were loaded on a truck for shipment to NASA, Figure 79 .

\section{2 .3 RESULTS OF BLADE INSPECTION}

The blades were inspected for dimensional accuracy, weight and balance, and finish and appearance.

DIMENSIONAL INSPECTION

Measurements were taken of the upper and lower airfoil contours at six points along the chord for a total of 12 points per. station. A total of eight stations from $r / R=0.125$ to $\mathrm{r} / \mathrm{R}-1.0$ were measured (each $1 / 8 \mathrm{R})$. The total points measured were therefore 96 per blade. The measurements utilized sheet metal airfoil contour templates made from the airfoil mylars.

Tables 35,36 and 37 present descriptive statistics. Tables 38 , 39 and 40 are frequency distributions, and Figures 80,81 and 82 are histograms for blades 018,019 and both blades taken together. Table 41 is an analysis of variance of the results from two blades. These analyses were conducted on a TRS -80 microcomputer, using the "advanced statistical analysis" program.

The results show a mean error for all measurements of -.085 in. This resulted from a general reduction in composite wall thicknesses and foam dimensions due to the vacuum bags used to reduce resin and void content, and the shrinkage of the foam during cure. The airfoil mylars had been plotted using the greater wall thicknesses experienced on the high radius of curvature areas (most of the blade) during normal winding of subscale models without vacuum bagging. (Figure 66)

The overall accuracy and fairness of the blade contour was adversely affected by the vacuum bagging which tended to pull the wet windings into any low spot in the mandre1s, whereas the windings normally tend to bridge and smooth out these places. The effect was especially pronounced in the fairing material used to smooth the transition from foam core to D-spar or first afterbody. (See Figure 78) 


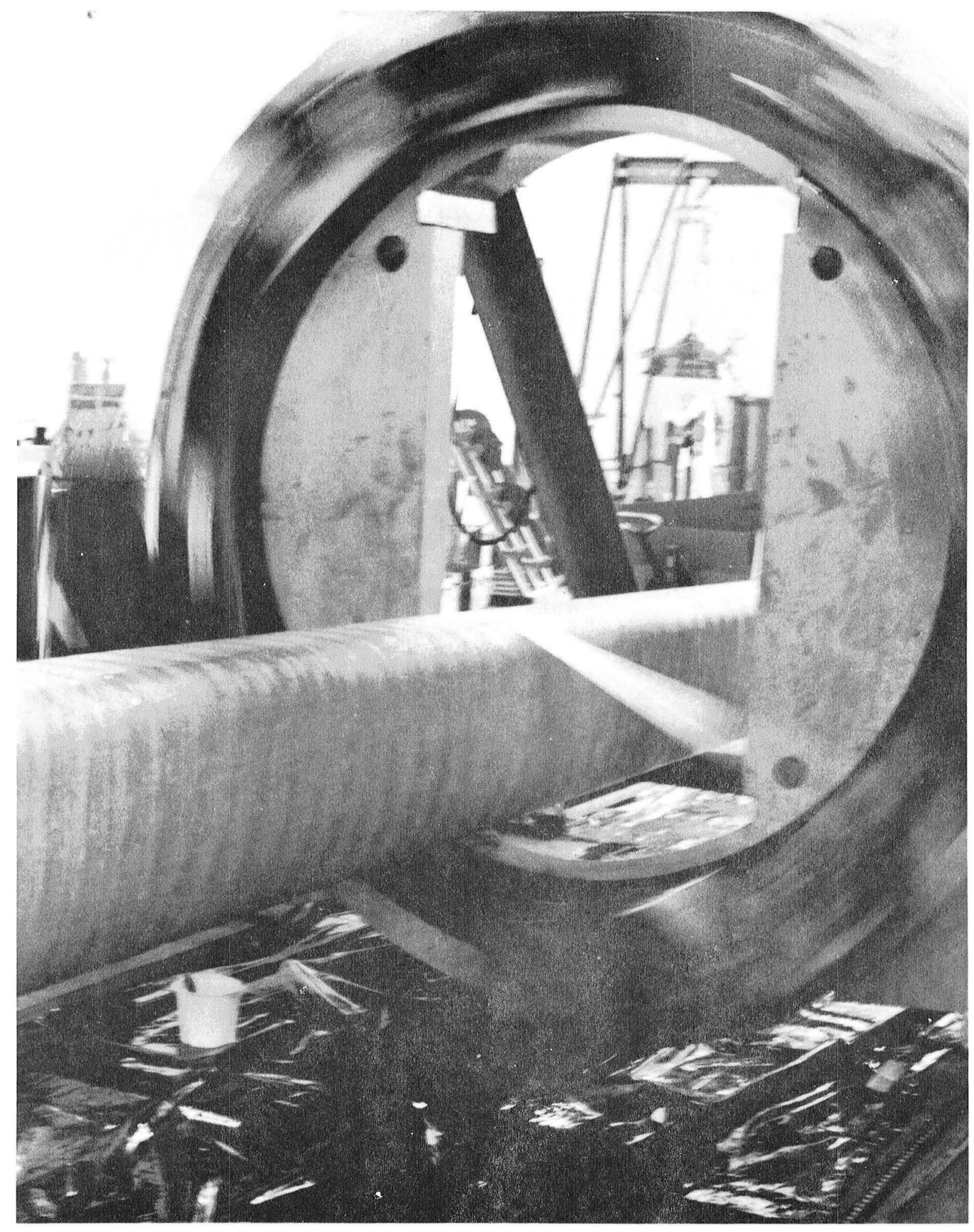

FIGURE 72 WINDING D-SPAR 


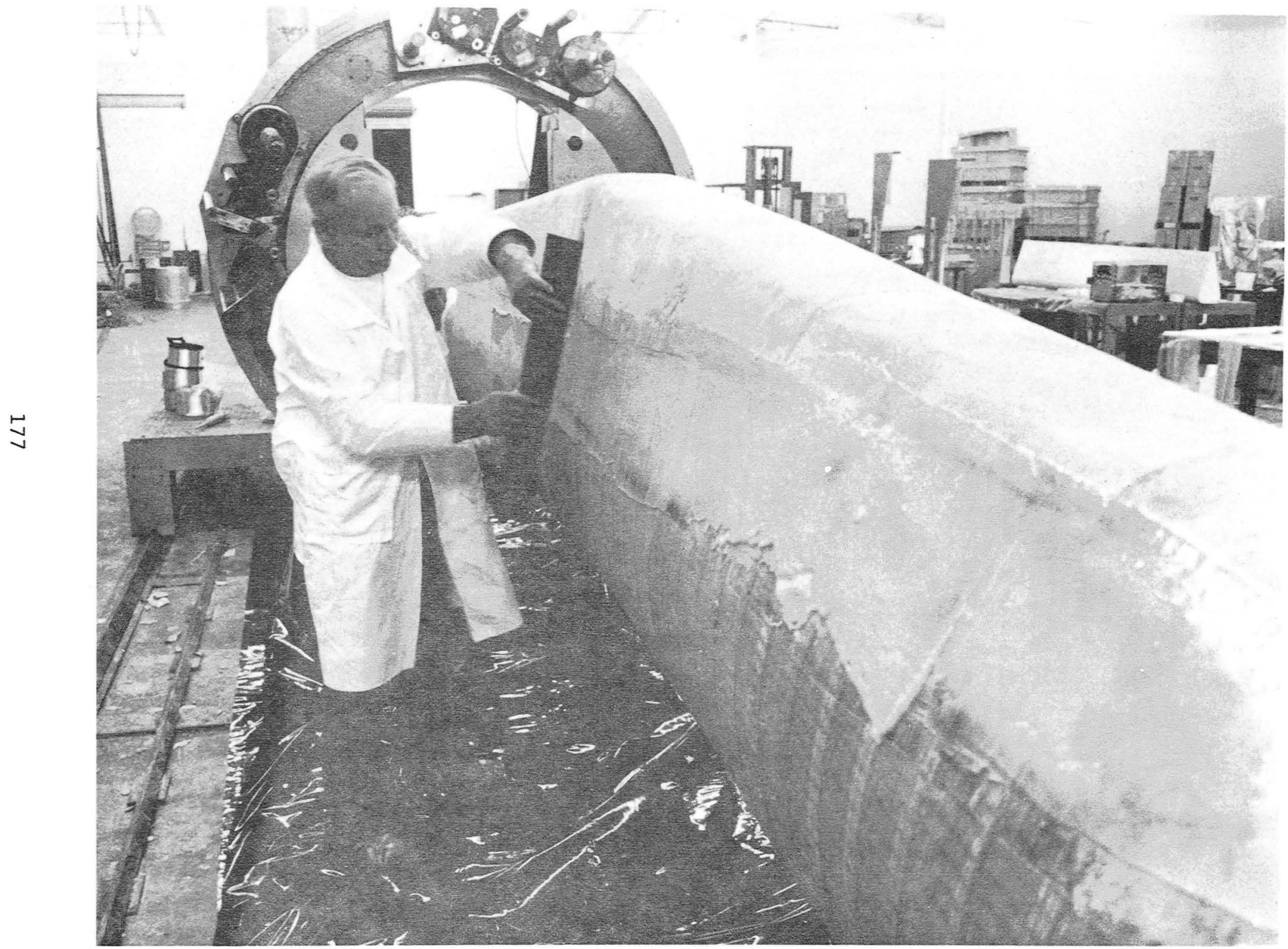

FIGURE 73 APPLYING FIRST AFTERBODY CORE TO D-SPAR 


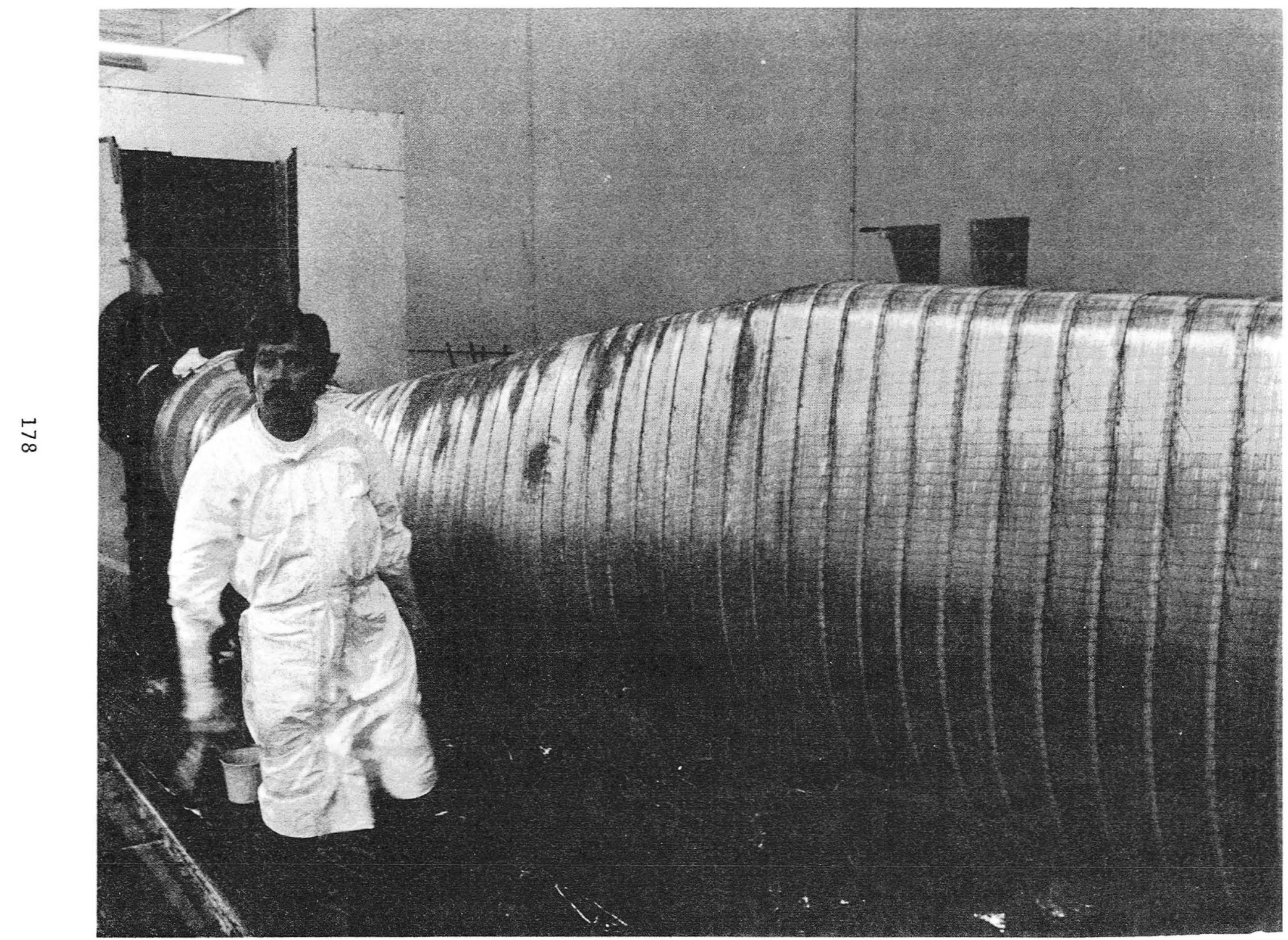

FIGURE 74 PARTIALLY WOUND FIRST AFTERBODY 


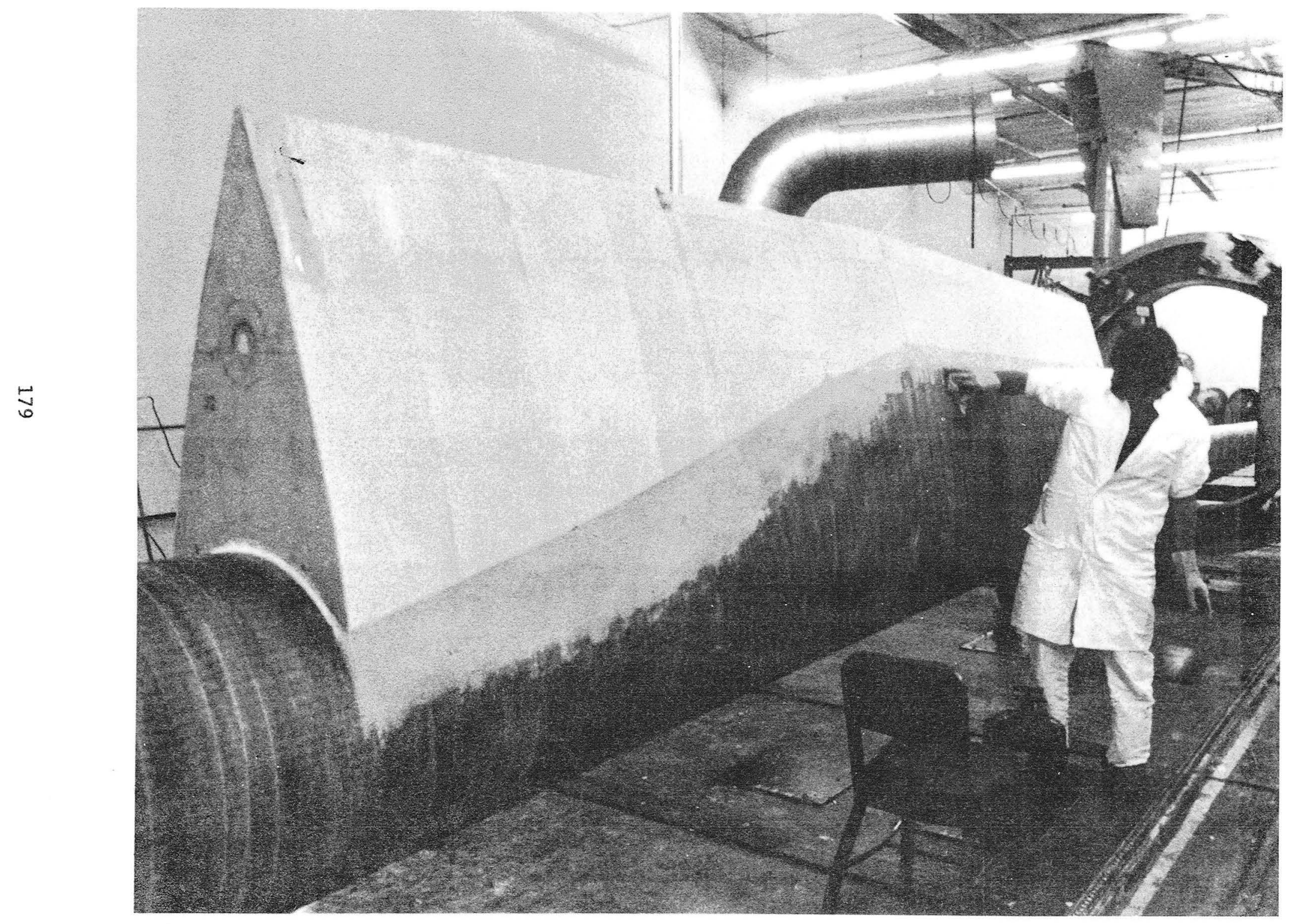

FIGURE 75 APPLICATION OF TRAILING EDGE CORE 


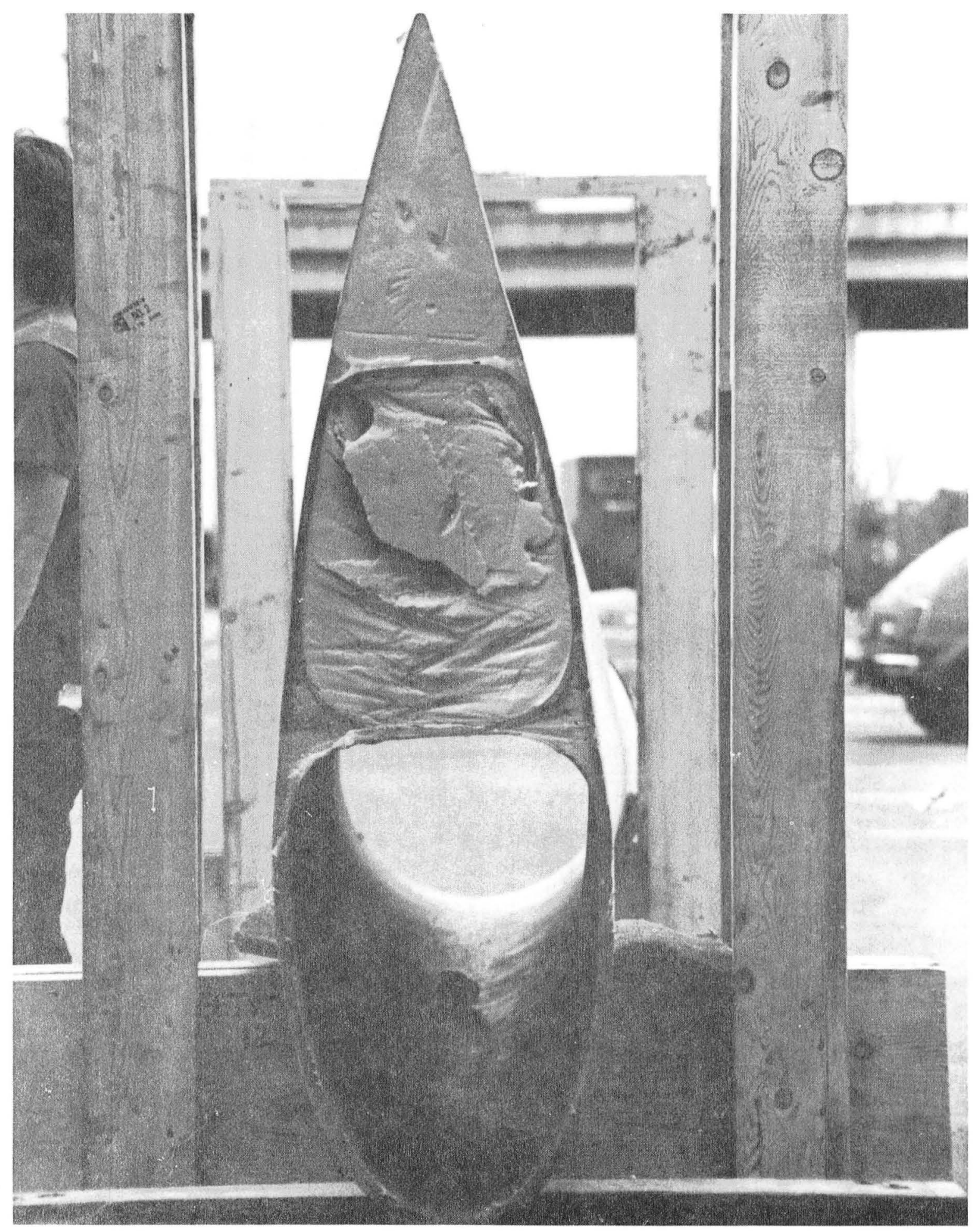

FIGURE 76 CROSS SECTION OF TOOL TRYOUT BLADE 


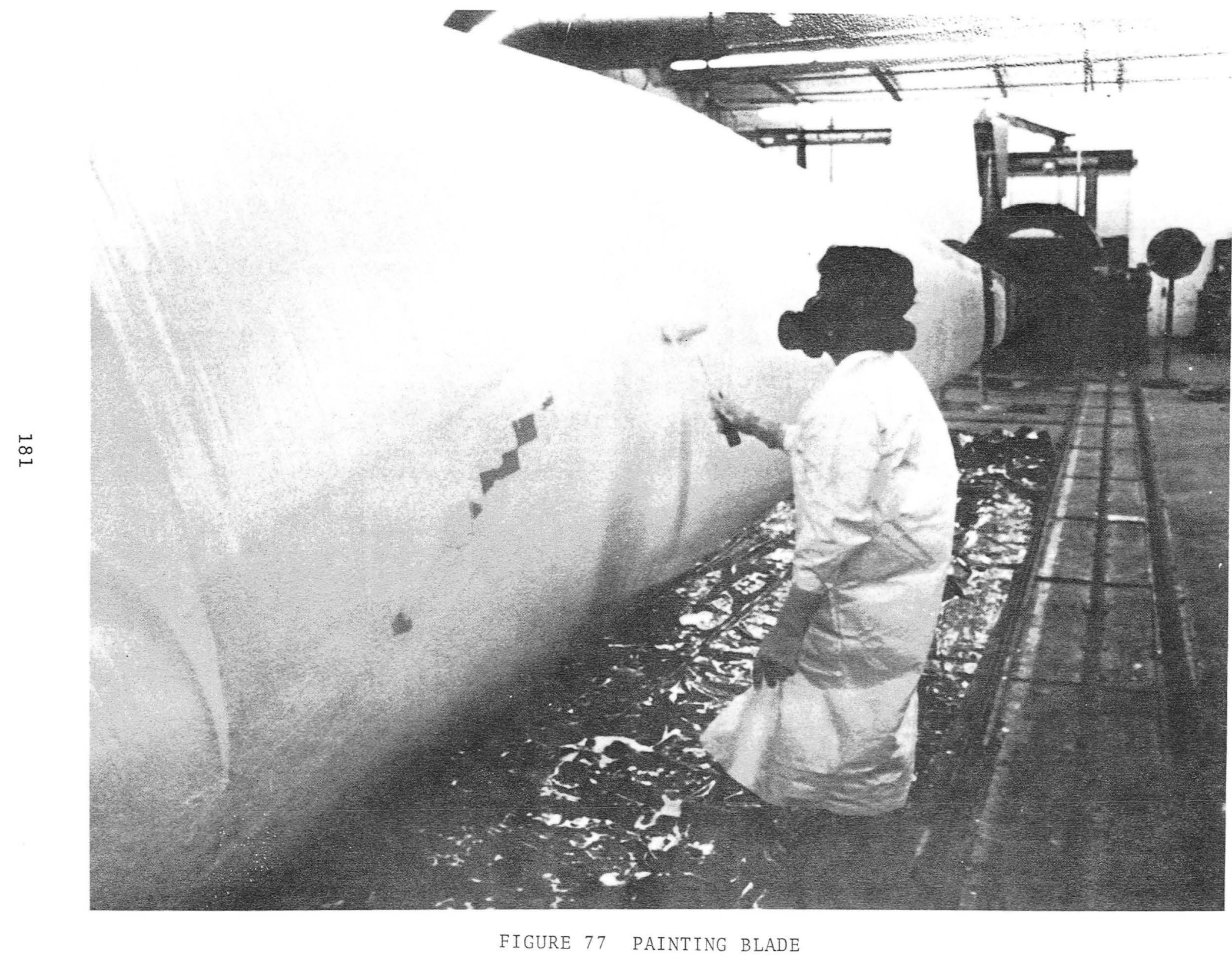




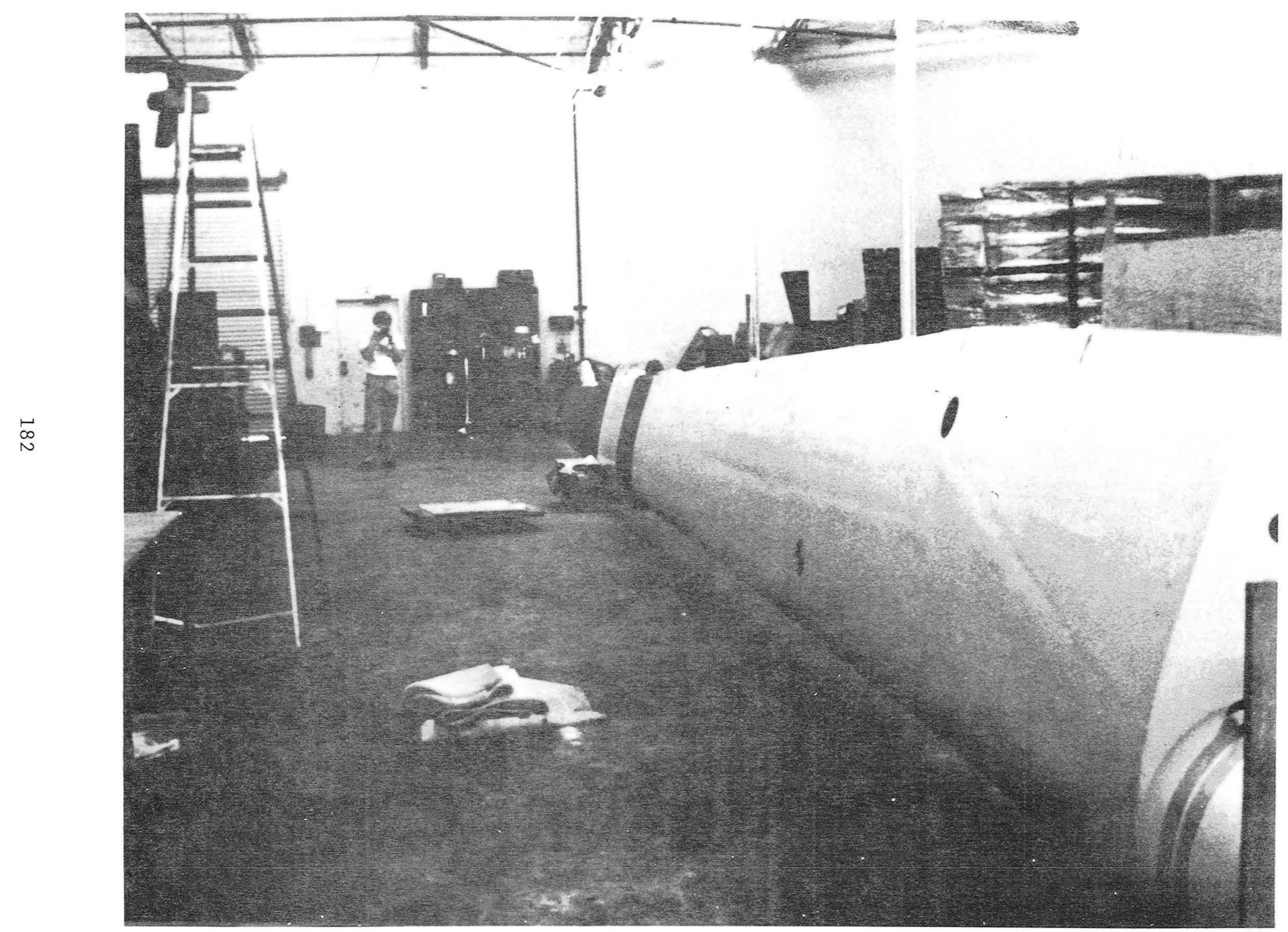

FIGURE 78 FINISHED BLADE WITH ICE DETECTOR AND BALANCE WEIGHT PROVISIONS AND TRIM PAINTING 


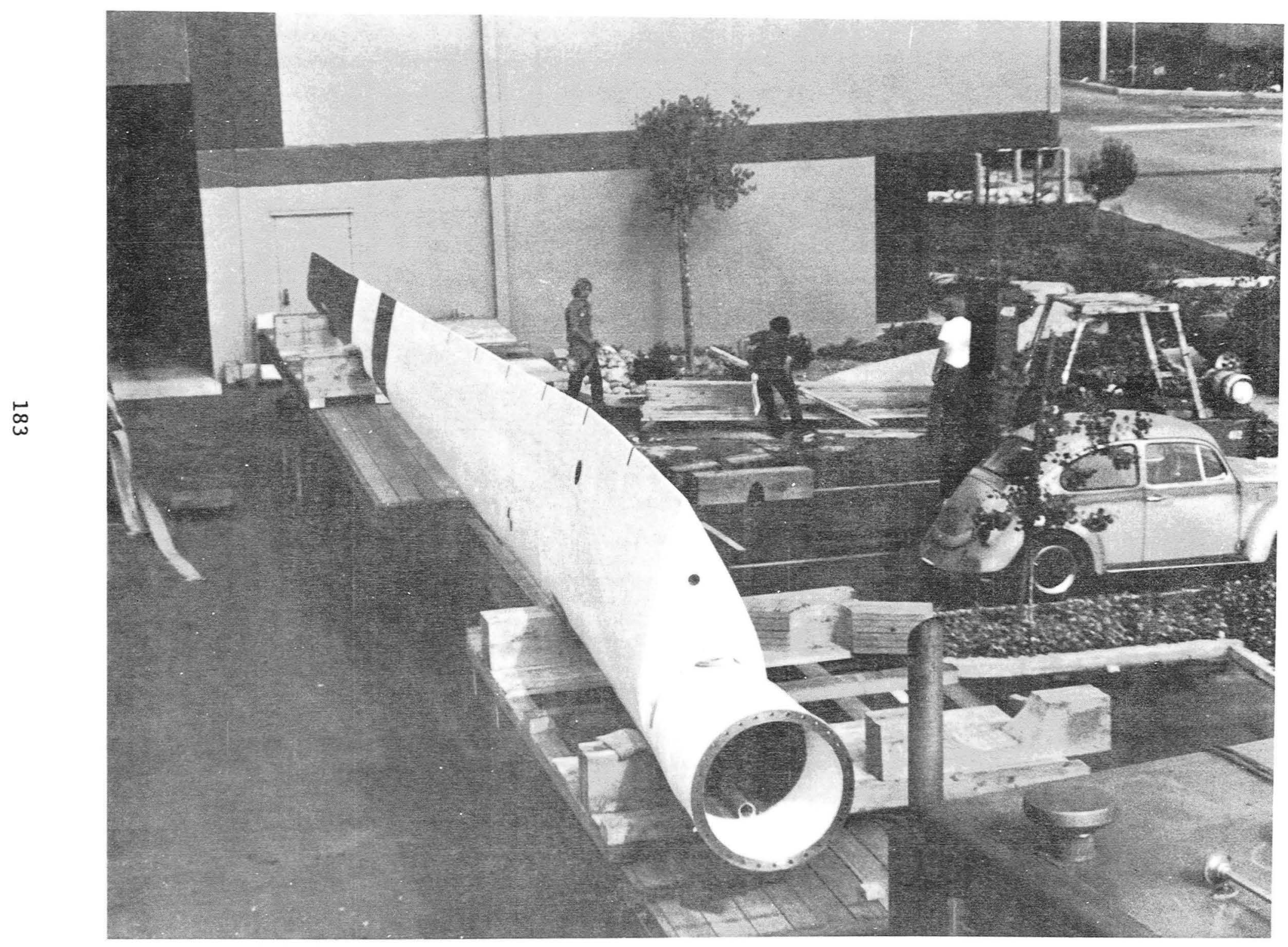

FIGURE 79 LOADING BLADE ON TRUCK 
S/N 018 DIMENSIONAL ERRORS, DESCRIPTIVE STATISTICS

DESCFIIFTIUE STATISTICS

VAFIAE:LE: 018 EFFIOFS $\$ 1000$

SAMFLE SIZE (N) $=96$

SAMF'LE STATISTICS:

\begin{tabular}{|c|c|c|c|}
\hline MEAN & $=-84.0625$ & FANGE & $=550$ \\
\hline VAFIANCE & $=6616.84$ & MINIMUM & $=-475$ \\
\hline STD. DE & 81.344 & MAXIMUM & \\
\hline
\end{tabular}

UNEIASED ESTIMATES OF FOF'ULATION FAFIAMETEFS:

VAFIANCE $=6686.49 \quad$ STD. DEV. $=81.771$

DATA DISTFIEUTION COEFFICIENTS:

SKEWNESS $=-1.06496$ KUFTOSIS $=4.31206$ 
S/N 019 DIMENSIONAL ERRORS, DESCRIPTIVE STATISTICS
D E S C F I I F T I U E
$S T A T I S T I C S$

VAFIIAELLE: 019 EFFERISX1000

SAMFLE SIZE $(N)=96$

SAMFLE STATISTICS:

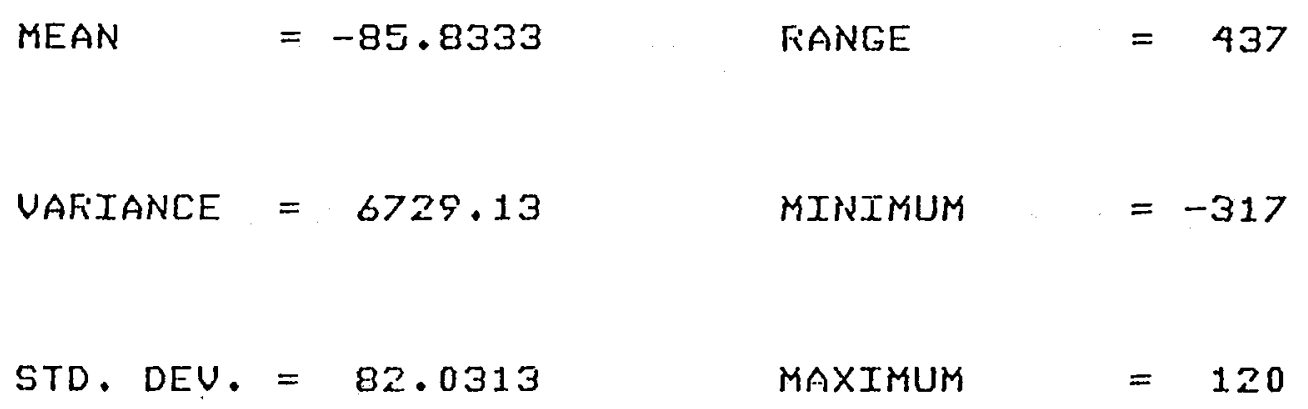

UNEIASED ESTIMATES OF FOFULATION F.AFIAMETEFS:

VAFIANCE $=6799.96 \quad$ STD. DEU. $=82.4619$

DATA DISTFIEUTION COEFFICIENTS:

SKEWNESS $=-.0851471$

KUETTOSIS

$=-6.80589 E-03$ 
TABLE 37

COMBINED DIMENSIONAL ERRORS, DESCRIPTIVE STATISTICS

$$
\text { DESCFIFTIUE STATISTICS }
$$

VAFIAE:LE: ALL EFFEOFS*1000 SAMFLE SIZE (N) $=192$

SAMFLE STATISTICS:
MEAN
$=-84.9479$
FFANGE
$=595$
VAFIIANCE $=6673.77$
MINIMUM
$=-475$
STD. DEU. $=81.6932$
MAXIMUM
$=120$

UNEIASED ESTIMATES OF FOFULATION FAFIAMETEFS:

VAFIANCE $=6708.71$

STD. DEV. $=81.9068$

DATA DISTFIEUTION COEFFICIENTS:

SKEWNESS $=-.569059$

KUETOSIS $=2.09523$ 
S/N 018 DIMENSIONAL ERROR, FREQUENCY DISTRIBUTION

FFIEQUENCY DISTFIEUTION

DISTFIEUUTION OF UAFIAELE: 018 EFFROFS*1000

\section{INTEFIVAL}

F.EFICENT

$\begin{array}{rrrccc}-475.000 & \text { TO } & -420.001 & 1 & 1.0 & 1.0 \\ -420.000 & \text { TO } & -365.001 & 0 & 0.0 & 1.0 \\ -365.000 & \text { TO } & -310.001 & 0 & 0.0 & 1.0 \\ -310.000 & \text { TO } & -255.001 & 1 & 1.0 & 2.1 \\ -255.000 & \text { TO } & -200.001 & 4 & 4.2 & 6.3 \\ -200.000 & \text { TO } & -145.001 & 6 & 6.3 & 12.5 \\ -145.000 & \text { TO } & -90.001 & 34 & 35.4 & 47.9 \\ -90.000 & \text { TO } & -35.001 & 23 & 24.0 & 71.9 \\ -35.000 & \text { TO } & 19.999 & 18 & 18.8 & 90.6 \\ 20.000 & \text { TO } & 75.000 & 9 & 9.4 & 100.0\end{array}$


TABLE 39

S/N 019 DIMENSIONAL ERROR, FREQUENCY DISTRIBUTION

FREQUENCY DISTFIEUTION

DISTFIEUUTION DF UAFIAAELE: 019 EFFIOFS 1000

INTEFIUAL

FFEEQUENCY
FEFICENT
CUMULATIUE \%

$\begin{array}{cccccc}-317.000 & \text { TO } & -273.301 & 2 & 2.1 & 2.1 \\ -273.300 & \text { TO } & -229.601 & 1 & 1.0 & 3.1 \\ -229.600 & \text { TO } & -185.901 & 7 & 7.3 & 10.4 \\ -185.900 & \text { TO } & -142.201 & 14 & 14.6 & 25.0 \\ -142.200 & \text { TO } & -98.501 & 21 & 21.9 & 46.9 \\ -98.500 & \text { TO } & -54.801 & 15 & 15.6 & 62.5 \\ -54.800 & \text { TO } & -11.101 & 20 & 20.8 & 83.3 \\ -11.100 & \text { TO } & 32.599 & 9 & 9.4 & 92.7 \\ 32.600 & \text { TO } & 76.299 & 5 & 5.2 & 97.9 \\ 76.300 & \text { TO } & 120.000 & 2 & 2.1 & 100.0\end{array}$

TOTAL

96

100.0 
TABLE 40

COMBINED DIMENSIONAL ERRORS, FREQUENCY DISTRIBUTION

F FIE QUENCY D I S T F I E U U T I ON

DISTFIEUTION OF UAFIAELLE: ALL EFFIOFS*1000

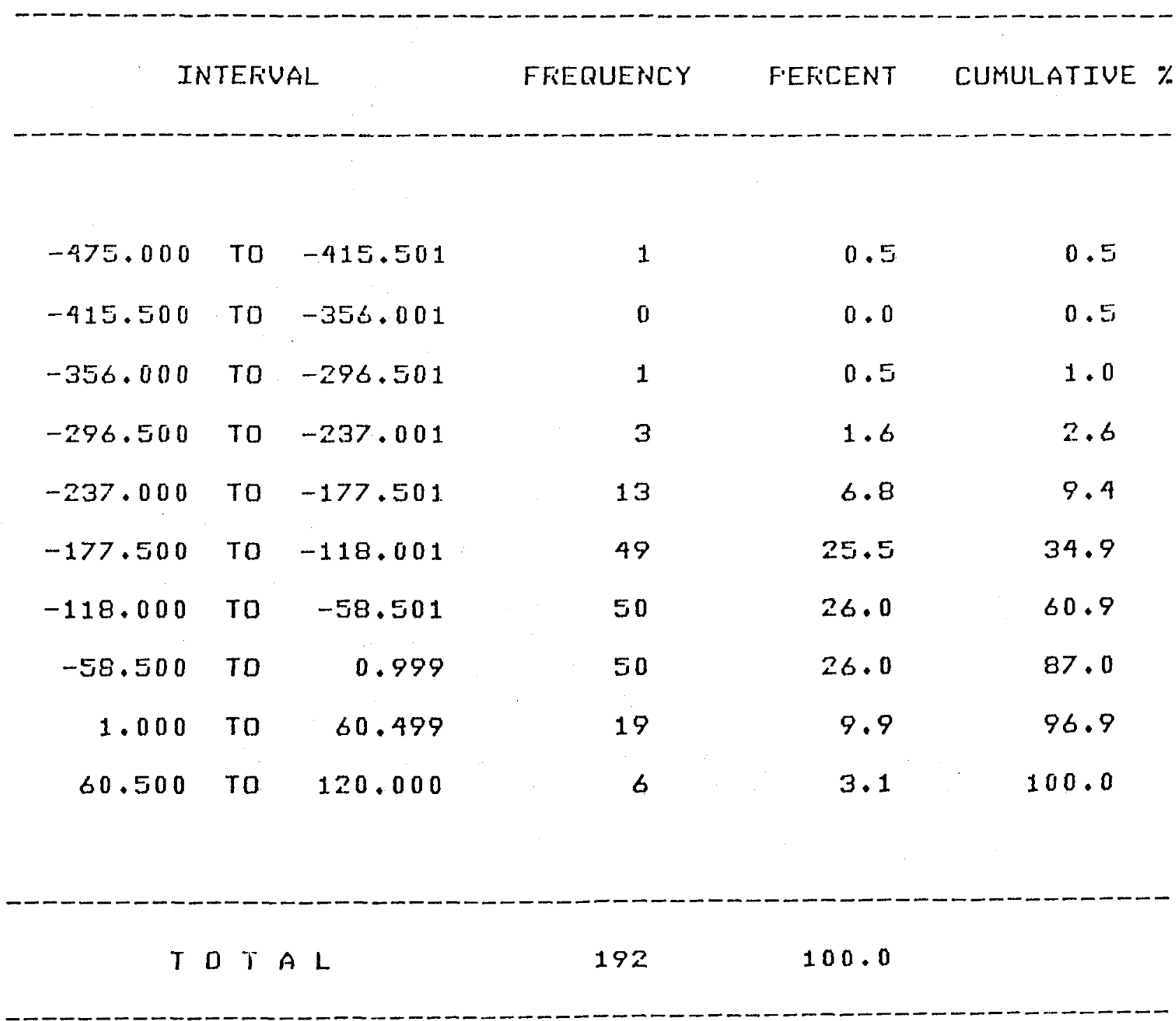


FFIEQUENCY

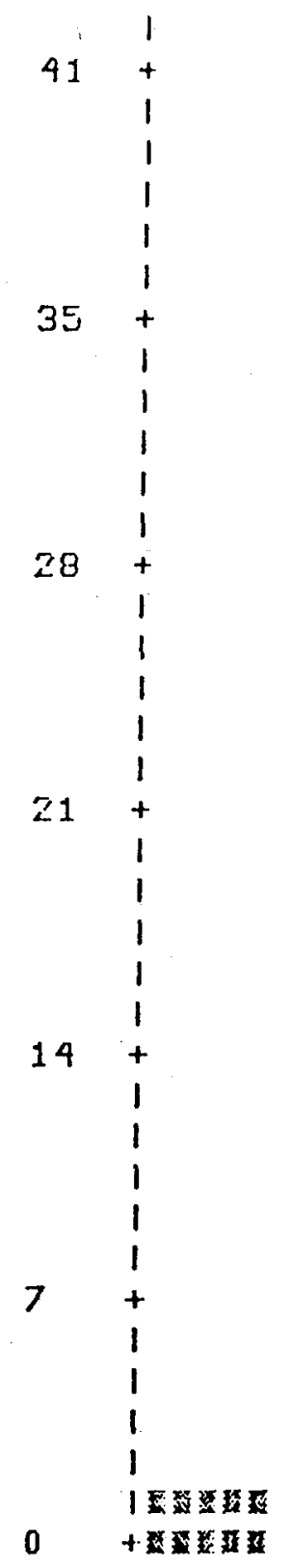

\section{E⿸厂二⿺乚一匕}

考政

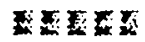

球现

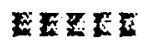

现

刑逐现

EXE

Exe

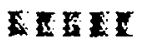

列政

政紧

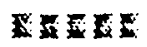

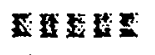

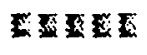

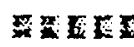

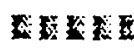

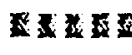

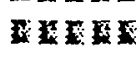

要五远正

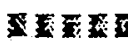

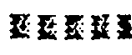

现

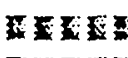

这这

西国

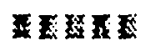

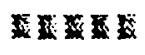

现现

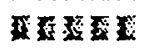

政政

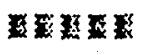

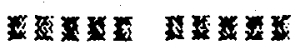

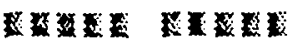

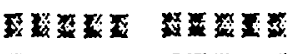

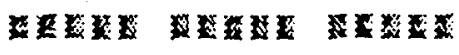

现现

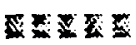

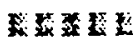

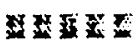

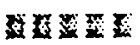

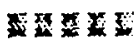

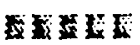

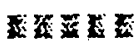

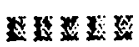

然现

F

球现

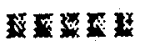

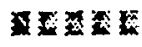

12

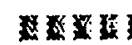

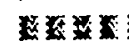

然国

is

1)

1

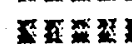

20
FEFICENT

1

$+42.7$

1

I

1

1

1

1

1

$+32.0$

1

1

1

1

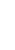

I

$+21.4$

I

1$$
\text { I }
$$$$
\text { ( }
$$

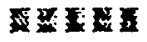

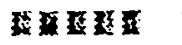

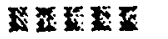

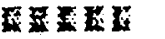

Ex

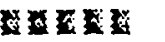

XX

这通 1

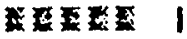

运政

4.

$+0.0$

$$
-475.0-406.3-337.5-268.8-200 \cdot 0-131.3-62.56 .2 \quad 75.0
$$

$\begin{array}{llllllllllllll}0 & 1 & 8 & E & F & F & 0 & F & 5 & * & 0 & 0 & 0\end{array}$

FIGURE 80

S/N 018 DIMENSIONAL ERRORS, HISTOGRAM 
FFE RUENCY

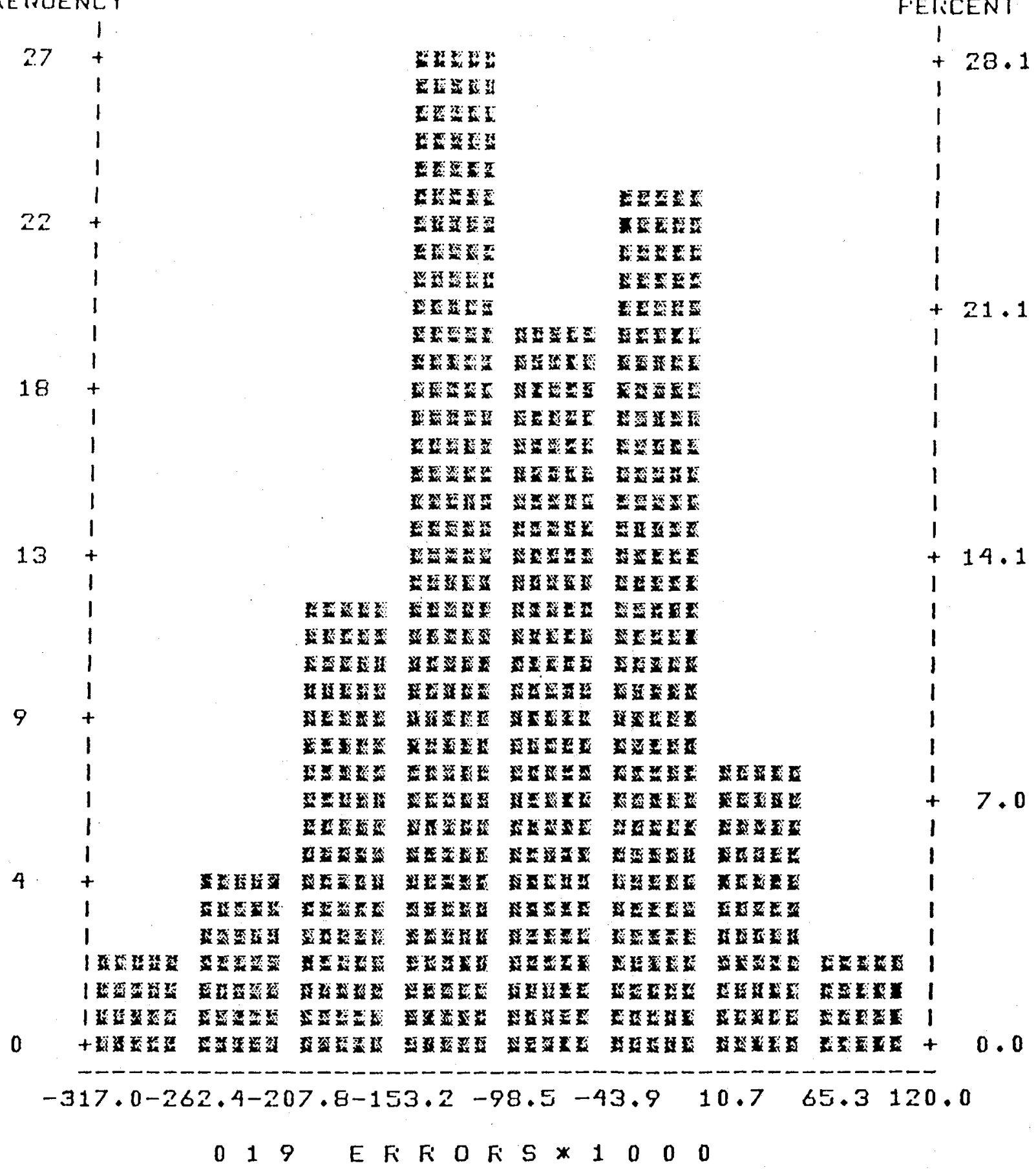

FIGURE 81

S/N 019 DIMENSIONAL ERRORS, HISTOGRAM 


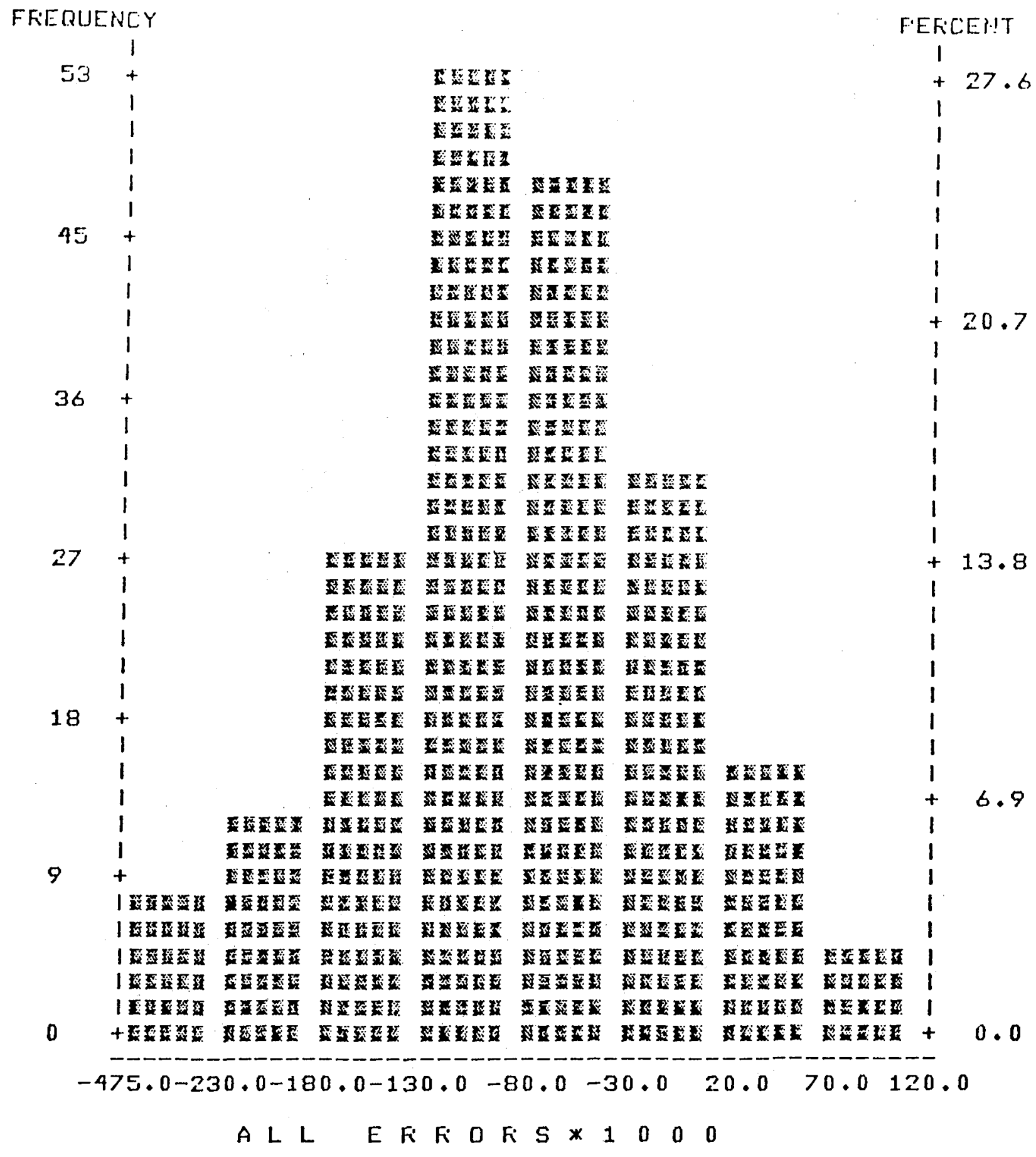

FIGURE 82

COMBINED DIMENSIONAL ERRORS, HISTOGRAM 
TABLE 41

LCCB DIMENSIONAL ERRORS, ANALYSIS OF VARIANCE

ANALYSIS DF UAFIANCE

SUMMAFY TAE:LE

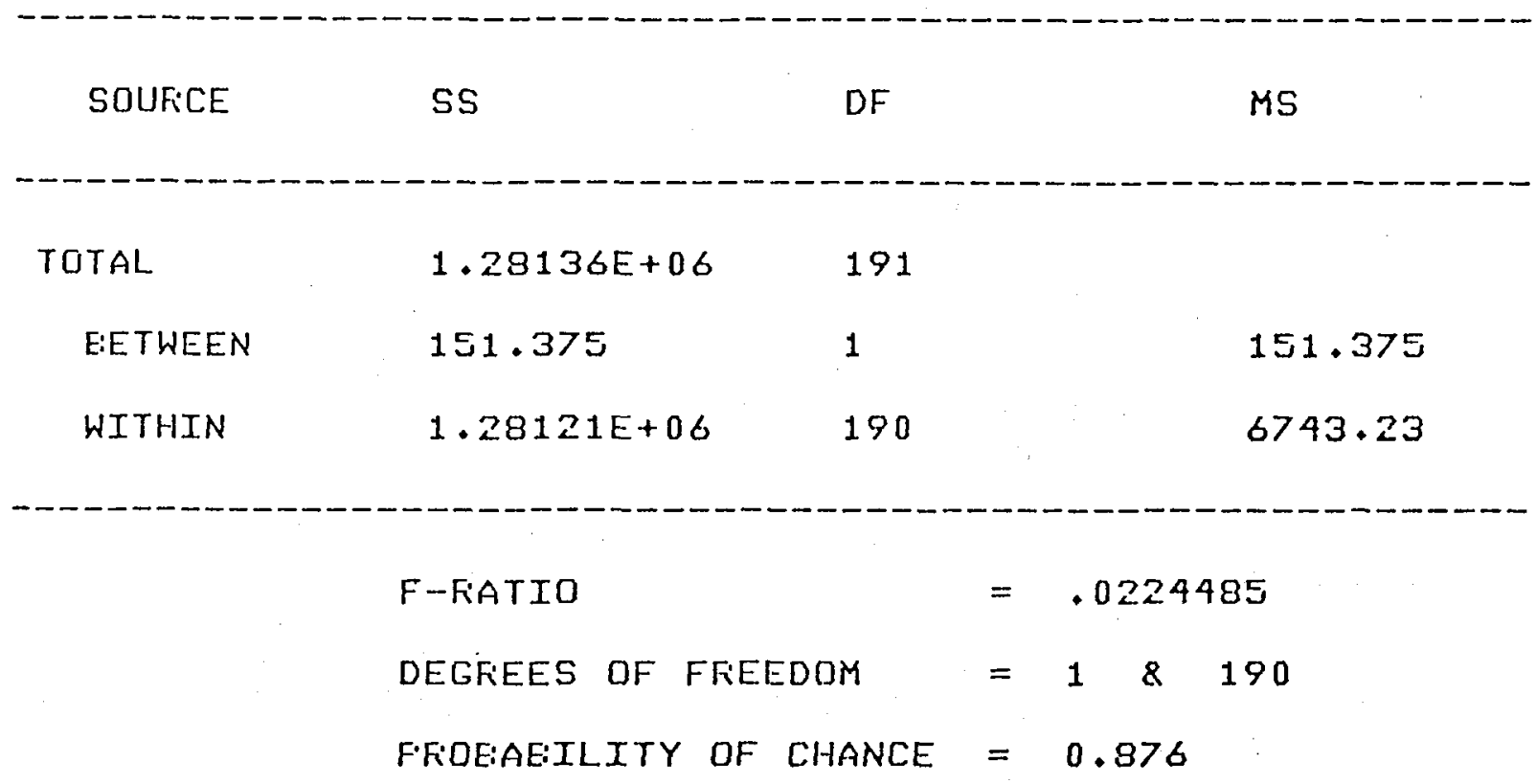

GEOUF' STATISTICS

$\begin{array}{lccc}\text { GROUP } & N & \text { MEAN } & \text { S.D. } \\ \text { ELADE SN } 018 & 96 & -84.0625 & 81.771 \\ \text { ELADE SN } 019 & 96 & -85.8333 & 82.4619\end{array}$


This material was changed from syntactic foam to low density polyurethane foam to save about $1001 \mathrm{bs}$ per blade (Table 34). This foam-in-place material tended to shrink and soften during blade cure, leaving a spanwise indentation or trough in the outer blade surface.

An indication of the contour accuracy can be gained from the statistical data. The mean and standard deviation for both blades and for the combined data from both blades are substantially the same. The variation in error is large compared to the mean error. Thus both blades have dimensional errors which are from the same statistical population, and the variation to be expected is relatively large, i.e., the blades are not very well faired.

Another problem encountered was local denting of the trailing edge by winding tension collapsing the foam core.

\section{FINISH AND APPEARANCE}

The exterior surface finish of filament-wound composites is a "natural" finish with some "grain" from the windings. The TFT process uses final passes of $90^{\circ}$ hoop windings or LFT to compact the composite and give a lay of the "grain" in the chordwise direction.

To improve this finish and prevent chordwise cracking due to blade flexing, a layer of number 120 glass cloth was used as the final wrap. In addition, flat paint was used to hide small surface irregularities which might be highlighted by glossy paint. Appearance, on close up viewing, leaves room for improvement due to the rough finish and the irregularities discussed under "Dimensional Inspection".

WEIGHT AND BALANCE

Table 34 shows an actual versus predicted weight summary of the blades. Within the accuracy of the scale used, the weights of the finished blades, prior to balancing, were identical at 2180 lbs (not including hub adapter). The as built center of gravity was also quite close, within $1 / 8$ inch. Both parameters were well within the NASA-specified tolerances of $\pm 2 \%$ (about $501 \mathrm{bs}$ blade to blade) on weight and \pm one inch on spanwise c.g. Chordwise c.g. was not checked. Total weight was $10 \%$ less than estimated, mostly due to the compaction achieved by vacuum bagging. These results are encouraging, promising good reproducibility from blade to blade. 


\section{2 .4 PROTOTYPE COST EVALUATION}

Table 42 presents the actual direct cost experience on the prototype blades, NASA serial numbers 018 and 019 . (The eighteenth and nineteenth MOD-O blades to be assigned serial numbers).

Note that the second blade cost is roughly $70 \%$ of the first blade and that the average cost of the two blades is roughy $85 \%$ of the cost of the first blade. This represents good learning. The estimated learning factor $k$ for the cost of the Nth item is thus .695 and the learning factor $K$ for the average cost of $\mathrm{N}$ items is thus.8475. We have adjusted the total costs to 1978 dollars by applying a factor of $(.88)^{3}$ to estimate the effect of $12 \%$ yearly escalation for 3 years.

In Table 43 we have compared the estimated costs of production and prototype blades, from Tables 21 and 42 . The same amortized tooling costs and fee were used to allow comparison on a uniform basis.

The results of this comparison are not surprising. The material costs for both designs tend to converge, but labor hours are much higher for the prototype design. This is due to the very labor intensive steps in the prototype design and process which would not be required with the production design.

\subsection{RECOMMENDATIONS FOR FUTURE PRODUCTION}

\section{3 .1 MOD-OA BLADES}

For blades to meet the same specification as the prototype blades (i.e., Section 4.1) the recommendations in Section 4.5 (as shown in Figure 54) should be implemented. These are:

(1) The use of foam in place cores for the afterbody and trailing edge.

(2) A web doubler wound into the D-spar.

(3) Continuous winding using polyester resin with only one cure cycle and no vacuum impregnation, vacuum bags or peel ply.

This modified sequence reduces labor substantially since the cutting, bonding and fairing of the foam cores and the hand layup and positioning of the web doublers on the prototype blades were very labor-intensive, as were the multiple cures, vacuum impregnation, vacuum bags and peel plies. In addition, the hub fitting and adapter should be fabricated from aluminum or mild steel. 
TABLE 42

PROTOTYPE BLADE COST EVALUATION

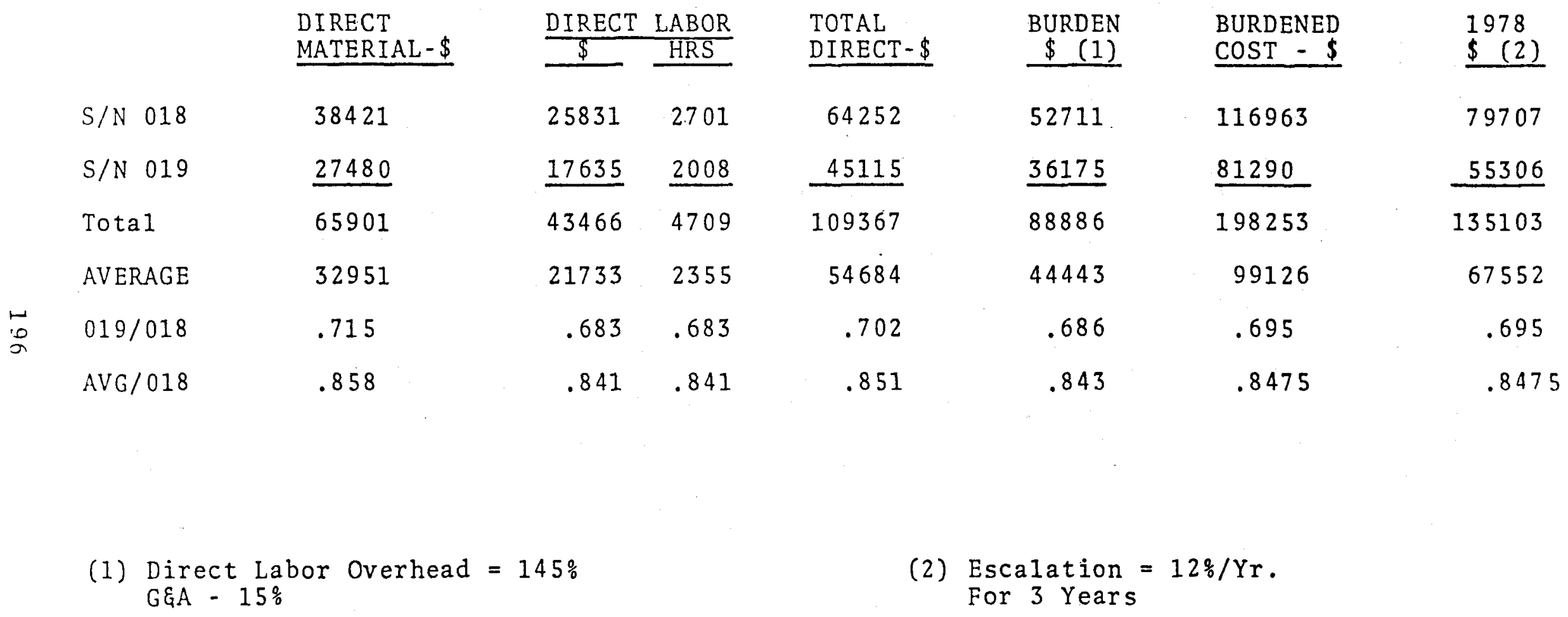


TABLE 43

COMPARISON OF PROTOTYPE BLADE COSTS WITH ESTIMATED PRODUCTION BLADE COSTS

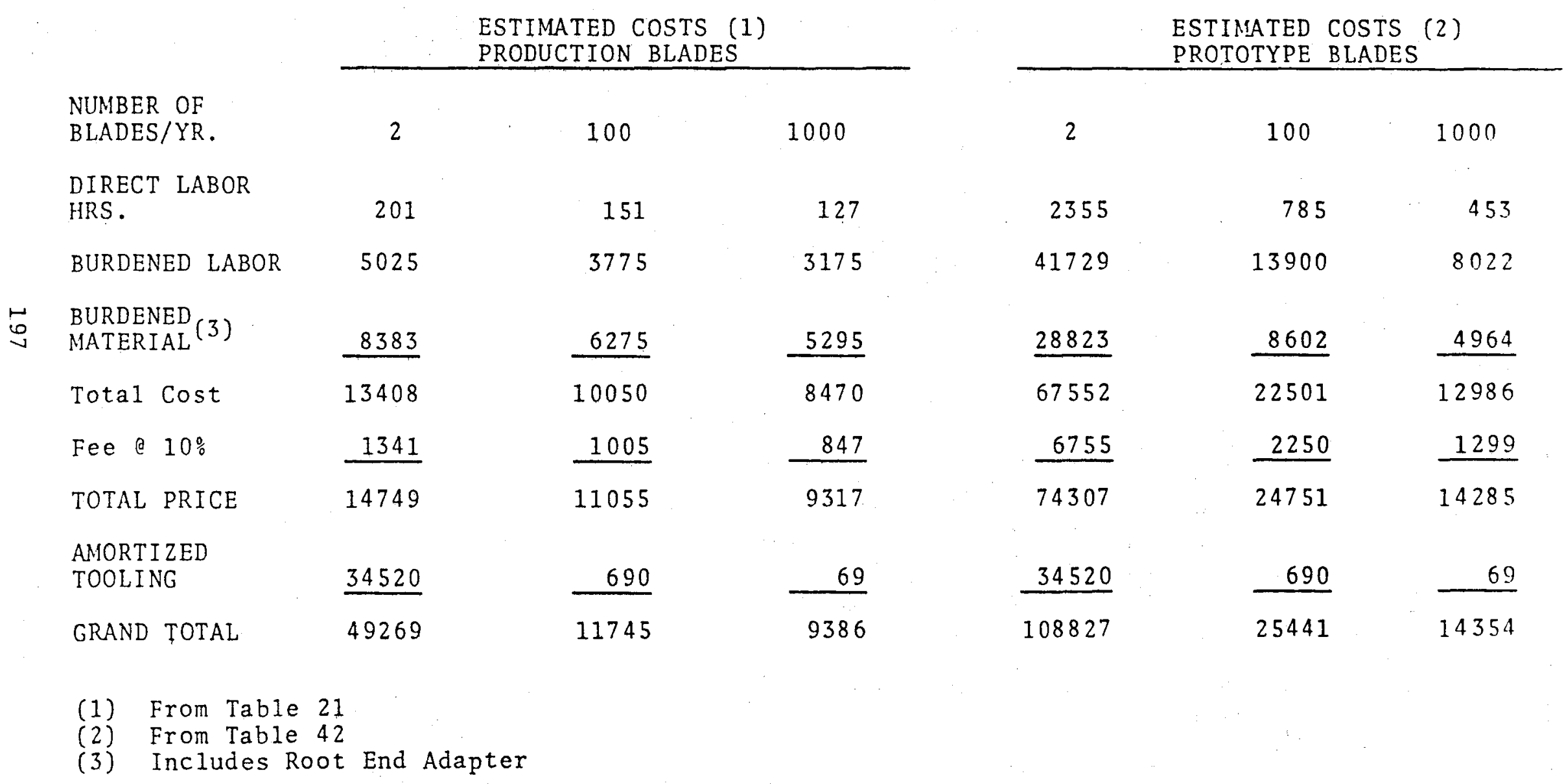


The costs projected in Table 21 should then be readily. achievable.

5.3 .2 OTHER LARGE COMPOSITE WIND TURBINE BLADES

For large composite wind turbine blades in general, the recommendations in Section 3.2 should be implemented. Future wind turbines should have hub designs which are coordinated with the blade design to give the lowest possible cost of energy. The following recommended changes in the present design and process could then be implemented:

(1) Two cell design with $D$-spar as the primary loadcarrying element.

(2) Larger hub diameter to allow extraction of larger mandrel without using a metal root end adapter.

(3) Aluminum or mild steel hub fitting for lower cost.

(4) Polyester resin for lower raw material and processing.

(5) Continuous winding process without costly vacuum bag, peel ply and gel between winding steps.

(6) Hollow afterbody wound on extractable mandre1. (If a foam core must be used in afterbody, then foam in-place in a mold).

(7) Consider use of modified airfoil with blunt trailing edge. 
1. Kaman Aerospace Company, "Design, Fabrication, Test and Evaluation of a Prototype 150-Foot Long Composite Wind Turbine Blade", NASA CR-159775, September 1979.

2. Hamilton-Standard, "Design, Fabrication, and Test of a Composite Material Wind Turbine Rotor Blade", NASA CR $-135389,1977$.

3. General Electric Company, "1500 kW Wind Turbine Generation Program, Preliminary Blade Design Review", Document No. $77 \operatorname{SDS} 4217$, March 1977.

4. Gewehr, H.W., "Large Low Cost Composite Wind Turbine Blades", NASA Conference Publication 2106, April 1979.

5. Boeing Engineering And Construction, "MOD-2 Wind Turbine System, Concept and Preliminary Design Report", NASA CR-159609, Ju1y 197.9 .

6. General Electric Company, "MOD-5A Preliminary Design Report", (to be published).

7. Westinghouse Electric Company, "Study of Various Airfoils For Wind Turbine Rotor Blades", (Not the exact title), Wind Energy Conference Co-sponsored by AIAA and SERI, Boulder, Colorado, April 9-11 1980 .

8. MIL-HDBK-5C, "Meta11ic Materials and Elements For Aerospace Vehicle Structures", September 1976.

9. MIL-HDBK-17A, "Plastics for Aerospace Vehicles", January 1971.

10. Marceau, J., McMillan, J., and Scardino, W., "Cyclic Testing of Adhesive Bonds", 22nd National SAMPE Symposium, San Diego, California, April 1977 .

11. Renton, W., Flaggs, D., and Vinson, J., "The Analysis and Design of Composite Material Bonded Joints, Report No. 3", AFOSR-TR-1371, July 1978 .

12. U.S. Air Force Materials Laboratory, "Point Stress Laminate Analysis", FZM-5494, Apri1 1979. 


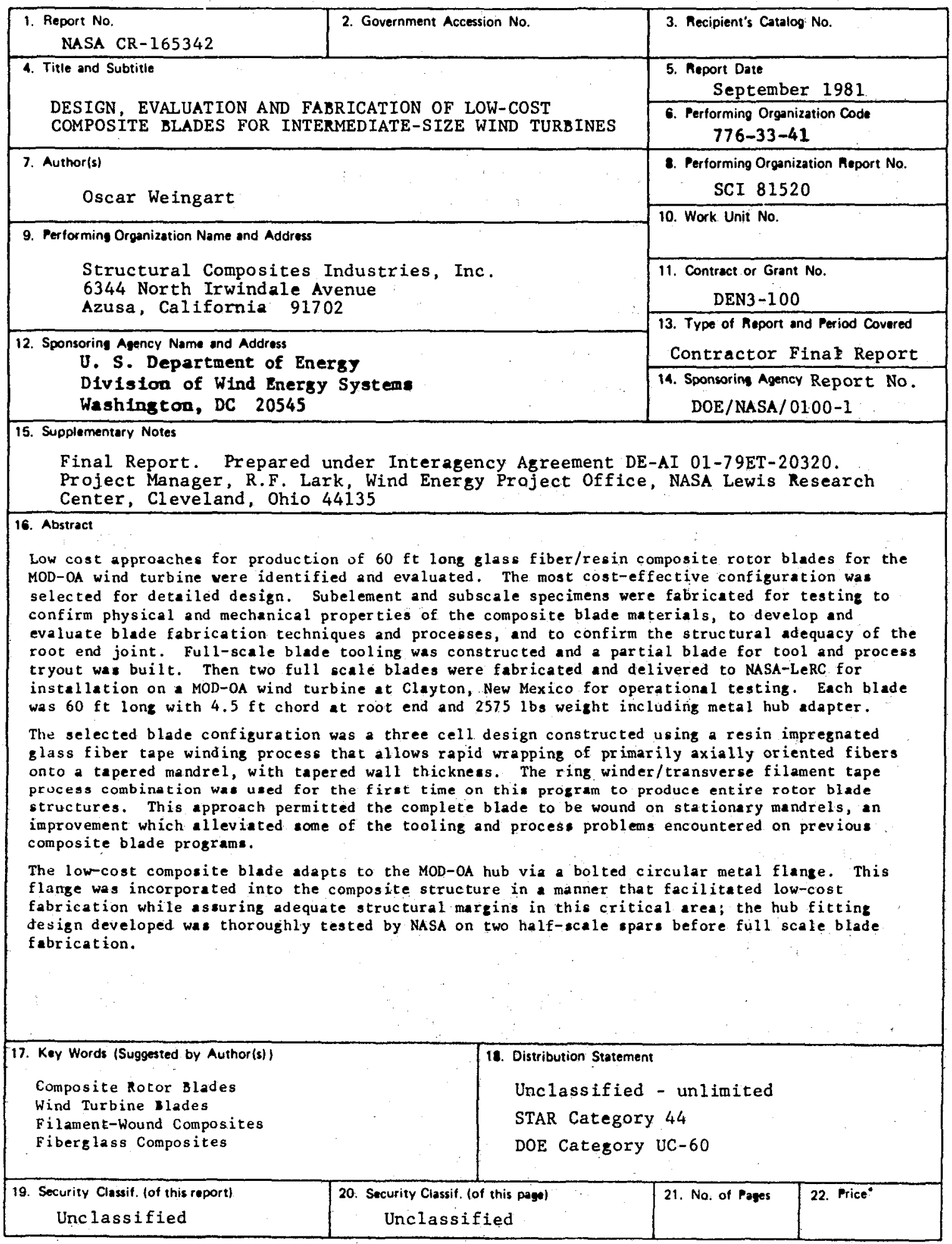

* For sale by the National Technical Information Service, Springtield, Virginia 22161 

,

- 